\title{
Beds, overlays and mattresses for preventing and treating pressure ulcers: an overview of Cochrane Reviews and network meta-analysis
}

DOI:

10.1002/14651858.CD013761.pub2

\section{Document Version}

Final published version

Link to publication record in Manchester Research Explorer

Citation for published version (APA):

Shi, C., Dumville, J. C., Cullum, N., Rhodes, S., Mcinnes, E., Goh, E. L., \& Norman, G. (2021). Beds, overlays and mattresses for preventing and treating pressure ulcers: an overview of Cochrane Reviews and network metaanalysis. Cochrane Database of Systematic Reviews, 2021(8). https://doi.org/10.1002/14651858.CD013761.pub2

\section{Published in:}

Cochrane Database of Systematic Reviews

\section{Citing this paper}

Please note that where the full-text provided on Manchester Research Explorer is the Author Accepted Manuscript or Proof version this may differ from the final Published version. If citing, it is advised that you check and use the publisher's definitive version.

\section{General rights}

Copyright and moral rights for the publications made accessible in the Research Explorer are retained by the authors and/or other copyright owners and it is a condition of accessing publications that users recognise and abide by the legal requirements associated with these rights.

\section{Takedown policy}

If you believe that this document breaches copyright please refer to the University of Manchester's Takedown Procedures [http://man.ac.uk/04Y6Bo] or contact uml.scholarlycommunications@manchester.ac.uk providing relevant details, so we can investigate your claim.

\section{OPEN ACCESS}




\section{Beds, overlays and mattresses for preventing and treating pressure ulcers: an overview of Cochrane Reviews and network meta- analysis (Review)}

Shi C, Dumville JC, Cullum N, Rhodes S, McInnes E, Goh EL, Norman G

Shi C, Dumville JC, Cullum N, Rhodes S, McInnes E, Goh EL, Norman G.

Beds, overlays and mattresses for preventing and treating pressure ulcers: an overview of Cochrane Reviews and network metaanalysis.

Cochrane Database of Systematic Reviews 2021, Issue 8. Art. No.: CD013761.

DOI: 10.1002/14651858.CD013761.pub2.

\section{www.cochranelibrary.com}

Beds, overlays and mattresses for preventing and treating pressure ulcers: an overview of Cochrane Reviews and network meta-analysis (Review) 
HEADER 1

ABSTRACT

PLAIN LANGUAGE SUMMARY

BACKGROUND

OBJECTIVES

METHODS

RESULTS

Figure 1.

Figure 2.

Figure 3.

Figure 4.

Figure 5.

Figure 6.

DISCUSSION

AUTHORS' CONCLUSIONS

ACKNOWLEDGEMENTS

REFERENCES

ADDITIONAL TABLES

APPENDICES

Figure 7.

Figure 8.

Figure 9.

Figure 10.

Figure 11.

Figure 12.

Figure 13.

Figure 14.

Figure 15.

Figure 16.

HISTORY

CONTRIBUTIONS OF AUTHORS

DECLARATIONS OF INTEREST

SOURCES OF SUPPORT

DIFFERENCES BETWEEN PROTOCOL AND REVIEW

\section{TABLE OF CONTENTS}


[Overview of Reviews]

\title{
Beds, overlays and mattresses for preventing and treating pressure ulcers: an overview of Cochrane Reviews and network meta-analysis
}

\author{
Chunhu Shi ${ }^{1}$, Jo C Dumville ${ }^{1}$, Nicky Cullum ${ }^{1}$, Sarah Rhodes 2 , Elizabeth McInnes ${ }^{3}$, En Lin Goh ${ }^{4}$, Gill Norman ${ }^{1}$
}

1Division of Nursing, Midwifery and Social Work, School of Health Sciences, Faculty of Biology, Medicine and Health, University of Manchester, Manchester Academic Health Science Centre, Manchester, UK. ${ }^{2}$ Division of Population Health, Health Services Research \& Primary Care, Faculty of Biology, Medicine and Health, University of Manchester, Manchester, UK. ${ }^{3}$ Nursing Research Institute, St Vincent's Health Australia Sydney, St Vincent's Hospital Melbourne \& Australian Catholic University, Fitzroy, Melbourne, Australia. ${ }^{4}$ Oxford Trauma, Nuffield Department of Orthopaedics, Rheumatology and Musculoskeletal Sciences, Oxford, UK

Contact address: Chunhu Shi, chunhu.shi@manchester.ac.uk.

Editorial group: Cochrane Wounds Group.

Publication status and date: New, published in Issue 8, 2021.

Citation: Shi C, Dumville JC, Cullum N, Rhodes S, Mclnnes E, Goh EL, Norman G. Beds, overlays and mattresses for preventing and treating pressure ulcers: an overview of Cochrane Reviews and network meta-analysis. Cochrane Database of Systematic Reviews 2021, Issue 8. Art. No.: CD013761. DOI: 10.1002/14651858.CD013761.pub2.

Copyright ( 2021 The Authors. Cochrane Database of Systematic Reviews published by John Wiley \& Sons, Ltd. on behalf of The Cochrane Collaboration. This is an open access article under the terms of the Creative Commons Attribution-Non-Commercial Licence, which permits use, distribution and reproduction in any medium, provided the original work is properly cited and is not used for commercial purposes.

\section{A B S T R A C T}

\section{Background}

Pressure ulcers (also known as pressure injuries, pressure sores and bed sores) are localised injuries to the skin or underlying soft tissue, or both, caused by unrelieved pressure, shear or friction. Specific kinds of beds, overlays and mattresses are widely used with the aim of preventing and treating pressure ulcers.

\section{Objectives}

To summarise evidence from Cochrane Reviews that assess the effects of beds, overlays and mattresses on reducing the incidence of pressure ulcers and on increasing pressure ulcer healing in any setting and population.

To assess the relative effects of different types of beds, overlays and mattresses for reducing the incidence of pressure ulcers and increasing pressure ulcer healing in any setting and population.

To cumulatively rank the different treatment options of beds, overlays and mattresses in order of their effectiveness in pressure ulcer prevention and treatment.

\section{Methods}

In July 2020, we searched the Cochrane Library. Cochrane Reviews reporting the effectiveness of beds, mattresses or overlays for preventing or treating pressure ulcers were eligible for inclusion in this overview. Two review authors independently screened search results and undertook data extraction and risk of bias assessment using the ROBIS tool. We summarised the reported evidence in an overview of reviews. Where possible, we included the randomised controlled trials from each included review in network meta-analyses. We assessed the relative effectiveness of beds, overlays and mattresses for preventing or treating pressure ulcers and their probabilities of being, comparably, the most effective treatment. We assessed the certainty of the evidence using the GRADE approach.

\section{Main results}

We include six Cochrane Reviews in this overview of reviews, all at low or unclear risk of bias.

Beds, overlays and mattresses for preventing and treating pressure ulcers: an overview of Cochrane Reviews and network meta-analysis 
Pressure ulcer prevention: four reviews (of 68 studies with 18,174 participants) report direct evidence for 27 pairwise comparisons between 12 types of support surface on the following outcomes: pressure ulcer incidence, time to pressure ulcer incidence, patient comfort response, adverse event rates, health-related quality of life, and cost-effectiveness. Here we focus on outcomes with some evidence at a minimum of low certainty.

(1) Pressure ulcer incidence: our overview includes direct evidence for 27 comparisons that mostly (19/27) have very low-certainty evidence concerning reduction of pressure ulcer risk. We included 40 studies (12,517 participants; 1298 participants with new ulcers) in a network meta-analysis involving 13 types of intervention. Data informing the network are sparse and this, together with the high risk of bias in most studies informing the network, means most network contrasts (64/78) yield evidence of very low certainty. There is low-certainty evidence that, compared with foam surfaces (reference treatment), reactive air surfaces (e.g. static air overlays) (risk ratio (RR) $0.46,95 \%$ confidence interval ( $\mathrm{Cl}) 0.29$ to 0.75 ), alternating pressure (active) air surfaces (e.g. alternating pressure air mattresses, large-celled ripple mattresses) (RR $0.63,95 \% \mathrm{Cl} 0.42$ to 0.93 ), and reactive gel surfaces (e.g. gel pads used on operating tables) (RR $0.47,95 \% \mathrm{Cl} 0.22$ to 1.01 ) may reduce pressure ulcer incidence. The ranking of treatments in terms of effectiveness is also of very low certainty for all interventions. It is unclear which treatment is best for preventing ulceration.

(2) Time to pressure ulcer incidence: four reviews had direct evidence on this outcome for seven comparisons. We included 10 studies (7211 participants; 699 participants with new ulcers) evaluating six interventions in a network meta-analysis. Again, data from most network contrasts (13/15) are of very low certainty. There is low-certainty evidence that, compared with foam surfaces (reference treatment), reactive air surfaces may reduce the hazard of developing new pressure ulcers (hazard ratio (HR) $0.20,95 \% \mathrm{Cl} 0.04$ to 1.05 ). The ranking of all support surfaces for preventing pressure ulcers in terms of time to healing is uncertain.

(3) Cost-effectiveness: this overview includes direct evidence for three comparisons. For preventing pressure ulcers, alternating pressure air surfaces are probably more cost-effective than foam surfaces (moderate-certainty evidence).

Pressure ulcer treatment: two reviews (of 12 studies with 972 participants) report direct evidence for five comparisons on: complete pressure ulcer healing, time to complete pressure ulcer healing, patient comfort response, adverse event rates, and cost-effectiveness. Here we focus on outcomes with some evidence at a minimum of low certainty.

(1) Complete pressure ulcer healing: our overview includes direct evidence for five comparisons. There is uncertainty about the relative effects of beds, overlays and mattresses on ulcer healing. The corresponding network meta-analysis (with four studies, 397 participants) had only three direct contrasts and a total of six network contrasts. Again, most network contrasts (5/6) have very low-certainty evidence. There was low-certainty evidence that more people with pressure ulcers may heal completely using reactive air surfaces than using foam surfaces (RR 1.32, 95\% Cl 0.96 to 1.80). We are uncertain which surfaces have the highest probability of being the most effective (all very low-certainty evidence).

(2) Time to complete pressure ulcer healing: this overview includes direct evidence for one comparison: people using reactive air surfaces may be more likely to have healed pressure ulcers compared with those using foam surfaces in long-term care settings ( $\mathrm{HR} 2.66,95 \% \mathrm{Cl}$ 1.34 to 5.17 ; low-certainty evidence).

(3) Cost-effectiveness: this overview includes direct evidence for one comparison: compared with foam surfaces, reactive air surfaces may cost an extra 26 US dollars for every ulcer-free day in the first year of use in long-term care settings (low-certainty evidence).

\section{Authors' conclusions}

Compared with foam surfaces, reactive air surfaces may reduce pressure ulcer risk and may increase complete ulcer healing. Compared with foam surfaces, alternating pressure air surfaces may reduce pressure ulcer risk and are probably more cost-effective in preventing pressure ulcers. Compared with foam surfaces, reactive gel surfaces may reduce pressure ulcer risk, particularly for people in operating rooms and long-term care settings. There are uncertainties for the relative effectiveness of other support surfaces for preventing and treating pressure ulcers, and their efficacy ranking.

More high-quality research is required; for example, for the comparison of reactive air surfaces with alternating pressure air surfaces. Future studies should consider time-to-event outcomes and be designed to minimise any risk of bias.

\section{PLAIN LANGUAGE SUMMARY}

\section{What are the benefits and risks of beds, mattresses and overlays for preventing and treating pressure ulcers?}

The overview presents a lot of data from randomised controlled trials and contains an advanced analysis called 'network meta-analysis'. The analysis allows comparisons of all types of support surfaces for preventing or treating pressure ulcers. This interactive tool may help with navigation of the data https://stopthepressure.shinyapps.io/Cochrane_support_surface_reviews/.

\section{Key messages}

Static air mattresses or overlays, alternating pressure air mattresses or overlays, and gel pads used on operating tables may be better than foam mattresses for preventing pressure ulcers.

Beds, overlays and mattresses for preventing and treating pressure ulcers: an overview of Cochrane Reviews and network meta-analysis

Copyright ( 2021 The Authors. Cochrane Database of Systematic Reviews published by John Wiley \& Sons, Ltd. on behalf of The Cochrane

Collaboration. 
Compared with foam mattresses, alternating pressure air mattresses or overlays probably result in health benefits that outweigh their costs in preventing pressure ulcers.

Static air mattresses or overlays may be better than foam mattresses for ulcer healing, but may cost more.

It is unclear what the best treatment is for either preventing or treating pressure ulcers; what the effects of these treatment options are on people's comfort and quality of life; and whether or not there are any unwanted effects.

\section{What are pressure ulcers?}

Pressure ulcers (also known as pressure sores or bed sores) are wounds to the skin and underlying tissue caused by prolonged pressure or rubbing. People who have mobility problems or who lie in bed for long periods are at risk of developing pressure ulcers.

\section{What did we want to find out?}

There are many types of beds, mattresses and overlays specifically designed for people with pressure ulcers. These can be made from a range of materials (such as foam, air cells and gel pads) and are divided into two groups:

- reactive (static) surfaces that apply a constant pressure to the skin; and

- active (alternating pressure) surfaces that regularly redistribute the pressure under the body.

We wanted to find out if different types of reactive and active surfaces:

- prevent pressure ulcers;

- help ulcers to heal;

- are comfortable and improve people's quality of life;

- have health benefits that outweigh their costs; and

- have any unwanted effects.

We also wanted to find out what the best treatment options are for either preventing or healing pressure ulcers.

\section{What did we do?}

We searched for Cochrane Reviews that summarised the results of all available carefully designed studies (controlled trials) evaluating different beds, mattresses and overlays in preventing and treating pressure ulcers. A Cochrane Review provides a high level of evidence on the effectiveness of healthcare interventions. We summarised the results of these reviews in a single document (called an overview of reviews).

We also collected studies included in these reviews and compared all available treatments at the same time in a single analysis (called network meta-analysis). We then summarised these results, and rated our confidence in the evidence, based on factors such as study methods and sizes.

\section{What did we find?}

\section{Effects in preventing pressure ulcers}

We found four reviews on the use of beds, mattresses and overlays for preventing pressure ulcers. From these, we included 40 studies (12,517 people) in a network meta-analysis evaluating reduction of pressure ulcer risk. The network meta-analysis evidence suggests that static (reactive) air overlays, alternating pressure air mattresses, and (reactive) gel pads used on operating tables may reduce pressure ulcer risk compared with foam mattresses.

We also included 10 studies (7211 people) in a network meta-analysis evaluating the time taken for new ulcers to develop. The network meta-analysis evidence suggests that reactive air surfaces may reduce the chances of developing new ulcers compared with foam surfaces.

\section{Effects in treating pressure ulcers}

We found two reviews on pressure ulcer healing. From these, we included four studies (397 people) in a network meta-analysis. The network meta-analysis evidence suggests that more people with ulcers may heal completely using reactive air surfaces than foam surfaces.

The overview evidence suggests that, if the time needed to completely heal an ulcer is looked at, reactive air surfaces may improve the chances of pressure ulcers healing when compared with foam mattresses.

Beds, overlays and mattresses for preventing and treating pressure ulcers: an overview of Cochrane Reviews and network meta-analysis 
However, it is unclear which treatment is best for either preventing or treating pressure ulcers.

\section{Other effects in preventing and treating pressure ulcers}

The overview evidence suggests that:

- compared with foam mattresses, alternating pressure air surfaces probably result in health benefits that outweigh their costs in preventing pressure ulcers;

- reactive air-filled surfaces may cost more than foam mattresses in healing ulcers; and

- the other benefits and risks of these beds, mattresses and mattress overlays are unclear.

\section{What are the limitations of the evidence?}

Although the reviews we found used reliable methods, most of the studies in them were small and used methods likely to introduce errors in their results.

\section{How up-to-date is this evidence?}

The evidence in this overview is current to July 2020.

Beds, overlays and mattresses for preventing and treating pressure ulcers: an overview of Cochrane Reviews and network meta-analysis 


\section{B A C K G R O U N D}

\section{Description of the condition}

Pressure ulcers (also known as pressure injuries, pressure sores, decubitus ulcers and bed sores) are localised injuries to the skin or underlying soft tissue, or both, caused by unrelieved pressure, shear (i.e. forces moving in opposite directions) or friction (NPIAP 2016). Pressure ulcer severity is generally classified using the National Pressure Injury Advisory Panel (NPIAP) system (NPIAP 2016).

- Stage 1: intact skin with a local appearance of non-blanchable erythema (i.e. skin redness)

- Stage 2: partial-thickness skin loss with exposed dermis

- Stage 3: full-thickness skin loss

- Stage 4: full-thickness skin and tissue loss with visible fascia (i.e. the soft connective tissue that holds structures in place), muscle, tendon, ligament, cartilage or bone

- Unstageable pressure injury: full-thickness skin and tissue loss that is obscured by slough or eschar (i.e. dead tissue) so that the severity of injury cannot be confirmed

- A deep tissue pressure injury: local injury of persistent, non-blanchable deep red, maroon, purple discolouration or epidermal separation revealing a dark wound bed or bloodfilled blister.

The stages of pressure ulceration described above are consistent with those described in the International Classification of Diseases for Mortality and Morbidity Statistics of the World Health Organization 2019.

Pressure ulcers are relatively common, complex wounds that affect people across different populations and different care settings. A systematic review found that prevalence estimates for people affected by pressure ulcers in communities of the United Kingdom (UK), USA, Ireland and Sweden ranged from 5.6 to 2300 per 10,000 , depending on the nature of the population surveyed and the denominators used for calculating these prevalence estimates (Cullum 2016). A subsequent, large, UK cross-sectional survey of people receiving community health services in one area of the UK estimated that 1.8 people per 10,000 have a pressure ulcer. This study used a total population figure denominator for the community services where the survey was undertaken (Gray 2018).

Pressure ulcers confer a heavy burden in terms of personal impact and health service resource use. Having a pressure ulcer may impair physical, social and psychological activities (Gorecki 2009). Ulceration impairs health-related quality of life (Essex 2009); can result in longer institution stays (Theisen 2012); and may increase the risk of systemic infection (Espejo 2018). Pressure ulceration also has substantial impacts on health systems: a 2015 systematic review of 14 studies across a range of care settings in Europe and North America showed that pressure ulcer-related treatment costs ranged between EUR 1.71 and 470.49 per person, per day (Demarré 2015). In the UK, the annual average National Health Service (NHS) cost attributable to managing one person with a pressure ulcer in the community was estimated to be GBP 1400 for a Stage 1 pressure ulcer and more than GBP 8500 for more severe stages (2015/2016 prices; Guest 2018). In Australia, the annual cost of treating pressure ulcers was estimated to be AUD 983 million (95\% confidence interval (CI) 815 to 1151 million) at 2012/2013 prices
(Nguyen 2015). The serious consequences of pressure ulceration have led to an intensive focus on their prevention.

\section{Description of the interventions}

Pressure ulcers are considered to be largely preventable via the use of pressure-relieving processes in those considered at risk. Additionally, pressure relief is part of the treatment offered to those with ulceration. Support surfaces are specialised medical devices designed to relieve or redistribute pressure on the body, or both, in order to prevent and treat pressure ulcers (NPIAP S3I 2019). Types of support surface include, but are not limited to, integrated bed systems, mattresses and overlays (NPIAP S3I 2019).

There are a number of different types of support surface, which can now be classified using the NPIAP Support Surface Standards Initiative (S3I) 'Terms and Definitions Related to Support Surfaces' (NPIAP S3I 2019). According to the NPIAP S3I terms and definitions, support surfaces may:

- be powered (i.e. require electrical power to function) or nonpowered;

- passively redistribute body weight (i.e. reactive pressure redistribution), or mechanically vary pressure on the body to reduce the duration of pressure on any one point (i.e. active pressure redistribution);

- be made of a range of materials including, but not limited to: air cells, foam materials, fibre materials, gel materials, sheepskin for medical use, and water-bags;

- be constructed of air-filled cells which have small holes on the surface through which air blows onto skin (i.e. low-air-loss feature) or have fluid-like characteristics via forcing filtered air through ceramic beads (i.e. air-fluidised feature), or have neither of these features.

Full details of support-surface classifications are listed in Appendix 1. Various types of beds, overlays and mattresses are available, with the aim of promoting pressure ulcer prevention and treatment, including alternating pressure (active) air surfaces, reactive air surfaces, foam surfaces and alternative reactive support surfaces that are made neither of foam materials nor air cells.

\section{How the intervention might work}

Support surfaces used with the aim of preventing and treating pressure ulcers aim to redistribute pressure beneath the skin of the body, in order to increase blood flow to tissues and relieve skin and soft tissue distortion (Wounds International 2010). Powered support surfaces are operated by electricity, unlike non-powered surfaces. Active support surfaces achieve pressure redistribution by frequently changing the points of contact between the surface and body, reducing the duration of the pressure applied to specific anatomical sites (Clark 2011; NPIAP S3I 2019). This contrasts with reactive support surfaces' mode of action, which is passive and includes immersion (i.e. 'sinking' of the body into a support surface) and envelopment (i.e. conforming of a support surface to the irregularities in the body). Reactive support surfaces distribute the pressure over a greater area, thereby reducing the magnitude of the pressure at specific sites (Clark 2011). Additionally, support surfaces with low-air-loss features are designed to improve the skin microclimate with the aim of maintaining skin and tissue integrity, particularly in people with incontinence (Wounds International 2010).

Beds, overlays and mattresses for preventing and treating pressure ulcers: an overview of Cochrane Reviews and network meta-analysis 


\section{Why it is important to do this overview}

Specific kinds of beds, mattresses and overlays are widely used for pressure ulcer prevention and treatment and are the focus of recommendations in key international and national guidelines, including the 2019 guideline published by a consortium of pressure ulcer organisations (EPUAP/NPIAP/PPPIA 2019), and the UK National Institute for Health and Care Excellence (NICE) 2014 guidelines (NICE 2014). These two guidelines both recommend using foam surfaces for preventing pressure ulcers. However, the EPUAP/NPIAP/PPPIA 2019 guideline also recommends considering the use of other support surface options but does not specify further options.

Several Cochrane Reviews evaluate the evidence for different beds, overlays and mattresses in preventing and treating pressure ulcers. These Cochrane Reviews include:

- 'Alternating pressure (active) air surfaces for preventing pressure ulcers' (Shi 2021a);

- 'Foam surfaces for preventing pressure ulcers' (Shi 2021b);

- 'Reactive air surfaces for preventing pressure ulcers' (Shi 2021c);

- 'Alternative reactive support surfaces (non-foam and non-airfilled) for preventing pressure ulcers' (Shi 2021d) (Differences between protocol and review);

- 'Beds, overlays and mattresses for treating pressure ulcers' (Shi 2021e) (Differences between protocol and review).

In this overview, we draw together key findings from these reviews into a single document for decision-makers. We summarise relevant Cochrane Reviews and the results of head-to-head comparisons of beds, overlays and mattresses in preventing and treating pressure ulcers. Where data are available, we also conduct network meta-analyses which simultaneously compare all alternative beds, overlays and mattresses to investigate which may be most effective for preventing and treating pressure ulcers.

\section{OB JECTIVES}

To summarise evidence from Cochrane Reviews that assess the effects of beds, overlays and mattresses on reducing the incidence of pressure ulcers and on increasing pressure ulcer healing in any setting and population.

To assess the relative effects of different types of beds, overlays and mattresses for reducing the incidence of pressure ulcers and increasing pressure ulcer healing in any setting and population.

To cumulatively rank the different treatment options of beds, overlays and mattresses in order of their effectiveness in pressure ulcer prevention and treatment.

\section{METHODS}

This section describes the methods for this overview of reviews and the network meta-analysis. We largely focus on describing the overview process. Where required, we briefly describe specific methods related to the network meta-analysis, for reference. Full details of the network meta-analysis can be found in Appendix 2.

\section{Criteria for considering reviews for inclusion}

\section{Types of reviews and studies}

We included current versions of published Cochrane Reviews, and Cochrane Reviews which are now published but were ongoing when the electronic search was run, where only randomised controlled trials (RCTs) evaluating beds, overlays and mattresses in pressure ulcer prevention and treatment were eligible (Differences between protocol and review). All studies included in these reviews are part of the overview and were considered for inclusion in the network meta-analysis.

We also re-screened RCTs that were excluded from the eligible systematic reviews for the network meta-analysis to assess if they could contribute data (an RCT may have been excluded due to comparison with an ineligible intervention but may still contribute information to the network meta-analysis if the ineligible intervention is a common comparator to link eligible support surfaces into a network) (see Appendix 2). We excluded the ongoing studies and studies awaiting assessment identified in eligible reviews.

\section{Types of participants}

For pressure ulcer prevention, Cochrane Reviews involving any population, in any setting, were eligible.

For pressure ulcer treatment, Cochrane Reviews involving people with existing pressure ulcers, of any stage and in any setting, were eligible.

\section{Types of interventions}

We included reviews that assessed the effects of specific kinds of beds, overlays and mattresses (see Description of the interventions). Based on the NPIAP S3I terms and definitions related to support surfaces (NPIAP S3I 2019), eligible interventions included but were not limited to:

- alternating pressure (active) air surfaces;

- foam surfaces;

- reactive air surfaces;

- reactive fibre surfaces;

- reactive gel surfaces;

- reactive sheepskin surfaces; and

- reactive water surfaces.

We excluded reviews that evaluated limb protectors, chair cushions, seat cushion overlays, traditional Chinese herb-filled surfaces, homemade surfaces, and turning beds.

\section{Types of outcome measures}

\section{Primary outcomes}

For pressure ulcer prevention, the primary outcome was pressure ulcer incidence, reported as proportion of participants developing a new pressure ulcer of any stage or time to pressure ulcer development.

For pressure ulcer treatment, the primary outcome was complete healing of existing pressure ulcers, reported as the proportion of participants with healed pressure ulcers or time to pressure ulcer healing.

Beds, overlays and mattresses for preventing and treating pressure ulcers: an overview of Cochrane Reviews and network meta-analysis 


\section{Secondary outcomes}

We included the following secondary outcomes in this overview of reviews. Our network meta-analyses only included primary outcomes.

- Support surface-associated patient comfort. The definition and measurement of this outcome varied from one review to another and were not restricted by included reviews; for example, the proportion of participants who report comfort, or comfort measured by a scale with continuous (categorical) numbers.

- All reported adverse events (measured using surveys, questionnaires, data capture process or visual analogue scales). We considered the assessment of any event in general defined as adverse by participants, health professionals, or both.

- Health-related quality of life (HRQOL) (measured using a standardised generic questionnaire such as EQ-5D (Herdman 2011), or pressure ulcer-specific questionnaires such as the PURPOSE Pressure Ulcer Quality of Life (PU-QOL) questionnaire (Gorecki 2013)). We present evidence on overall scores of questionnaires used rather than reporting multiple domain scores from the same measure.

- Cost-effectiveness. Data extracted were incremental mean cost per incremental gain in benefit (incremental cost-effectiveness ratio (ICER)) and other measures of relative cost-effectiveness (e.g. net monetary benefit, net health benefit).

We recorded outcome data from any time points specified in eligible reviews. Eligible reviews considered evidence on an outcome measure at multiple time points. We considered outcome measures at three months, or those closest to three months, as the primary interest of this overview (Schoonhoven 2007), regardless of the time points specified as being of primary interest by the review itself. Where a review only reported a single time point or did not specify a time point for its outcome measurement, we nevertheless included these data in this overview. For all outcomes, we classed:

- one week or less up to eight weeks as short-term follow-up;

- more than 8 weeks to 16 weeks as medium-term follow-up;

- more than 16 weeks as long-term follow-up.

\section{Search methods for identification of reviews}

\section{Electronic searches}

We searched the Cochrane Database of Systematic Reviews (CDSR) in the Cochrane Library for any reviews with search terms related to 'support surfaces' and 'pressure ulcers' in the title, abstract or keyword fields. We identified studies to include in the network meta-analysis by screening the reviews that met our inclusion criteria.

\section{Data collection and analysis}

\section{Selection of reviews}

Two overview authors (CS and ELG) independently assessed the titles and abstracts of the search results for relevance. These authors then independently inspected the full texts of all potentially eligible reviews for the overview. They resolved disagreements by discussion to reach consensus.
Once decisions had been made on the included reviews, two overview authors (CS and ELG) independently screened the included and excluded studies from each review for inclusion in the network meta-analysis. The two reviewers resolved disagreements by discussion to reach consensus.

\section{Data extraction and management}

For this overview, we extracted the following data from each included review onto a pre-prepared and piloted data extraction form.

- Review identification and the review author.

- Review titles and objectives.

- Search date.

- Review inclusion and exclusion criteria.

- Number of included trials and participants.

- Settings included.

- Participant characteristics including mean age, proportions of participants by gender, and participants' baseline skin status if available.

- All comparisons of beds, overlays and mattresses.

- Methods and results of risk of bias of the included trials.

- Outcomes presented and time points of outcome data.

- Narrative summary of data and meta-analysis results (e.g. effect sizes and 95\% confidence intervals (Cls)).

- Details of heterogeneity assessment.

- GRADE assessments.

- Details of subgroup and sensitivity analyses where available.

One overview author extracted data, which a second author independently checked.

For network meta-analyses, we extracted the following data for each relevant study, ideally from the review and, where required, from the trial publication itself.

- Study design.

- Care setting.

- Characteristics of participants (average age, proportions of participants by gender, and participants' baseline skin status).

- Beds, overlays and mattresses or other interventions being compared.

- Follow-up duration.

- Number of participants randomised and analysed.

- Number of participants lost to follow-up.

- Number of participants developing new ulcers or healing rates of existing pressure ulcers.

We found that several trials of beds, overlays and mattresses for pressure ulcer prevention appeared in more than one review. In this case we reconciled data across these reviews to avoid duplication of evidence in the overview and double-counting of trial data in the network meta-analysis.

\section{Assessment of methodological quality of included reviews}

\section{Assessment of risk of bias in included reviews for overview}

Two overview authors (CS and ELG; or ELG and GN) who were not authors of the included Cochrane Review independently assessed

Beds, overlays and mattresses for preventing and treating pressure ulcers: an overview of Cochrane Reviews and network meta-analysis 
risk of bias using the ROBIS tool (Whiting 2016). ROBIS assesses risk of bias in three phases: first, assessing relevance (optional); second, identifying concerns with the review process; and third, forming an overall judgement of the risk of bias. In the second phase, concerns with the review process can be identified for four specific domains:

- Study eligibility criteria: assessing whether eligibility criteria of included reviews were pre-specified, clear and appropriate to the review question.

- Identification and selection of studies: assessing whether any trials that would have met the inclusion criteria of a review were not included in the review.

- Data collection and study appraisal: assessing whether bias may have been introduced during the data collection or risk of bias assessment processes.

- Synthesis and findings: assessing whether, when the review authors decided to pool data from the included trials (either in a quantitative or qualitative synthesis), the review authors have used appropriate methods to do so (Whiting 2016).

Concerns can be graded as 'low', 'high' or 'unclear'. We noted the rationale for decisions at each stage. As this overview only included Cochrane Reviews and relevance has been considered as part of our screening and selection process, we did not assess relevance using the ROBIS tool (an optional first phase).

Any disagreements between two overview authors were resolved by discussion; involvement of a third overview author was not required.

\section{Assessment of risk of bias in included studies for network meta-analyses}

For RCTs in the network meta-analyses, we used the results of the overall risk of bias of the included trials that had already been assessed by the review authors.

One RCT in the network meta-analyses had not previously undergone risk of bias assessment. Two overview authors (CS and ELG) independently undertook this using Cochrane's risk of bias tool (Higgins 2017).

We present overall risk of bias judgements for the included studies based on (1) all risk of bias domains; and (2) all but the performance bias domain (Differences between protocol and review). We note further details about risk of bias assessment in Appendix 3.

\section{Assessment of risk of bias for direct comparisons, each network contrast and a network as a whole}

We used the approach proposed in Salanti 2014 to assess the overall risk of bias for direct evidence (i.e. evidence from the headto-head comparison of two interventions), each network contrast (any pair of interventions in the network), and each network as a whole, as follows.

- We used the study-level overall risk of bias judgement without considering the performance bias domain to assess the risk of bias for each direct comparison of two interventions.

- We assessed risk of bias for each contrast in the network, taking into account the study-level risk of bias and their percentage contributions to the network estimate.
- We also calculated the overall risk of bias in the network as a whole by considering the risk of bias for each direct comparison and their percentage contributions to the whole network.

For changes to this section, please see Differences between protocol and review.

\section{Data synthesis}

\section{Measures of treatment effect}

For dichotomous outcome data (e.g. pressure ulcer incidence), we present the risk ratio (RR) with its $95 \%$ confidence interval $(\mathrm{Cl})$. For continuous outcome data, we present the mean difference (MD) with $95 \% \mathrm{Cls}$ for studies that used the same assessment scale. If studies reporting continuous data used different assessment scales, we report the standardised mean difference (SMD) with $95 \%$ Cls.

For time-to-event data (e.g. time to pressure ulcer development), we present the hazard ratio (HR) with its $95 \% \mathrm{Cl}$. For those included studies reporting time-to-event data that did not report an $\mathrm{HR}$, we estimated this using other reported outcomes, such as numbers of events, through employing available statistical methods (Parmar 1998; Tierney 2007).

For network meta-analyses, we also present the relative ranking of each bed, overlay and mattress support surface based on the estimated probability of that surface being the most effective (in terms of ulcer prevention or healing). These values are a cumulative probability called the Surface Under the Cumulative RAnking (SUCRA) (Salanti 2011). A SUCRA value can range from 0\% to $100 \%$ and the larger the SUCRA value, the higher the ranking of a bed, overlay or mattress support surface for the outcome of interest (Chaimani 2013; Salanti 2011).

\section{Methods for overview data presentation and synthesis}

The aim of this overview was to present a detailed summary of evidence on beds, overlays and mattresses for pressure ulcer prevention and treatment. We present all eligible comparisons grouped by intervention type. We used tabular formats and narrative techniques to present evidence summaries alongside the GRADE assessment for each comparison; and if the included reviews did not undertake GRADE assessment then we undertook it. Where possible, we also present results of meta-analyses, along with details of effects models and measures of statistical heterogeneity (i.e. Chi ${ }^{2}$ tests and relevant $P$ values, and $\mathrm{I}^{2}$ statistics). Where meta-analyses had not been undertaken, we report studylevel effects narratively. We did not present results of subgroup and sensitivity analyses as the included reviews did not have sufficient data for any planned subgroup analysis, and sensitivity analyses reported in included reviews did not suggest any differences (Differences between protocol and review).

We present the certainty of evidence for eligible outcomes and comparisons from each included Cochrane Review in a summary of findings table. The table is designed according to the summary of findings table template proposed in Yepes-Nuñez 2019 for network meta-analysis. The table includes participants, interventions, comparators, outcomes, settings, the number of studies, the number of total participants, effect sizes and $95 \% \mathrm{Cls}$, anticipated absolute effects and $95 \% \mathrm{Cls}$ of each group and difference between groups, certainty of evidence, and interpretation of findings.

Beds, overlays and mattresses for preventing and treating pressure ulcers: an overview of Cochrane Reviews and network meta-analysis 


\section{Methods for network meta-analyses}

We conducted three separate network meta-analyses: one for the proportion of participants developing a new pressure ulcer; one for time to pressure ulcer development; and one for the proportion of participants with healed pressure ulcers. We did not identify sufficient data for the pre-planned analysis for time to pressure ulcer healing outcome.

Unit of analysis, missing data, homogeneity and transitivity assumptions, and reporting bias have impacts on the validity of network meta-analysis. Prior to carrying out network metaanalysis, we addressed those issues using methods described in Appendix 2. Here, transitivity means that important clinical and methodological characteristics (effect modifiers) at the comparison (rather than study) level are similar enough that we can assume that intervention effects are transitive across network contrasts.

We synthesised RCT data using the published network commands and network graph packages of STATA for network meta-analysis and graphically present results (Chaimani 2013; Chaimani 2015; White 2015). We estimated the relative effectiveness of any two interventions as a function of each intervention relative to the reference intervention (foam surfaces).

Using STATA (networkplot), we produced a network plot of the included beds, overlays and mattresses for each network metaanalysis, to understand the geometry of the evidence base and to inform the analysis. The term 'networkplot', as well as 'network meta' and 'sucra' in the paragraphs below, refer to commands developed for the STATA software package. We excluded studies with one eligible arm where the arm could not be connected to the network in any way.

We performed network meta-analyses using multivariate metaregression models in STATA (network meta) to estimate the relative effects for network contrasts. This modelling approach addresses correlations between the effect sizes from multi-arm studies. We fitted a consistency model that assumes an agreement between direct and indirect evidence, and we assumed that a bed, overlay or mattress support surface has the average effect size for a range of similar populations (random-effects model). Note that indirect evidence is obtained from comparisons of treatments via a common comparator.

\section{Methods for network meta-analyses' relative rankings}

On the basis of relative effect estimates of each bed, overlay and mattress, we calculated the SUCRA percentages to estimate the relative rankings of bed, overlay and mattress support surfaces in STATA (sucra), and also presented a cumulative rank probability plot (Differences between protocol and review). We estimated the relative rankings for each network meta-analysis, presenting a cumulative rank probability plot for each bed, overlay and mattress - this is a plot of the cumulative rank probabilities that each intervention is less than or equal to a specific rank order against the possible rankings (Chaimani 2013).

\section{Assessing the certainty of evidence and summary of findings tables for network meta-analyses}

We assessed the certainty of evidence for the network metaanalyses using the GRADE approach proposed by Salanti 2014 via the Confidence in the Results of Network Meta-Analysis (CINeMA) tool (Nikolakopoulou 2020). We assessed the certainty of evidence in two ways: (1) for each network contrast; and (2) for the network as a whole (assessing the certainty of the relative ranking)

The GRADE assessment using CINeMA involves consideration of six domains: within-study bias; across-studies bias (publication bias); indirectness; imprecision; heterogeneity; and incoherence (inconsistency). To make the within-study bias judgement, CINeMA evaluates the contributions of the included studies to each network contrast, producing the percentage contribution matrix (Nikolakopoulou 2020). These contributions are then used to weight study-level risk of bias results to estimate the network contrast-level within-study bias (Nikolakopoulou 2020). The certainty of evidence can be assessed as being high, moderate, low or very low. RCT evidence has the potential to be high certainty.

We present a separate summary of findings table for each network meta-analysis undertaken. We present the following primary outcomes in the summary of findings tables.

- Proportion of participants developing a new pressure ulcer.

- Time to pressure ulcer development.

- Proportion of participants with healed pressure ulcers.

- Time to pressure ulcer healing.

\section{Subgroup analysis and investigation of heterogeneity in the network meta-analyses}

\section{Assessment of statistical heterogeneity and inconsistency}

We assessed the presence of the common network statistical heterogeneity in network meta-analyses using the $\mathrm{I}^{2}$ statistic and its $95 \% \mathrm{Cls}$ or $\mathrm{Tau}^{2}$, or both (see Appendix 2 for further details). We also assessed inconsistency at levels of local loops, and the whole network using methods described in Appendix 2. Inconsistency refers to statistical disagreement between direct and indirect evidence and is a manifestation of non-transitivity (Cipriani 2013).

\section{Investigation of heterogeneity (including subgroup analysis)}

Where a network had important heterogeneity, we followed steps proposed by Cipriani 2013 to investigate this further. We performed subgroup analyses for binary and categorical factors (or metaregression for continuous factors) for the following four study-level characteristics.

- Overall risk of bias (binary: low or unclear risk of bias; and high risk of bias) (Schulz 1995).

- Settings (categorical: acute care and other hospital settings; long-term care settings; operating theatre setting; and intensive care unit).

- Baseline skin status (categorical: participants at risk, other skin status or non-reporting; non-blanchable erythema; existing ulcers of stage 2 or more severe) (Shi 2018b).

- Follow-up duration (categorical: short-term; medium-term; and long-term) (Schoonhoven 2007) (Differences between protocol and review).

\section{Sensitivity analysis for the network meta-analyses}

We assessed the robustness of our findings via a sensitivity analysis to assess the impact of missing data. We also undertook a post hoc sensitivity analysis to assess the impact of including only well-

Beds, overlays and mattresses for preventing and treating pressure ulcers: an overview of Cochrane Reviews and network meta-analysis 
defined support surfaces in the pressure ulcer incidence network meta-analysis.

Further details about heterogeneity investigation and sensitivity analysis are given in Appendix 2.

\section{RESULTS}

See Characteristics of included reviews (Appendix 4).

\section{Description of included reviews}

\section{Overview of reviews: description of included reviews}

The search generated 22 records. We excluded 13 records based on the title and abstract, and assessed nine in full text. Of these, we considered six Cochrane Reviews eligible for this overview: McGinnis 2014 and another five reviews (Shi 2021a; Shi 2021b; Shi 2021c; Shi 2021d; Shi 2021e) that were ongoing when the electronic search was run but are published now (See Figure 1). 
Figure 1. Study flow diagram

One additional
record identified
through other
sources

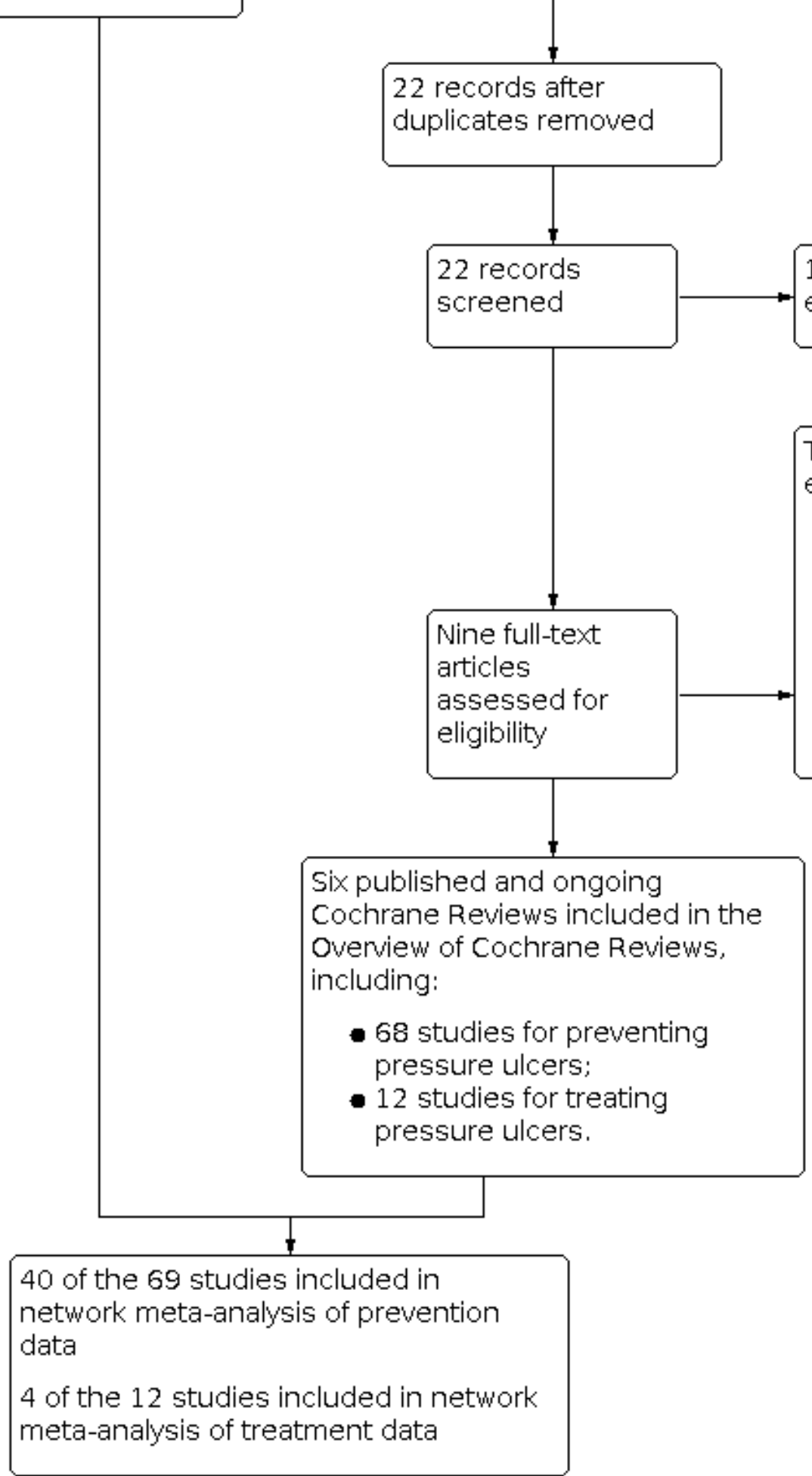
duplicates removed

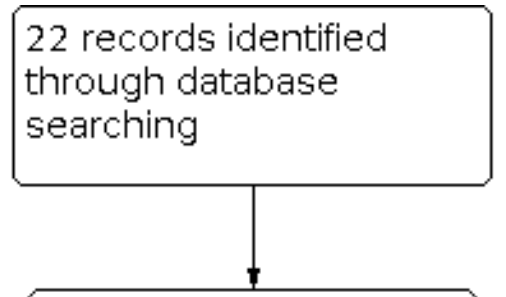

22 records after

Three full-text articles excluded, with reasons

- Two reviews are the previous versions of the included ongoing reviews

- One is a withdrawn Cochrane Review protocol 
We excluded two reviews as they are previous versions of the included reviews (Mclnnes 2015; Mclnnes 2018). We also excluded a withdrawn Cochrane Review protocol (Greenwood 2017).

See Appendix 4 for a summary of characteristics of the six included reviews.

Of the six reviews, four focused on the use of beds, mattresses or overlays for preventing pressure ulcers (Shi 2021a; Shi 2021b; Shi 2021c; Shi 2021d). These four reviews report evidence on pressure ulcer incidence for 27 pairwise comparisons, time to pressure ulcer incidence for seven comparisons, patient comfort responses for 11 comparisons, all reported adverse events for six comparisons, health-related quality of life for two comparisons, and cost-effectiveness for four comparisons (see Appendix 5). These comparisons involved 12 types of beds, mattresses and overlays:

- alternating pressure (active) air surfaces;

- foam surfaces;

- reactive gel surfaces followed by foam surfaces;

- reactive air surfaces;

- reactive gel surfaces;

- reactive fibre surfaces;

- reactive sheepskin surfaces;

- reactive water surfaces;

- reactive foam and gel surfaces;

- Aiartex surfaces, a brand of support surfaces that could not be classified using the NPIAP S3I support surface terms and definitions;

- Bedcare surfaces, a brand of support surfaces that could not be classified; and

- 'standard hospital surfaces' that could not be classified.

Two of the six reviews focused on the use of beds, mattresses or overlays for treating pressure ulcers (McGinnis 2014; Shi 2021e). These reviews report evidence on the proportion of participants with pressure ulcers completely healed for five comparisons, time to complete pressure ulcer healing for one comparison, support surface-associated patient comfort for five comparisons, all reported adverse events for six comparisons, and cost-effectiveness for one comparison (see Appendix 6). These comparisons involved seven types of beds, mattresses or overlays:

- alternating pressure (active) air surfaces;

- reactive air surfaces;

- foam surfaces;

- reactive gel surfaces;

- reactive water surfaces;

- a type of reactive surface (Aiartex) that we could not define using NPIAP S3I 2007 support surface terms; and

- 'standard hospital surfaces' that could not be classified.

\section{Methodological quality of included reviews}

\section{ROBIS quality of included reviews}

\section{See Appendix 7.}

We judged the overall risk of bias of included reviews using the ROBIS tool to be low for five reviews (Shi 2021a; Shi 2021b; Shi 2021c; Shi 2021d; Shi 2021e), and unclear for one review (McGinnis 2014).

Our judgements of the risk of bias for the four domains in ROBIS were as follows:

- we judged the domain of 'study eligibility' to be of low concern for all included reviews;

- we judged the domain of 'study identification and selection' to be of low concern for all included reviews;

- we judged the domain of 'data collection and study appraisal' to be of low concern for five included reviews (Shi 2021a; Shi 2021b; Shi 2021c; Shi 2021d; Shi 2021e), but unclear for McGinnis 2014 because it evaluated the ulcer healing outcome but appeared not to collect data on key baseline characteristics of pressure ulcers from its included studies;

- we judged the domain of 'synthesis and findings' to be of low concern for five included reviews (Shi 2021a; Shi 2021b; Shi 2021c; Shi 2021d; Shi 2021e), but unclear for McGinnis 2014 because it did not consider certainty of evidence assessment.

\section{Certainty of evidence in included reviews}

Of the six included reviews, five reported GRADE assessment, whilst McGinnis 2014 did not assess the certainty of evidence. For this latter review, we undertook GRADE assessment of relative treatment-effect data.

Overall, the GRADE certainty of evidence was mainly low or very low, as summarised in Appendix 5 and Appendix 6. Of the 27 comparisons with pressure ulcer incidence data, we judged $3.7 \%$ of findings (1/27) to be of moderate certainty, $25.9 \%(7 / 27)$ of low certainty, and $63.0 \%(17 / 27)$ of very low certainty. The remaining two $(7.4 \%)$ comparisons included studies that had no analysable data or results for evidence synthesis, thus no GRADE assessment.

Of the five comparisons presenting pressure ulcer healing outcome data, we judged $20.0 \%(1 / 5)$ of findings to be of low certainty and $80.0 \%(4 / 5)$ to be of very low certainty.

Common reasons for downgrading the certainty of evidence were risk of bias of included studies, imprecision and inconsistency.

\section{Effect of interventions}

We report evidence on pressure ulcer prevention in Section 1 and treatment evidence in Section 2. In each section, we summarise the key findings of the overview of reviews for each available outcome: we present full review findings in Appendix 5 (for prevention evidence) and Appendix 6 (for treatment evidence). For primary outcomes, we also report findings of network metaanalysis, following their overview summaries.

\section{Section 1. Beds, overlays and mattresses for preventing pressure ulcers}

See Appendix 5 for full details of evidence for all outcomes as reported in included reviews.

For pressure ulcer incidence and time to ulcer development, we give a summary of overviews of reviews and then focus on findings from the relevant network meta-analyses.

Beds, overlays and mattresses for preventing and treating pressure ulcers: an overview of Cochrane Reviews and network meta-analysis 


\section{Pressure ulcer incidence}

\section{Overview of reviews}

Four reviews reported evidence on 27 specific direct comparisons of beds, overlays and mattresses for preventing pressure ulcers (Shi 2021a, Shi 2021b, Shi 2021c, Shi 2021d; Appendix 5). Of the 27 comparisons,

- 21 are between two different types of support surface and their results are reported in Table 1;

- four are between two support surfaces of the same type;

- two have no data on this outcome for any synthesis (foam surfaces versus reactive water surfaces; and reactive water surfaces versus reactive fibre surfaces), thus no corresponding results are presented.

As Table 1 indicates, of the 21 comparisons between different types of support surface, 14 comparisons yield very low-certainty evidence regarding their relative effects (downgraded mainly for risk of bias and imprecision). The remaining seven comparisons have moderate-certainty or low-certainty evidence, suggesting that:

- reactive air surfaces may reduce pressure ulcer risk compared with foam surfaces for people in acute and long-term care settings;

- alternating pressure (active) air surfaces may reduce pressure ulcer risk compared with foam surfaces for people in acute and long-term care settings;

- alternating pressure (active) air surfaces applied on both operating tables and hospital beds may reduce pressure ulcer risk compared with reactive gel surfaces used on operating tables followed by foam surfaces applied on hospital beds;

- alternating pressure (active) air surfaces may reduce pressure ulcer risk compared with standard hospital surfaces for people in acute and long-term care settings;

- in operating rooms, reactive gel surfaces probably reduce pressure ulcer risk compared with 'standard hospital surfaces' that were not well described;

- reactive water surfaces may reduce pressure ulcer risk compared with 'standard hospital surfaces' for people in acute care settings; and

- reactive sheepskin surfaces may reduce pressure ulcer risk compared with 'standard hospital surfaces' for people in acute and long-term care settings.

For the four comparisons between two support surfaces of the same type, there may be little to no difference in pressure ulcer incidence between different alternating pressure (active) air surfaces. However, it is unclear if there is a difference in pressure ulcer incidence between different types of reactive air surfaces, foam surfaces or reactive gel surfaces. These comparisons each yield very low-certainty evidence.

\section{Network meta-analysis (prevention network)}

\section{Descriptions of included studies for network meta-analysis}

We identified 68 potentially eligible studies ( 18,174 participants) for the network meta-analysis from the four reviews noted above (Shi 2021a; Shi 2021b; Shi 2021c; Shi 2021d). These studies compared two or more eligible beds, mattresses or overlays.

Of these 68 studies:

- 39 compared two or more eligible interventions and were included in the NMA; and

- 29 compared two or more eligible interventions but could not be joined into the NMA: 22 of these studies compared two or more of the same type of support surface and the remaining seven studies did not report any relevant data for analysis.

By screening the reference lists of four included reviews, we identified one more eligible study (Vanderwee 2005): it compared alternating pressure air surfaces (an eligible intervention) with foam surfaces plus four-hourly turning (an ineligible intervention) and could connect to the network (see Figure 1). We also identified an ongoing RCT (NCT03351049): it compared reactive support surfaces with low air loss (i.e. reactive air surfaces) with reactive support surfaces without low air loss but provided no data for analysis. Overall, there was a total of 69 studies $(18,621$ participants). See Table 1 in Appendix 8 for the characteristics of these studies. See Appendix 9 for the references of these 69 studies.

Of the 69 studies, 40 connected to a network (with 12,517 participants having available data; median study sample size: 119 participants). See Table 2 in Appendix 8 for the summary characteristics across the 40 studies. The average participant age, specified in 38 studies, ranged from 37.2 to 87.0 years (median: 72.5 years). Among the 38 studies with participant sex specified, 4702 (45.1\%) of participants were male and 5730 (54.9\%) were female. Most of the studies (34/40) recruited people at risk of having a new ulcer, with risk assessed largely using the Waterlow, Norton or Braden scales $(n=11,845)$, and most of these participants were free of pressure ulcers at baseline $(n=9018)$. The median followup duration of the included studies was 14 days (range: 5 days to 7 months). Most of the 27 studies with specified details were funded by industry. Most of the studies were conducted at acute care settings $(21 / 40)$.

\section{Descriptions of base-case network}

As Appendix 8 notes, 40 of the 69 studies connect into a network involving 13 interventions (termed base-case network hereafter) (Figure 2). 
Figure 2. Prevention network: network plot for the base-case network for pressure ulcer incidence outcome. We weighted node (circle) size by the number of studies reporting each intervention and weighted the thickness of the edge lines according to the inverse variance of the treatment effect estimates for the direct evidence contrast. We indicated the overall risk of bias for each direct comparison in the network diagram, using colour for three risk of bias ratings: low (green), unclear (yellow), and high (red).

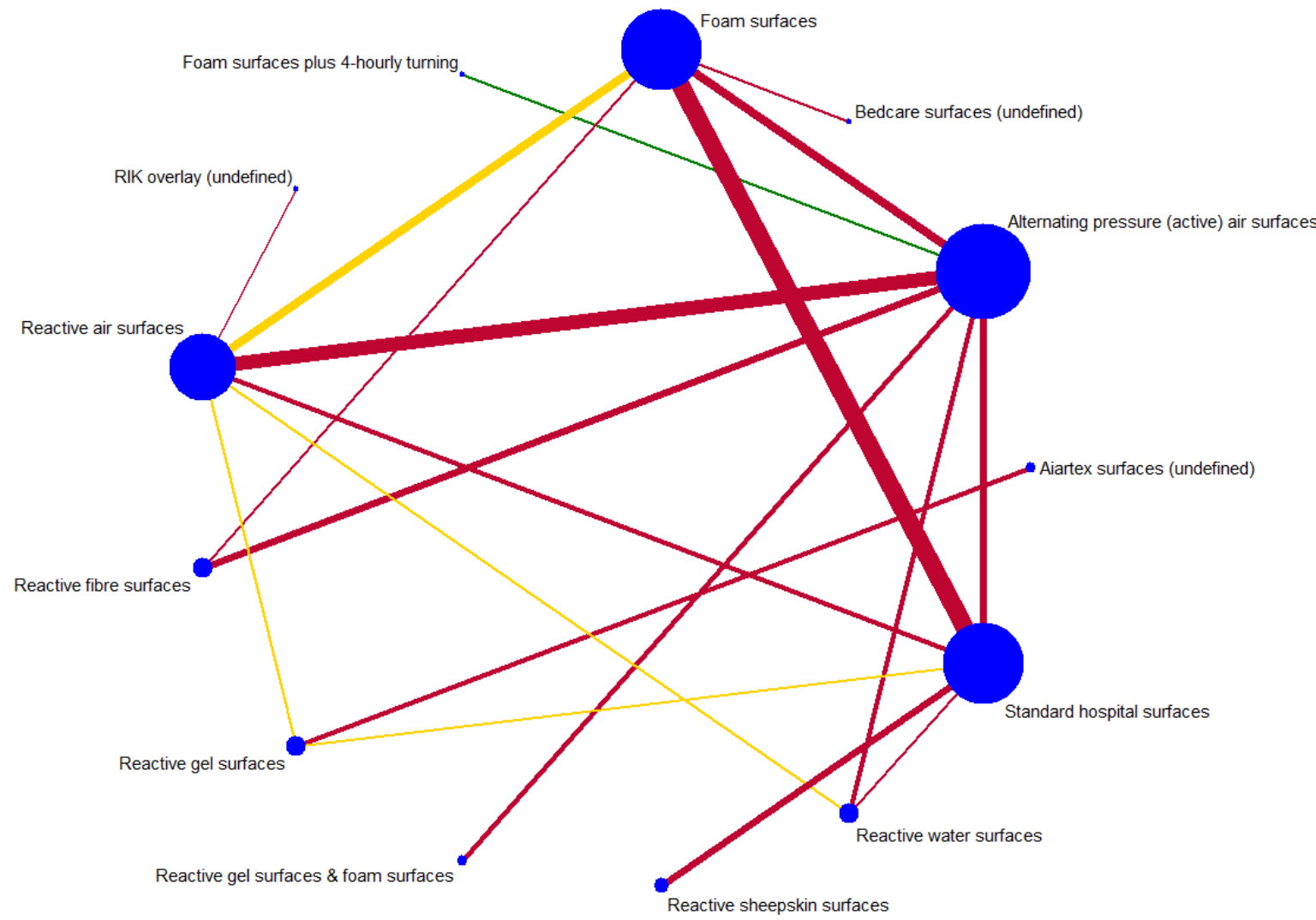

The network has nine triangular loops (i.e. a set of three interventions that are connected to make a triangle in a network). This network has 78 network contrasts and 19 of these are direct contrasts: $42.1 \%(8 / 19)$ of direct contrasts were informed by only one study (see Table 3 in Appendix 8). Of the total 12,517 participants, $1298(10.5 \%)$ participants developed new pressure ulcers. The 19 direct contrasts have a median of 316 participants (range: 37 to 4042), and $73.7 \%$ (14/19) of direct contrasts had fewer than 500 participants. The average number of events per network contrast was around 17 (1298/78).

Risk of bias for direct comparisons, each network contrast and the whole base-case network

We summarise risk of bias assessments for the included studies in the topic of prevention (see Figure 7 in Appendix 8). Of the 40 studies contributing data to network meta-analysis, two were rated low risk of bias, 16 were rated unclear, and 22 were rated high.

We have indicated the overall risk of bias for each direct comparison in the network diagram in Figure 2: five of the 19 direct comparisons were at low (green) or unclear (yellow) risk of bias whilst the remaining 14 were at high risk (red). Therefore, the overall risk of bias in the network as a whole was high.

We report risk of bias for each network contrast (see Figure 8 in Appendix 8). We considered eight of all 78 contrasts having data at low risk of bias (less than $25 \%$ of study data being of high risk of bias), 32 having data at unclear risk of bias (25\% to $50 \%$ of study data being of high risk of bias), and 38 having data at high risk of bias (more than $50 \%$ of study data being of high risk of bias).

\section{Network meta-analysis results}

See Table 2 summary of findings table for key comparisons with foam surfaces from the prevention network. Here we report relative effectiveness evidence for network contrasts between each eligible and well-defined support surface versus foam surfaces. We did not include in the table support surfaces that could not be classified and the ineligible intervention.

We undertook random-effects network meta-analyses. We assessed the transitivity, homogeneity and consistency assumptions for the base-case network and considered that transitivity and consistency assumptions held (see Appendix

Beds, overlays and mattresses for preventing and treating pressure ulcers: an overview of Cochrane Reviews and network meta-analysis 14 (Review)

Copyright (C) 2021 The Authors. Cochrane Database of Systematic Reviews published by John Wiley \& Sons, Ltd. on behalf of The Cochrane Collaboration. 
8). In terms of transitivity, the 19 direct contrasts - though heterogeneous in terms of risk of bias, and follow-up duration - are homogeneous in terms of care settings, and participants' characteristics summarised at the level of direct contrasts (i.e. the proportions of sex, age and baseline skin status). Regarding consistency, the estimates of treatment effects from direct and indirect evidence are consistent globally (global design-bytreatment interaction model: $\mathrm{X} 2$ statistic $=3.853, \mathrm{P}$ value $=0.921$ ) and locally (no inconsistency resulting from the tests of separating indirect from direct evidence). We present the results of the heterogeneity assessment below.

We report the analysis results in two ways:

\section{- Relative effectiveness results}

We report risk ratios (RRs) with their $95 \% \mathrm{Cls}$ for each network contrast. See Figure 3.

Figure 3. Prevention network: relative effectiveness results for $\mathbf{7 8}$ network contrasts

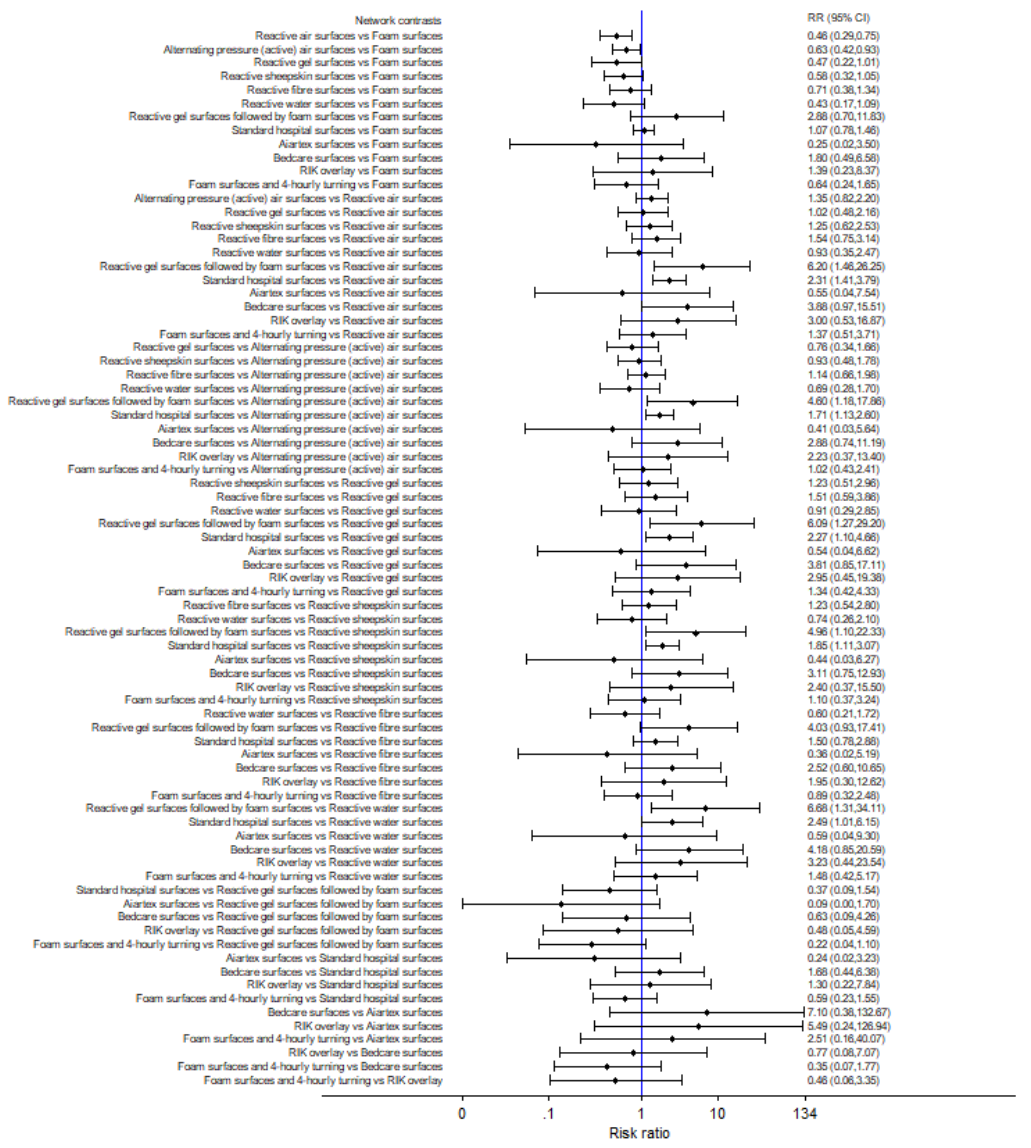

The relative effectiveness estimates of almost all network contrasts had wide confidence intervals and crossed $R R=1$, meaning imprecise estimates that do not rule out the possibility of noeffect. Nine contrasts had moderate or substantial heterogeneity (Appendix 8) and the majority of network contrasts were informed by studies at high risk of bias (see Figure 8 in Appendix 8). For GRADE assessment, the wide confidence intervals, heterogeneity and high risk of bias resulted in:

- $82.1 \%$ of contrasts (64/78) having very low-certainty evidence (downgraded three times);

- $14.1 \%(11 / 78)$ having low-certainty evidence (downgraded twice);

- $3.8 \%(3 / 78)$ having moderate-certainty evidence (downgraded once)
Full details of the GRADE assessment can be found in Appendix 8 .

Because of the volume of available data presented in this network analysis, we will focus on contrasts involving the five key types of support surface, chosen post hoc as likely to be the most informative for practice: alternating pressure (active) air surfaces, reactive air surfaces, foam surfaces, reactive sheepskin surfaces, and reactive gel surfaces (these support surfaces are probably more widely used than other options). None of the comparisons between these surfaces yields moderate-certainty evidence. (The only contrasts where the evidence was of moderate certainty were those involving reactive gel surfaces on operating tables followed by foam surfaces on ward beds. However, the sequential use of these two types of support surfaces is relevant specifically to operating rooms and we did not consider this combination as a key intervention here). We have low-certainty evidence (downgraded

Beds, overlays and mattresses for preventing and treating pressure ulcers: an overview of Cochrane Reviews and network meta-analysis 
once for within-study bias and once for heterogeneity, or twice for imprecision) for four key comparisons:

- compared with foam surfaces, reactive air surfaces may reduce pressure ulcer incidence ( $\mathrm{RR} 0.46,95 \% \mathrm{Cl} 0.29$ to 0.75 ). Extrapolating from the data, if 106 people per 1000 on foam surfaces will develop a new pressure ulcer by an average of 14 days' follow-up, then 57 fewer people per 1000 will develop a pressure ulcer on reactive air surfaces ( $95 \% \mathrm{Cl} 26$ to 75 fewer) (see Table 2);

- compared with foam surfaces, alternating pressure (active) air surfaces may reduce pressure ulcer incidence (RR 0.63, $95 \% \mathrm{Cl} 0.42$ to 0.93 ). Extrapolating from the data, if 106 people per 1000 on foam surfaces will develop a new pressure ulcer by an average of 14 days' follow-up, then 39 fewer people per 1000 will develop a pressure ulcer on alternating pressure (active) air surfaces (95\% Cl 8 to 62 fewer) (see Table 2);

- compared with foam surfaces, reactive gel surfaces may reduce pressure ulcer incidence (RR $0.47,95 \% \mathrm{Cl} 0.22$ to 1.01 ). Extrapolating from the data, if 106 people per 1000 on foam surfaces will develop a new pressure ulcer by an average of 14 days' follow-up, then 56 fewer people per 1000 will develop a pressure ulcer on reactive gel surfaces $(95 \% \mathrm{Cl} 83$ fewer to 1 more) (see Table 2); and

- the difference between reactive gel surfaces and reactive air surfaces is unclear in terms of their effectiveness on reducing pressure ulcer risk as the point estimate of RR suggests no difference but the very wide $\mathrm{Cl}$ includes a ulcer risk reduction of $52 \%$ and a risk increase of $116 \%$ (RR $1.02,95 \% \mathrm{Cl} 0.48$ to 2.16).

We note that all study data on reactive gel surfaces, regardless of the comparators, were from operating rooms or long-term care settings.

For the remaining comparisons, it is unclear whether there are differences in pressure ulcer incidence at an average of 14 days' follow-up (all yielding very low-certainty evidence, downgraded for within-study bias, heterogeneity and/or imprecision):

- between reactive sheepskin surfaces and foam surfaces (RR $0.58,95 \% \mathrm{Cl} 0.32$ to 1.05 ), reactive air surfaces (RR $1.25,95 \%$ $\mathrm{Cl} 0.62$ to 2.53 ), alternating pressure (active) air surfaces (RR
$0.93,95 \% \mathrm{Cl} 0.48$ to 1.78 ), or reactive gel surfaces (RR 1.23 , $95 \% \mathrm{Cl} 0.51$ to 2.96$)$; and

- between alternating pressure (active) air surfaces and reactive air surfaces ( $\mathrm{RR} 1.35,95 \% \mathrm{Cl} 0.82$ to 2.20 ) or reactive gel surfaces (RR $0.76,95 \% \mathrm{Cl} 0.34$ to 1.66 ).

\section{- Ranking of interventions}

We consider the network as a whole and report full results of ranking evidence in Appendix 8.

Here we present the cumulative probability plot for each support surface (see Figure 9 in Appendix 8), and the corresponding SUCRA values $($ higher values $=$ higher probabilities of being the most effective), ordered from the highest to the lowest probability:

1. Aiartex surfaces: $78.3 \%$;

2. reactive air surfaces: $78.1 \%$;

3. reactive water surfaces: $77.7 \%$;

4. reactive gel surfaces: $74.6 \%$;

5. reactive sheepskin surfaces: $64.1 \%$;

6. alternating pressure (active) air surfaces: $59.3 \%$;

7. foam surfaces and four-hourly turning: $57.5 \%$;

8. reactive fibre surfaces: $50.6 \%$;

9. foam surfaces: $30.2 \%$;

10.a brand of overlay (RIK overlay): $29.0 \%$;

11.standard hospital surfaces: $25.7 \%$;

12.Bedcare surfaces: $17.3 \%$; and

13.reactive gel surfaces followed by foam surfaces: $7.6 \%$.

However, it is important to emphasise that all SUCRA values are lower than $80.0 \%$ and the ranking probabilities and rank order are highly uncertain (the ranking evidence is of very low certainty; downgraded once for risk of bias, once for both heterogeneity and inconsistency together, and twice for imprecision; see Appendix 8).

Whilst the Aiartex surface has the highest SUCRA value, and is ranked highest, this is probably artificially high as there is very sparse data for the direct evidence and the NMA estimates all have very wide $\mathrm{Cls}$ (consequently, the ranking is highly uncertain). There is no strong evidence of publication bias (see Figure 4). 
Figure 4. Prevention network: funnel plot of the base-case analysis for pressure ulcer incidence outcome

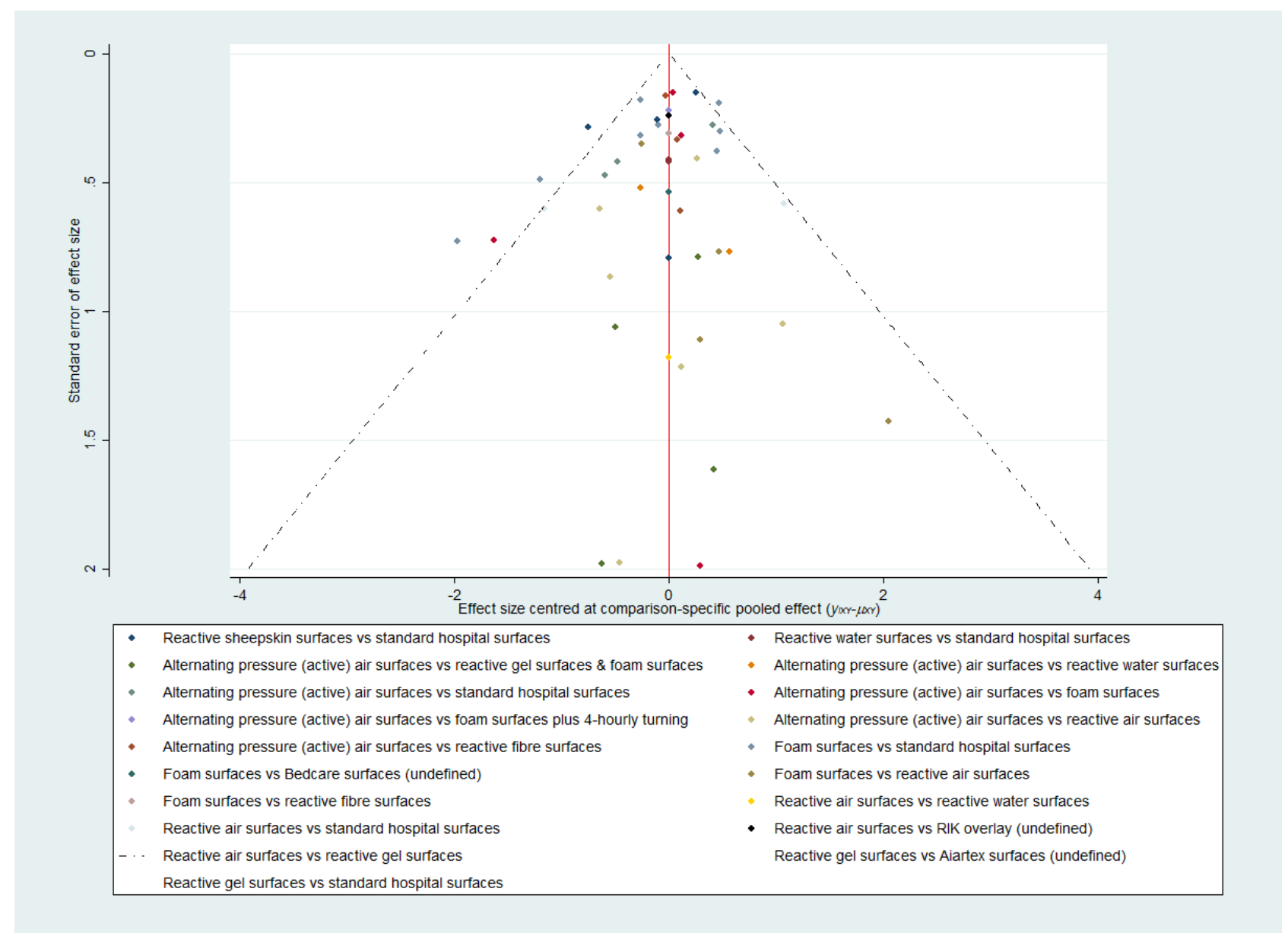

\section{Subgroup analyses}

We performed pre-planned subgroup analyses for four factors (see Homogeneity assumption tests and subgroup analysis section of Appendix 8). We found that the analyses for the factors of care settings and follow-up duration reduced the $\mathrm{Tau}^{2}$ of the basecase analysis (0.146) to be 0.075 and 0.117 , respectively, meaning these factors could explain some heterogeneity whilst study-level risk of bias (resulting in a Tau $^{2}$ of 0.146 ) and baseline skin status (with a $\mathrm{Tau}^{2}$ of 0.202 ) did not explain heterogeneity. Therefore, the care setting and follow-up duration may be important effect modifiers for the network meta-analysis. However, due to the small number of included studies, we did not undertake analyses for individual care settings or categorised follow-up durations and these exploratory analyses may be under-powered.

\section{Sensitivity analyses}

We performed two sensitivity analyses to assess the robustness of the base-case analysis: one pre-planned sensitivity analysis using complete case data (40 studies and 12,183 available participants) and one post hoc sensitivity analysis assessing seven well-defined support surfaces (24 studies with 5686 participants). See Appendix 8 for results of both analyses. These two sensitivity analysis networks shared similar limitations in terms of risk of bias and data sparseness with the base-case analysis. Neither of these two sensitivity analyses resulted in substantial difference in relative effectiveness results for all network contrasts where available. The complete case sensitivity analysis did not change the rank order of interventions. The post hoc sensitivity analysis, which only included the seven well-defined surfaces and only 24 studies, inevitably changed the SUCRA values (increased in general); however, the rank order did not change substantially (see Appendix 8). Therefore, the base-case network meta-analysis appears to be insensitive to missing data and the restriction of the analysis to the data from evaluations of well-defined support surfaces.

\section{Comparison of results from standard (pairwise) meta-analysis with NMA findings}

We compared the results of the base-case analysis with the pairwise analysis results for the 12 of 19 direct comparisons that had data pooled in the included reviews (see Table 7 in Appendix 8). The NMA findings agree with the results of corresponding pairwise analyses for all 12 comparisons.

\section{Time to pressure ulcer development}

\section{Overview of reviews}

Four reviews included data on this outcome for seven direct comparisons of beds, overlays and mattresses (Shi 2021a, Shi 2021b, Shi 2021c, Shi 2021d; Appendix 5).

There are four comparisons of two different types of support surface (see Table 1 for full details). In nursing home settings,

Beds, overlays and mattresses for preventing and treating pressure ulcers: an overview of Cochrane Reviews and network meta-analysis 17 (Review)

Copyright $\odot 2021$ The Authors. Cochrane Database of Systematic Reviews published by John Wiley \& Sons, Ltd. on behalf of The Cochrane Collaboration. 
reactive air surfaces may reduce the hazard of having new pressure ulcers over 14 days' follow-up compared with alternating pressure (active) air surfaces (low-certainty evidence). In acute and longterm care settings, reactive sheepskin surfaces may decrease the hazard of having new ulcers up to six months compared with 'standard hospital surfaces' (low-certainty evidence). However, it is uncertain if there is a difference in the hazard of having new ulcers between alternating pressure (active) air surfaces and foam surfaces, or between foam surfaces and 'standard hospital surfaces' that were not well described: both have very low-certainty evidence.

There are three comparisons of different types of the same category of surfaces (alternating pressure (active) air surfaces, foam surfaces and reactive air surfaces). In acute and long-term care settings, there may be little to no difference in the risk of developing new pressure ulcers over 60 days' follow-up between different types of alternating pressure (active) air surfaces (low-certainty evidence). In intensive care units, viscoelastic foam surfaces with a density of 40 to $60 \mathrm{~kg} / \mathrm{m}^{3}$ may decrease the risk of having new pressure ulcers over 11.5 days' follow-up compared with foam surfaces with a density of $33 \mathrm{~kg} / \mathrm{m}^{3}$ (low-certainty evidence). In acute and long-term care settings, solid foam surfaces may decrease the risk of having new pressure ulcers over one month's follow-up compared with convoluted foam surfaces (low-certainty evidence). It is unclear whether there is a difference in the hazard of having new pressure ulcers between two different brands (EHOB and KinAir) of reactive air surfaces (very low-certainty evidence).

\section{Network meta-analysis (time-to-event network)}

\section{Descriptions of the network}

The network meta-analysis for this outcome comprised 10 studies evaluating six interventions (Figure 5). This network had five direct contrasts, a total of 15 network contrasts, but no triangular or quadratic loops. Of the five direct contrasts, two (40\%) were informed by one study, one (20\%) by two studies, and two (40\%) by three studies. The network included a total of 7211 participants, 699 (9.6\%) of whom developed new pressure ulcers. The five direct contrasts have a median of 1281 participants (range: 308 to 3072; see Appendix 10). The average number of events per network contrast was around 47 (699/15).

\section{Figure 5. Time-to-event network: network diagram for time to pressure ulcer development outcome}

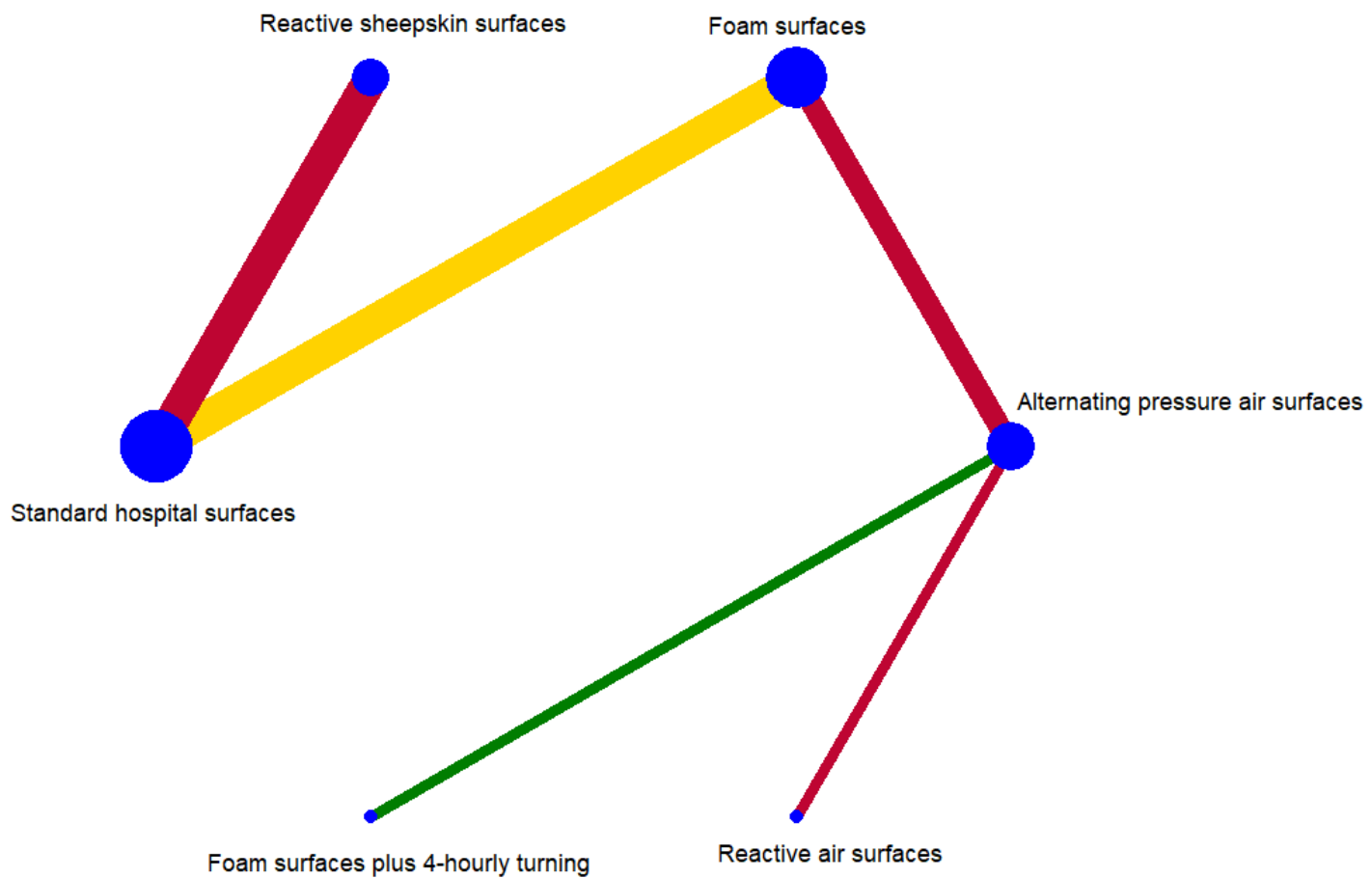

Beds, overlays and mattresses for preventing and treating pressure ulcers: an overview of Cochrane Reviews and network meta-analysis 
Risk of bias for direct comparisons, each network contrast and the whole base-case network

Four of the 10 studies included for this network meta-analysis were at low or unclear risk of bias whilst the remaining six were at high risk of bias (see Figure 7 in Appendix 8).

The overall risk of bias for direct comparisons is reported in Figure 5: one is at low risk of bias (green), one is at unclear (yellow), and three are at high risk (red). Therefore, the overall risk of bias in the network as a whole was high.

We assessed risk of bias for all 15 network contrasts: two of the 15 contrasts were at low risk of bias (less than $25 \%$ of study data being of high risk of bias), six at unclear risk of bias (25\% to $50 \%$ of study data being of high risk of bias), and seven at high risk of bias (more than $50 \%$ of study data being of high risk of bias).

\section{Network meta-analysis results}

See Table 3 summary of findings table for three key comparisons versus foam surfaces (reference) from the time-to-event network. Here we report relative effectiveness evidence for network contrasts between well-defined support surfaces versus foam surfaces. We did not include support surfaces that could not be classified in the table.

We undertook random-effects network meta-analyses. We assessed the transitivity, homogeneity and consistency assumptions for the network and considered that these assumptions held (see Appendix 10).

\section{- Relative effectiveness results}

We report relative effectiveness results for all 15 network contrasts alongside their GRADE assessment in Table 4. There is low-certainty evidence that reactive air surfaces may reduce the hazard of developing new pressure ulcers compared with foam surfaces (HR $0.20,95 \% \mathrm{Cl} 0.04$ to 1.05 ). Extrapolating from these data, if 106 people per 1000 develop a new ulcer on foam surfaces, 84 fewer per 1000 may develop them on reactive air surfaces $(95 \% \mathrm{Cl} 102$ fewer to 5 more). It is not clear whether there is a difference in the time to pressure ulcer development for all the other comparisons.

Half of network contrasts included data from studies that were mainly at high risk of bias (reasons for downgrading in Table 4). The data sparseness resulted in most relative effectiveness estimates for most network contrasts (13/15) having wide confidence intervals, crossing HR $=1$. The network had no triangular loop and therefore inconsistency was not identified. The network had substantial heterogeneity $\left(\mathrm{Tau}^{2}=0.329\right)$ and we identified two contrasts with heterogeneity: alternating pressure (active) air surfaces versus foam surfaces, $P$ value $=0.009$; and foam surfaces versus standard hospital surfaces, $P$ value $=0.029$ (see Appendix 10).

\section{- Ranking of interventions}

Here we present SUCRA values for each support surface (higher = better), showing how likely it is for each intervention to be the most effective:

1. reactive air surfaces: $89.7 \%$;

2. foam surfaces plus four-hourly turning: $65.9 \%$;

3. alternating pressure (active) air surfaces: $62.1 \%$;
4. reactive sheepskin surfaces: $50.6 \%$;

5. foam surfaces: $24.4 \%$; and

6. standard hospital surfaces: $7.2 \%$.

However, these ranking probabilities and rank order are highly uncertain (very low-certainty evidence, downgraded twice for risk of bias, once for both heterogeneity and inconsistency together, and once for imprecision). The funnel plot did not strongly suggest publication bias (see Figure 14 in Appendix 10).

\section{- Subgroup and sensitivity analyses}

The small number of studies in the network precluded any of the pre-specified subgroup analyses.

Due to the nature of the outcome of time to pressure ulcer development, we did not consider missing data as an issue for this analysis and therefore did not undertake the related sensitivity analysis.

\section{Comparison of results from standard (pairwise) meta-analysis with NMA findings}

There is no substantial difference between the results (for available comparisons) of the network meta-analysis and pairwise analyses (see Table 4). However, we note that among those network contrasts with uncertain evidence, the important network contrast of reactive air surfaces versus alternating pressure air surfaces has a spuriously wide confidence interval ( $\mathrm{HR} 2.25,95 \% \mathrm{Cl} 0.58$ to 8.75 ) as a result of data sparseness in the network. We consider the direct evidence to be more reliable: reactive air surfaces may reduce the hazard of having new pressure ulcers over 14 days' follow-up compared with alternating pressure air surfaces in nursing home settings ( $\mathrm{HR} 2.25,95 \% \mathrm{Cl} 1.05$ to 4.83 ).

\section{Support surface-associated patient comfort}

The four included reviews report evidence for this outcome in 12 comparisons; all data were deemed at low or very low-certainty (see Appendix 5). It is unclear whether there is a difference in support surface-associated patient comfort between:

- alternating pressure (active) air surfaces and foam surfaces, reactive air surfaces, reactive fibre surfaces, or between types of alternating pressure (active) air surface;

- foam surfaces and reactive air surfaces, standard hospital surfaces, or between types of foam surface;

- reactive air surfaces and either alternating pressure (active) air surfaces or RIK overlay, or between types of reactive air surface;

- reactive gel surfaces and Aiartex surfaces; and between reactive sheepskin surfaces and standard hospital surfaces.

\section{All reported adverse events}

The four included reviews report evidence for this outcome for six comparisons; all data were deemed to be low or very low-certainty evidence (see Appendix 5). It is unclear if there is a difference in adverse event rates between:

- alternating pressure (active) air surfaces and foam surfaces, reactive gel surfaces used in the operating room followed by foam surfaces used on the ward bed, or between types of alternating pressure (active) air surface;

Beds, overlays and mattresses for preventing and treating pressure ulcers: an overview of Cochrane Reviews and network meta-analysis 
- foam surfaces and reactive air surfaces, or Bedcare (undefined surfaces);

- reactive gel surfaces and Aiartex surfaces.

\section{Health-related quality of life}

Three included reviews report evidence on this outcome for two comparisons (Shi 2021a; Shi 2021b; Shi 2021d). See Appendix 5. There is low-certainty evidence (downgraded twice for risk of bias) suggesting that there may be little or no difference between reactive sheepskin surfaces and standard hospital surfaces in health-related quality of life, measured using a 100point visual analogue scale (higher = better), in long-term care settings. It is unclear if there is a difference in health-related quality of life measured using EQ-5D-5L or PU-QoL-UI at 90day follow-up between alternating pressure (active) air surfaces and foam surfaces (low-certainty evidence, downgraded twice for imprecision).

\section{Cost-effectiveness}

Three reviews report evidence on this outcome for four comparisons (Shi 2021a; Shi 2021b; Shi 2021c). See Appendix 5. There is moderate-certainty evidence (downgraded once for imprecision or risk of bias), suggesting that alternating pressure (active) air surfaces are probably more cost-effective than foam surfaces for preventing pressure ulcers in acute and long-term care settings; and that alternating pressure air mattresses are probably more cost-effective than alternating pressure air overlays in acute and long-term care settings.

There is low-certainty evidence (downgraded twice for risk of bias, or downgraded once for risk of bias and once for indirectness) that foam surfaces may be more cost-effective than standard hospital surfaces in preventing pressure ulceration in an acute care setting; and that reactive air surfaces are more cost-effective than standard hospital surfaces in an acute care setting.

\section{Section 2. Beds, overlays and mattresses for treating pressure ulcers}

In this section, we summarise review evidence, alongside network meta-analysis, where available, on the outcomes of the proportion of participants with pressure ulcers completely healed, time to complete pressure ulcer healing, support surface-associated patient comfort, all reported adverse events, and cost-effectiveness separately below. See Appendix 6 for full details of the evidence for these outcomes reported in included reviews.

For the first outcome, we also report (and focus on) findings of the associated network meta-analyses following the summary of the overview of reviews.

\section{Proportion of participants with pressure ulcers completely healed}

\section{Overview of reviews}

Two reviews report evidence on this outcome for five comparisons (Shi 2021e; McGinnis 2014). However, evidence for all these comparisons is of low or very low certainty, mainly downgraded for risk of bias and imprecision. It is uncertain whether there is a difference in the proportion of participants with pressure ulcers completely healed between:
- foam surfaces and alternating pressure (active) air surfaces, reactive air surfaces, or reactive water surfaces;

- different types of alternating pressure (active) air surface;

- reactive gel surfaces and Aiartex reactive surfaces.

\section{Network meta-analysis (treatment network)}

See Table 5 summary of findings table for interventions compared with foam surfaces.

\section{Descriptions of included studies for network meta-analysis}

From the included reviews (McGinnis 2014; Shi 2021e), we identified 12 studies that compared two or more eligible beds, mattresses or overlays for the network meta-analysis of treatment data. We did not identify any studies from other resources. See Appendix 9 for the references of these 12 studies.

See Appendix 11 for the characteristics of the included studies.

There were two types of included studies:

- studies which compared two or more eligible interventions and which were included in the NMA $(n=4)$; and

- studies which compared two or more eligible interventions but which could not be joined into the NMA $(n=8)$ : four studies evaluated the same interventions; three did not report relevant data for any analysis; and one reported a comparison that does not connect to the network.

A total of 12 studies with 972 randomised participants (median study sample size: 72 participants) was included in one or more of these categories. Each included RCT had two arms. The median duration of follow-up of these included studies was 37.5 days (range: 7 days to 18 months). Most of the studies (11/12) were completely or partly funded by industry or received mattresses under evaluation from industries.

Participants enrolled were older adults (median of average participant age: 82.7 years; range: 64.0 to 86.5 years). Among those studies which specified sex, $284(46.3 \%)$ of participants were male and 329 (53.7\%) were female.

All 12 studies recruited people with existing pressure ulcers and participants were from either acute care settings (6/12 studies), or community and long-term care settings (6/12 studies). For studies which reported these details, the average size of pressure ulcers at baseline ranged from 4.2 to $18.6 \mathrm{~cm}^{2}$ (median: $6.6 \mathrm{~cm}^{2}$ ).

\section{Descriptions of base-case network}

As Appendix 11 notes, four studies (with 397 participants) connected into a network with four interventions (termed basecase network hereafter; see Figure 6). This network had three direct contrasts, a total of six network contrasts, but no triangular or quadratic loop. Two of the three direct contrasts were informed by only one study and the third was informed by two studies. Of the total of 397 participants, 143 (36.0\%) participants had complete ulcer healing. There were fewer than 200 participants in all direct contrasts (median: 120, range: 49 to 186). The average number of events per network contrast was $24(143 / 6)$.

Beds, overlays and mattresses for preventing and treating pressure ulcers: an overview of Cochrane Reviews and network meta-analysis 
Figure 6. Treatment network: network diagrams for pressure ulcer healing outcome

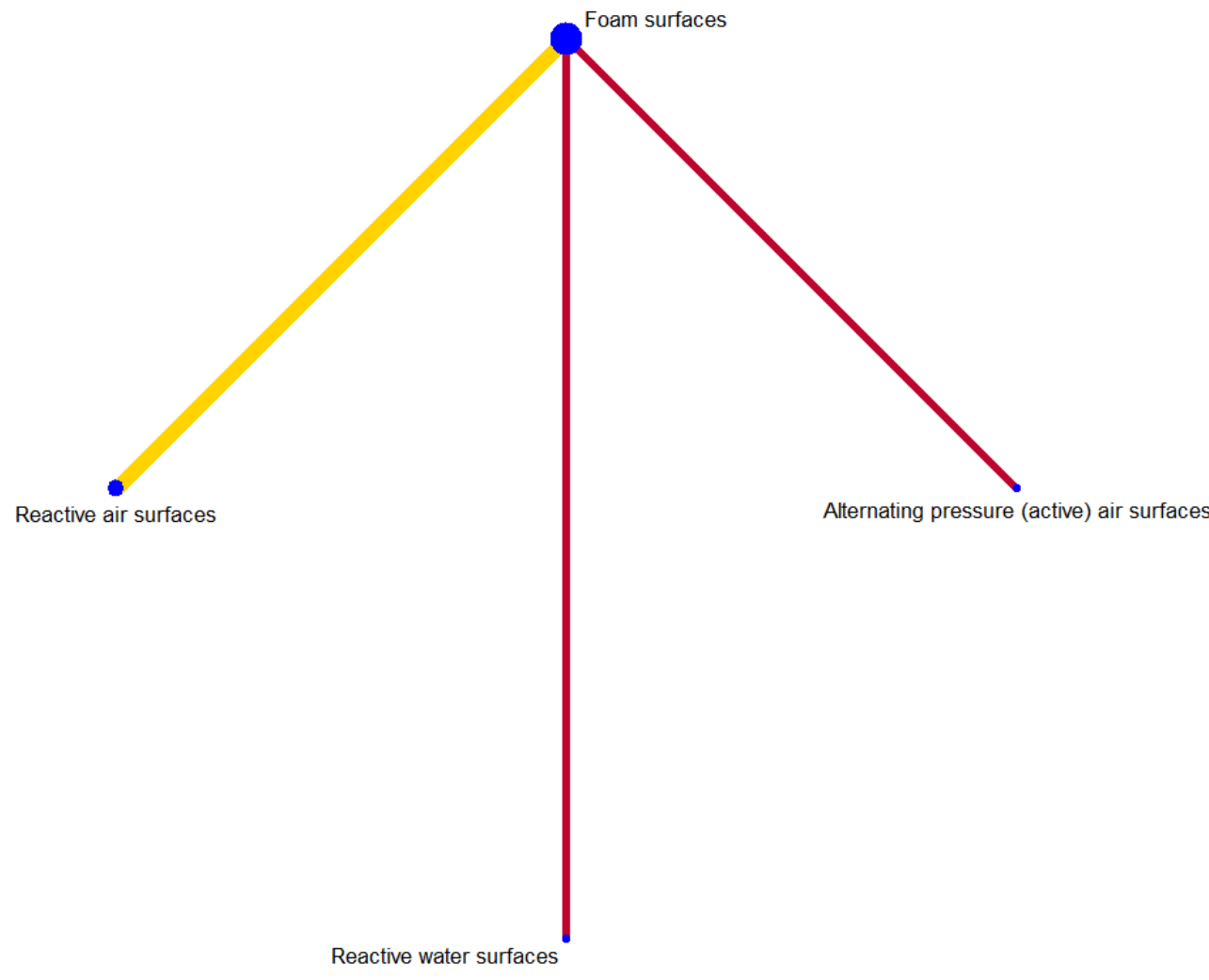

Risk of bias for direct comparisons, each network contrast and the whole network

We summarise risk of bias assessments for the included studies in the topic of treatment (see Figure 15 in Appendix 11). Of the four studies connecting to the network, two were at unclear risk of bias and the other two were at high risk of bias.

We have indicated the overall risk of bias for each direct comparison in the network diagram in Figure 6: one with unclear risk of bias (yellow), and two with high (red). Therefore, the overall risk of bias in the network as a whole was high.

We assessed risk of bias for each of the six contrasts in the network:

- one has data at low risk of bias (less than $25 \%$ of data being of high risk of bias): foam surfaces versus reactive air surfaces;

- two have unclear risk of bias ( $25 \%$ to $50 \%$ of data being of high risk of bias): alternating pressure active air surfaces versus reactive air surfaces, and reactive air surfaces versus reactive water surfaces; and

- the remaining three have high risk of bias (more than $50 \%$ of data being of high risk of bias).

\section{Network meta-analysis results}

We undertook random-effects network meta-analyses. Given the small number of included studies, we considered the transitivity assumption held. The network has no heterogeneity and no inconsistency and we considered these two assumptions held too.

\section{- Relative effectiveness results}

See Table 6 for relative effectiveness results of all network contrasts and their GRADE assessment. As a result of data sparseness in the network, the relative effectiveness estimates for all network contrasts had wide confidence intervals, crossing RR = 1. Considering the limitations of data sparseness and risk of bias, we judged all but one network contrast as being of very low certainty evidence.

There is low-certainty evidence that more people with pressure ulcers using reactive air surfaces may heal completely than those using foam surfaces (RR 1.32, $95 \% \mathrm{Cl} 0.96$ to 1.80). However, it is uncertain if there is a difference in pressure ulcer healing for all other comparisons (alternating pressure (active) air surfaces, foam surfaces, reactive air surfaces, and reactive water surfaces).

\section{- Ranking of interventions}

Here we present SUCRA values, indicating the probability of each intervention being the most effective in healing pressure ulcers (see Appendix 11):

1. reactive air surfaces: $83.9 \%$;

Beds, overlays and mattresses for preventing and treating pressure ulcers: an overview of Cochrane Reviews and network meta-analysis

Copyright (c) 2021 The Authors. Cochrane Database of Systematic Reviews published by John Wiley \& Sons, Ltd. on behalf of The Cochrane 
2. alternating pressure (active) air surfaces: $43.0 \%$;

3. reactive water surfaces: $37.9 \%$;

4. foam surfaces: $35.3 \%$.

Whilst reactive air surfaces have the highest estimated probability of being the most effective, the ranking evidence is of very low certainty (downgraded twice for risk of bias, once for imprecision (see Appendix 11).

\section{- Subgroup analysis}

Given the very limited number of included studies in the network, we did not undertake any pre-specified subgroup analyses.

\section{- Sensitivity analysis}

The sensitivity analysis using complete case data included the same four studies and 378 available participants (removing 19 cases from the base-case analysis of 397 participants). The sensitivity analysis had the same network as the base-case analysis, and shared the same issues of risk of bias, heterogeneity, inconsistency, and imprecision as the base-case analysis. There is no substantial difference in relative effectiveness results and rank orders of interventions between the base-case analysis and this sensitivity analysis. We therefore did not report full results of this sensitivity analysis network. We considered the base-case metaanalysis to be robust to missing data.

\section{Comparison of results from standard (pairwise) meta-analysis with NMA findings}

The NMA findings agree with the results of the corresponding pairwise analyses for all three direct comparisons (see Table 6).

\section{Time to complete pressure ulcer healing}

Only Shi 2021e reports evidence on this outcome, for one comparison (see Appendix 6). There is low-certainty evidence (downgraded twice for imprecision) that people using reactive air surfaces may be more likely to experience pressure ulcer healing than those using foam surfaces in long-term care settings (HR 2.66, $95 \% \mathrm{Cl} 1.34$ to $5.17 ; 1$ study, 84 participants).

\section{Support surface-associated patient comfort}

Two reviews report evidence on this outcome for five comparisons (Shi 2021e; McGinnis 2014). However, evidence for all these comparisons is of very low certainty, downgraded mainly for risk of bias and imprecision. See Appendix 6. It is uncertain if there is a difference in patient comfort responses between:

- alternating pressure (active) air surfaces and foam surfaces or between different types of alternating pressure (active) air surface;

- reactive air surfaces and foam surfaces or standard hospital surfaces;

- reactive gel surfaces and Aiartex reactive surfaces.

\section{All reported adverse events}

Two reviews report evidence for this outcome for six comparisons (Shi 2021e; McGinnis 2014). However, evidence for all these comparisons is of low or very low certainty, downgraded mainly for risk of bias and imprecision. See Appendix 6 . It is uncertain whether there is a difference in adverse event rates between:
- alternating pressure (active) air surfaces and foam surfaces, or between different types of alternating pressure (active) air surface;

- reactive air surfaces and foam surfaces, or standard hospital surfaces;

- foam surfaces and reactive water surfaces;

- reactive gel surfaces and Aiartex reactive surfaces.

\section{Cost-effectiveness}

Only Shi 2021e reports cost-effectiveness evidence for one comparison: reactive air surfaces may cost USD 26 per additional day without an ulcer in the first year in long-term care settings (low-certainty evidence, downgraded twice for imprecision; see Appendix 6).

\section{DISCUSSION}

\section{Summary of main results}

In this overview of reviews, we have synthesised the main results of six Cochrane Reviews regarding the effects of beds, mattresses and overlays for preventing and treating pressure ulcers. We also used data from these reviews to conduct three network metaanalyses: one network of 13 interventions for pressure ulcer incidence (informed by 40 studies with 12,517 participants); one examining the effect of six support surfaces on time to pressure ulcer development (informed by 10 studies with 7211 participants); and one examining the effects of four support surfaces on pressure ulcer healing (informed by four studies with 397 participants).

The results of our overview of direct evidence, where it was available, are consistent with our network analyses. Results generally indicate that the evidence is unclear regarding the relative effectiveness of the majority of available comparisons regarding pressure ulcer prevention (both risk and time to pressure ulcer development) and ulcer healing (all with very low-certainty evidence). Additionally, it is unclear which support surface is the most effective in preventing and treating pressure ulcers (all ranking evidence is of very low certainty).

However, some important support surface comparisons have better quality evidence (i.e. those with better than very lowcertainty evidence):

- compared with foam surfaces, reactive air surfaces may reduce the risk and hazard of developing new pressure ulcers (low-certainty evidence from the network meta-analysis). Furthermore, people with open pressure ulcers using reactive air surfaces may be more likely to heal completely than those using foam surfaces (low-certainty evidence from the network metaanalysis). In comparison with foam surfaces, reactive air surfaces may cost USD 26 per additional day without an ulcer in the first year in long-term care settings (low-certainty cost-effectiveness evidence).

- alternating pressure (active) air surfaces may reduce pressure ulcer incidence compared with foam surfaces (low-certainty evidence from the network meta-analysis). Alternating pressure (active) air surfaces are probably more cost-effective than foam surfaces in preventing pressure ulcers (moderate-certainty costeffectiveness evidence).

Beds, overlays and mattresses for preventing and treating pressure ulcers: an overview of Cochrane Reviews and network meta-analysis 
- reactive gel surfaces may reduce pressure ulcer incidence compared with foam surfaces (low-certainty evidence from the network meta-analysis).

We note the evidence on reactive gel surfaces appears to be particularly applicable to operating room and long-term care settings, where the studies involving gel surfaces were conducted.

\section{There is also low-certainty direct evidence that:}

- alternating pressure (active) air surfaces used on both operating tables and hospital beds may reduce pressure ulcer risk compared with reactive gel surfaces used on operating tables followed by foam surfaces applied on hospital beds.

- reactive air surfaces may reduce the hazard of having new pressure ulcers over 14 days' follow-up compared with alternating pressure air surfaces at a nursing home.

Included reviews also show that, irrespective of using surfaces for prevention or treatment, there is little known about any differences in support surface-associated patient comfort and adverse event rates (all with low or very low-certainty evidence). There is lowcertainty evidence on the health-related quality of life for two comparisons in terms of preventing pressure ulcers, suggesting (1) little or no difference in health-related quality of life between reactive sheepskin surfaces and standard hospital surfaces, but (2) uncertainty between alternating pressure (active) air surfaces and foam surfaces.

\section{Overall completeness and applicability of evidence}

The completeness of an overview is necessarily affected by how up to date the evidence of the reviews it includes is. This overview covers evidence from all eligible Cochrane Reviews. One of the six included reviews, McGinnis 2014, although the latest version, was published in 2014. However, we are still confident in the completeness of this overview. As for the other five included reviews, new searches were conducted in November 2019, and they contain all the evidence which was included in McGinnis 2014. Cochrane overviews tend not to include non-Cochrane Reviews and so we only included Cochrane Reviews.

The completeness of a network meta-analysis is related to its included studies and the related characteristics. The studies included in our three network meta-analyses may not represent all potential data sources and relevant interventions. This is because, for example, seven of the 69 studies identified for the network of pressure ulcer incidence did not report the ulcer incidence outcome data and were excluded. As a result, among these seven studies, Hoshowsky 1994 (see Appendix 9), the only study evaluating reactive foam and gel surfaces, was excluded and reactive foam and gel surfaces disconnected from the network. Consequently, the network for pressure ulcer incidence only covers 13 interventions rather than all 14 interventions identified.

The impact of disconnecting reactive foam and gel surface on evidence completeness is clear: there was no evidence from network contrasts on these surfaces. However, we can see the direct evidence for these comparisons in the overview, as well as evidence on other direct comparisons between two support surfaces of the same type that could not be included in any network meta-analysis. The availability of this evidence in the overview, alongside network meta-analysis, means that all potential evidence is identifiable.
We examined the stability of the pressure ulcer incidence network by undertaking a post hoc sensitivity analysis. In this sensitivity analysis, we excluded five interventions that could not be classified, or were ineligible (Aiartex surfaces, Bedcare surfaces, RIK overlay, standard hospital surfaces, and foam surfaces plus four-hourly turning) and as a result of these removals, reactive sheepskin surfaces also disconnected from the network. We included only seven support surfaces that could be classified and are widely accessible in practice. The sensitivity analysis did not substantially change the evidence for most network contrasts, indicating the stability of the network. We therefore have confidence in the full network of 13 interventions and report it as the primary analysis. We believe reporting the full network is likely to maximise its relevance to clinical decision-making.

Regardless of the overview of reviews or network meta-analysis, the populations in the included studies appear representative of the people who probably use the majority of pressure ulcer-related care services in terms of care settings (acute and long-term care settings), age (older adults), gender (almost half of participants were male) and pressure ulcer risk (or ulcer characteristics) at enrolment.

Evidence we report here appears to be largely applicable for people from any care setting. Indeed, we had evidence from exploratory subgroup analysis that care settings could be an effect modifier for the use of support surfaces in preventing pressure ulcers. However, due to the small number of included studies, we did not undertake analysis for individual care settings. Future reviews may want to identify evidence for separate care settings.

\section{Quality of the evidence}

We used the ROBIS tool to assess the risk of bias of the included reviews. With this assessment, we judged whether the original reviewers' conclusions were appropriate and based on the available data. We judged five of the six included reviews to be at low overall risk of bias across the ROBIS assessment and the remaining one at unclear risk of bias. This is likely to be because we only included Cochrane Reviews, which are expected to follow the stringent guidance required for their publication.

We reported the certainty of the evidence reported in our included reviews and used the generic GRADE approach to assess the evidence certainty for McGinnis 2014, which has no GRADE assessment. The evidence presented in the majority of comparisons $(65.6 \%)$ was rated very low certainty. The main reasons for downgrading the certainty of evidence included high risk of bias in the included studies and imprecision, caused by small sample sizes or low event rates, and/or heterogeneity.

We also assessed the certainty of evidence for all network metaanalyses using the GRADE approach (with the CINeMA tool). We judged most of the network contrasts from each network meta-analysis as having low or very low-certainty evidence and judged ranking evidence from each network as having very lowcertainty. We mainly downgraded evidence certainty for risk of bias, heterogeneity and imprecision.

We downgraded for risk of bias for the results of most network contrasts and all the evidence relating to the rank ordering. This is mainly because we considered a high proportion of the included studies to be at high risk of bias for one or more domains. One

Beds, overlays and mattresses for preventing and treating pressure ulcers: an overview of Cochrane Reviews and network meta-analysis 
reason for the high risk of bias judgement was lack of blinding of participants and personnel. However, if we disregarded risk of performance bias in the overall risk of bias assessment, most of the included studies were still at high risk of bias overall: 14 of the 40 studies contributing data to network meta-analysis had unblinded outcome assessment. As a result, we judged the majority of the direct evidence (e.g. 14/19 for the pressure ulcer incidence network) to be at high risk of bias, and judged most of the network contrasts and whole networks as being at high risk of bias.

We downgraded for imprecision due to the sparse data in each network. For example, the network for pressure ulcer incidence has $42.1 \%$ of direct contrasts (8/19) informed by only one study. The network has $73.7 \%$ (14/19) of direct contrasts with fewer than 500 participants; and its average number of events per network contrast was only 17 (1298/78). The data sparseness means imprecision of estimates in terms of the relative effectiveness estimates (i.e. the very wide confidence intervals for most network contrasts) and ranking (i.e. the overlaps of rank orders between different support surfaces).

We note that the network contrast of reactive air surfaces versus alternating pressure air surfaces in the time-to-event network (for the pressure ulcer development outcome) needs careful GRADE assessment (particularly in terms of downgrading for imprecision). The confidence interval for the mixed estimate from network meta-analysis ( $\mathrm{HR} 2.25,95 \% \mathrm{Cl} 0.58$ to 8.75 ) appears to be spuriously wide whilst the corresponding direct estimate from pairwise meta-analysis has a narrower interval ( $\mathrm{HR} 2.25,95 \% \mathrm{Cl} 1.05$ to 4.83), meaning that pooling direct and indirect evidence in this network did not improve its precision. This situation has been previously acknowledged in the case of sparse networks (Brignardello-Petersen 2019), and may be related to high heterogeneity as in our time-to-event network (Brignardello-Petersen 2019). Given the greater imprecision in the mixed estimate, we downgraded the certainty of the evidence for imprecision and regard the direct evidence for this comparison as being more reliable.

We downgraded the certainty of the evidence for heterogeneity for network contrasts and networks' ranking under different considerations. The networks for both pressure ulcer incidence and time to pressure ulcer development have substantial heterogeneity but have no global or local inconsistency. We considered downgrading the results from these two networks for heterogeneity on the basis of network contrast by network contrast. The substantial heterogeneity in both networks was related to specific direct comparisons or evidence. We therefore identified those comparisons and downgraded evidence certainty for these network contrasts only (rather than for all network contrasts). We mainly downgraded the evidence certainty once for heterogeneity, though substantial, as no inconsistency was identified.

Regarding the rankings from these two networks, we considered the whole network heterogeneity in downgrading evidence certainty. We downgraded for heterogeneity only once as no inconsistency was identified and the heterogeneity, though substantial, has limited impact on the rank order for each network: the predicted probabilities that incorporated heterogeneity into probability estimates and estimated probabilities matched for all support surfaces (see Figure 9 and Figure 12 in Appendix 8). The ulcer healing network has no heterogeneity, thus no downgrading for heterogeneity for any evidence.
We did not downgrade evidence certainty for indirectness or publication bias (across-studies bias). The funnel plots for two networks appear to indicate some evidence of small-study effects (see Figure 4 and Figure 14 in Appendix 10). However, we did not consider the evidence for small-study effects to be strong, given the small number of included studies per each direct contrast in each network; and we therefore did not downgrade for publication bias.

\section{Potential biases in the overview process}

The overview has some limitations. We only searched the Cochrane Library and only included Cochrane Reviews, and may have missed non-Cochrane Reviews. However, to our knowledge, these included reviews probably cover all potential RCT evidence and, importantly, Cochrane Reviews are considered as higher-quality and reliable evidence sources due to their quality criteria (Pollock 2017). Therefore, we are confident in the findings of this overview.

Five of the six included reviews involved authors of this overview which may introduce bias, particularly in study selection and risk of bias assessment. In order to reduce risk of these biases, two authors who were not authors of the included reviews, were invited to assess the risk of bias in the five reviews. The lead author (CS) and another author (ELG), not involved in McGinnis 2014, assessed the risk of bias of this review.

We identified primary studies from the included reviews of the overview for our network meta-analysis rather than running separate literature searches. We may have missed some potentially eligible studies, particularly those comparing eligible support surfaces with ineligible interventions. However, the co-authors of this overview have been researching this topic for decades and we believe that it is unlikely that we have missed eligible studies.

\section{Agreements and disagreements with other studies or reviews}

This is the first summary of evidence of Cochrane Reviews on preventing and treating pressure ulcers. We are not aware of any similar overviews of evidence on pressure ulcer prevention and treatment.

To our knowledge, Shi 2018a is the only network meta-analysis evaluating all types of beds, mattresses and overlays for preventing pressure ulcers. This overview and network meta-analysis are different from Shi 2018a in how specific support surfaces are classified and termed. In line with the included reviews (Shi 2021a; Shi 2021b; Shi 2021c; Shi 2021d; Shi 2021e), we classified support surfaces using the NPIAP S3I approach (NPIAP S3I 2007), whilst the network in Shi 2018a used specific terms. For example, reactive air-fluidised surfaces, reactive air surfaces, and reactive low-airloss surfaces were separate groups in Shi 2018a but all grouped to be 'reactive air surfaces' here. Similarly, the separate groups of alternating pressure (active) low-air-loss surfaces, alternating pressure (active) air surfaces, and hybrid air surfaces in Shi 2018a are all grouped into the classification of 'alternating pressure (active) air surfaces' here. Additionally, we re-defined four interventions in our networks here: alternating pressure (active) air surfaces or RIK overlay, Aiartex surfaces, and reactive gel surfaces followed by foam surfaces were all classified as reactive gel surfaces in Shi 2018a, but further investigation suggested they are distinct interventions and all different from reactive gel surfaces. Foam surfaces plus four-hourly turning were classified as 'foam surfaces'

Beds, overlays and mattresses for preventing and treating pressure ulcers: an overview of Cochrane Reviews and network meta-analysis 24 (Review)

Copyright (c) 2021 The Authors. Cochrane Database of Systematic Reviews published by John Wiley \& Sons, Ltd. on behalf of The Cochrane Collaboration. 
in Shi 2018a but we now consider turning as part of the intervention protocol rather than as a co-intervention. We identified one new support surface (Bedcare) as a result of including a new study. We considered the factorial design study, Laurent 1998 (see Appendix 9), having two different, parallel comparisons in this network metaanalysis, on the basis of the Cochrane guidance (Higgins 2020), rather than being a study with four parallel arms as used in Shi 2018a. As a result of these re-classifications of support surfaces, the inclusion of new interventions, and the new treatment of the factorial trial, the network in Shi 2018a with 14 interventions/nodes became a network with 13 interventions here. We note that we also retained the term 'foam surfaces' in the overview and network meta-analysis, as the included reviews did, rather than using 'high specification foam' surfaces which is not a classification in NPIAP S3I.

Shi 2018a used the term 'standard hospital surfaces' in their network, by grouping some ill-defined interventions (e.g. 'standard care', 'standard mattress'). Whilst the definition of 'standard' surface is likely to have varied over time and by place, and NPIAP S3l 2007 discourages the term 'standard hospital surfaces,' we acknowledged the efforts to define standard hospital surfaces made in the included reviews (as originally described in primary studies). Consequently, we only termed things as 'standard' if no detail was provided with which to further classify the type of surface. We therefore kept using 'standard hospital surfaces' in our network meta-analyses, but in order to assess the stability of the network, we excluded some interventions including 'standard hospital surfaces' for a post hoc sensitivity analysis. Exclusion of those surfaces did not result in substantial difference in network estimates.

Shi 2018a ran literature searches in August 2016 for all search databases and sources considered in the included reviews. Shi 2018a also searched the Chinese Biomedical Literature Database, which was not searched for the included reviews, due to concern about the validity of RCTs from China (Woodhead 2016). Searches for the included reviews were run in November 2019 with revised search strategies. The reviews included in the overview and network meta-analysis did not include those trials from China $(\mathrm{n}=$ 7) but identified eight new studies (Allman 1987; Beeckman 2019; Berthe 2007; Cassino 2013; Nixon 2019; Park 2017; Rosenthal 2003; Sauvage 2017; see Appendix 9).

Given the differences in network constructions and included studies between Shi 2018a and this work, we compared the results for relative effectiveness. We found that this new analysis, with an improved network and the inclusion of more data, is consistent with Shi 2018a for key comparisons, but improves the precision of effect estimates.

A Cochrane Review (Mclnnes 2015), international guidelines (EPUAP/NPIAP/PPPIA 2019), and the UK's NICE pressure ulcer guidelines (NICE 2014), all appear to favour the use of foam surfaces in preventing pressure ulcers. McInnes 2015 concluded by noting the benefits of using 'higher-specification foam mattresses rather than standard hospital foam mattresses' and stated that the 'relative merits of higher-specification constant lowpressure and alternating-pressure support surfaces for preventing pressure ulcers are unclear....' In this review, 'constant lowpressure' surfaces include what we now term 'reactive air surfaces', and 'alternating-pressure support surfaces' are what we now call 'alternating pressure (active) air surfaces'. Foam surfaces are widely recommended in pressure ulcer guidelines (EPUAP/ NPIAP/PPPIA 2019; NICE 2014), and foam surfaces are probably widely used routinely for pressure ulcer prevention. However, our network evidence suggests both reactive air surfaces and alternating pressure (active) air surfaces have an advantage over foam surfaces in preventing pressure ulcers, and that alternating pressure (active) air surfaces are more cost-effective than foam surfaces in preventing pressure ulcers. When looking at the relative effectiveness of alternating pressure (active) air surfaces and reactive air surfaces, we found the evidence is unclear, which is consistent with McInnes 2015. This result, however, tends to favour the benefits of using reactive air surfaces, which requires further evaluation. Additionally, there is cost-effectiveness evidence on reactive air surfaces compared with foam surfaces, and reactive air surfaces compared with alternating pressure air surfaces, in preventing pressure ulcers. McInnes 2015 also suggests 'sheepskin overlays are effective in reducing the incidence of pressure ulcers' whilst our network meta-analysis suggests uncertain evidence.

Our overview and network meta-analysis also suggest that reactive air surfaces may be superior to foam surfaces in treating pressure ulcers. This is new evidence that the previous pairwise metaanalysis of McInnes 2018 did not identify.

\section{AUTHORS' CONCLUSIONS}

\section{Implications for practice}

This overview of current Cochrane Reviews provides the most up-to-date evidence on the use of beds, mattresses or overlays in preventing and treating pressure ulcers. Generally, we found the evidence to be insufficient or of very low certainty for both prevention and treatment. However, compared with foam surfaces (which are recommended and routinely used surfaces in most countries), reactive air surfaces may reduce pressure ulcer risk and may improve complete ulcer healing (although they may be associated with higher costs in long-term care settings). Compared with foam surfaces, alternating pressure (active) air surfaces may reduce pressure ulcer risk and are probably more cost-effective in preventing pressure ulcers. Additionally, reactive air surfaces may reduce the hazard of developing new pressure ulcers over 14 days' follow-up compared with alternating pressure air surfaces in nursing homes. Finally, compared with foam surfaces, reactive gel surfaces may reduce pressure ulcer risk, particularly for people in operating room and long-term care settings.

\section{Implications for research}

The individual reviews and this overview have highlighted the lack of high-certainty evidence on the use of most types of beds, mattresses or overlays for preventing and treating pressure ulcers. The scarcity of ulcer healing-related evidence is particularly serious. The networks, all with sparse and low-quality data, suggest that more high-quality research is required. More RCT evidence is important for reactive air surfaces versus alternating pressure (active) air surfaces as both these types of support surface may reduce pressure ulcer risk but the direct and network evidence is still uncertain. Future research reports must fully describe the evaluated support surfaces.

The care setting might be a source of heterogeneity in results and future reviews may want to explore the influence of care settings.

Beds, overlays and mattresses for preventing and treating pressure ulcers: an overview of Cochrane Reviews and network meta-analysis 25 (Review)

Copyright (C) 2021 The Authors. Cochrane Database of Systematic Reviews published by John Wiley \& Sons, Ltd. on behalf of The Cochrane Collaboration. 
Many of the existing RCTs in this field are poorly designed or reported, or both, and future research needs to be much more rigorous. Whilst it is challenging to avoid the risk of performance bias in studies of some types of support surfaces, as blinding of participants and personnel is seldom possible, stringent protocols (e.g. in terms of encouraging consistent care) can help minimise the risk of bias. It is also important to fully describe co-interventions (e.g. repositioning) and ensure protocols mandate balanced use of co-interventions across trial arms. The risk of detection bias can also be minimised with the use of digital photography and by masking adjudicators of the photographs to the types of support surfaces being evaluated (Baumgarten 2009). As most pressure ulcers occur in the first two to four weeks after admission, followup periods should be longer than 14 days and clinically relevant in different settings.

One key limitation in included studies is small sample size. Future research should consider that pressure ulcer incidence can be low in certain settings for sample size calculations, and could incorporate relative effectiveness results produced here.
Trialists should carefully consider the choice of outcomes. Future research should use and report time-to-event data for pressure ulcer incidence and ulcer healing. Future research could nest costeffectiveness analysis in the conduct of trials where possible. Costeffectiveness evidence on reactive air surfaces compared with foam surfaces and alternating pressure air surfaces is particularly needed. If trialists consider measuring a quality of life outcome, then a validated health-related quality of life measurement tool could be used to detect important change in individuals' status. The public sector should be encouraged to invest in further research.

\section{ACKNOWLEDGEMENTS}

The authors are grateful to the following peer reviewers: Duncan Chambers and Una Adderley for feedback on the protocol, Zena Moore and Gill Worthy for feedback on the overview, and Janet Wale for feedback on both. Thanks are also due to Cochrane's Copy Edit Support team for copy-editing the protocol and the overview, and to Cochrane Musculoskeletal, Oral, Skin and Sensory Network Editors Peter Tugwell and Jennifer Hilgart for feedback and final approval of the overview for publication. 


\section{RE F E R E N C E S}

\section{References to included reviews}

\section{McGinnis 2014}

McGinnis E, Stubbs N. Pressure-relieving devices for treating heel pressure ulcers. Cochrane Database of Systematic Reviews 2014, Issue 2. Art. No: CD005485. [DOI: 10.1002/14651858.CD005485.pub3]

\section{Shi 2021a}

Shi C, Dumville JC, Cullum N, Rhodes S, Jammali-Blasi A, McInnes E. Alternating pressure (active) air surfaces for preventing pressure ulcers. Cochrane Database of Systematic Reviews 2021, Issue 5. Art. No: CD013620. [DOI: 10.1002/14651858.CD013620.pub2]

\section{Shi 2021b}

Shi C, Dumville JC, Cullum N, Rhodes S, McInnes E. Foam surfaces for preventing pressure ulcers. Cochrane Database of Systematic Reviews 2021, Issue 5. Art. No: CD013621. [DOI: 10.1002/14651858.CD013621.pub2]

\section{Shi 2021c}

Shi C, Dumville JC, Cullum N, Rhodes S, Leung V, McInnes E. Reactive air surfaces for preventing pressure ulcers. Cochrane Database of Systematic Reviews 2021, Issue 5. Art. No: CD013622. [DOI: 10.1002/14651858.CD013622.pub2]

\section{Shi 2021d}

Shi C, Dumville JC, Cullum N, Rhodes S, McInnes E. Alternative reactive support surfaces (non-foam and non-air-filled) for preventing pressure ulcers. Cochrane Database of Systematic Reviews 2021, Issue 5. Art. No: CD013623. [DOI: 10.1002/14651858.CD013623.pub2]

\section{Shi 2021e}

Shi C, Dumville JC, Cullum N, Rhodes S, Jammali-Blasi A, Ramsden V, Mclnnes E. Beds, overlays and mattresses for treating pressure ulcers. Cochrane Database of Systematic Reviews 2021, Issue 5. Art. No: CD013624. [DOI: 10.1002/14651858.CD013624.pub2]

\section{References to excluded reviews}

\section{Greenwood 2017}

Greenwood CE, Nelson EA, Nixon J, McGinnis E. Pressurerelieving devices for preventing heel pressure ulcers. Cochrane Database of Systematic Reviews 2017, Issue 5. Art. No: CD011013. [DOI: 10.1002/14651858.CD011013.pub2]

\section{McInnes 2015}

Mclnnes E, Jammali-Blasi A, Bell-Syer SE, Dumville JC, Middleton V, Cullum N. Support surfaces for pressure ulcer prevention. Cochrane Database of Systematic Reviews 2015, Issue 9. Art. No: CD001735. [DOI: 10.1002/14651858.CD001735.pub5]

\section{McInnes 2018}

McInnes E, Jammali-Blasi A, Bell-Syer SE, Leung V. Support surfaces for treating pressure ulcers. Cochrane Database of
Systematic Reviews 2018, Issue 10. Art. No: CD009490. [DOI: 10.1002/14651858.CD009490.pub2]

\section{Additional references \\ Brignardello-Petersen 2019}

Brignardello-Petersen R, Murad MH, Walter SD, McLeod S, Carrasco-Labra A, Rochwerg B, et al. GRADE approach to rate the certainty from a network meta-analysis: avoiding spurious judgments of imprecision in sparse networks. Journal of Clinical Epidemiology 2019;105:60-7.

\section{Caldwell 2005}

Caldwell DM, Ades AE, Higgins JP. Simultaneous comparison of multiple treatments: combining direct and indirect evidence. BMJ 2005;331(7521):897-900.

\section{Chaimani 2013}

Chaimani A, Higgins JP, Mavridis D, Spyridonos P, Salanti G. Graphical tools for network meta-analysis in STATA. PLoS One 2013;8:e76654.

\section{Chaimani 2015}

Chaimani A, Salanti G. Visualizing assumptions and results in network meta-analysis: the network graphs package. Stata Journal 2015;15(4):905-50.

\section{Cipriani 2013}

Cipriani A, Higgins JP, Geddes JR, Salanti G. Conceptual and technical challenges in network meta-analysis. Annals of Internal Medicine 2013;159(2):130-7.

\section{Clark 2011}

Clark M. Technology update: understanding support surfaces. Wounds International 2011;2(3):17-21.

\section{Cullum 2016}

Cullum N, Buckley H, Dumville J, Hall J, Lamb K, Madden M, et al. Wounds Research for Patient Benefit: A 5-year Programme of Research. Southampton (UK): NIHR Journals Library, 2016.

\section{Deeks 2020}

Deeks JJ, Higgins JP, Altman DG (editors). Chapter 10: Analysing data and undertaking meta-analyses. In: Higgins JP, Thomas J, Chandler J, Cumpston M, Li T, Page MJ, et al (editors). Cochrane Handbook for Systematic Reviews of Interventions version 6.1 (updated September 2020). Cochrane, 2020. Available from www.training.cochrane.org/handbook.

\section{Demarré 2015}

Demarré L, Van Lancker A, Van Hecke A, Verhaeghe S, Grypdonck M, Lemey J, et al. The cost of prevention and treatment of pressure ulcers: a systematic review. International Journal of Nursing Studies 2015;52(11):1754-74.

\section{Dias 2014}

Dias S, Welton NJ, Sutton AJ, Caldwell DM, Lu G, Ades AE. NICE DSU Technical Support Document 4: Inconsistency in Networks

Beds, overlays and mattresses for preventing and treating pressure ulcers: an overview of Cochrane Reviews and network meta-analysis 
of Evidence Based on Randomised Controlled Trials. London: National Institute for Health and Care Excellence (NICE) 2014.

\section{EPUAP/NPIAP/PPPIA 2019}

European Pressure Ulcer Advisory Panel, National Pressure Injury Advisory Panel, Pan Pacific Pressure Injury Alliance (EPUAP/NPIAP/PPPIA). Prevention and Treatment of Pressure Ulcers/Injuries: Quick Reference Guide. Emily Haesler (Ed.). EPUAP/NPIAP/PPPIA, 2019.

\section{Espejo 2018}

Espejo E, Andrés M, Borrallo RM, Padilla E, Garcia-Restoy E, Bella F, Complex Wounds Working Group. Bacteremia associated with pressure ulcers: a prospective cohort study. European Journal of Clinical Microbiology \& Infectious Diseases: Official Publication of the European Society of Clinical Microbiology 2018;37(5):969-75.

\section{Essex 2009}

Essex HN, Clark M, Sims J, Warriner A, Cullum N. Health-related quality of life in hospital inpatients with pressure ulceration: assessment using generic health-related quality of life measures. Wound Repair and Regeneration 2009;17(6):797-805.

\section{Glenny 2005}

Glenny AM, Altman DG, Song F, Sakarovitch C, Deeks JJ, D'Amico R, et al. Indirect comparisons of competing interventions. Health Technology Assessment (Winchester, England) 2005;9:1-134, iii-iv.

\section{Gorecki 2009}

Gorecki C, Brown JM, Nelson EA, Briggs M, Schoonhoven L, Dealey $C$, et al. Impact of pressure ulcers on quality of life in older patients: a systematic review. Journal of the American Geriatrics Society 2009;57(7):1175-83.

\section{Gorecki 2013}

Gorecki C, Brown JM, Cano S, Lamping DL, Briggs M, Coleman S, et al. Development and validation of a new patient-reported outcome measure for patients with pressure ulcers: the PU-QOL instrument. Health and Quality of Life Outcomes 2013;11:95. [PMID: 23764247]

\section{Gray 2018}

Gray TA, Rhodes S, Atkinson RA, Rothwell K, Wilson P, Dumville JC, et al. Opportunities for better value wound care: a multiservice, cross-sectional survey of complex wounds and their care in a UK community population. BMJ Open 2018;8(3):e019440. [PMID: 29572395]

\section{Guest 2018}

Guest JF, Fuller GW, Vowden P, Vowden KR. Cohort study evaluating pressure ulcer management in clinical practice in the UK following initial presentation in the community: costs and outcomes. BMJ Open 2018;8(7):e021769. [PMID: 30049697]

\section{Herdman 2011}

Herdman M, Gudex C, Lloyd A, Janssen M, Kind P, Parkin D, et al. Development and preliminary testing of the new fivelevel version of EQ-5D (EQ-5D-5L). Quality of Life Research 2011;21(10):1727-36. [PMID: 21479777]

\section{Higgins 1996}

Higgins JP, Whitehead A. Borrowing strength from external trials in a meta-analysis. Statistics in Medicine 1996;15:2733-49.

\section{Higgins 2003}

Higgins JP, Thompson SG, Deeks JJ, Altman DG. Measuring inconsistency in meta-analyses. BMJ 2003;327(7414):557-60.

\section{Higgins 2017}

Higgins JP, Altman DG, Sterne JA (editors). Chapter 8: Assessing risk of bias in included studies. In: Higgins JP, Churchill R, Chandler J, Cumpston MS (editors), Cochrane Handbook for Systematic Reviews of Interventions version 5.2.0 (updated June 2017). The Cochrane Collaboration, 2017. Available from www.training.cochrane.org/handbook.

\section{Higgins 2020}

Higgins JP, Eldridge S, Li T (editors). Chapter 23: Including variants on randomized trials. In: Higgins JP, Thomas J, Chandler J, Cumpston M, Li T, Page MJ, et al (editors). Cochrane Handbook for Systematic Reviews of Interventions version 6.1 (updated September 2020). Cochrane, 2020. Available from www.training.cochrane.org/handbook.

\section{Kew 2014}

Kew KM, Dias S, Cates CJ. Long-acting inhaled therapy (beta-agonists, anticholinergics and steroids) for COPD: a network meta-analysis. Cochrane Database of Systematic Reviews 2014, Issue 3. Art. No: CD010844. [DOI: 10.1002/14651858.CD010844.pub2]

\section{Kirkham 2018}

Kirkham JJ, Altman DG, Chan AW, Gamble C, Dwan KM, Williamson PR. Outcome reporting bias in trials: a methodological approach for assessment and adjustment in systematic reviews. BMJ 2018;362:k3802.

\section{Krahn 2013}

Krahn U, Binder H, König J. A graphical tool for locating inconsistency in network meta-analyses. BMC Medical Research Methodology 2013;13:35.

\section{Lexchin 2003}

Lexchin J, Bero LA, Djulbegovic B, Clark O. Pharmaceutical industry sponsorship and research outcome and quality: systematic review. BMJ 2003;326(7400):1167-70.

\section{Lu 2004}

Lu G, Ades AE. Combination of direct and indirect evidence in mixed treatment comparisons. Statistics in Medicine 2004;23:3105-24.

\section{NCT03351049}

NCT03351049. An RCT on support surfaces for pressure ulcer prevention. ClinicalTrials.gov/show/NCT03351049 (first received 22 November 2017).

\section{Nguyen 2015}

Nguyen KH, Chaboyer W, Whitty JA. Pressure injury in Australian public hospitals: a cost-of-illness study. Australian Health Review 2015;39(3):329-36.

Beds, overlays and mattresses for preventing and treating pressure ulcers: an overview of Cochrane Reviews and network meta-analysis 


\section{NICE 2014}

National Institute for Health and Care Excellence

(NICE). Pressure ulcers: prevention and management. www.nice.org.uk/guidance/cg179 (accessed 08 October 2019).

\section{Nikolakopoulou 2020}

Nikolakopoulou A, Higgins JP, Papakonstantinou T, Chaimani A, Del Giovane C, Egger M, et al. CINeMA: an approach for assessing confidence in the results of a network meta-analysis. PLoS Medicine 2020;17:e1003082.

\section{NPIAP 2016}

National Pressure Injury Advisory Panel (NPIAP). NPUAP Pressure Injury Stages; 2016. Available at cdn.ymaws.com/npuap.site-ym.com/resource/resmgr/ npuap_pressure_injury_stages.pdf.

\section{NPIAP S3I 2019}

National Pressure Injury Advisory Panel (NPIAP) Support Surface Standards Initiative (S3I). Terms and Definitions Related to Support Surfaces; November 2019. Available at cdn.ymaws.com/npiap.com/resource/resmgr/website_version_ terms_and_de.pdf.

\section{Page 2020}

Page MJ, Higgins JP, Sterne JA. Chapter 13: Assessing risk of bias due to missing results in a synthesis. In: Higgins JP, Thomas J, Chandler J, Cumpston M, Li T, Page MJ, et al (editors). Cochrane Handbook for Systematic Reviews of Interventions version 6.1 (updated September 2020). Cochrane, 2020. Available from www.training.cochrane.org/handbook.

\section{Parmar 1998}

Parmar MK, Torri V, Stewart L. Extracting summary statistics to perform meta-analyses of the published literature for survival endpoints. Statistics in Medicine 1998;17(24):2815-34.

\section{Peters 2008}

Peters JL, Sutton AJ, Jones DR, Abrams KR, Rushton L. Contour-enhanced meta-analysis funnel plots help distinguish publication bias from other causes of asymmetry. Journal of Clinical Epidemiology 2008;61(10):991-6.

\section{Pollock 2017}

Pollock A, Campbell P, Brunton G, Hunt H, Estcourt L. Selecting and implementing overview methods: implications from five exemplar overview. Systematic Reviews 2017;6:145.

\section{Riley 2017}

Riley RD, Jackson D, Salanti G, Burke DL, Price M, Kirkham J, et al. Multivariate and network meta-analysis of multiple outcomes and multiple treatments: rationale, concepts, and examples. BMJ 2017;358:j3932.

\section{Salanti 2008}

Salanti G, Higgins JP, Ades AE, loannidis JP. Evaluation of networks of randomized trials. Statistical Methods in Medical Research 2008;17:279-301.

\section{Salanti 2011}

Salanti G, Ades AE, loannidis JP. Graphical methods and numerical summaries for presenting results from multipletreatment meta-analysis: an overview and tutorial. Journal of Clinical Epidemiology 2011;64:163-71.

\section{Salanti 2014}

Salanti G, Giovane CD, Chaimani A, Caldwell DM, Higgins JP. Evaluating the quality of evidence from a network metaanalysis. PLoS One 2014;9(7):e99682.

\section{Schoonhoven 2007}

Schoonhoven L, Bousema Mente T, Buskens E, on behalf of the prePURSE-study group. The prevalence and incidence of pressure ulcers in hospitalised patients in the Netherlands: a prospective inception cohort study. International Journal of Nursing Studies 2007;44(6):927-35.

\section{Schulz 1995}

Schulz KF, Chalmers I, Hayes RJ, Altman DG. Empirical evidence of bias. Dimensions of methodological quality associated with estimates of treatment effects in controlled trials. JAMA 1995;273(5):408-12.

\section{Shi 2018a}

Shi C, Dumville JC, Cullum N. Support surfaces for pressure ulcer prevention: a network meta-analysis. PLoS One 2018;13:e0192707.

\section{Shi 2018b}

Shi C, Dumville JC, Cullum N. Skin status for predicting pressure ulcer development: a systematic review and meta-analyses. International Journal of Nursing Studies 2018;87:14-25.

\section{Song 2011}

Song F, Xiong T, Parekh-Bhurke S, Loke YK, Sutton AJ, Eastwood AJ, et al. Inconsistency between direct and indirect comparisons of competing interventions: meta-epidemiological study. BMJ 2011;343:d4909.

\section{Theisen 2012}

Theisen S, Drabik A, Stock S. Pressure ulcers in older hospitalised patients and its impact on length of stay: a retrospective observational study. Journal of Clinical Nursing 2012;21(3-4):380-7.

\section{Tierney 2007}

Tierney JF, Stewart LA, Ghersi D, Burdett S, Sydes MR. Practica methods for incorporating summary time-to-event data into meta-analysis. Trials 2007;8:16.

\section{Turner 2012}

Turner RM, Davey J, Clarke MJ, Thompson SG, Higgins JP. Predicting the extent of heterogeneity in meta-analysis, using empirical data from the Cochrane Database of Systematic Reviews. International Journal of Epidemiology 2012;41(3):818-27.

Beds, overlays and mattresses for preventing and treating pressure ulcers: an overview of Cochrane Reviews and network meta-analysis 


\section{Vanderwee 2005}

Vanderwee K, Grypdonck MH, Defloor T. Effectiveness of an alternating pressure air mattress for the prevention of pressure ulcers. Age and Ageing 2005;34(3):261-7.

\section{Veroniki 2013}

Veroniki AA, Vasiliadis HS, Higgins JP, Salanti G. Evaluation of inconsistency in networks of interventions. International Journal of Epidemiology 2013;42(1):332-45.

\section{White 2015}

White IR. Network meta-analysis. Stata Journal 2015;15:951-85.

\section{Whiting 2016}

Whiting P, Savović J, Higgins JP, Caldwell DM, Reeves BC, Shea B, et al. ROBIS: a new tool to assess risk of bias in systematic reviews was developed. Journal of Clinical Epidemiology 2016;69:225-34.

\section{Woodhead 2016}

Woodhead M. $80 \%$ of China's clinical trial data are fraudulent, investigation finds. BMJ 2016;355:i5396.

\section{World Health Organization 2019}

World Health Organization. EH90 Pressure ulceration. ICD-11 for Mortality and Morbidity Statistics (Version: 04/2019). Available at icd.who.int/browse11/l-m/en\#/http\%3a\%2f\%2fid.who.int \%2ficd\%2fentity\%2f455330172 (accessed 17 February 2020).

\section{Wounds International 2010}

Wounds International. International Review. Pressure Ulcer Prevention: Pressure, Shear, Friction and Microclimate in Context. A Consensus Document. London (UK): Wounds International, 2010.

\section{Yepes-Nuñez 2019}

Yepes-Nuñez JJ, Li SA, Guyatt G, Jack SM, Brozek JL, Beyene J, et al. Development of the summary of findings table for network meta-analysis. Journal of Clinical Epidemiology 2019;115:1-3.

\section{References to other published versions of this review Shi $2020 f$}

Shi C, Dumville JC, Cullum N, Rhodes S, McInnes E. Beds, overlays and mattresses for preventing and treating pressure ulcers: an overview of Cochrane reviews and network metaanalysis. Cochrane Database of Systematic Reviews 2020, Issue 10. Art. No: CD013761. [DOI: 10.1002/14651858.CD013761] 


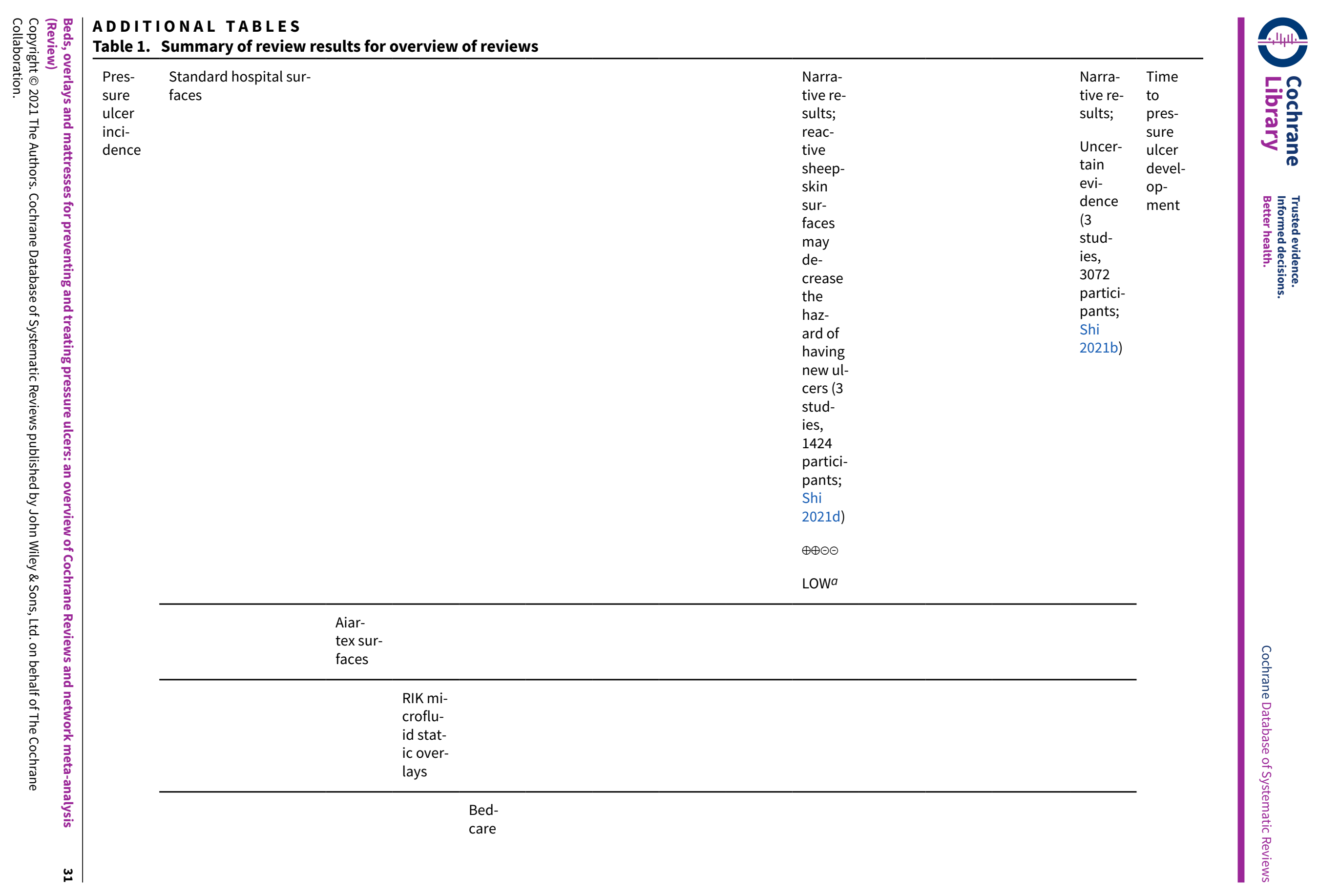




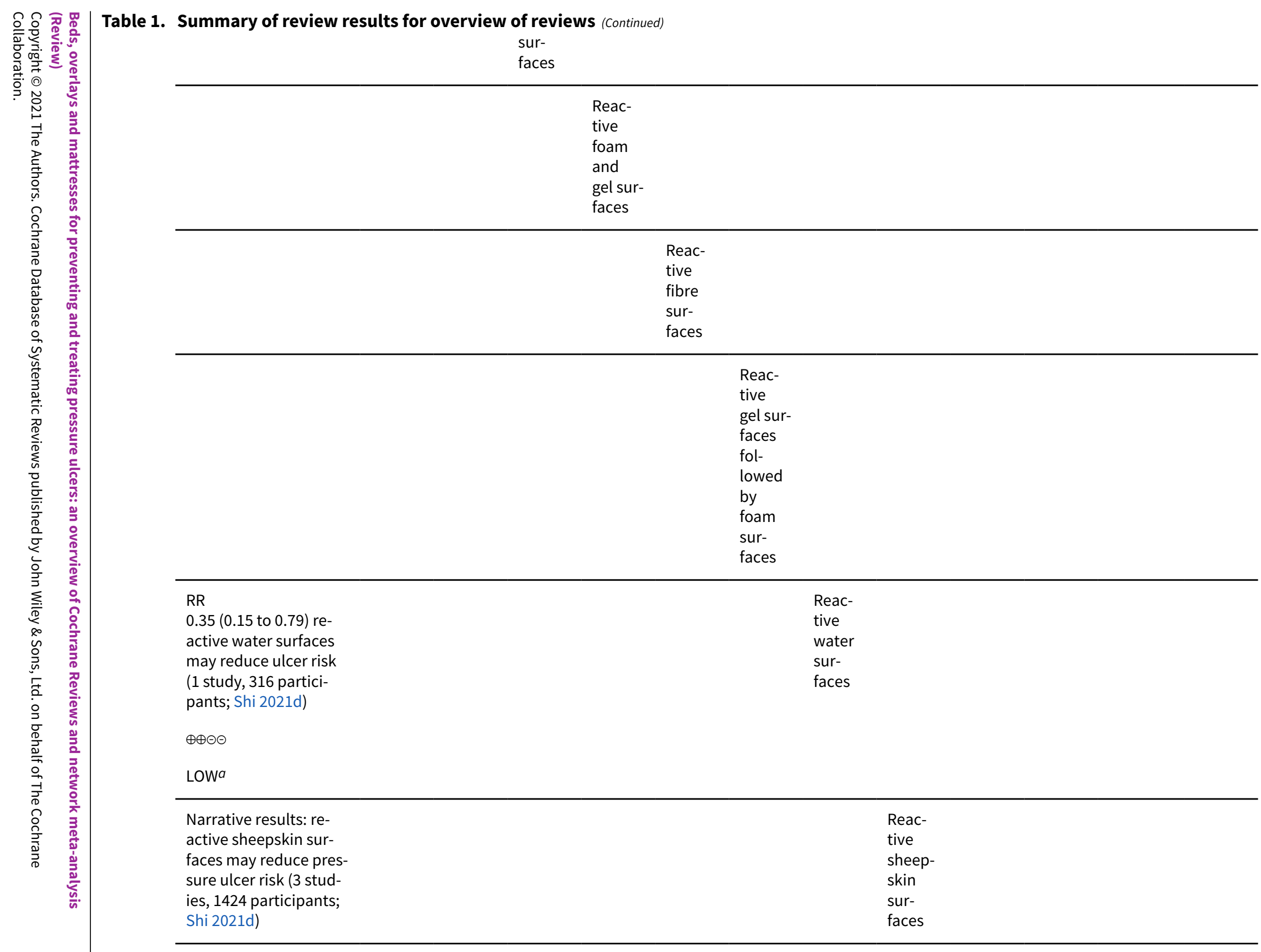




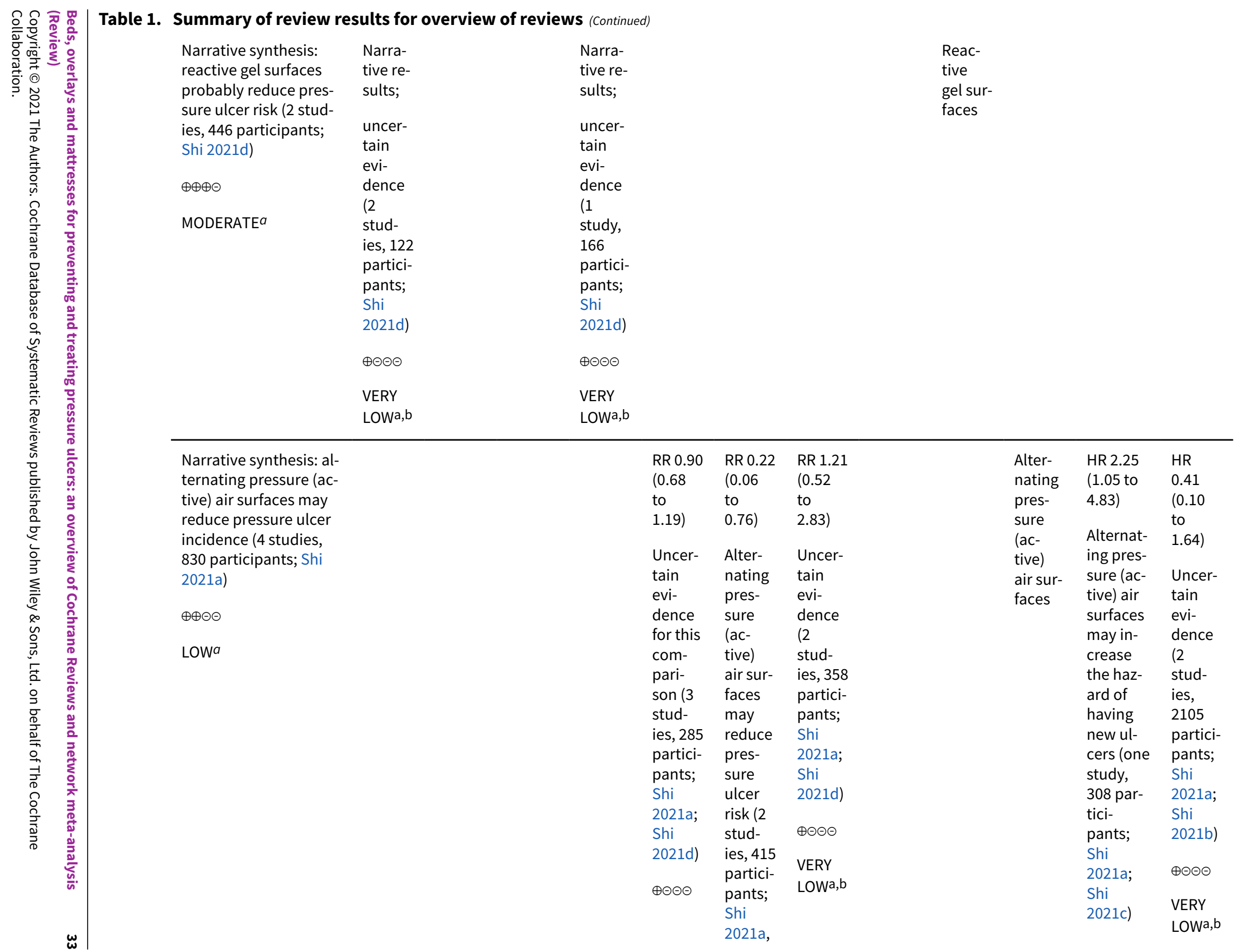




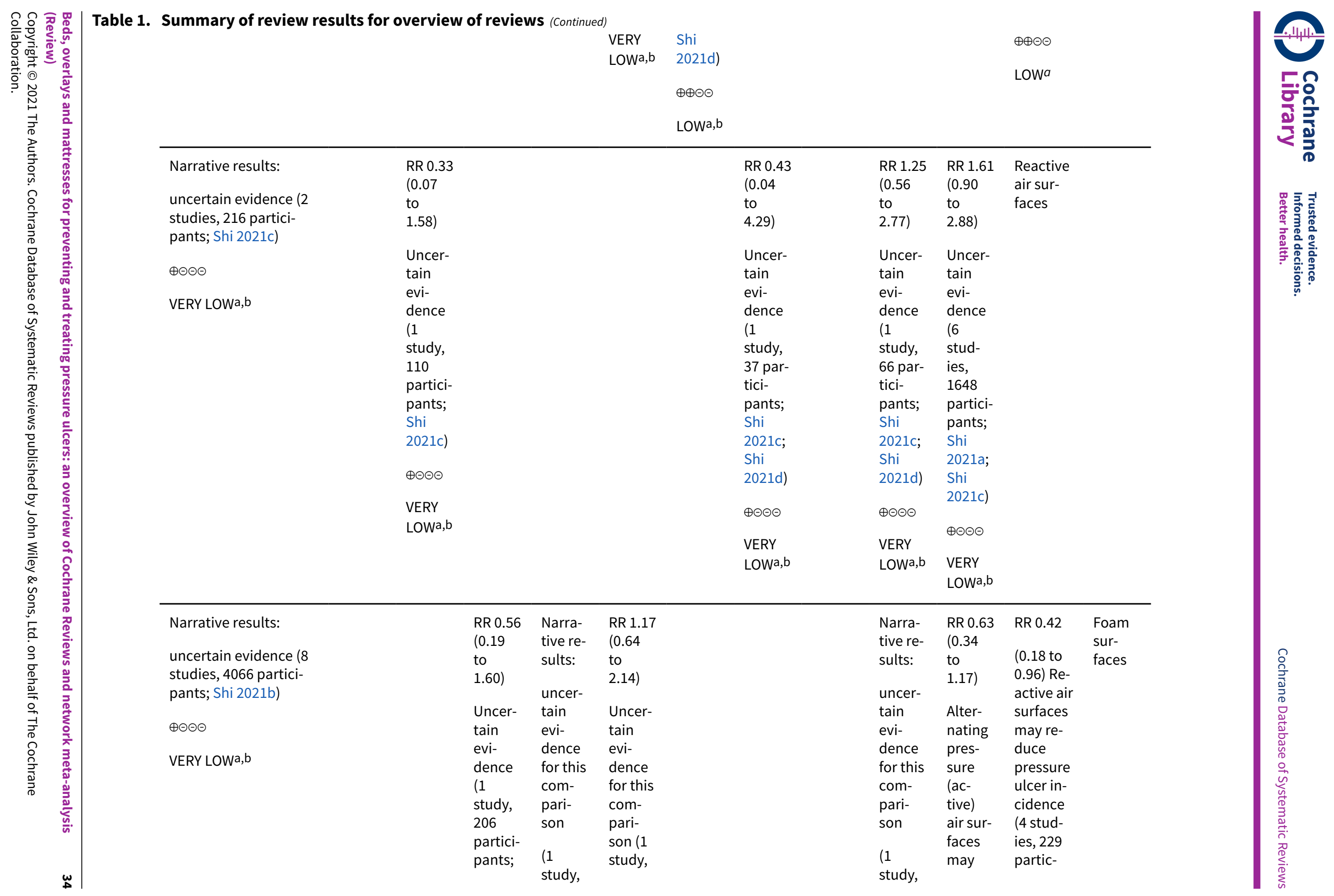




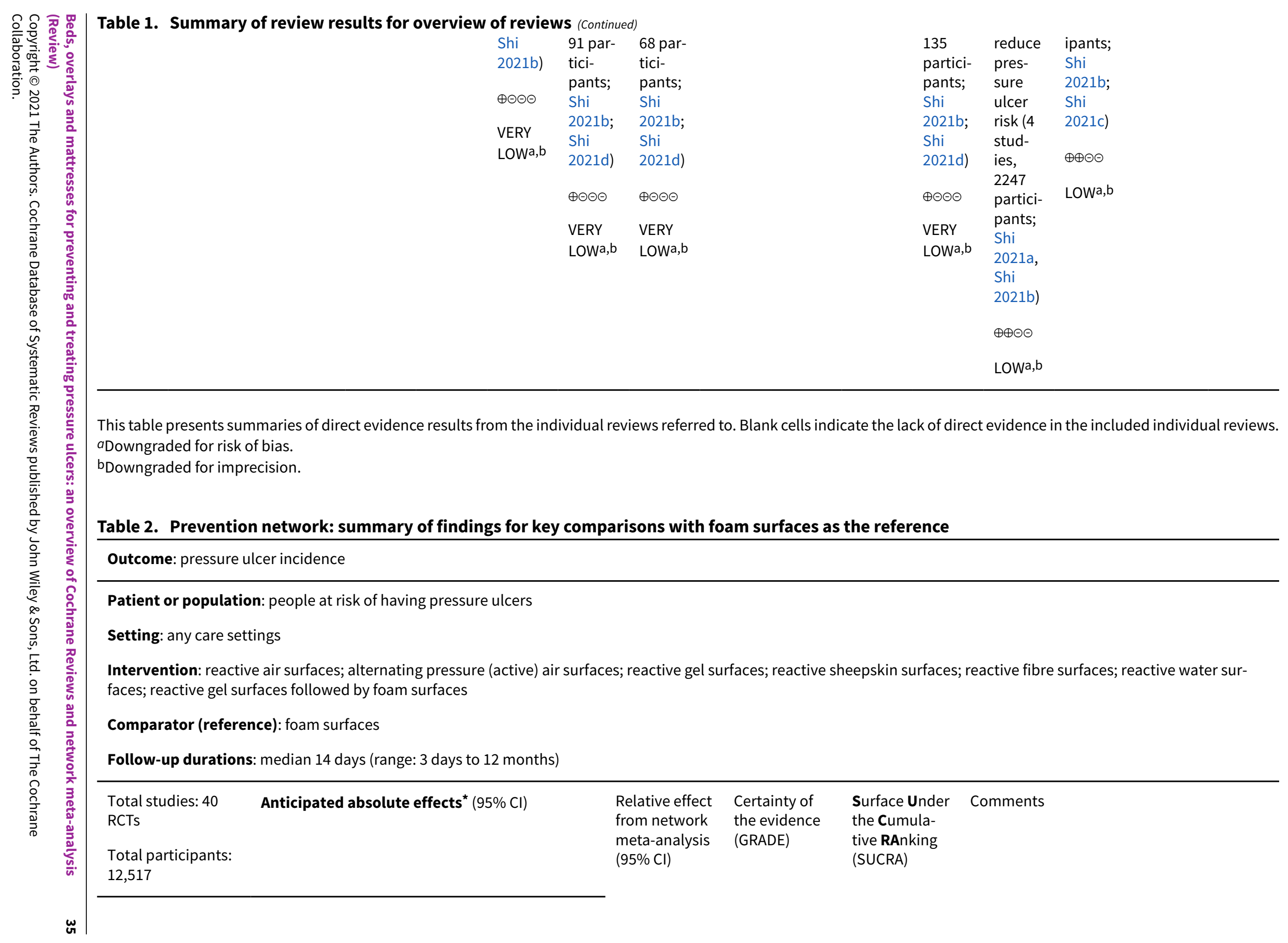

This table presents summaries of direct evidence results from the individual reviews referred to. Blank cells indicate the lack of direct evidence in the included individual reviews. a Downgraded for risk of bias.

\section{Table 2. Prevention network: summary of findings for key comparisons with foam surfaces as the reference}

Pient or population: people at risk of having pressure ulcers

meta-analysis (GRADE) tive RAnking

otal participants:

pants; 


\begin{tabular}{|c|c|c|c|c|c|c|c|c|c|}
\hline 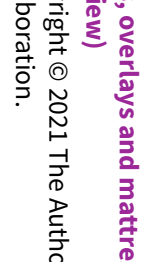 & $\begin{array}{l}\text { Interventions } \\
\text { (numbers of stud- } \\
\text { ies and partici- } \\
\text { pants comparing } \\
\text { the named inter- } \\
\text { vention with foam } \\
\text { surfaces) }\end{array}$ & $\begin{array}{l}\text { Risk with } \\
\text { foam sur- } \\
\text { faces }\end{array}$ & $\begin{array}{l}\text { Risk with a } \\
\text { type of sup- } \\
\text { port surface }\end{array}$ & Difference & & & & & 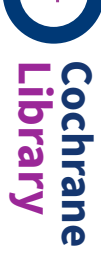 \\
\hline 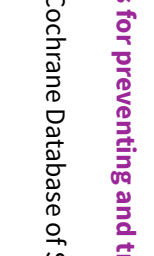 & $\begin{array}{l}\text { Reactive air sur- } \\
\text { faces ( } 4 \text { RCTs, } 229 \\
\text { participants) }\end{array}$ & 106 per 1000 & $\begin{array}{l}49 \text { per } 1000 \\
(31 \text { to } 80)\end{array}$ & $\begin{array}{l}57 \text { fewer per } \\
1000 \\
\\
(26 \text { fewer to } \\
75 \text { fewer })\end{array}$ & $\begin{array}{l}\text { RR } \mathbf{0 . 4 6} \\
\text { (0.29 to } 0.75)\end{array}$ & $\begin{array}{l}\oplus \oplus 00 \\
\text { LOWa,b }\end{array}$ & $\begin{array}{l}78.1 \% \\
\oplus 000 \\
\text { VERY LOWa,b,c }\end{array}$ & $\begin{array}{l}\text { Reactive air surfaces may reduce pressure } \\
\text { ulcer incidence compared with foam sur- } \\
\text { faces. } \\
\text { It is uncertain how likely it is that reactive } \\
\text { air surfaces are the best intervention in re- } \\
\text { ducing pressure ulcer incidence. }\end{array}$ & 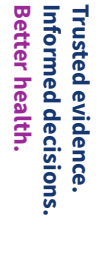 \\
\hline 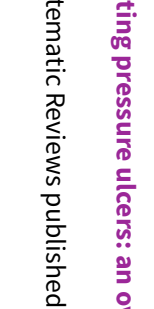 & $\begin{array}{l}\text { Alternating pres- } \\
\text { sure (active) air } \\
\text { surfaces ( } 4 \text { RCTs, } \\
2247 \text { participants) }\end{array}$ & 106 per 1000 & $\begin{array}{l}67 \text { per } 1000 \\
\text { (44 to } 98)\end{array}$ & $\begin{array}{l}39 \text { fewer per } \\
1000 \\
\text { (8 fewer to } 62 \\
\text { fewer) }\end{array}$ & $\begin{array}{l}\text { RR } 0.63 \\
(0.42 \text { to } 0.93)\end{array}$ & $\begin{array}{l}\oplus \oplus 00 \\
\text { LOWa,b }\end{array}$ & $\begin{array}{l}59.3 \% \\
\text { ФOOO } \\
\text { VERY LOWa,b,c }\end{array}$ & $\begin{array}{l}\text { Alternating pressure (active) air surfaces } \\
\text { may reduce pressure ulcer incidence com- } \\
\text { pared with foam surfaces. } \\
\text { It is uncertain how likely it is that alternat- } \\
\text { ing pressure (active) air surfaces are the } \\
\text { best intervention in reducing pressure ulcer } \\
\text { incidence. }\end{array}$ & \\
\hline 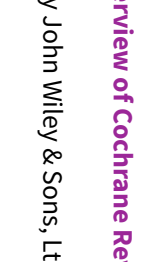 & $\begin{array}{l}\text { Reactive gel } \\
\text { surfaces (no } \\
\text { analysable data for } \\
\text { this direct compar- } \\
\text { ison) }\end{array}$ & 106 per 1000 & $\begin{array}{l}51 \text { per } 1000 \\
(23 \text { to } 108)\end{array}$ & $\begin{array}{l}56 \text { fewer per } \\
1000 \\
\text { (83 fewer to } 1 \\
\text { more) }\end{array}$ & $\begin{array}{l}\text { RR } 0.47 \\
(0.22 \text { to } 1.01)\end{array}$ & $\begin{array}{l}\oplus \oplus 00 \\
\text { LOWC }\end{array}$ & $\begin{array}{l}74.6 \% \\
\oplus 000 \\
\text { VERY LOWa,b,c }\end{array}$ & $\begin{array}{l}\text { Reactive gel surfaces may reduce pressure } \\
\text { ulcer incidence compared with foam sur- } \\
\text { faces. } \\
\text { It is uncertain how likely it is that reactive } \\
\text { gel surfaces are the best intervention in re- } \\
\text { ducing pressure ulcer incidence. }\end{array}$ & \\
\hline 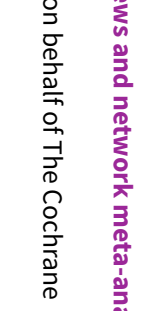 & $\begin{array}{l}\text { Reactive sheep- } \\
\text { skin surfaces (no } \\
\text { analysable data for } \\
\text { this direct compar- } \\
\text { ison) }\end{array}$ & 106 per 1000 & $\begin{array}{l}\mathbf{6 1} \text { per } 1000 \\
(34 \text { to } 111)\end{array}$ & $\begin{array}{l}45 \text { fewer per } \\
1000 \\
\text { ( } 72 \text { fewer to } 5 \\
\text { more) }\end{array}$ & $\begin{array}{l}\text { RR } \mathbf{0 . 5 8} \\
(0.32 \text { to } 1.05)\end{array}$ & $\begin{array}{l}\oplus 00 \bigcirc \\
\text { VERY LOWc,d }\end{array}$ & $\begin{array}{l}64.1 \% \\
\oplus 000 \\
\text { VERY LOWa,b,c }\end{array}$ & $\begin{array}{l}\text { It is uncertain if there is a difference be- } \\
\text { tween reactive sheepskin surfaces and } \\
\text { foam surfaces in reducing pressure ulcer } \\
\text { risk. } \\
\text { It is uncertain how likely it is that reactive } \\
\text { sheepskin surfaces are the best intervention } \\
\text { in reducing pressure ulcer incidence. }\end{array}$ & 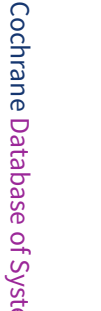 \\
\hline$\omega$ & $\begin{array}{l}\text { Reactive fibre sur- } \\
\text { faces ( } 1 \mathrm{RCT}, 68 \\
\text { participants) }\end{array}$ & 106 per 1000 & $\begin{array}{l}75 \text { per } 1000 \\
(40 \text { to } 142)\end{array}$ & $\begin{array}{l}31 \text { fewer per } \\
1000\end{array}$ & $\begin{array}{l}\text { RR } \mathbf{0 . 7 1} \\
\text { (0.38 to } 1.34)\end{array}$ & $\begin{array}{l}\oplus 00 \bigcirc \\
\text { VERY LOWc,d }\end{array}$ & $\begin{array}{l}50.6 \% \\
\oplus 000\end{array}$ & $\begin{array}{l}\text { It is uncertain if there is a difference be- } \\
\text { tween reactive fibre surfaces and foam sur- } \\
\text { faces in reducing pressure ulcer risk. }\end{array}$ & 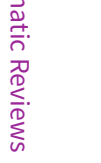 \\
\hline
\end{tabular}




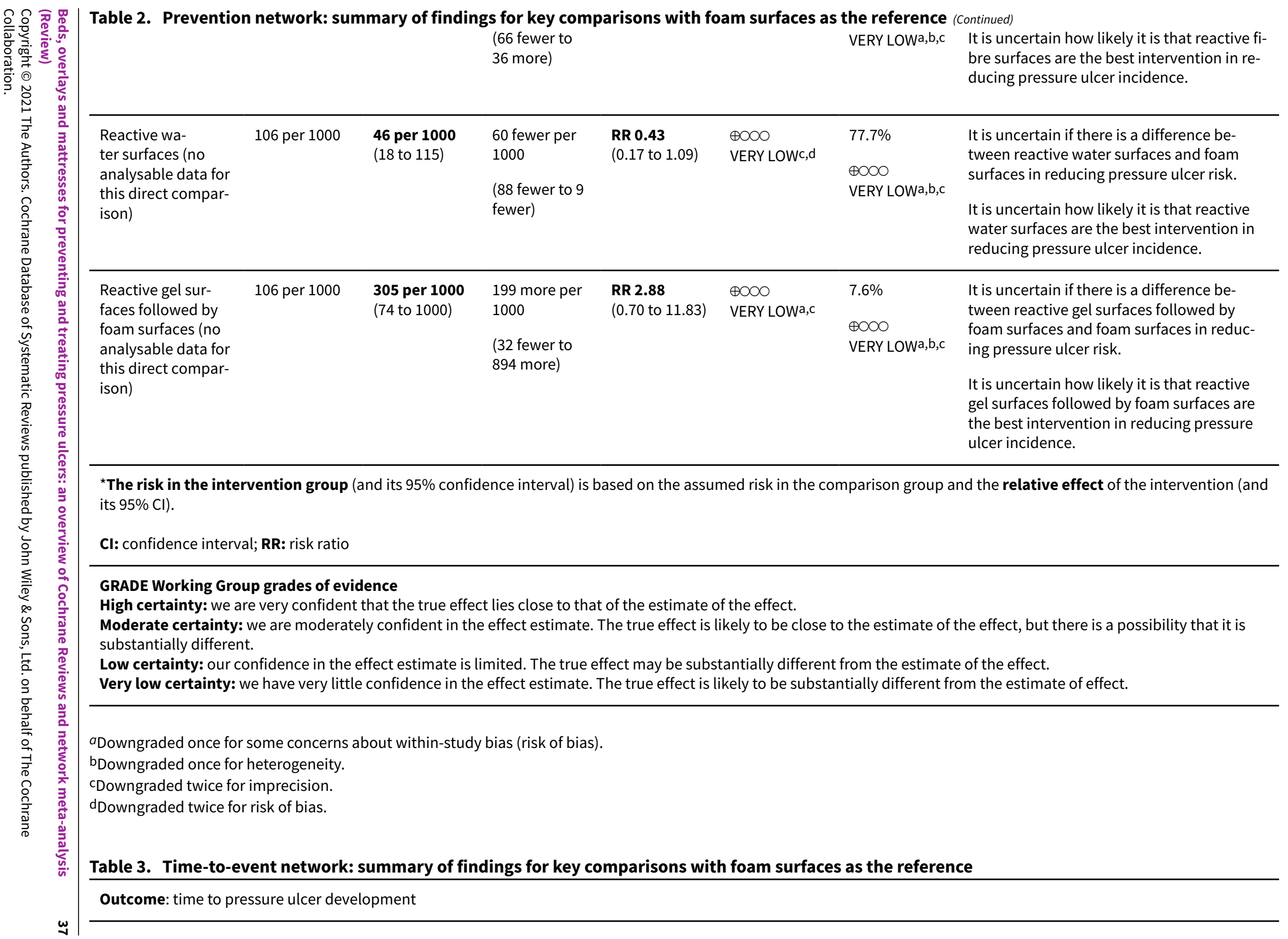
this direct compar-

( 32 fewer to

RR 2.88

$\oplus 000$

$\oplus \circ \circ$

It is uncertain if there is a difference between reactive gel surfaces followed by g pressure ulcer risk.

It is uncertain how likely it is that reactive tollowed by foam surfaces are lcer incidence.

The risk in the intervention group (and its 95\% confidence interval) is based on the assumed risk in the comparison group and the relative effect of the intervention (and its $95 \% \mathrm{Cl}$.

\section{GRADE Working Group grades of evidence}

substantially different.

Low certainty: our confidence in the effect estimate is limited. The true effect may be substantially different from the estimate of the effect.

Very low certainty: we have very little confidence in the effect estimate. The true effect is likely to be substantially different from the estimate of effect.

aDowngraded once for some concerns about within-study bias (risk of bias).

once for heterogeneity.

cDowngraded twice for imprecision.

Table 3. Time-to-event network: summary of findings for key comparisons with foam surfaces as the reference 


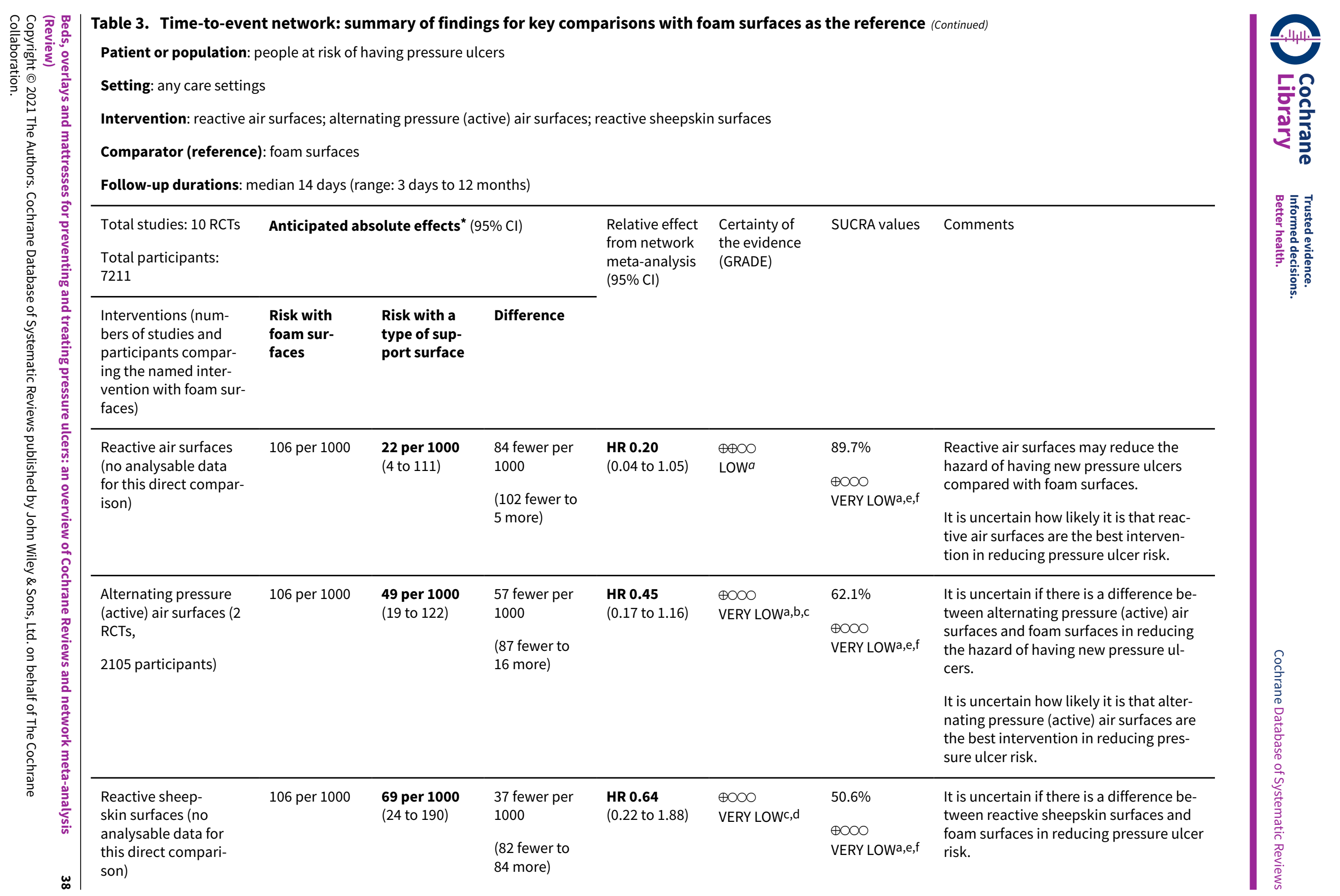




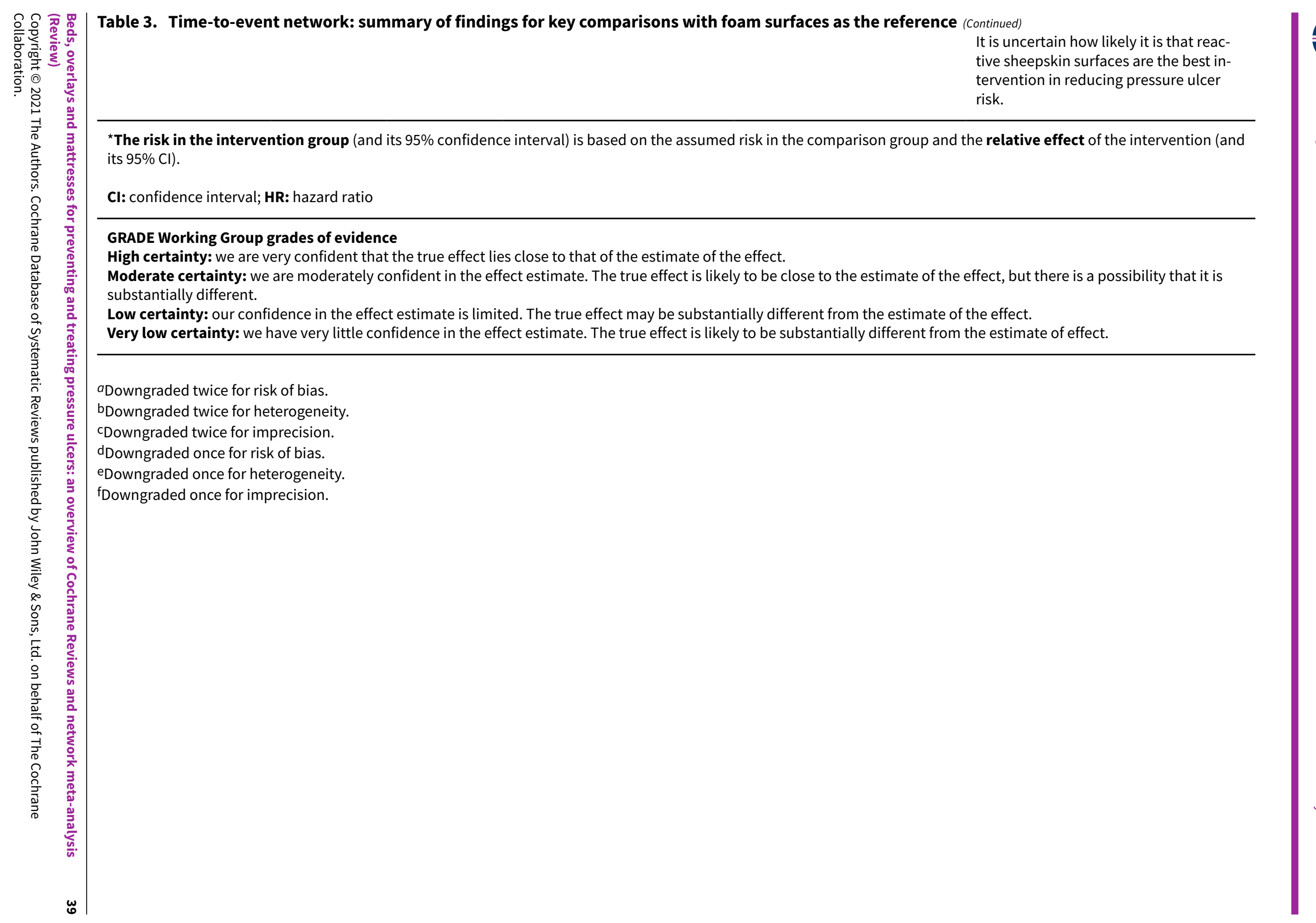


Table 4. League table for time-to-event network: results of network meta-analysis with GRADE assessment (below diagonal) and available pairwise meta-analyses (above diagonal)a

\begin{tabular}{|c|c|c|c|}
\hline $\begin{array}{l}\text { Alternating pressure (active) } \\
\text { air surfaces }\end{array}$ & 2.25 (1.05 to 4.83$)$ & $\begin{array}{l}0.41(0.10 \text { to } \\
1.64)\end{array}$ & $\begin{array}{l}1.12(0.70 \text { to } \\
1.79)\end{array}$ \\
\hline
\end{tabular}

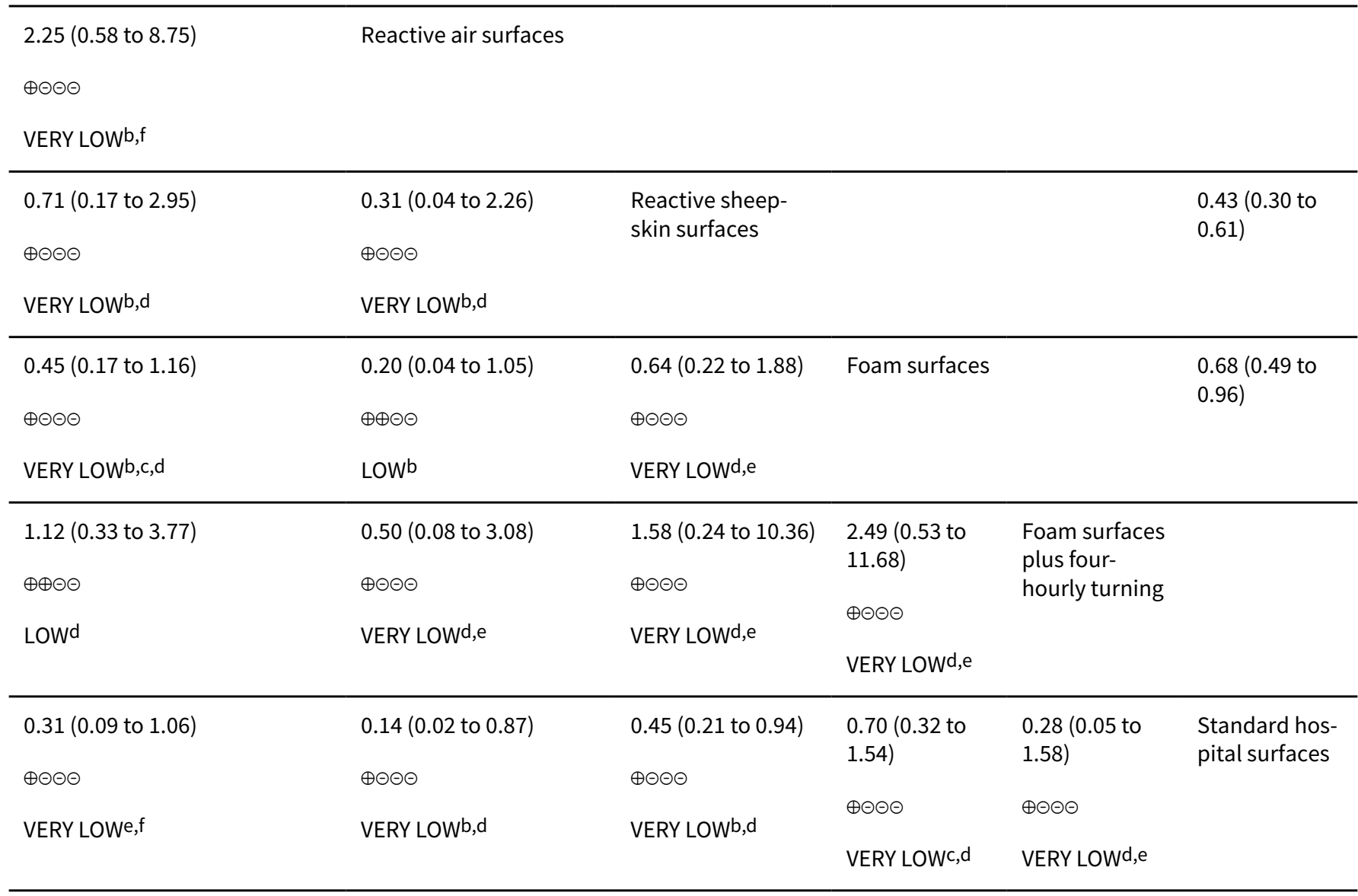

$a$ Results of available pairwise meta-analyses are presented in the upper right triangle above the diagonal, results of network meta-analysis with GRADE assessment are presented in the lower left triangle. All results are $\mathrm{HRs}$ and their $95 \% \mathrm{Cls}$. For each cell, the $\mathrm{HR}$ and $\mathrm{Cl}$ correspond to support surfaces in the same row and column, with the top-left support surface compared to the lower right support surface in each case. bDowngraded twice for risk of bias.

cDowngraded twice for heterogeneity.

dDowngraded twice for imprecision.

eDowngraded once for risk of bias.

fDowngraded once for imprecision. 


\section{Table 5. Treatment network: summary of findings for key comparisons with foam surfaces as the reference}

Outcome: proportion of participants with pressure ulcers completely healed

Patient or population: people with pressure ulcers

Setting: any care settings

Intervention: reactive air surfaces; alternating pressure (active) air surfaces; reactive water surfaces

Comparator (reference): foam surfaces

Follow-up durations: median 37.5 days (range: 7 days to 18 months).

\begin{tabular}{|c|c|c|c|c|c|c|c|}
\hline & \multicolumn{3}{|c|}{ Anticipated absolute effects ${ }^{*}(95 \% \mathrm{Cl})$} & \multirow{2}{*}{$\begin{array}{l}\text { Relative effect } \\
\text { from network } \\
\text { meta-analysis } \\
(95 \% \mathrm{Cl})\end{array}$} & \multirow{2}{*}{$\begin{array}{l}\text { Certainty of } \\
\text { the evidence } \\
\text { (GRADE) }\end{array}$} & \multirow{2}{*}{$\begin{array}{l}\text { Surface Under } \\
\text { the Cumula- } \\
\text { tive RAnking } \\
\text { (SUCRA) }\end{array}$} & \multirow[t]{2}{*}{ Comments } \\
\hline $\begin{array}{l}\text { Interventions (num- } \\
\text { bers of studies and } \\
\text { participants compar- } \\
\text { ing the named inter- } \\
\text { vention with foam } \\
\text { surfaces) }\end{array}$ & $\begin{array}{l}\text { Risk with } \\
\text { foam sur- } \\
\text { faces }\end{array}$ & $\begin{array}{l}\text { Risk with a } \\
\text { type of sup- } \\
\text { port surface }\end{array}$ & Difference & & & & \\
\hline $\begin{array}{l}\text { Reactive air surfaces } \\
\text { ( } 2 \text { RCTs, } 156 \text { partici- } \\
\text { pants) }\end{array}$ & 410 per 1000 & $\begin{array}{l}\mathbf{5 4 1} \text { per } \mathbf{1 0 0 0} \\
\text { (393 to } 783 \text { ) }\end{array}$ & $\begin{array}{l}131 \text { more per } \\
1000 \\
\text { (17 fewer to } \\
373 \text { more) }\end{array}$ & $\begin{array}{l}\text { RR } 1.32 \\
(0.96 \text { to } 1.80)\end{array}$ & $\begin{array}{l}\oplus \oplus \circ \bigcirc \\
\text { LOWa }\end{array}$ & $\begin{array}{l}83.9 \% \\
\oplus 000 \\
\text { VERY LOWa,c }\end{array}$ & $\begin{array}{l}\text { Reactive air surfaces may increase pres- } \\
\text { sure ulcer healing compared with foam } \\
\text { surfaces. } \\
\text { It is uncertain how likely it is that reactive } \\
\text { air surfaces are the best intervention in } \\
\text { healing pressure ulcers. }\end{array}$ \\
\hline $\begin{array}{l}\text { Alternating pressure } \\
\text { (active) air surfaces } \\
\text { (1 } \mathrm{RCT}, 49 \text { partici- } \\
\text { pants) }\end{array}$ & 410 per 1000 & $\begin{array}{l}397 \text { per } 1000 \\
(107 \text { to } 1000)\end{array}$ & $\begin{array}{l}13 \text { fewer per } \\
1000 \\
\text { (303 fewer to } \\
590 \text { more) }\end{array}$ & $\begin{array}{l}\text { RR } 0.97 \\
(0.26 \text { to } 3.58)\end{array}$ & $\begin{array}{l}\oplus 00 \bigcirc \\
\text { VERY LOWa,b }\end{array}$ & $\begin{array}{l}43.0 \% \\
\text { ๑OOO } \\
\text { VERY LOWa,c }\end{array}$ & $\begin{array}{l}\text { It is uncertain if there is a difference in } \\
\text { complete pressure ulcer healing between } \\
\text { alternating pressure (active) air surfaces } \\
\text { and foam surfaces. } \\
\text { It is uncertain how likely it is that alternat- } \\
\text { ing pressure (active) air surfaces are the } \\
\text { best intervention in healing pressure ul- } \\
\text { cers. }\end{array}$ \\
\hline $\begin{array}{l}\text { Reactive water sur- } \\
\text { faces ( } 1 \text { RCT, } 101 \text { par- } \\
\text { ticipants) }\end{array}$ & 410 per 1000 & $\begin{array}{l}\mathbf{4 1 0} \text { per } \mathbf{1 0 0 0} \\
\text { (295 to } 565 \text { ) }\end{array}$ & $\begin{array}{l}0 \text { fewer per } \\
1000\end{array}$ & $\begin{array}{l}\text { RR } 1.00 \\
(0.72 \text { to } 1.38)\end{array}$ & $\begin{array}{l}\oplus 000 \\
\text { VERY LOWa,b,c }\end{array}$ & $\begin{array}{l}37.9 \% \\
\oplus 000 \\
\text { VERY LOWa,c }\end{array}$ & $\begin{array}{l}\text { It is uncertain if there is a difference be- } \\
\text { tween reactive water surfaces and foam } \\
\text { surfaces in complete pressure ulcer heal- } \\
\text { ing. }\end{array}$ \\
\hline
\end{tabular}




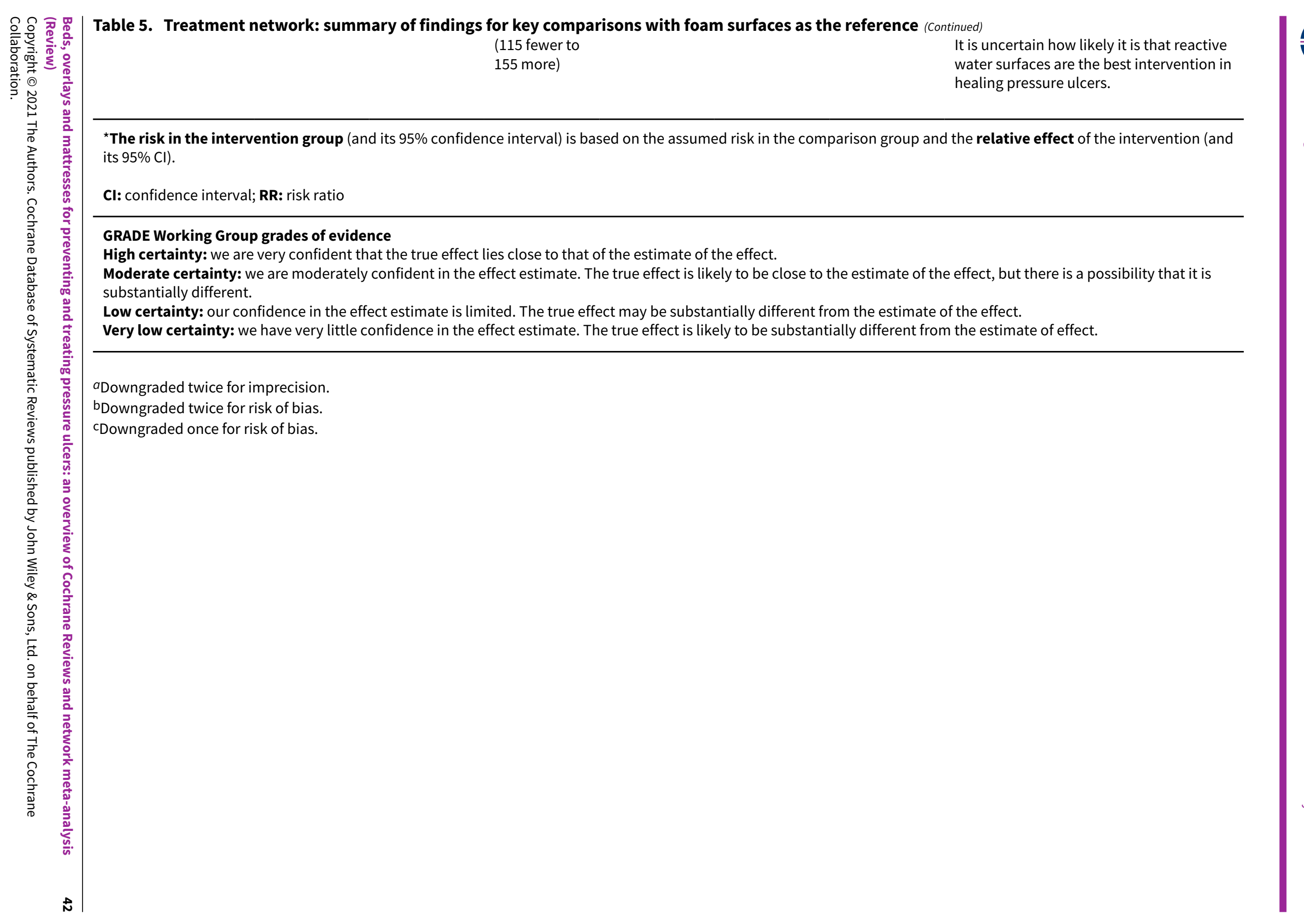


Table 6. League table for treatment network: results of network meta-analysis with GRADE assessment (below diagonal) and available pairwise meta-analyses (above diagonal)a

\begin{tabular}{|c|c|c|c|}
\hline Reactive water surfaces & & & $1.07(0.70$ to 1.64$)$ \\
\hline $\begin{array}{l}1.03(0.27 \text { to } 3.98) \\
\oplus \Theta \Theta \Theta\end{array}$ & $\begin{array}{l}\text { Alternating pressure (active) air sur- } \\
\text { faces }\end{array}$ & & $0.97(0.26$ to 3.58$)$ \\
\hline \multicolumn{4}{|l|}{ VERY LOWb,c } \\
\hline $0.76(0.48$ to 1.19$)$ & $0.74(0.19$ to 2.82$)$ & $\begin{array}{l}\text { Reactive air sur- } \\
\text { faces }\end{array}$ & $1.32(0.96$ to 1.80$)$ \\
\hline$\oplus \Theta \odot \Theta$ & $\oplus \Theta \Theta \Theta$ & & \\
\hline VERY LOWc,d & VERY LOWc,d & & \\
\hline $1.00(0.72$ to 1.38$)$ & 0.97 (0.26 to 3.58$)$ & $1.32(0.96$ to 1.80$)$ & Foam surfaces \\
\hline$\oplus \Theta \Theta \Theta$ & $\oplus \Theta \Theta \Theta$ & $\oplus \oplus \Theta \Theta$ & \\
\hline VERY LOWb,c & VERY LOWb,c & LOWC & \\
\hline
\end{tabular}

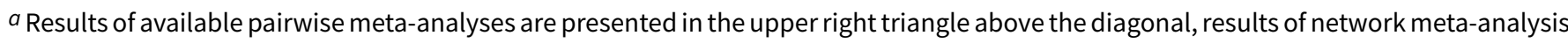
with GRADE assessment are presented in the lower left triangle. All results are RRs and their $95 \% \mathrm{Cls}$. For each cell, the RR and Cl correspond to support surfaces in the same row and column, with the top-left support surface compared to the lower right support surface in each case. bDowngraded twice for risk of bias.

cDowngraded twice for imprecision.

dDowngraded once for risk of bias.

\section{APPENDICES}

Appendix 1. Full details of support surfaces classifications

\begin{tabular}{|c|c|c|c|}
\hline $\begin{array}{l}\text { Overarching class } \\
\text { of support surface } \\
\text { (as used in this re- } \\
\text { view) }\end{array}$ & $\begin{array}{l}\text { Corresponding } \\
\text { subclasses of sup- } \\
\text { port surfaces used } \\
\text { in Shi } 2018 a\end{array}$ & Descriptions of support surfaces & $\begin{array}{l}\text { Selected examples (with } \\
\text { example brands where } \\
\text { possible) }\end{array}$ \\
\hline \multirow[t]{3}{*}{$\begin{array}{l}\text { Reactive air sur- } \\
\text { faces }\end{array}$} & $\begin{array}{l}\text { Powered/non-pow- } \\
\text { ered reactive air } \\
\text { surfaces }\end{array}$ & $\begin{array}{l}\text { A group of support surfaces constructed of air cells, } \\
\text { which redistribute body weight over a maximum sur- } \\
\text { face area (i.e. has reactive pressure redistribution } \\
\text { mode), with or without the requirement for electrical } \\
\text { power }\end{array}$ & $\begin{array}{l}\text { Static air mattress overlay, } \\
\text { dry flotation mattress (e.g. } \\
\text { Roho, Sofflex), static air } \\
\text { mattress (e.g. EHOB), and } \\
\text { static mode of Duo } 2 \text { mat- } \\
\text { tress }\end{array}$ \\
\hline & $\begin{array}{l}\text { Powered/non-pow- } \\
\text { ered reactive low- } \\
\text { air-loss air surfaces }\end{array}$ & $\begin{array}{l}\text { A group of support surfaces made of air cells, which } \\
\text { have reactive pressure redistribution modes and a low- } \\
\text { air-loss function, with or without the requirement for } \\
\text { electrical power }\end{array}$ & Low-air-loss hydrotherapy \\
\hline & $\begin{array}{l}\text { Powered reactive } \\
\text { air-fluidised sur- } \\
\text { faces }\end{array}$ & $\begin{array}{l}\text { A group of support surfaces made of air cells, which } \\
\text { have reactive pressure redistribution modes and an air- } \\
\text { fluidised function, with the requirement for electrical } \\
\text { power }\end{array}$ & $\begin{array}{l}\text { Air-fluidised bed (e.g. Clini- } \\
\text { tron) }\end{array}$ \\
\hline
\end{tabular}

Beds, overlays and mattresses for preventing and treating pressure ulcers: an overview of Cochrane Reviews and network meta-analysis 43 (Review)

Copyright (C) 2021 The Authors. Cochrane Database of Systematic Reviews published by John Wiley \& Sons, Ltd. on behalf of The Cochrane Collaboration. 
(Continued)

\section{Foam surfaces}

Non-powered reactive foam surfaces
A group of support surfaces made of foam materials, which have a reactive pressure redistribution function, without the requirement for electrical power
Convoluted foam overlay (or pad), elastic foam overlay (e.g. Aiartex, microfluid static overlay), polyether foam pad, foam mattress replacement (e.g. MAXIFLOAT), solid foam overlay, viscoelastic foam mattress/overlay (e.g. Tempur, CONFOR-Med, Akton, Thermo)

Silicore (e.g. Spenco) overlay/pad supporternative reactive (non-foam or airfilled): reactive fibre surfaces
Non-powered reactive fibre surfaces
A group of support surfaces made of fibre materials, which have a reactive pressure redistribution function, without the requirement for electrical power
Gel mattress, gel pad used

\section{in operating theatre}

Alternative reactive support surfaces (non-foam or airfilled): reactive gel surfaces
Non-powered reactive gel surfaces
A group of support surfaces made of gel materials, which have a reactive pressure redistribution function, without the requirement for electrical power

\section{Alternative reac-} tive support surfaces (non-foam or air-filled): reactive sheepskin surfaces
Non-powered reac- A group of support surfaces made of sheepskin, which tive sheepskin surfaces

\section{have a reactive pressure redistribution function, with-} out the requirement for electrical power
Australian Medical Sheepskins overlay
Alternative reactive support surfaces (non-foam or airfilled): reactive water surfaces
Non-powered reac- A group of support surfaces based on water, which tive water surfaces

\section{has the capability of a reactive pressure redistribution} function, without the requirement for electrical power

\section{Water mattress}

\section{Alternating pres-} sure (active) air surfaces
Powered active air surfaces
A group of support surfaces made of air cells, which mechanically alternate the pressure beneath the body to reduce the duration of the applied pressure (mainly via inflating and deflating to alternately change the contact area between support surfaces and the body) (i.e. alternating pressure, or active, mode), with the requirement for electrical power
Alternating pressure-relieving air mattress (e.g. Nimbus II, Cairwave, Airwave, MicroPulse), large-celled ripple mattresses

\begin{tabular}{lll}
\hline $\begin{array}{l}\text { Powered active } \\
\text { low-air-loss air sur- } \\
\text { faces }\end{array}$ & $\begin{array}{l}\text { A group of support surfaces made of air cells, which } \\
\text { have the capability of alternating pressure redistribu- } \\
\text { tion as well as low air loss for drying local skin, with the } \\
\text { requirement for electrical power }\end{array}$ & $\begin{array}{l}\text { Alternating pressure low- } \\
\text { air-loss air mattress }\end{array}$ \\
\hline $\begin{array}{l}\text { Powered hybrid } \\
\text { system air surfaces }\end{array}$ & $\begin{array}{l}\text { A group of support surfaces made of air cells, which } \\
\text { offer both reactive and active pressure redistribution } \\
\text { modes, with the requirement for electrical power }\end{array}$ & $\begin{array}{l}\text { Foam mattress with dynam- } \\
\text { ic and static modes (e.g. } \\
\text { Softform Premier Active) }\end{array}$ \\
\hline $\begin{array}{l}\text { Powered hybrid } \\
\text { system low-air-loss } \\
\text { air surfaces }\end{array}$ & $\begin{array}{l}\text { A group of support surfaces made of air cells, which } \\
\text { offer both reactive and active pressure redistribution } \\
\text { modes as well as a low-air-loss function, with the re- } \\
\text { quirement for electrical power }\end{array}$ & $\begin{array}{l}\text { Stand-alone bed unit with } \\
\text { alternating pressure, static } \\
\text { modes and low air-loss (e.g. } \\
\text { TheraPulse) }\end{array}$
\end{tabular}

Beds, overlays and mattresses for preventing and treating pressure ulcers: an overview of Cochrane Reviews and network meta-analysis 
(Continued)

Standard hospital surfaces
Standard hospital surfaces
A group of support surfaces made of any materials, used as-usual in a hospital and without reactive or active pressure redistribution capabilities, nor any other functions (e.g. low air loss, or air-fluidised).
Standard hospital (foam) mattress, National Health Service Contract hospital mattress, standard operating theatre surface configuration, standard bed unit and usual care

\section{Appendix 2. Network meta-analysis and relevant methods}

\section{Network meta-analysis}

Network meta-analysis is an advanced meta-analysis technique that can simultaneously compare multiple competing interventions for a given condition in a single statistical model, whilst maintaining randomisation (Caldwell 2005). Network meta-analysis can produce 'indirect evidence' for a potential comparison where interventions are not evaluated in head-to-head RCTs. A network can link the direct evidence of $A$ vs $C$ and the direct evidence of B vs C, via a common comparator (i.e. C). Due to this, an indirect relative treatment effect for $A$ vs B can be calculated (Glenny 2005; Riley 2017). Where there is also direct evidence for a comparison, the direct and indirect evidence can be combined to obtain a mixed estimate, which improves the precision of effect estimates (Higgins 1996; Lu 2004). Effect estimates from network meta-analysis can be linked to probabilistic modelling to allow the ranking of treatments in terms of which is likely to be the most effective for the outcome of interest, which is likely to be the second best and so on (Salanti 2008).

\section{Methods for network meta-analysis}

\section{Unit of analysis issues}

Some RCTs in the overview of reviews had unit of analysis issues identified as part of the review process. We did not report these as these RCTs were not included in any analysis. For the single RCT that was excluded from the Cochrane Reviews but was eligible for the network meta-analysis, we noted there were no unit of analysis issues as the study presented outcomes at the level of participants (i.e. the unit of randomisation). We noted also that the included reviews had recorded whether the same participant was reported having multiple pressure ulcers. Where studies randomised at the participant level and outcomes were measured at the level of the ulcer, we would have considered the participant as the unit of analysis if the number of ulcers observed appeared to be equal to the number of participants (e.g. one pressure ulcer per person). However, we did not include any such RCTs for analysis.

Unit of analysis issues could have occurred if studies randomised at the participant level but outcomes of interest (e.g. the incidence of multiple pressure ulcers) were observed and data were presented and analysed at the level of the ulcer (clustered data). We noted that the included reviews had recorded whether data regarding multiple ulcers on a participant were (incorrectly) treated as independent within a study, or were analysed using within-participant analysis methods. If clustered data were incorrectly analysed, the included reviews had recorded this as part of the risk of bias assessment.

Where a cluster trial was not incorrectly analysed, we planned to use available information to adjust for clustering ourselves, if possible, in accordance with the guidance described in Chapter 23 of the Cochrane Handbook for Systematic Reviews of Interventions (Higgins 2020). We planned to focus on the following.

- The number of clusters randomly assigned to each intervention; and the average (mean) number of participants per cluster.

- Outcome data ignoring the cluster design for the total number of participants.

- Estimate of the intra-cluster (or intra-class) correlation coefficient (ICC).

However, we did not include any clustered trials in our analyses. We did note that included reviews recorded clustering issues for their included RCTs where appropriate.

\section{Dealing with missing data}

RCTs from the reviews included in the overview of reviews had missing data issues identified as part of the review process. We noted that the included reviews had addressed and reported these. For any RCTs that were excluded from the Cochrane Reviews but that were eligible for the network meta-analysis, where there were missing data, and where relevant, we planned to contact study authors to pose specific queries about missing data. However, the only such RCT had no missing data issue. In the absence of other information, for pressure ulcer incidence we assumed that participants with missing data did not develop new pressure ulcers for the main analysis (i.e. we added missing data to the denominator but not the numerator). We examined the impact of this assumption through undertaking a sensitivity analysis (see Sensitivity analysis). For healing rates of pressure ulcers, we assumed that participants with missing data had unhealed pressure ulcers for the main analysis (i.e. we added missing data to the denominator but not the numerator). Again, we examined the impact of this assumption using a sensitivity analysis.

Beds, overlays and mattresses for preventing and treating pressure ulcers: an overview of Cochrane Reviews and network meta-analysis 


\section{Assessment of heterogeneity}

Assessment of heterogeneity was considered for network meta-analysis as below.

\section{Assessment of clinical and methodological heterogeneity within pairwise meta-analysis}

We noted that the included Cochrane Reviews had undertaken pairwise meta-analyses based on their included trials where possible and assessed clinical and methodological heterogeneity within each analysis. We recorded the results of such assessments.

For the only trial that was previously excluded from the included Cochrane Reviews but was re-considered as eligible in network metaanalysis, we conducted pairwise meta-analysis and compared information in terms of study design, participant, intervention and outcome measurement characteristics and overall risk of bias judgement at study level across the included studies in each meta-analysis, in order to assess the presence of clinical and methodological heterogeneity.

\section{Assessment of transitivity across network contrasts}

Transitivity is an important concept when considering the validity of conducting a network meta-analysis. It means that important clinical and methodological characteristics (effect modifiers) at the comparison (rather than study) level are similar enough that we can assume that intervention effects are transitive across network contrasts. This assumption means that it is then valid to calculate indirect treatment effects from direct data (Cipriani 2013). Transitivity can be considered an extension of clinical and methodological homogeneity at the comparison level (Cipriani 2013).

We did not have prior knowledge about potential effect modifiers from previous literature except for:

- type of funding (e.g. industry, academic, government); we dichotomised this into not-for-profit and other (Lexchin 2003);

- risk of bias; we considered the three judgements for the overall risk of bias judgement: low risk of bias, unclear risk of bias, and high risk of bias (Schulz 1995);

- baseline skin status (pressure ulcer risk); we considered this as a categorical variable: participants at (high) risk of pressure ulcer development or with mixed skin status, participants with non-blanchable erythema, participants with existing ulcers of stage 2 or serious, and non-reporting. (Shi 2018a).

Also, we summarised information in terms of study designs, participants, interventions and outcome measurements and overall risk of bias judgements for each pairwise meta-analysis and compared such information across all direct comparisons of a network to assess the transitivity assumption (Kew 2014). When data were insufficient for this assessment and the above assessment did not suggest any effect modification, we assumed that the transitivity assumption held. See Appendix 8; Appendix 10.

\section{Assessment of reporting biases}

For network meta-analysis, we followed the systematic framework recommended by Page 2020 to assess risk of bias due to missing results (non-reporting bias) in the network meta-analysis of specific primary outcome data. To make an overall judgement about risk of bias due to missing results, we:

- identified whether primary outcome data were unavailable by comparing the details of outcomes in trials registers, protocols or statistical analysis plans, if available, with the reported results. If the above information sources were unavailable, we compared outcomes in the conference abstracts or in the Methods section of the publication, or both, with the reported results. If non-reporting of study results was found, we then planned to judge whether the non-reporting was associated with the nature of findings by using the "Outcome Reporting Bias In Trials" (ORBIT) system (Kirkham 2018). However, following this approach, we did not identify substantial non-reporting of study results.

- assessed the influence of definitely missing primary outcome data on network meta-analysis (see Effects of interventions).

- assessed the likelihood of bias where a study had been conducted but not reported in any form. For this assessment, we considered whether the literature search was comprehensive and produced a comparison-adjusted funnel plot for network meta-analysis for seeking more evidence about the extent of missing results, provided there were at least 10 included studies (Peters 2008; Salanti 2014). To obtain a meaningful comparison-adjusted funnel plot, we ordered the support surfaces by assuming that small studies were likely to favour advanced support surfaces (Chaimani 2015): Aiartex surfaces, Bedcare surfaces, alternating pressure (active) air surfaces, reactive air surfaces, reactive sheepskin surfaces, reactive gel surfaces followed by foam surfaces, reactive gel surfaces, reactive fibre surfaces, reactive water surfaces, reactive foam and gel surfaces, foam surfaces, and 'standard hospital surfaces'.

\section{Subgroup analysis and investigation of heterogeneity}

\section{Assessment of statistical heterogeneity}

We assessed the presence of common network statistical heterogeneity in network meta-analysis using the $\mathrm{I}^{2}$ measure and its $95 \% \mathrm{Cls}$ and $\mathrm{Tau}^{2}$ measure. We considered a P value less than 0.10 to indicate statistically significant heterogeneity given that the Chi ${ }^{2}$ test has low power. We explored the common network heterogeneity via R (decomp.design) to locate potential sources of heterogeneity (Krahn 2013). Very broadly, we considered that $\mathrm{I}^{2}$ values of $25 \%$ or less may indicate a low level of heterogeneity and values of $75 \%$ or more may indicate very high heterogeneity (Higgins 2003).

Beds, overlays and mattresses for preventing and treating pressure ulcers: an overview of Cochrane Reviews and network meta-analysis 46 (Review)

Copyright (c) 2021 The Authors. Cochrane Database of Systematic Reviews published by John Wiley \& Sons, Ltd. on behalf of The Cochrane Collaboration. 


\section{Assessment of inconsistency}

Inconsistency refers to statistical disagreement between direct and indirect evidence and is a manifestation of non-transitivity (Cipriani 2013). In a simple network, for example one with three interventions A, B and C, where there are studies comparing each of these treatments in a pairwise way, they can be linked in a network to form a single loop: A vs B, B vs C, C vs A trials. Inconsistency occurs when indirect evidence values do not statistically agree with available direct evidence (Cipriani 2013).

A complex network, however, often consists of multiple independent loops of evidence, and inconsistency could occur in each of the loops as well as in a whole network. Therefore, we assessed inconsistency at two levels: local inconsistency; and inconsistency in the whole network.

\section{Local approaches to assessing inconsistency}

Firstly, we used a loop-specific approach (inconsistency plot test) to evaluate local inconsistency via STATA (ifplot). The approach focuses on each independent loop in isolation and calculates the difference between direct evidence and indirect evidence for a comparison, and tests whether the difference is significant (Song 2011). We assumed a common loop-specific heterogeneity for this approach (Veroniki 2013).

We present the difference between direct and indirect evidence as the ratio of risk ratios with its $90 \% \mathrm{Cl}-\mathrm{using}$ its $90 \% \mathrm{Cl}$ is due to the low power of the inconsistency plot test (Song 2011). If the $\mathrm{Cl}$ covers the value of one, there is no statistical difference between direct and indirect evidence (i.e. consistency assumption holds); otherwise, there may be the presence of local inconsistency. We particularly considered the ratio of risk ratio of 2 or more (or 0.5 or less) as an indication of inconsistency; a value of 2 or more means the treatment effects estimated from direct evidence may be at least twice as large as the indirect evidence (Chaimani 2013).

Secondly, we used the node-splitting approach in STATA (network sidesplit) to also explore local inconsistency. This approach focuses on the network contrasts with direct evidence available (termed "node" by Dias 2014). Mixed estimate of such contrasts can be split into 'direct' and 'indirect' evidence, and the approach tests whether the difference between direct and indirect evidence is significant (Dias 2014).

\section{Global approach to evaluating inconsistency}

To assess global inconsistency, we ran a consistency and an inconsistency model and, from these, calculated the total inconsistency of all independent loops by comparing both models. Finally, we tested whether the total inconsistency was null using a global Wald test in the design-by-treatment interaction model (White 2015).

\section{Investigation of heterogeneity}

When important inconsistency or heterogeneity, or both, occurred, we followed steps proposed by Cipriani 2013 to investigate further:

- checked the data extraction and data entry for errors and possible outlying studies;

- planned to perform sensitivity analysis by removing outliers, if they had existed;

- performed sub-group analyses for study-level characteristics (see below) if heterogeneity was still present, in order to explain heterogeneity as far as possible.

\section{Sub-group analysis}

We investigated heterogeneity using the methods described in Chapter 10 of the Cochrane Handbook for Systematic Reviews of Interventions (Deeks 2020). We performed subgroup analyses/meta-regression to determine whether the size of treatment effects was influenced by the following four study-level characteristics.

- Risk of bias (binary: low or unclear risk of bias; and high risk of bias) (Schulz 1995).

- Settings (categorical: acute care and other hospital settings; long-term care settings; operating theatre setting; and intensive care unit).

- Baseline skin status (categorical: participants at risk, mixed skin status or non-reporting; non-blanchable erythema; existing ulcers of stage 2 or above) (Shi 2018a).

- Follow-up duration (categorical: short-term; medium-term; and long-term as Criteria for considering reviews for inclusion specified) (Schoonhoven 2007) (Differences between protocol and review).

We did not perform subgroup analysis/meta-regression when the number of studies included in the network meta-analysis was not reasonable (i.e. fewer than 10 ).

\section{Sensitivity analysis}

We assessed the robustness of our findings via the following sensitivity analysis.

\section{- Impact of missing data}

For pressure ulcer incidence outcome, we did this by repeating the analysis using complete case data (instead of assuming that participants with missing data did not develop new pressure ulcers, as in the main analysis).

Beds, overlays and mattresses for preventing and treating pressure ulcers: an overview of Cochrane Reviews and network meta-analysis 
For healing rates of pressure ulcers, we did this by repeating the analysis using complete case data (instead of assuming that participants with missing data had ulcers healed, as in the main analysis).

\section{- Post hoc sensitivity analysis of using eligible and well-defined support surfaces in the prevention network}

For the network meta-analysis of pressure ulcer incidence data, we undertook a post hoc sensitivity analysis that involved seven welldefined support surfaces but excluded interventions that were not well described and could not be classified, or were ineligible: Aiartex surfaces, Bedcare surfaces, RIK overlay, 'standard hospital surfaces', and foam surfaces plus four-hourly turning.

\section{Appendix 3. Risk of bias}

\section{Risk of bias assessment in individually randomised controlled trials}

\section{Was the allocation sequence randomly generated?}

\section{Low risk of bias}

The study authors describe a random component in the sequence generation process, such as referring to a random number table, using a computer random number generator, coin tossing, shuffling cards or envelopes, throwing dice, drawing of lots.

\section{High risk of bias}

The study authors describe a non-random component in the sequence generation process. Usually, the description would involve some systematic, non-random approach: for example, sequence generated by odd or even date of birth, sequence generated by some rule based on date (or day) of admission, sequence generated by some rule based on hospital or clinic record number.

Unclear

Insufficient information about the sequence generation process to permit judgement of low or high risk of bias.

\section{Was the treatment allocation adequately concealed?}

\section{Low risk of bias}

Participants and study authors enrolling participants could not foresee assignment because one of the following, or an equivalent method, was used to conceal allocation: central allocation (including telephone, web-based and pharmacy-controlled randomisation); sequentially numbered drug containers of identical appearance; sequentially numbered, opaque, sealed envelopes.

\section{High risk of bias}

Participants or study authors enrolling participants could possibly foresee assignments and thus introduce selection bias, e.g. allocation was based on: using an open random allocation schedule (e.g. a list of random numbers); or assignment envelopes were used without appropriate safeguards (e.g. if envelopes were unsealed or non-opaque or not sequentially numbered), alternation or rotation, date of birth, case record number, any other explicitly unconcealed procedure.

\section{Unclear}

Insufficient information to permit judgement of low or high risk of bias. This is usually the case if the method of concealment is not described or not described in sufficient detail to allow a definite judgement, for example if the use of assignment envelopes is described, but it remains unclear whether envelopes were sequentially numbered, opaque and sealed.

\section{Blinding: was knowledge of the allocated interventions by participants and personnel adequately prevented during the study?}

\section{Low risk of bias}

Any one of the following.

- No blinding, but the review authors judge that the outcome is not likely to be influenced by lack of blinding.

- Blinding of participants and key study personnel ensured, and unlikely that the blinding could have been broken.

\section{High risk of bias}

Any one of the following.

- No blinding or incomplete blinding, and the outcome is likely to be influenced by lack of blinding.

- Blinding of key study participants and personnel attempted, but likely that the blinding could have been broken.

- Either participants or some key study personnel were not blinded, and the non-blinding of others is likely to introduce bias.

Unclear

Any one of the following.

Beds, overlays and mattresses for preventing and treating pressure ulcers: an overview of Cochrane Reviews and network meta-analysis 
- Insufficient information to permit a judgement of low or high risk of bias.

- The study did not address this outcome.

\section{Blinding: was knowledge of the allocated interventions by outcome assessors adequately prevented during the study?}

\section{Low risk of bias}

Any one of the following.

- No blinding, but the review authors judge that the outcome measurement is not likely to be influenced by lack of blinding.

- Blinding of outcome assessment ensured, and unlikely that the blinding could have been broken.

\section{High risk of bias}

Any one of the following.

- No blinding or incomplete blinding, and the outcome measurement is likely to be influenced by lack of blinding.

- Blinding of outcome assessment attempted, but likely that the blinding could have been broken.

\section{Unclear}

Any one of the following.

- Insufficient information to permit a judgement of low or high risk of bias.

- The study did not address this outcome.

\section{Were incomplete outcome data adequately addressed?}

\section{Low risk of bias}

Any one of the following.

- No missing outcome data.

- Reasons for missing outcome data unlikely to be related to true outcome (for survival data, censoring unlikely to be introducing bias).

- Missing outcome data balanced in numbers across intervention groups, with similar reasons for missing data across groups.

- For dichotomous outcome data, the proportion of missing outcomes compared with observed event risk is not sufficient to have a clinically relevant impact on the intervention effect estimate.

- For continuous outcome data, the plausible effect size (difference in means or standardised difference in means) among missing outcomes is not sufficient to have a clinically relevant impact on observed effect size.

- Missing data have been imputed using appropriate methods.

\section{High risk of bias}

Any one of the following.

- Reason for missing outcome data is likely to be related to the true outcome, with either imbalance in numbers or reasons for missing data across intervention groups.

- For dichotomous outcome data, the proportion of missing outcomes compared with observed event risk is sufficient to induce clinically relevant bias in intervention effect estimate.

- For continuous outcome data, the plausible effect size (difference in means or standardised difference in means) among missing outcomes is sufficient to induce clinically relevant bias in the observed effect size.

- 'As-treated' analysis done, with substantial departure of the intervention received from that assigned at randomisation.

- Potentially inappropriate application of simple imputation.

\section{Unclear}

Any one of the following.

- Insufficient reporting of attrition/exclusions to permit judgement of low or high risk of bias (e.g. number randomised not stated; no reasons for missing data provided).

- The study did not address this outcome.

\section{Are reports of the study free of suggestion of selective outcome reporting?}

\section{Low risk of bias}

Any of the following.

Beds, overlays and mattresses for preventing and treating pressure ulcers: an overview of Cochrane Reviews and network meta-analysis 
- The study protocol is available and all of the study's prespecified (primary and secondary) outcomes that are of interest in the review have been reported in the prespecified way.

- The study protocol is not available but it is clear that the published reports include all expected outcomes, including those that were prespecified (convincing text of this nature may be uncommon).

\section{High risk of bias}

Any one of the following.

- Not all of the study's prespecified primary outcomes have been reported.

- One or more primary outcomes are reported using measurements, analysis methods or subsets of the data (e.g. subscales) that were not prespecified.

- One or more reported primary outcomes were not prespecified (unless clear justification for their reporting is provided, such as an unexpected adverse effect).

- One or more outcomes of interest in the review are reported incompletely so that they cannot be entered in a meta-analysis.

- The study report fails to include results for a key outcome that would be expected to have been reported for such a study.

\section{Unclear}

Insufficient information to permit judgement of low or high risk of bias. It is likely that the majority of studies will fall into this category.

\section{Other sources of potential bias}

\section{Low risk of bias}

The study appears to be free of other sources of bias.

\section{High risk of bias}

There is at least one important risk of bias. For example, the study:

- had a potential source of bias related to the specific study design used; or

- has been claimed to have been fraudulent; or

- had some other problem.

\section{Unclear}

There may be a risk of bias, but there is either:

- insufficient information to assess whether an important risk of bias exists; or

- insufficient rationale or evidence that an identified problem will introduce bias.

\section{Risk of bias assessment in cluster-randomised controlled trials (cluster-RCTs)}

\section{Recruitment bias}

Recruitment bias (or identification bias) is the bias that occurs in cluster-RCTs if the personnel recruiting participants know individuals' allocation, even when the allocation of clusters has been concealed appropriately. The knowledge of the allocation of clusters may lead to bias because the individuals' recruitment in cluster trials is often behind the clusters' allocation to different interventions; and the knowledge of allocation can determine whether individuals are recruited selectively.

This bias can be judged through considering the following questions.

- Were all the individual participants identified/recruited before randomisation of clusters?

- Is it likely that selection of participants was affected by knowledge of the intervention?

- Were there baseline imbalances that suggest differential identification or recruitment of individual participants between arms?

\section{Baseline imbalance}

Baseline imbalance between intervention groups can occur due to chance, problems with randomisation, or identification/recruitment bias. The issue of recruitment bias has been considered above.

In terms of study design, the risk of chance baseline imbalance can be reduced by the use of stratified or pair-matched randomisation. Minimisation - an equivalent technique to randomisation - can be used to achieve better balance in cluster characteristics between intervention groups if there is a small number of clusters.

Concern about the influence of baseline imbalance can be reduced if trials report the baseline comparability of clusters, or statistical adjustment for baseline characteristics.

Beds, overlays and mattresses for preventing and treating pressure ulcers: an overview of Cochrane Reviews and network meta-analysis 50 (Review)

Copyright (c) 2021 The Authors. Cochrane Database of Systematic Reviews published by John Wiley \& Sons, Ltd. on behalf of The Cochrane Collaboration. 


\section{Loss of clusters}

Similar with missing outcome data in individually randomised trials, bias can occur if clusters are completely lost from a cluster trial, and are omitted from the analysis.

The amount of missing data, the reasons for missingness and the way of analysing data given the missingness should be considered in assessing the possibility of bias.

\section{Incorrect analysis}

Data analyses which do not take the clustering into account in cluster trials will be incorrect. Such analyses lead to a "unit of analysis error" and over-precise results (overly small standard error) and overly small P values. Though these analyses will not result in biased estimates of effect, if not correctly adjusted, they will lead to too much weight allocated to cluster trials in a meta-analysis.

Note that the issue of analysis may not lead to concern any more and will not be considered substantial if approximate methods are used by reviewers to address clustering in data analysis.

\section{Comparability with individually randomised trials}

In the case that a meta-analysis includes, for example, both cluster-randomised and individually randomised trials, potential differences in the intervention effects between different trial designs should be considered. This is because the "contamination" of intervention effects may occur in cluster-randomised trials, which would lead to underestimates of effect. The contamination could be known as a "herd effect", i.e. within clusters, individuals' compliance with using an intervention may be enhanced, which in return affects the estimation of effect. 


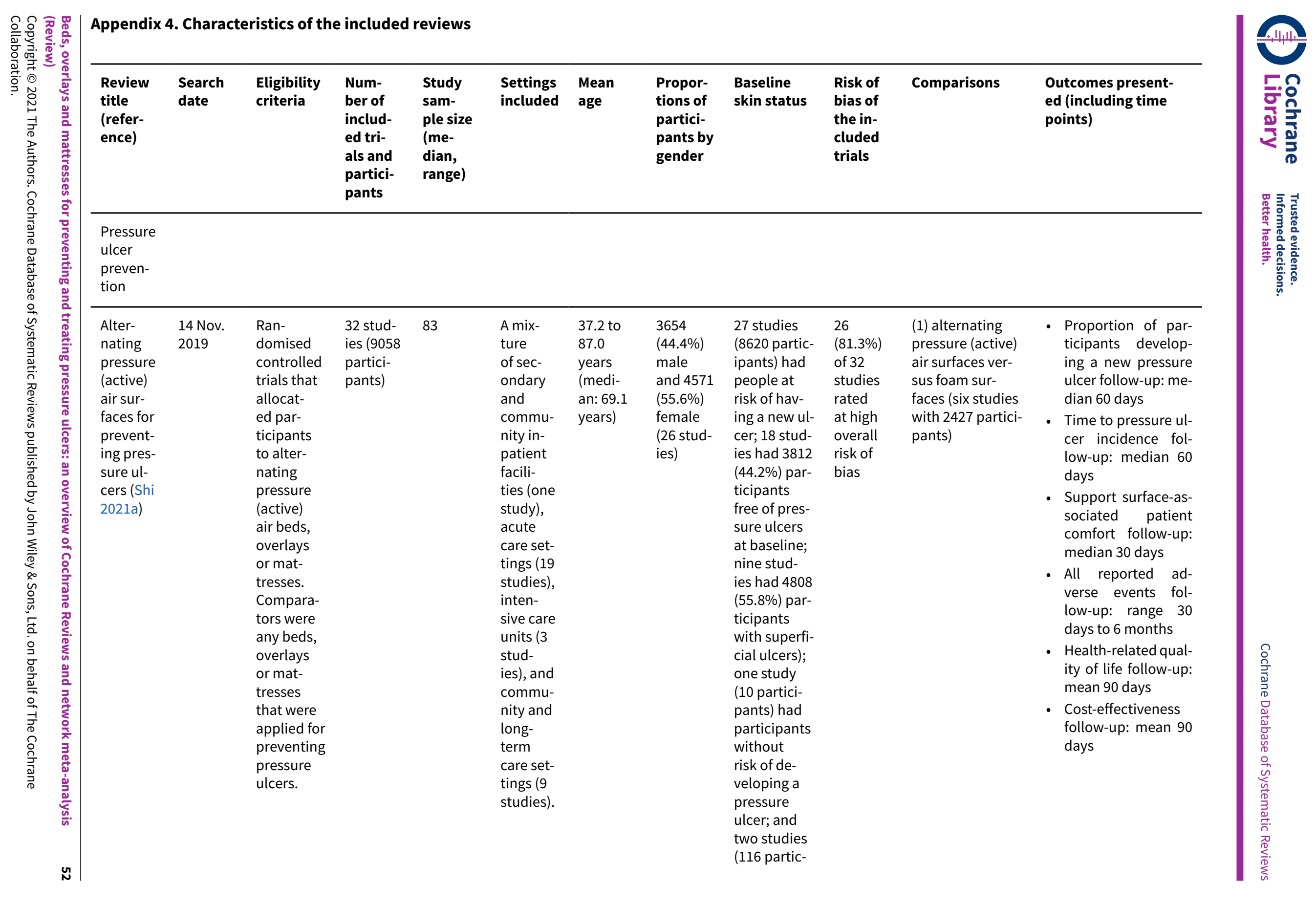




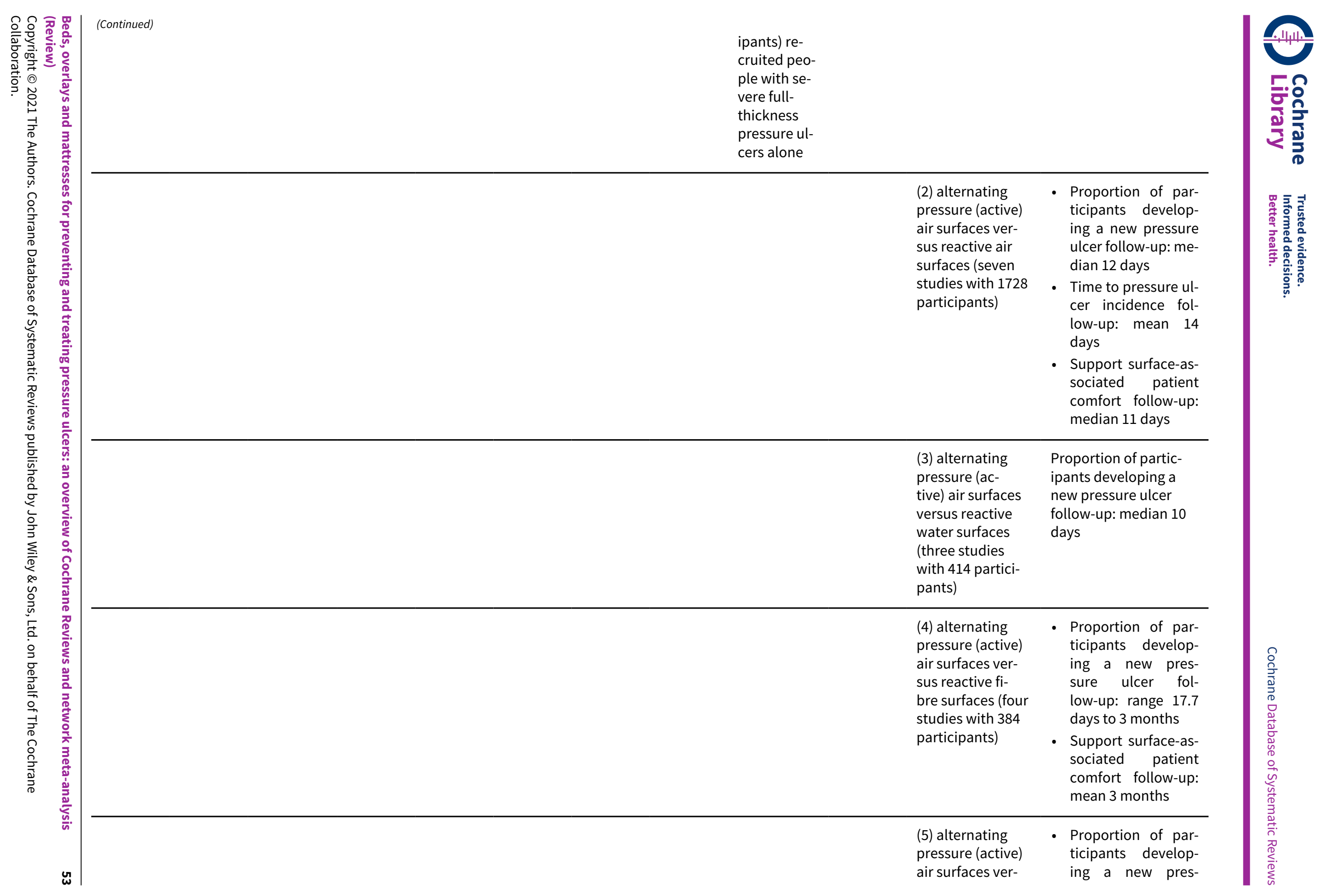


sus reactive ge surfaces used in operating room followed by foam surfaces used on ward bed (two studies with 415

participants) sure ulcer follow-up: mean 7 days

- All reported adverse events follow-up: mean 7 days

(1) foam surfaces

versus alternat-

ing pressure air

surfaces (six stud-

ies, 2427 partici-

and

years

trials that pants)

ing pres-

sure ul-

cers (Shi

ticipants

to foam

beds,

overlays

or mat-

tresses.

Compara-

tors were

any beds,

overlays

tresses

that were

applied for

venting

pressur

ulcers

$\begin{array}{lllll}\text { an: } 76.0 & (56.6 \%) & \text { risk of hav- } & \text { studies } & \text { ies, 2427 } \\ \text { years) } & \text { female } & \text { ing a new ul- } & \text { rated } & \text { pants) }\end{array}$

- Proportion of participants developing a new pressure ulcer follow-up: median 60 days

- Time to pressure ulcer incidence follow-up: median 60 days

- Support surface-associated patient comfort follow-up: median 30 days

- All reported adverse events follow-up: range 30 days to 6 months

- Health-related quality of life follow-up: mean 90 days

- Cost-effectiveness

follow-up: mean 90 days commu-

patient

facili-

ties $(2$

studies),

acute

care set-

tings (16

studies),

inten-

sive care

units (3

stud-

ies), op-

erating

rooms

(2 stud-

ies), and

commu-

nity and

long-

term

care set-

tings $(6$

studies)
(24 stud-

cer; 21 stud-

ticipants

free of pres-

sure ulcers

at baseline;

four stud-

ies had 3089

(35.9\%) par-

ticipants

with su-

perficial ul-

cers); and

two studies

(148 partic-

ipants) had

people with

severe full-

thickness

pressure ul-

cers alone 
studies, 236 participants) low-up: range 13 days to 6 month

- Support surface-associated patient comfort follow-up: mean 13 days

- All reported adverse events follow-up: mean 13 days

3) foam surfaces versus reactive fibre surfaces (two studies, 228 participants)

Proportion of participants developing a new pressure ulcer follow-up: mean 17.7 days

(4) foam surfaces versus reactive

Proportion of participants developing a

gel surfaces (one new pressure ulcer study, 135 participants)

\begin{tabular}{|c|c|c|c|c|c|c|c|c|c|}
\hline $\begin{array}{l}\text { Reactive } \\
\text { air sur- } \\
\text { faces for } \\
\text { prevent- } \\
\text { ing pres- } \\
\text { sure ul- } \\
\text { cers (Shi } \\
\text { 2021c) }\end{array}$ & $\begin{array}{l}14 \text { Nov. } \\
2019\end{array}$ & $\begin{array}{l}\text { Ran- } \\
\text { domised } \\
\text { controlled } \\
\text { trials that } \\
\text { allocat- } \\
\text { ed partic- } \\
\text { ipants to } \\
\text { reactive } \\
\text { air beds, } \\
\text { overlays } \\
\text { or mat- } \\
\text { tresses. } \\
\text { Compara- } \\
\text { tors were } \\
\text { any beds, } \\
\text { overlays }\end{array}$ & $\begin{array}{l}17 \text { stud- } \\
\text { ies ( } 2604 \\
\text { partici- } \\
\text { pants) }\end{array}$ & 83 & $\begin{array}{l}\text { A mix- } \\
\text { ture of } \\
\text { acute } \\
\text { care and } \\
\text { long- } \\
\text { term } \\
\text { care set- } \\
\text { tings } \\
\text { (two } \\
\text { studies), } \\
\text { acute } \\
\text { care set- } \\
\text { tings } \\
\text { (seven } \\
\text { studies), } \\
\text { inten- }\end{array}$ & $\begin{array}{l}56 \text { to } 87 \\
\text { years } \\
\text { (median: } \\
72 \text { years) }\end{array}$ & $\begin{array}{l}1125 \\
(44.8 \%) \\
\text { male } \\
\text { and } 1386 \\
(55.2 \%) \\
\text { female } \\
\text { (17 stud- } \\
\text { ies) }\end{array}$ & $\begin{array}{l}13 \text { studies } \\
\text { ( } 2335 \text { partic- } \\
\text { ipants) had } \\
\text { people at } \\
\text { risk of hav- } \\
\text { ing a new ul- } \\
\text { cer; } 10 \text { stud- } \\
\text { ies had } 2033 \\
\text { ( } 87.1 \%) \text { par- } \\
\text { ticipants } \\
\text { free of pres- } \\
\text { sure ulcers } \\
\text { at baseline; } \\
\text { three stud- } \\
\text { ies had } 302 \\
\text { (12.9\%) par- }\end{array}$ & $\begin{array}{l}\text { eight } \\
\text { (47.1\%) } \\
\text { of the } \\
17 \text { stud- } \\
\text { ies ratec } \\
\text { at high } \\
\text { overall } \\
\text { risk of } \\
\text { bias }\end{array}$ \\
\hline
\end{tabular}
versus reactive foam and gel sur-

faces (one study,

91 participants)

\section{(1) reactive air}

surfaces versus

alternating pres-

sure (active) air

surfaces (seven

studies with 1728

participants)

Proportion of participants developing a new pressure ulcer

- Proportion of participants developing a new pressure ulcer follow-up: range 5 days to 15 days cer incidence fol-

low-up: mean 14 days

- Support surface-associated patient comfort (median follow-up duration 11 days, minimum
- Time to pressure ul-

studies)

(12.9\%) par- 
one study

pressure

ies), and

ulcers.

commu-

nity and

(57 par-

long-

ticipants;

Sideranko

pants free of

ulcers; and

tings

two studies

(four

(112 partic-

ipants) had

people with

severe full-

thickness

pressure ul-

(2) reactive air

- Proportion of parsurfaces versus ticipants develop-

foam surfaces

(four studies with

236 participants

ing a new pres-

sure ulcer fol-

low-up: range 13

days to 6 months

- Support surface-associated patient comfort follow-up:

13 days

- All reported adverse events follow-up: 13 days

(3) reactive air surfaces versus reactive water

Proportion of participants developing a

surfaces (one new pressure ulcer fol-

study with 37 parlow-up: mean 9.5 days

ticipants)

(4) reactive air 


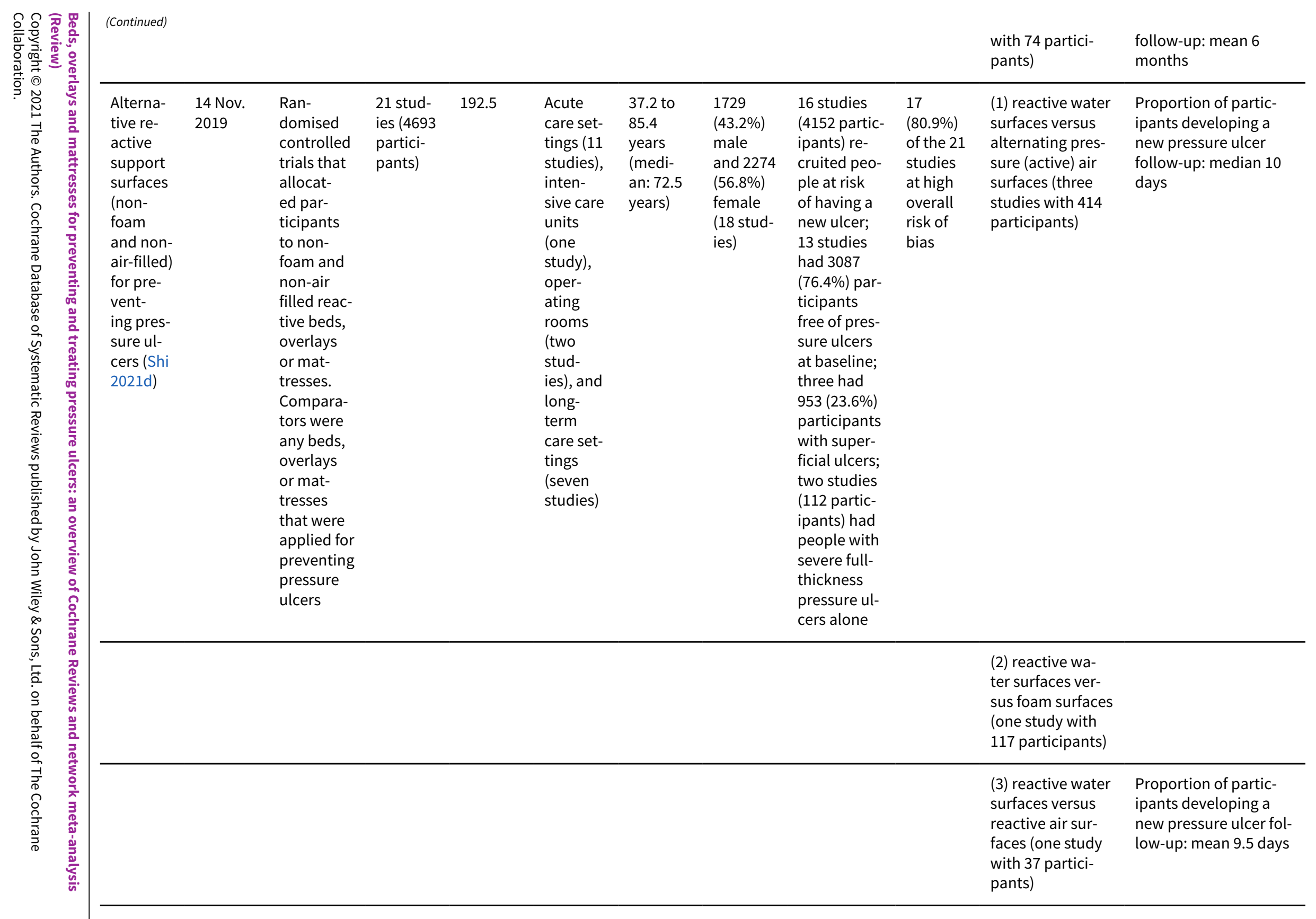


(4) reactive water

surfaces versus

reactive fibre sur-

faces (one study

with 87 partici-

pants)

(5) reactive fibre

surfaces versus

alternating pres-

sure (active) air

surfaces (four

studies with 384

participants

- Proportion of par-

ticipants develop-

ing a new pres-

sure ulcer fol-

low-up: range 17.7

days to 3 months

- Support surface-as-

sociated patient

comfort follow-up:

mean 3 months

\section{(6) reactive fibre}

surfaces versus

foam surfaces

Proportion of partic-

ipants developing a

(two studies with

new pressure ulcer fol-

228 participants)

(7) reactive gel

surfaces on oper-

- Proportion of par-

ating tabl

ticipants develop-

lowed by foam

ing a new pres-

sure ulcer fol-

surfaces on ward

low-up: mean 7 days

beds versus al-

- All reported ad-

ternating pres-

verse events fol-

sure (active) air

low-up: mean 7 days

subsequently on

ward beds (two

participants)

(8) reactive gel

Proportion of partic-

surfaces versus

reactive air sur-

ipants developing a

new pressure ulcer

faces (one study

follow-up: mean 6

months 


\begin{tabular}{|c|c|c|c|c|c|c|c|c|c|c|c|c|c|}
\hline 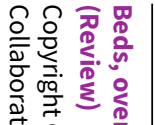 & (Continued) & & & & & & & & & & $\begin{array}{l}\text { with } 74 \text { partici- } \\
\text { pants) }\end{array}$ & & 0.111 \\
\hline 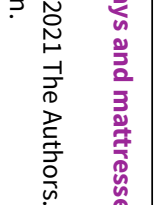 & & & & & & & & & & & $\begin{array}{l}\text { (9) reactive gel } \\
\text { surfaces versus } \\
\text { foam surfaces } \\
\text { (one study with } \\
135 \text { participants) }\end{array}$ & $\begin{array}{l}\text { Proportion of partic- } \\
\text { ipants developing a } \\
\text { new pressure ulcer }\end{array}$ & 룰 \\
\hline 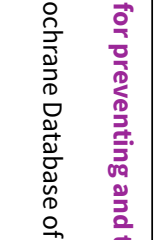 & & & & & & & & & & & $\begin{array}{l}\text { (10) reactive gel } \\
\text { surfaces versus } \\
\text { reactive gel sur- } \\
\text { faces (one study } \\
\text { with } 113 \text { partici- } \\
\text { pants) }\end{array}$ & & 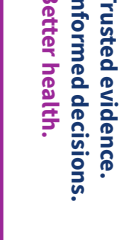 \\
\hline 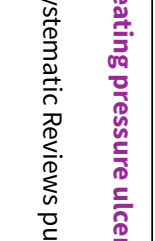 & & & & & & & & & & & $\begin{array}{l}\text { (11) reactive } \\
\text { foam and gel sur- } \\
\text { faces versus foam } \\
\text { surfaces (one } \\
\text { study with } 91 \text { par- } \\
\text { ticipants) }\end{array}$ & $\begin{array}{l}\text { Proportion of partic- } \\
\text { ipants developing a } \\
\text { new pressure ulcer }\end{array}$ & \\
\hline 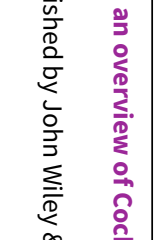 & & & & & & & & & & & $\begin{array}{l}\text { (12) reactive } \\
\text { foam and gel sur- } \\
\text { faces versus reac- } \\
\text { tive gel surfaces } \\
\text { (one study with } \\
166 \text { participants) }\end{array}$ & $\begin{array}{l}\text { Proportion of partic- } \\
\text { ipants developing a } \\
\text { new pressure ulcer }\end{array}$ & \\
\hline 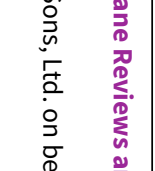 & $\begin{array}{l}\text { Pres- } \\
\text { sure ul- } \\
\text { cer treat- } \\
\text { ment }\end{array}$ & & & & & & & & & & & & $\stackrel{\circ}{\circ}$ \\
\hline 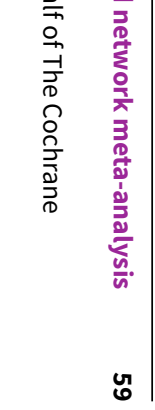 & $\begin{array}{l}\text { Beds, } \\
\text { overlays } \\
\text { and mat- } \\
\text { tresses } \\
\text { for treat- } \\
\text { ing pres- } \\
\text { sure ul- } \\
\text { cers (Shi } \\
\text { 2021e) }\end{array}$ & $\begin{array}{l}14 \text { Nov. } \\
2019\end{array}$ & $\begin{array}{l}\text { Ran- } \\
\text { domised } \\
\text { controlled } \\
\text { trials that } \\
\text { allocat- } \\
\text { ed par- } \\
\text { ticipants } \\
\text { to pres- } \\
\text { sure re- } \\
\text { distribut- }\end{array}$ & $\begin{array}{l}13 \text { stud- } \\
\text { ies ( } 972 \\
\text { partici- } \\
\text { pants) }\end{array}$ & 72 & $\begin{array}{l}\text { Acute } \\
\text { care set- } \\
\text { tings (in- } \\
\text { cluding } \\
\text { hospi- } \\
\text { tals in } \\
\text { general; } \\
\text { six stud- } \\
\text { ies), and } \\
\text { commu- }\end{array}$ & $\begin{array}{l}64.0 \text { to } \\
86.5 \\
\text { years } \\
\text { (medi- } \\
\text { an: } 82.7 \\
\text { years) }\end{array}$ & $\begin{array}{l}284 \\
(46.3 \%) \\
\text { male } \\
\text { and } 329 \\
(53.7 \%) \\
\text { female } \\
\text { (10 stud- } \\
\text { ies) }\end{array}$ & $\begin{array}{l}\text { All people } \\
\text { with exist- } \\
\text { ing pressure } \\
\text { ulcers; aver- } \\
\text { age size of } \\
\text { pressure ul- } \\
\text { cers in sev- } \\
\text { en studies } \\
\text { ( } 353 \text { partic- } \\
\text { ipants) me- }\end{array}$ & $\begin{array}{l}6 \\
(46.2 \%) \\
\text { of the } 13 \\
\text { included } \\
\text { studies } \\
\text { at high } \\
\text { overall } \\
\text { risk of } \\
\text { bias }\end{array}$ & $\begin{array}{l}\text { (1) alternating } \\
\text { pressure (active) } \\
\text { air surfaces ver- } \\
\text { sus foam surfaces } \\
\text { (two studies with } \\
132 \text { participants) }\end{array}$ & $\begin{array}{l}\text { - Proportion of par- } \\
\text { ticipants with pres- } \\
\text { sure ulcers com- } \\
\text { pletely healed fol- } \\
\text { low-up: range } 7 \text { days } \\
\text { to } 12 \text { weeks } \\
\text { - Support surface-as- } \\
\text { sociated patient } \\
\text { comfort follow-up: } \\
\text { mean } 7 \text { days }\end{array}$ & 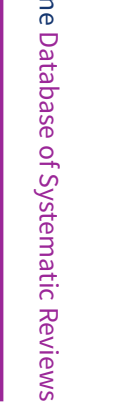 \\
\hline
\end{tabular}




$\begin{array}{lll}\begin{array}{l}\text { ing beds, } \\ \text { overlays }\end{array} & \text { nity and } & \text { dian } 6.6 \mathrm{~cm}^{2} \\ \text { or mat- } & \text { long- } & (\text { range } 4.2 \text { to } \\ \text { tresses. } & \text { term } & \left.18.6 \mathrm{~cm}^{2}\right) \\ \text { Compara- } & \text { care set- } & \\ \text { tors were } & \text { tings (in- } & \\ \text { any beds, } & \text { cluding } & \\ \text { overlays } & \text { com- } & \\ \text { or mat- } & \text { munity, } & \\ \text { tresses } & \text { nursing } & \\ \text { that were } & \text { homes, } & \\ \text { applied for } & \text { long- } & \\ \text { treating } & \text { term fa- } & \\ \text { pressure } & \text { cilities, } & \\ \text { ulcers. } & \text { geriatric } & \\ & \text { unit; sev- } & \end{array}$

dian $6.6 \mathrm{~cm}^{2}$

range 4.2 to

en stud-

ies)
- All reported adverse events follow-up: median 12 weeks

\section{(2) reactive air surfaces versus foam surfaces \\ (three studies \\ with 156 partici- pants)}

- Proportion of participants with pressure ulcers completely healed follow-up: 13.0 days and 37.5 days

- Time to complete pressure ulcer healing follow-up: median 37.5 days

- Support surface-as sociated patient comfort follow-up median 13 days

- All reported ad verse events follow-up: range 13.0 days to 37.5 days

- Cost-effectiveness follow-up: mean 37.5 days

(3) foam surfaces versus reactive

- Proportion of participants with preswater surfaces
(one study with 120 participants) 


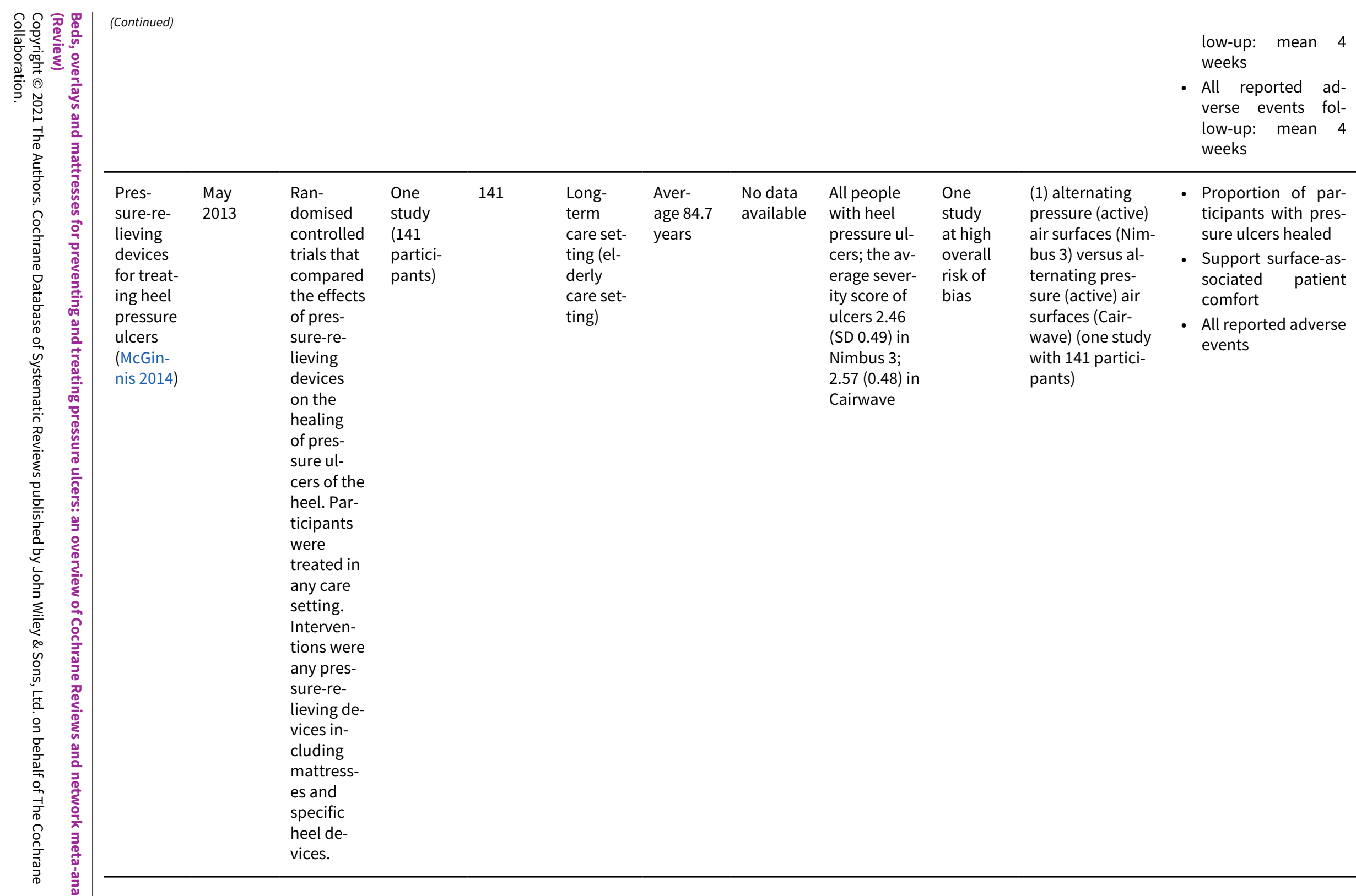




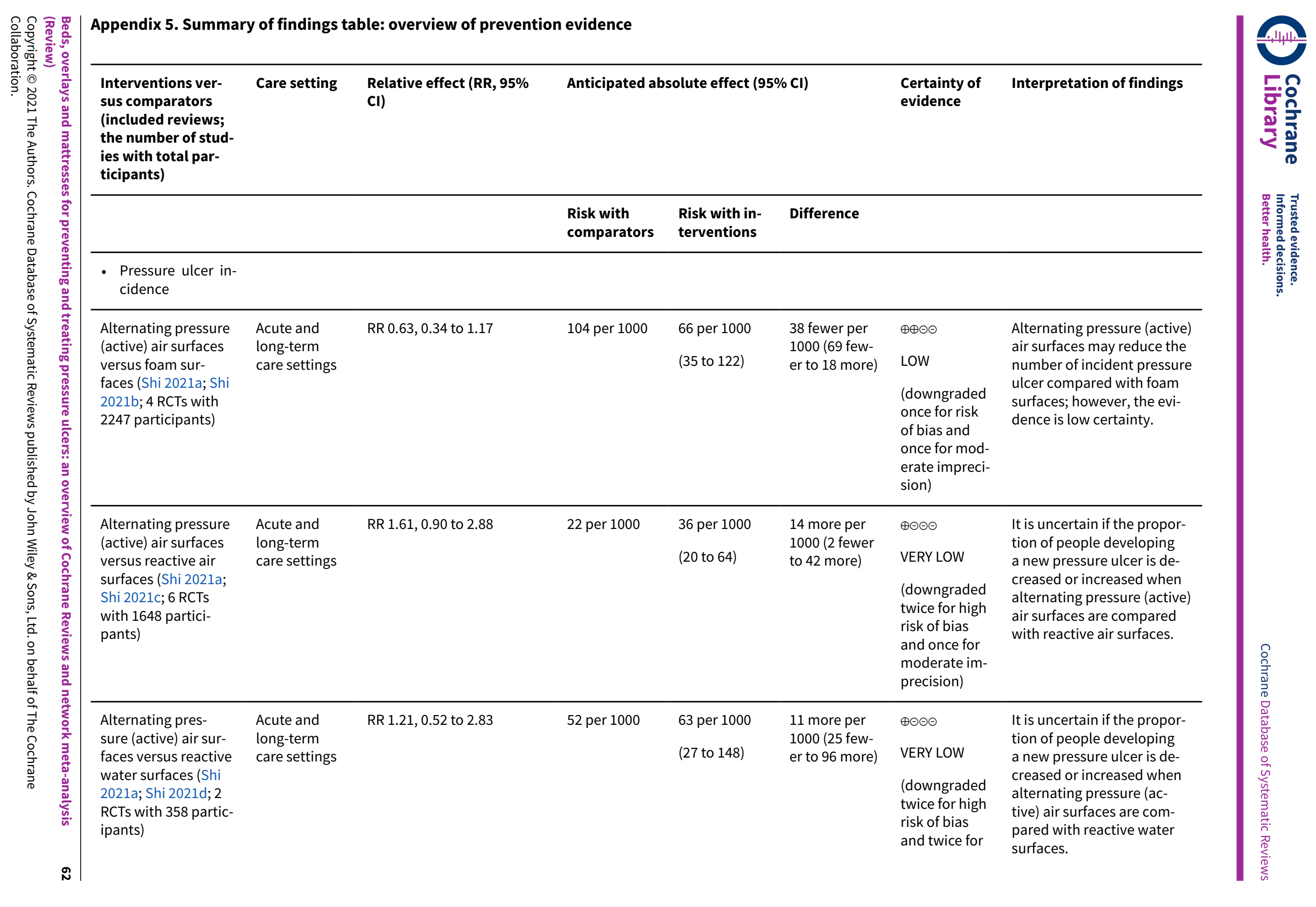




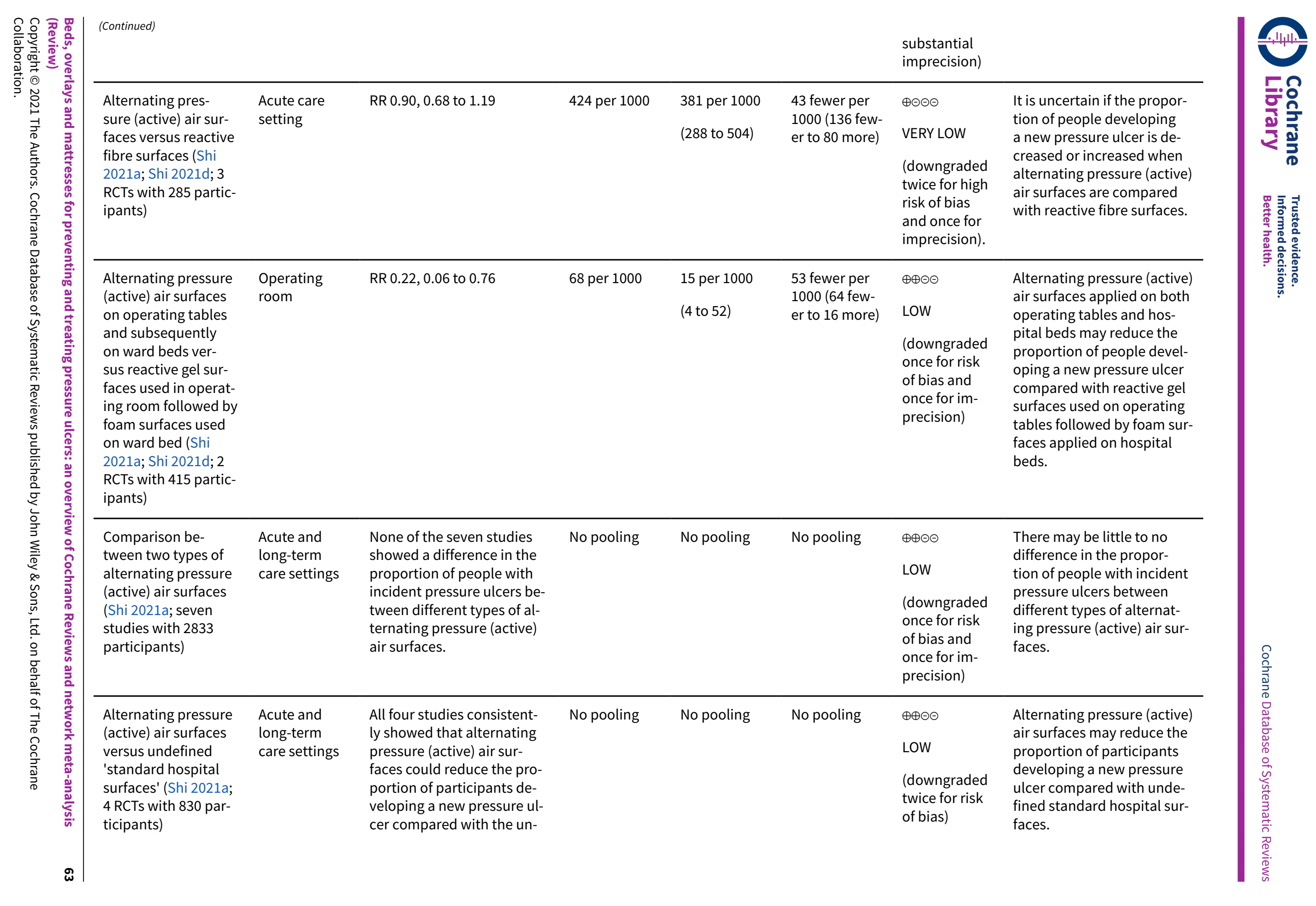




\begin{tabular}{|c|c|c|c|c|c|c|c|c|}
\hline 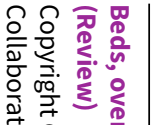 & (Continued) & & $\begin{array}{l}\text { defined 'standard hospital } \\
\text { surfaces'. }\end{array}$ & & & & & \\
\hline 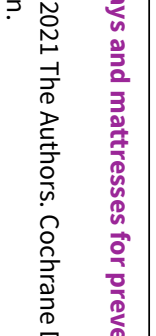 & $\begin{array}{l}\text { Foam surfaces ver- } \\
\text { sus reactive air sur- } \\
\text { faces (Shi 2021b; Shi } \\
2021 \text { c; } 4 \text { RCTs with } \\
229 \text { participants) }\end{array}$ & $\begin{array}{l}\text { Acute and } \\
\text { long-term } \\
\text { care settings }\end{array}$ & RR $2.40,1.04$ to 5.54 & 106 per 1000 & $\begin{array}{l}255 \text { per } 1000 \\
(110 \text { to } 588)\end{array}$ & $\begin{array}{l}149 \text { more per } \\
1000 \\
\text { (4 more to } 482 \\
\text { more) }\end{array}$ & $\begin{array}{l}\oplus \oplus \ominus \ominus \\
\text { LOW } \\
\text { (downgraded } \\
\text { once for risk } \\
\text { of bias and } \\
\text { once for im- } \\
\text { precision) }\end{array}$ & $\begin{array}{l}\text { Foam surfaces may increase } \\
\text { the proportion of partic- } \\
\text { ipants developing a new } \\
\text { pressure ulcer compared } \\
\text { with reactive air surfaces. }\end{array}$ \\
\hline 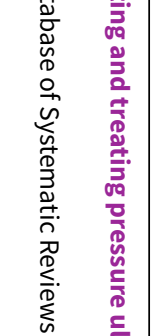 & $\begin{array}{l}\text { Foam surfaces ver- } \\
\text { sus reactive fibre sur- } \\
\text { faces (Shi } 2021 \text { b; Shi } \\
\text { 2021d; one RCT with } \\
68 \text { participants) }\end{array}$ & $\begin{array}{l}\text { Acute care } \\
\text { setting }\end{array}$ & RR $1.17,0.64$ to 2.14 & 353 per 1000 & $\begin{array}{l}413 \text { per } 1000 \\
\text { ( } 226 \text { to } 755)\end{array}$ & $\begin{array}{l}60 \text { more per } \\
1000 \\
\text { ( } 127 \text { fewer to } \\
402 \text { more) }\end{array}$ & $\begin{array}{l}\oplus \odot \ominus \ominus \\
\text { VERY LOW } \\
\text { (downgraded } \\
\text { twice for risk } \\
\text { of bias, and } \\
\text { once for im- } \\
\text { precision). }\end{array}$ & $\begin{array}{l}\text { It is uncertain if there is a } \\
\text { difference in the proportion } \\
\text { of participants developing a } \\
\text { new pressure ulcer between } \\
\text { foam surfaces with reactive } \\
\text { fibre surfaces. }\end{array}$ \\
\hline 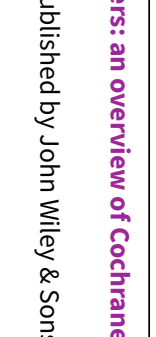 & $\begin{array}{l}\text { Foam surfaces ver- } \\
\text { sus reactive gel sur- } \\
\text { faces (Shi 2021b; Shi } \\
2021 \text { d; one RCT with } \\
135 \text { participants) }\end{array}$ & $\begin{array}{l}\text { Operating } \\
\text { room }\end{array}$ & $\begin{array}{l}\text { One study involving a total- } \\
\text { ity of } 135 \text { individuals ( } 270 \\
\text { halves of bodies) indicat- } \\
\text { ed no pressure ulcers devel- } \\
\text { oped in either group. }\end{array}$ & No pooling & No pooling & No pooling & $\begin{array}{l}\oplus \ominus \ominus \ominus \\
\text { VERY LOW } \\
\text { (downgraded } \\
\text { twice for risk } \\
\text { of bias, and } \\
\text { twice for im- } \\
\text { precision) }\end{array}$ & $\begin{array}{l}\text { It is uncertain if there is a } \\
\text { difference in the proportion } \\
\text { of participants developing a } \\
\text { new pressure ulcer between } \\
\text { foam surfaces and reactive } \\
\text { gel surfaces. }\end{array}$ \\
\hline 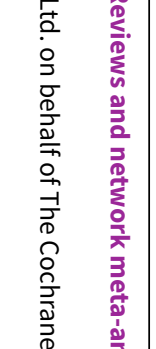 & $\begin{array}{l}\text { Foam surfaces ver- } \\
\text { sus reactive foam } \\
\text { and gel surfaces (Shi } \\
2021 \text { b; Shi } 2021 d \text {; } \\
\text { one RCT with } 91 \text { par- } \\
\text { ticipants) }\end{array}$ & $\begin{array}{l}\text { Operating } \\
\text { room }\end{array}$ & $\begin{array}{l}\text { One study compared foam } \\
\text { surfaces and reactive foam } \\
\text { and gel surfaces in } 91 \text { par- } \\
\text { ticipants (with } 182 \text { halves of } \\
\text { bodies) using a split body } \\
\text { design and found no pres- } \\
\text { sure ulcers developed in ei- } \\
\text { ther group. }\end{array}$ & No pooling & No pooling & No pooling & $\begin{array}{l}\oplus \odot \ominus \ominus \\
\text { VERY LOW } \\
\text { (downgraded } \\
\text { twice for risk } \\
\text { of bias, and } \\
\text { twice for im- } \\
\text { precision) }\end{array}$ & $\begin{array}{l}\text { It is uncertain if there is a } \\
\text { difference in the proportion } \\
\text { of participants developing a } \\
\text { new pressure ulcer between } \\
\text { foam surfaces and reactive } \\
\text { foam and gel surfaces. }\end{array}$ \\
\hline$\sum_{\frac{w}{v}}^{\frac{m}{u}}$ & $\begin{array}{l}\text { Foam surfaces versus } \\
\text { reactive water sur- } \\
\text { faces (Shi 2021b; Shi }\end{array}$ & $\begin{array}{l}\text { Acute care } \\
\text { setting }\end{array}$ & $\begin{array}{l}\text { One RCT with } 117 \text { partic- } \\
\text { ipants did not report any } \\
\text { outcomes that were direct- } \\
\text { ly relevant to this review }\end{array}$ & $\begin{array}{l}\text { Not applica- } \\
\text { ble }\end{array}$ & $\begin{array}{l}\text { Not applica- } \\
\text { ble }\end{array}$ & $\begin{array}{l}\text { Not applica- } \\
\text { ble }\end{array}$ & $\begin{array}{l}\text { Not applica- } \\
\text { ble }\end{array}$ & Not applicable \\
\hline
\end{tabular}




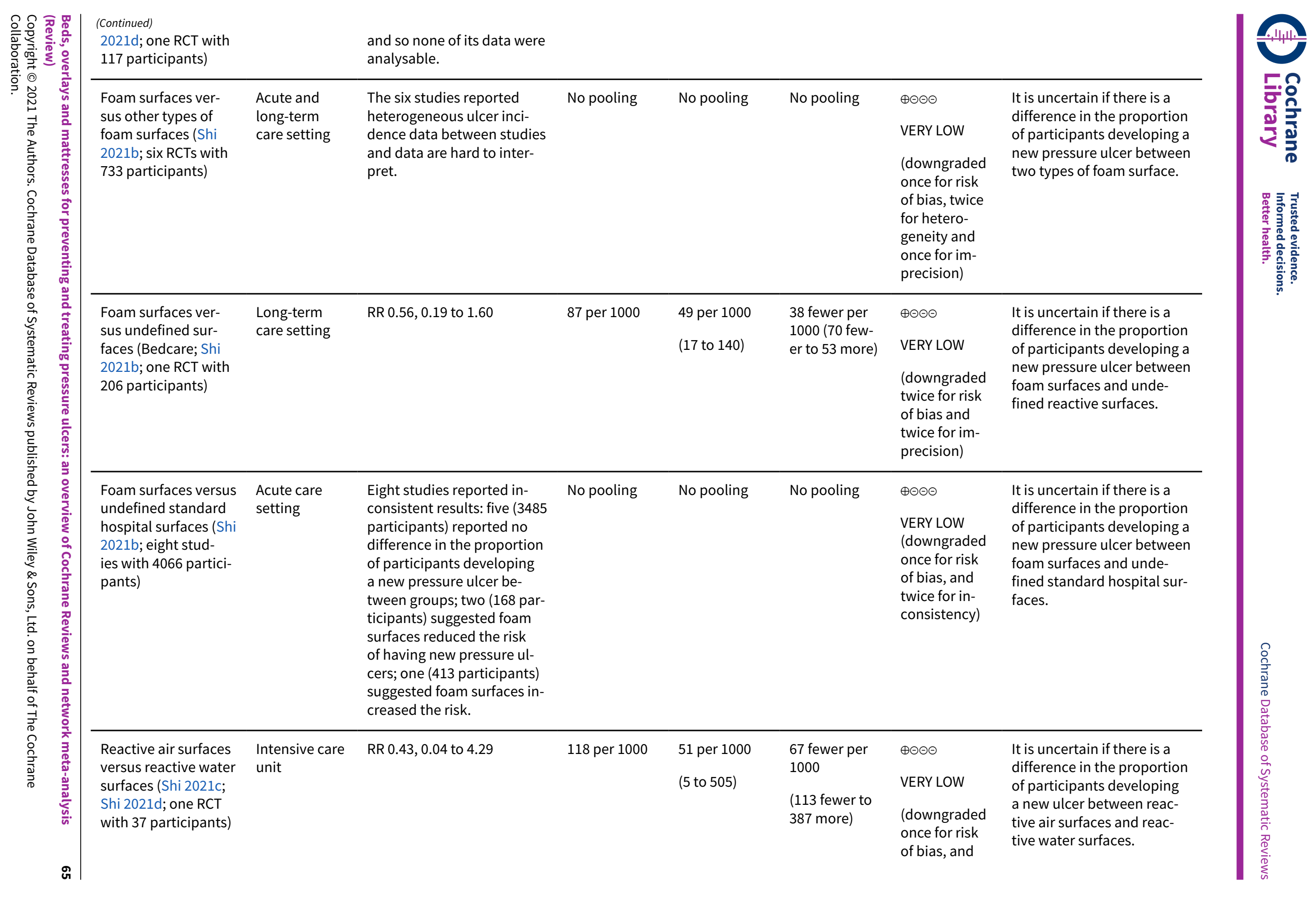




\begin{tabular}{|c|c|c|c|c|c|c|c|c|c|}
\hline 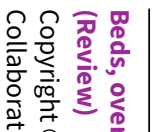 & (Continued) & & & & & & $\begin{array}{l}\text { twice for im- } \\
\text { precision) }\end{array}$ & & 0.11 \\
\hline 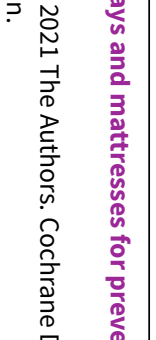 & $\begin{array}{l}\text { Reactive air surfaces } \\
\text { versus reactive gel } \\
\text { surfaces (Shi 2021c; } \\
\text { Shi } 2021 \text { d; one RCT } \\
\text { with } 66 \text { participants) }\end{array}$ & $\begin{array}{l}\text { Long-term } \\
\text { care setting }\end{array}$ & RR $1.25,0.56$ to 2.77 & 242 per 1000 & $\begin{array}{l}302 \text { per } 1000 \\
\text { (136 to } 670)\end{array}$ & $\begin{array}{l}60 \text { more per } \\
1000 \\
(106 \text { fewer to } \\
428 \text { more) }\end{array}$ & $\begin{array}{l}\oplus \ominus \ominus \ominus \\
\text { VERY LOW } \\
\text { (downgraded } \\
\text { once for risk } \\
\text { of bias, and } \\
\text { twice for im- } \\
\text { precision) }\end{array}$ & $\begin{array}{l}\text { It is uncertain if there is a } \\
\text { difference in the proportion } \\
\text { of participants developing a } \\
\text { new ulcer between reactive } \\
\text { air surfaces and reactive gel } \\
\text { surfaces. }\end{array}$ & 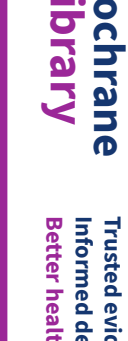 \\
\hline 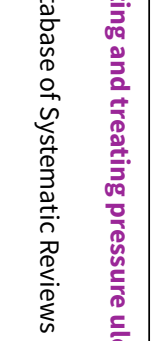 & $\begin{array}{l}\text { Reactive foam and } \\
\text { gel surfaces ver- } \\
\text { sus reactive gel sur- } \\
\text { faces (Shi } 2021 \mathrm{~d} \text {; one } \\
\text { RCT with } 166 \text { partici- } \\
\text { pants) }\end{array}$ & $\begin{array}{l}\text { Operating } \\
\text { room }\end{array}$ & $\begin{array}{l}\text { The only study reported no } \\
\text { pressure ulcers developed. }\end{array}$ & No pooling & No pooling & No pooling & $\begin{array}{l}\oplus \ominus \ominus \ominus \\
\text { VERY LOW } \\
\text { (downgraded } \\
\text { twice for risk } \\
\text { of bias and } \\
\text { once for im- } \\
\text { precision) }\end{array}$ & $\begin{array}{l}\text { It is uncertain if there is a } \\
\text { difference in the proportion } \\
\text { of participants developing a } \\
\text { new pressure ulcer between } \\
\text { reactive foam and gel sur- } \\
\text { faces and reactive gel sur- } \\
\text { faces. }\end{array}$ & \\
\hline 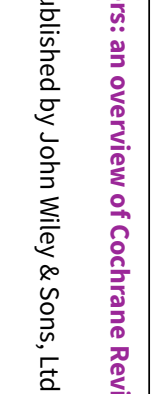 & $\begin{array}{l}\text { Reactive air surfaces } \\
\text { versus another type } \\
\text { of reactive air sur- } \\
\text { faces (Shi 2021c; two } \\
\text { studies with } 223 \text { par- } \\
\text { ticipants) }\end{array}$ & $\begin{array}{l}\text { Acute care } \\
\text { setting }\end{array}$ & $\begin{array}{l}\text { Neither study found a differ- } \\
\text { ence in the proportions of } \\
\text { participants developing a } \\
\text { new pressure ulcer between } \\
\text { two different brands (EHOB } \\
\text { and KinAir) of reactive air } \\
\text { surface or between anoth- } \\
\text { er two different brands (Sof- } \\
\text { flex and Roho) of reactive } \\
\text { air surface. }\end{array}$ & No pooling & No pooling & No pooling & $\begin{array}{l}\oplus \ominus \ominus \ominus \\
\text { VERY LOW } \\
\text { (downgraded } \\
\text { once for risk } \\
\text { of bias and } \\
\text { twice for im- } \\
\text { precision) }\end{array}$ & $\begin{array}{l}\text { It is uncertain if there is a } \\
\text { difference in the propor- } \\
\text { tions of participants devel- } \\
\text { oping a new pressure ul- } \\
\text { cer between two different } \\
\text { brands (EHOB and KinAir) } \\
\text { of reactive air surface or be- } \\
\text { tween another two different } \\
\text { brands (Sofflex and Roho) of } \\
\text { reactive air surface. }\end{array}$ & \\
\hline 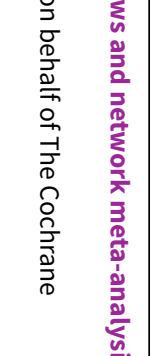 & $\begin{array}{l}\text { Reactive air surfaces } \\
\text { versus undefined } \\
\text { surfaces (alternating } \\
\text { pressure (active) air } \\
\text { surfaces or RIK mi- } \\
\text { crofluid static over- } \\
\text { lay) (Shi 2021c; one } \\
\text { RCT with } 110 \text { partici- } \\
\text { pants) }\end{array}$ & $\begin{array}{l}\text { Acute care } \\
\text { setting }\end{array}$ & RR $0.33,0.07$ to 1.58 & 109 per 1000 & $\begin{array}{l}36 \text { per } 1000 \\
(8 \text { to } 172 \text { ) }\end{array}$ & $\begin{array}{l}73 \text { fewer per } \\
1000 \text { (101 few- } \\
\text { er to } 63 \text { more) }\end{array}$ & $\begin{array}{l}\oplus \ominus \ominus \ominus \\
\text { VERY LOW } \\
\text { (downgraded } \\
\text { twice for risk } \\
\text { of bias and } \\
\text { twice for im- } \\
\text { precision) }\end{array}$ & $\begin{array}{l}\text { It is uncertain if there is a } \\
\text { difference in the proportion } \\
\text { of participants developing a } \\
\text { new ulcer between reactive } \\
\text { air surfaces and undefined } \\
\text { reactive surfaces. }\end{array}$ & 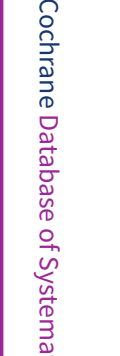 \\
\hline ร & $\begin{array}{l}\text { Reactive air surfaces } \\
\text { versus undefined }\end{array}$ & $\begin{array}{l}\text { Acute care } \\
\text { setting }\end{array}$ & $\begin{array}{l}\text { Two studies ( } 216 \text { partici- } \\
\text { pants) reported inconsis- }\end{array}$ & No pooling & No pooling & No pooling & $\oplus \odot \odot \ominus$ & $\begin{array}{l}\text { It is uncertain if there is a } \\
\text { difference in the proportion }\end{array}$ & 畩. \\
\hline
\end{tabular}


of participants developing a

new ulcer between groups

risk of bias,

hospital surfaces.

whilst another study (100

participants) suggested re-

consistency

active air surf

and twice for

the risk of having new pres-

imprecision)

sure ulcers (RR $0.21,95 \% \mathrm{Cl}$

0.07 to 0.70 ).

\section{Reactive water sur-}

faces versus unde-

Acute care

RR $0.35,0.15$ to 0.79

setting

130

130 per 1000

46 per 1000

84 fewer per

1000 (110 few-

$\oplus \oplus \odot \ominus$

pined 'standard hos

2021d; one RCT with

316 participants)

(20 to 103 )

er to 27 fewer)

LOW

downgraded

twice for risk

of bias)

Reactive water surfaces

may reduce the proportion

of participants developing

a new pressure ulcer com-

pared with undefined stan-

dard hospital surfaces.

$\begin{array}{ll}\text { Reactive gel surfaces } & \text { Operating } \\ \text { versus undefined } & \text { room }\end{array}$

One study reported that re-

active gel surfaces signif-

No pooling

No pooling

$\oplus \oplus \oplus \ominus$

standard hospital

icantly reduced the inci-

aces' (Shi 2021d;

dence rates of sacral pres-

two RCTs with 446

sure ulcers compared with

standard hospital surfaces

$(P=0.01)$. Another study re-

ported $10.7 \%(22 / 205)$ of

people using reactive gel

surfaces developed new

pressure ulcers and the pro-

portion was $20.4 \%$ (43/211)

for those using standard

hospital surfaces (RR 0.53,

$95 \% \mathrm{Cl} 0.33$ to 0.85 ).

Reactive gel surfaces Long-term Of the two studies, one re-

versus undefined

care setting

ported one of 37 partici-

No pooling

No pooling

$\oplus \odot \odot \odot$

MODERATE

Reactive gel surfaces prob-

(downgraded

once for risk

of bias)

ably reduce the proportion

of participants developing a

pants using reactive gel sur-

faces developed new pres-

sure ulcers whilst none of

the participants developed

new ulcers when using un-

defined surfaces; another

study reported none of 25

VERY LOW

(downgraded

twice for risk

of bias, and

twice for im-

precision)
It is uncertain if there is a difference between reactive

gel surfaces and undefined reactive surfaces in the proportion of participants developing a new pressure ul- 


\begin{tabular}{|c|c|c|c|c|c|c|c|c|}
\hline 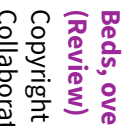 & (Continued) & & $\begin{array}{l}\text { participants in each study } \\
\text { arm developed new ulcers. }\end{array}$ & & & & & \\
\hline 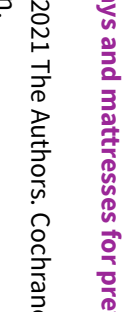 & $\begin{array}{l}\text { Reactive sheep- } \\
\text { skin surfaces ver- } \\
\text { sus undefined 'stan- } \\
\text { dard hospital sur- } \\
\text { faces' (Shi 2021d; } \\
\text { three RCTs with } 1424 \\
\text { participants) }\end{array}$ & $\begin{array}{l}\text { Acute and } \\
\text { long-term } \\
\text { care settings }\end{array}$ & $\begin{array}{l}\text { Three studies (1424 partici- } \\
\text { pants) all suggested that re- } \\
\text { active sheepskin surfaces } \\
\text { were associated with lower } \\
\text { proportions of participants } \\
\text { developing a new pressure } \\
\text { ulcer than 'standard hospi- } \\
\text { tal surfaces'. }\end{array}$ & No pooling & No pooling & No pooling & $\begin{array}{l}\oplus \oplus \odot \ominus \\
\text { LOW } \\
\text { (downgraded } \\
\text { twice for risk } \\
\text { of bias) }\end{array}$ & $\begin{array}{l}\text { Reactive sheepskin surfaces } \\
\text { may reduce the proportion } \\
\text { of participants developing } \\
\text { a new pressure ulcer com- } \\
\text { pared with standard hospi- } \\
\text { tal surfaces. }\end{array}$ \\
\hline 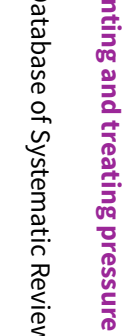 & $\begin{array}{l}\text { Reactive gel surfaces } \\
\text { versus reactive gel } \\
\text { surfaces (Shi } 2021 \mathrm{~d} \text {; } \\
\text { one study, } 113 \text { par- } \\
\text { ticipants) }\end{array}$ & $\begin{array}{l}\text { Operating } \\
\text { room }\end{array}$ & $\begin{array}{l}\text { One study reported this out- } \\
\text { come but indicated no pres- } \\
\text { sure ulcers developed. }\end{array}$ & No pooling & No pooling & No pooling & $\begin{array}{l}\oplus \ominus \ominus \ominus \\
\text { VERY LOW } \\
\text { (downgraded } \\
\text { twice for risk } \\
\text { of bias and } \\
\text { twice for im- } \\
\text { precision) }\end{array}$ & $\begin{array}{l}\text { It is uncertain if there is a } \\
\text { difference in the proportion } \\
\text { of participants developing a } \\
\text { new pressure ulcer between } \\
\text { these two types of use of re- } \\
\text { active gel surfaces. }\end{array}$ \\
\hline 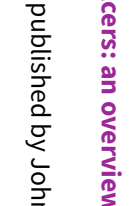 & $\begin{array}{l}\text { Reactive water sur- } \\
\text { faces versus reactive } \\
\text { fibre surfaces (Shi } \\
\text { 2021d; one study, } 87 \\
\text { participants) }\end{array}$ & $\begin{array}{l}\text { Acute care } \\
\text { setting }\end{array}$ & $\begin{array}{l}\text { One study reported no out- } \\
\text { comes directly relevant to } \\
\text { this review and so none of } \\
\text { its data were analysable. }\end{array}$ & $\begin{array}{l}\text { Not applica- } \\
\text { ble }\end{array}$ & $\begin{array}{l}\text { Not applica- } \\
\text { ble }\end{array}$ & $\begin{array}{l}\text { Not applica- } \\
\text { ble }\end{array}$ & $\begin{array}{l}\text { Not applica- } \\
\text { ble }\end{array}$ & Not applicable \\
\hline 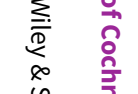 & $\begin{array}{l}\text { - Time to pressure } \\
\text { ulcer incidence }\end{array}$ & & & & & & & \\
\hline 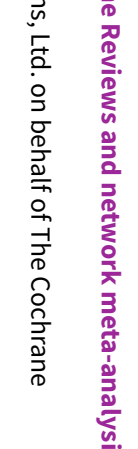 & $\begin{array}{l}\text { Alternating pressure } \\
\text { (active) air surfaces } \\
\text { versus foam sur- } \\
\text { faces (Shi 2021a; Shi } \\
2021 \text { b; } 2 \text { RCTs with } \\
2105 \text { participants) }\end{array}$ & $\begin{array}{l}\text { Acute and } \\
\text { long-term } \\
\text { care setting }\end{array}$ & HR $0.41,0.10$ to 1.64 & 98 per 1000 & $\begin{array}{l}41 \text { per } 1000 \\
(10 \text { to } 156)\end{array}$ & $\begin{array}{l}57 \text { fewer per } \\
1000 \text { ( } 88 \text { few- } \\
\text { er to } 58 \text { more) }\end{array}$ & $\begin{array}{l}\oplus \odot \odot \odot \\
\text { VERY LOW } \\
\text { (downgraded } \\
\text { once for risk } \\
\text { of bias, once } \\
\text { for moderate } \\
\text { imprecision, } \\
\text { and twice for } \\
\text { substantial in- } \\
\text { consistency) }\end{array}$ & $\begin{array}{l}\text { It is uncertain if there is a } \\
\text { difference between alter- } \\
\text { nating pressure (active) air } \\
\text { surfaces and foam surfaces } \\
\text { in the hazard of developing } \\
\text { new pressure ulcers. }\end{array}$ \\
\hline
\end{tabular}


People treated with alterversus reactive air surfaces (Shi 2021a;

Shi 2021c; 1 RCT with

(54 to 227

to 175 more)

LOW

nating pressure (active) air surfaces may have a high-

er risk of developing an in

(downgraded twice for high

risk of detec-

cident pressure ulcer than

308 participants)

tion bias)

air surfaces over 14 days

follow-up at nursing home.

Alternating pressure (active) air surfaces Acute and Both of the two included long-term studies suggested no clear versus another type care setting

difference in the risk of de-

alternating

(active) air surfaces

(Shi 2021a; two stud-

veloping an incident pressure ulcer at time up to 60 days' follow-up between

es with 2581 partici-

these support surfaces.

No pooling No pooling No pooling $\oplus \oplus \Theta \Theta$

LOW

There may be little to no difference in the risk of developing an incident pres-

sure ulcer over 60 days' folport surfaces.

pants)

once for im-

precision)

Foam surfaces versus Acute care One study reported an un-

and long-term adjusted $\mathrm{HR}$ of $0.33(95 \% \mathrm{C}$

surfaces (Shi 2021b;

care setting

0.17 to 0.64$)$ for the compar-

No pooling

0.17 to 0.64 ) for the compar-

ison of the viscoelastic foam

surfaces with a density of

40 to $60 \mathrm{~kg} / \mathrm{m}^{3}$ versus foam

surfaces with a density of 33

$\mathrm{kg} / \mathrm{m}^{3}$ in intensive care unit

setting whilst another study

reported an adjusted HR of

0.40 ( $95 \% \mathrm{Cl} 0.20$ to 0.80$)$

for the comparison of solid

foam surfaces versus convo-

luted foam surfaces at acute

care and long-term care set-

tings.

Foam surfaces com- Acute care One study (1729 partici-

One study (1729 partici-
pants) suggested foam sur-

No pooling

No pooling

No pooling

$\oplus \ominus \ominus \odot$

faces reduced the hazard

ed standard hos-

of developing a new ulcer,

pital surfaces (Shi

2021b; three stud-

ies with 3072 partici-

whilst another two studies

(1343 participants) suggest-

pants)

$\oplus \oplus \odot \odot$
LOW
(downgraded
once for risk
of bias and
once for im-
precision)

Viscoelastic foam surfaces with a density of 40 to 60 $\mathrm{kg} / \mathrm{m}^{3}$ and solid foam surfaces may decrease the risk of developing incident pressure ulcers at any point in time up to one month com pared with the control foam surfaces. 


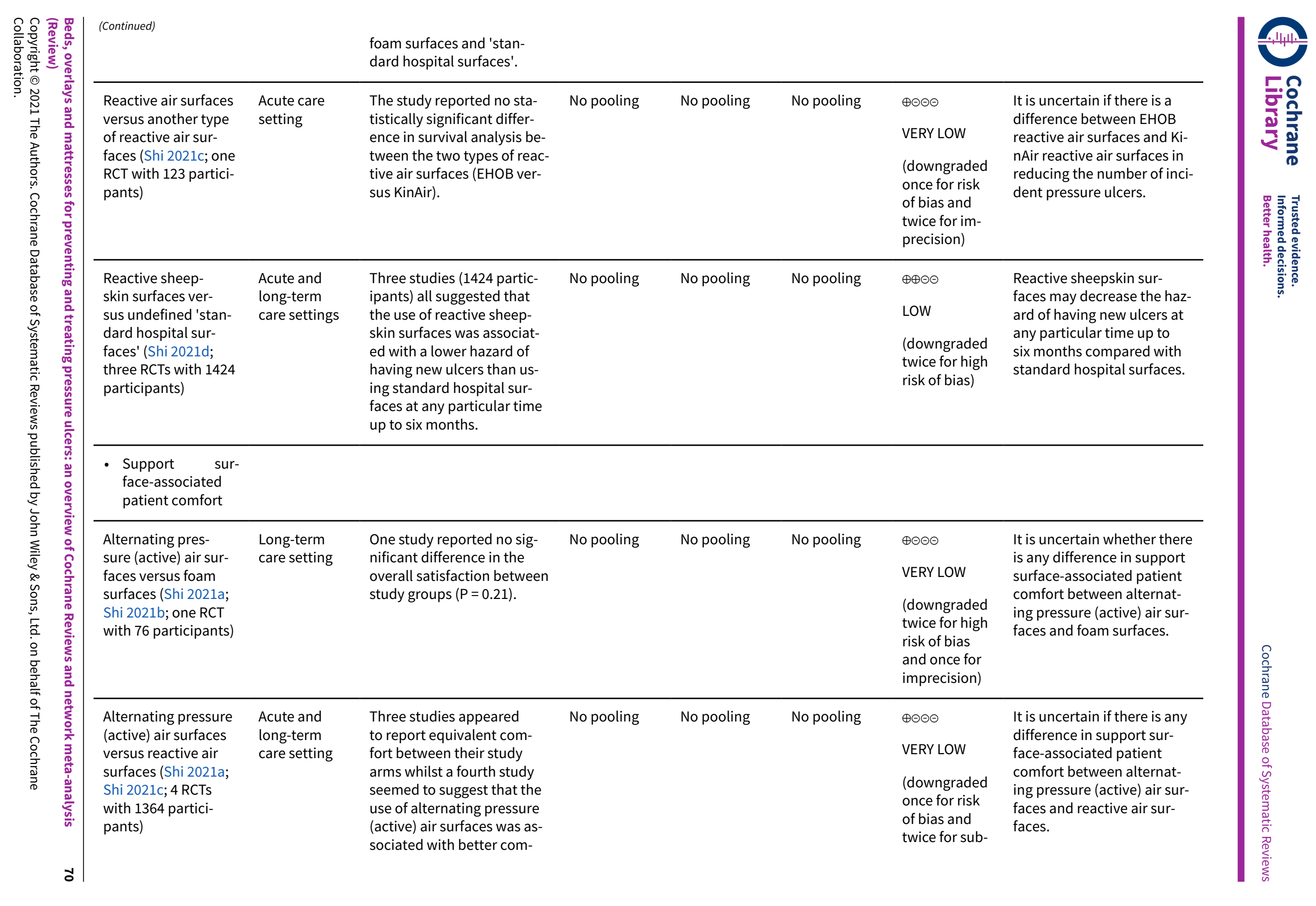




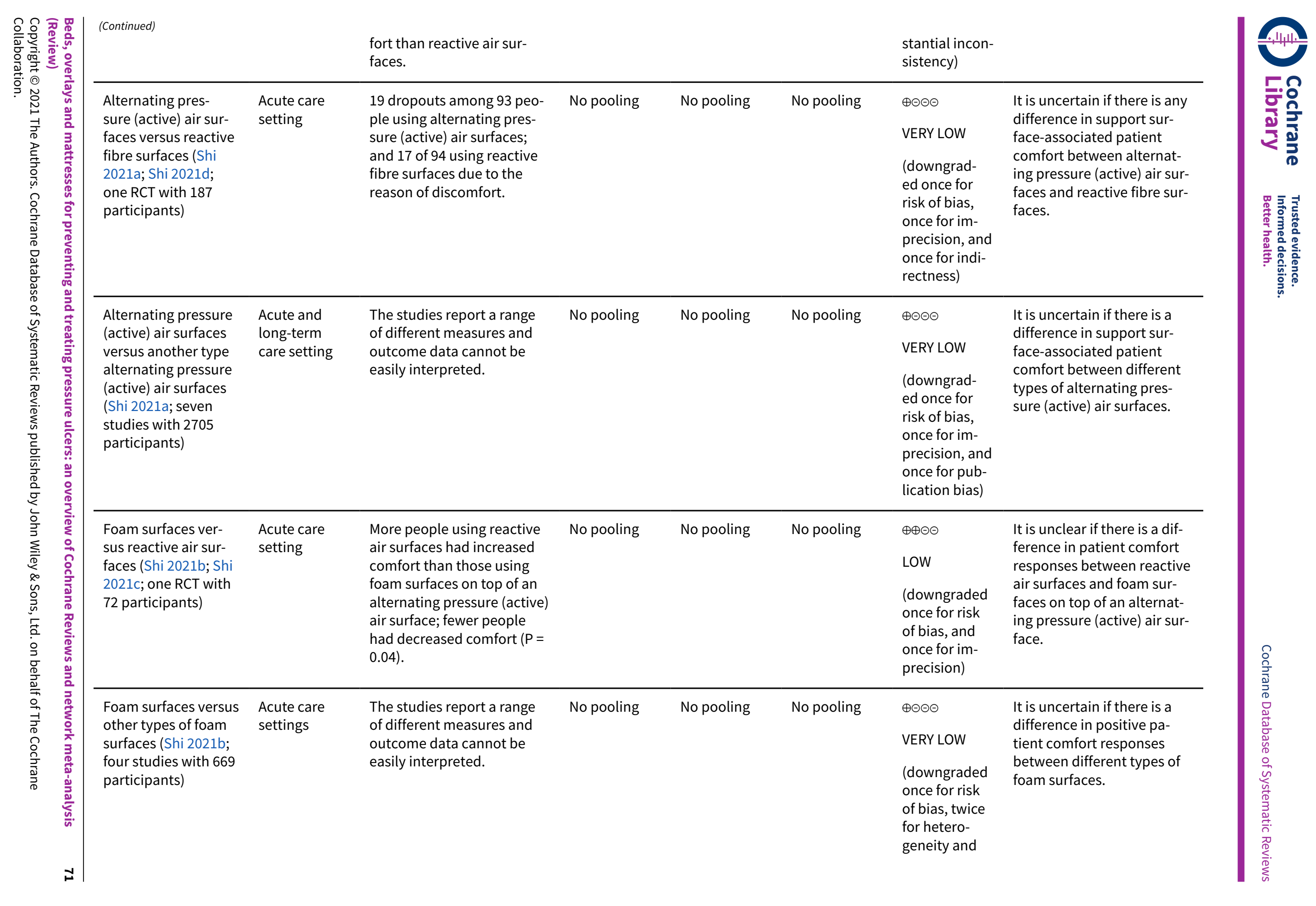




\begin{tabular}{|c|c|c|c|c|c|c|c|}
\hline 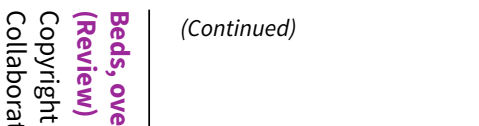 & & & & & & $\begin{array}{l}\text { once for im- } \\
\text { precision) }\end{array}$ & \\
\hline 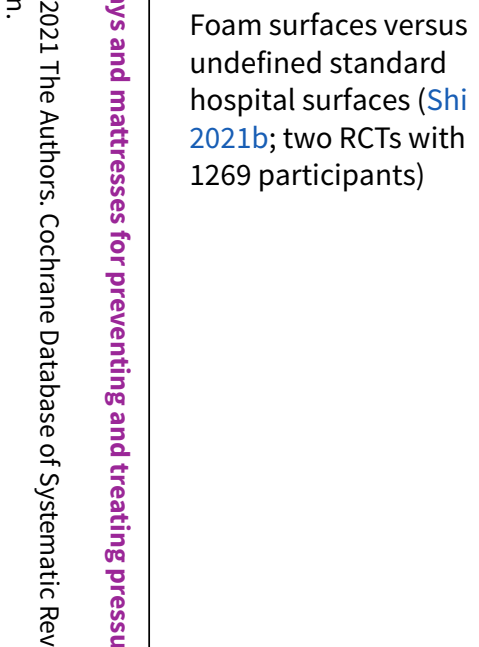 & $\begin{array}{l}\text { Acute care } \\
\text { setting }\end{array}$ & $\begin{array}{l}\text { One study measured com- } \\
\text { fort using a 5-point scale } \\
\text { (higher score = better com- } \\
\text { fort) and reported a mean } \\
\text { comfort rating of } 4.2 \text { for } \\
\text { foam surfaces and } 4.0 \text { for } \\
\text { standard hospital mattress. } \\
\text { Another study measured } \\
\text { comfort using a 10-point } \\
\text { scale (higher score = poor- } \\
\text { er comfort) but reported } \\
\text { no significant differences in } \\
\text { comfort between foam mat- } \\
\text { tresses (mean } 2.33 \text { and SD } \\
0.98 \text { ) and standard hospital } \\
\text { mattress (mean } 2.46 \text { and SD } \\
1.0 \text { ). }\end{array}$ & No pooling & No pooling & No pooling & $\begin{array}{l}\oplus \ominus \ominus \ominus \\
\text { VERY LOW } \\
\text { (downgraded } \\
\text { twice for risk } \\
\text { of bias and } \\
\text { once for het- } \\
\text { erogeneity) }\end{array}$ & $\begin{array}{l}\text { It is uncertain if there is a } \\
\text { difference in support sur- } \\
\text { face-associated patient } \\
\text { comfort between foam sur- } \\
\text { faces and undefined stan- } \\
\text { dard hospital surfaces. }\end{array}$ \\
\hline $\begin{array}{l}\text { Reactive air surfaces } \\
\text { versus undefined } \\
\text { surfaces (alternating } \\
\text { pressure (active) air } \\
\text { surfaces or RIK mi- } \\
\text { crofluid static over- } \\
\text { lay) (Shi } 2021 c \text {; one } \\
\text { RCT with } 110 \text { partici- } \\
\text { pants) }\end{array}$ & $\begin{array}{l}\text { Acute care } \\
\text { setting }\end{array}$ & $\begin{array}{l}68 \text { participants rated com- } \\
\text { fort: } 27 \text { of } 30 \text { participants } \\
\text { using undefined reactive } \\
\text { surfaces and } 29 \text { of } 34 \text { using } \\
\text { reactive air surfaces had } \\
\text { comfort responses. }\end{array}$ & No pooling & No pooling & No pooling & $\begin{array}{l}\oplus \ominus \ominus \ominus \\
\text { VERY LOW } \\
\text { (downgraded } \\
\text { twice for risk } \\
\text { of bias and } \\
\text { once for im- } \\
\text { precision) }\end{array}$ & $\begin{array}{l}\text { It is uncertain if there is a } \\
\text { difference in support sur- } \\
\text { face-associated patient } \\
\text { comfort between reactive } \\
\text { air surfaces and undefined } \\
\text { reactive surfaces. }\end{array}$ \\
\hline $\begin{array}{l}\text { Reactive air surfaces } \\
\text { versus another type } \\
\text { of reactive air sur- } \\
\text { face (Shi 2021c; one } \\
\text { RCT with } 84 \text { partici- } \\
\text { pants) }\end{array}$ & $\begin{array}{l}\text { Acute care } \\
\text { setting }\end{array}$ & $\begin{array}{l}\text { None of } 84 \text { participants } \\
\text { gave a 'very uncomfortable' } \\
\text { response in either reactive } \\
\text { air surfaces; } 5 \text { gave an 'un- } \\
\text { comfortable' response (all } \\
\text { using Roho); } 8 \text { gave an 'ad- } \\
\text { equate' response ( } 4 \text { in each } \\
\text { group), } 48 \text { gave a 'comfort- } \\
\text { able' response ( } 24 \text { in each } \\
\text { group), and } 23 \text { responded } \\
\text { 'very comfortable' ( } 13 \text { using } \\
\text { Sofflex and } 10 \text { using Roho). }\end{array}$ & No pooling & No pooling & No pooling & $\begin{array}{l}\oplus \oplus \ominus \ominus \\
\text { LOW } \\
\text { (downgraded } \\
\text { once for risk } \\
\text { of bias and } \\
\text { once for im- } \\
\text { precision) }\end{array}$ & $\begin{array}{l}\text { It is unclear if there is a dif- } \\
\text { ference in the support sur- } \\
\text { face-associated patient } \\
\text { comfort between the two } \\
\text { specific reactive air surfaces } \\
\text { under evaluation. }\end{array}$ \\
\hline
\end{tabular}


of bias and difference between reactive

once for im-

precision)

\begin{tabular}{|c|c|c|c|c|c|c|c|}
\hline $\begin{array}{l}\text { Reactive sheep- } \\
\text { skin surfaces ver- } \\
\text { sus undefined 'stan- } \\
\text { dard hospital sur- } \\
\text { faces' (Shi } 2021 d \text {; } \\
\text { one RCT with } 297 \\
\text { participants) }\end{array}$ & $\begin{array}{l}\text { Acute care } \\
\text { setting }\end{array}$ & $\begin{array}{l}\text { The study reported that } \\
\text { people using reactive } \\
\text { sheepskin surfaces rated } \\
\text { comfort significantly higher } \\
\text { than those using standard } \\
\text { hospital surfaces ( } Z \text { value of } \\
\text { the Mann-Whitney } U \text { test = } \\
-7.74, P<0.001 \text { ). }\end{array}$ & No pooling & No pooling & No pooling & $\begin{array}{l}\oplus \odot \odot \ominus \\
\text { VERY LOW } \\
\text { (downgraded } \\
\text { twice for risk } \\
\text { of bias and } \\
\text { once for im- } \\
\text { precision) }\end{array}$ & $\begin{array}{l}\text { It is uncertain if there is a } \\
\text { difference between reac- } \\
\text { tive sheepskin surfaces and } \\
\text { standard hospital surfaces } \\
\text { in support surface-associat- } \\
\text { ed patient comfort. }\end{array}$ \\
\hline
\end{tabular}

- All reported ad-

verse events

\begin{tabular}{|c|c|c|c|c|c|c|c|}
\hline $\begin{array}{l}\text { Alternating pressure } \\
\text { (active) air surfaces } \\
\text { versus foam sur- } \\
\text { faces (Shi 2021a; Shi } \\
\text { 2021b; three RCTs } \\
\text { with } 2181 \text { partici- } \\
\text { pants) }\end{array}$ & $\begin{array}{l}\text { Acute and } \\
\text { long-term } \\
\text { care setting }\end{array}$ & $\begin{array}{l}\text { Two studies reported simi- } \\
\text { lar rates of adverse events } \\
\text { between their study arms; } \\
\text { and a third study reported } \\
\text { one death but did not spec- } \\
\text { ify which study group the } \\
\text { death was associated with. }\end{array}$ & No pooling & No pooling & No pooling & $\begin{array}{l}\oplus \ominus \ominus \ominus \\
\text { VERY LOW } \\
\text { (downgraded } \\
\text { once for risk } \\
\text { of bias and } \\
\text { twice for sub- } \\
\text { stantial incon- } \\
\text { sistency). }\end{array}$ & $\begin{array}{l}\text { Available evidence was from } \\
3 \text { RCTs ( } 2181 \text { participants) } \\
\text { that reported a variety of } \\
\text { adverse events but data } \\
\text { were not pooled. It is uncer- } \\
\text { tain if there is any difference } \\
\text { in reported adverse events } \\
\text { between alternating pres- } \\
\text { sure (active) air surfaces } \\
\text { and foam surfaces. }\end{array}$ \\
\hline $\begin{array}{l}\text { Alternating pressure } \\
\text { (active) air surfaces } \\
\text { on operating tables } \\
\text { and subsequently } \\
\text { on ward beds ver- } \\
\text { sus reactive gel sur- } \\
\text { faces used in operat- } \\
\text { ing room followed by } \\
\text { foam surfaces used } \\
\text { on ward bed (Shi }\end{array}$ & $\begin{array}{l}\text { Operating } \\
\text { room }\end{array}$ & $\begin{array}{l}\text { Approximately one half of } \\
\text { people in each group re- } \\
\text { ported adverse events. No } \\
\text { difference in adverse events } \\
\text { between groups was report- } \\
\text { ed. No adverse events were } \\
\text { related to the mattresses } \\
\text { assigned. }\end{array}$ & No pooling & No pooling & No pooling & $\begin{array}{l}\oplus \ominus \ominus \ominus \\
\text { VERY LOW } \\
\text { (downgraded } \\
\text { once for risk } \\
\text { of bias and } \\
\text { twice for im- } \\
\text { precision). }\end{array}$ & $\begin{array}{l}\text { It is uncertain if there is any } \\
\text { difference in all reported } \\
\text { adverse events between al- } \\
\text { ternating pressure (active) } \\
\text { air surfaces applied on both } \\
\text { operating tables and hos- } \\
\text { pital beds and reactive gel } \\
\text { surfaces used on operating } \\
\text { tables followed by foam sur- } \\
\text { faces applied on hospital }\end{array}$ \\
\hline
\end{tabular}




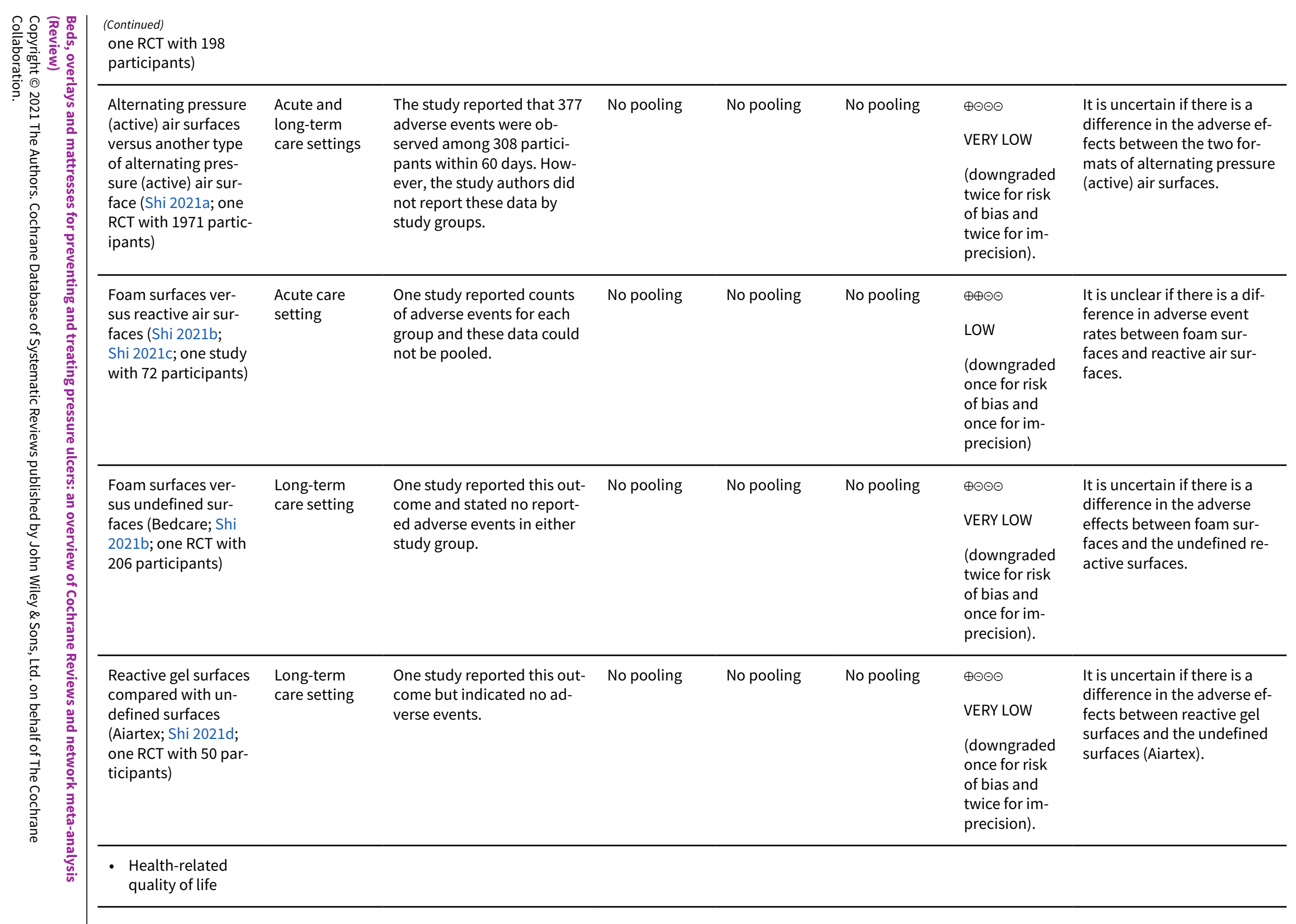


Alternating pressure (active) air sur-

faces versus foam

surfaces (Shi 2021a;

hi 2021b; one RCT

with 2029 partici-

pants; the EQ-5D-5L

measured 267 partic

ipants; and PU-QoL-

II measured 233 par-

ticipants)
Acute and

long-term

care setting

M in the 90-day EQ-5D-5L of $0.00(95 \% \mathrm{Cl}-0.05$ to

$0.05)$; and MD in 90-day PU

QoL-UI of $0.00(95 \% \mathrm{Cl}-0.03$

to 0.03 )

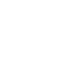

\section{The mean - \\ health- \\ related \\ quality of \\ life (90-day \\ EQ-5D-5L) \\ was 0.52 \\ - The mean \\ health- \\ related \\ quality of \\ day $P U$ \\ QoL-UI) \\ was 0.60}

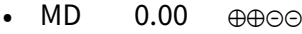

(0.05 low-

er to 0.05 LOW

higher)

(0.03 low-

twice for sub-

higher)
It is unclear if there is a difference in health-related

quality of life measured us ing EQ-5D-5L or PU-QoL-

$\mathrm{UI}$ at 90-day follow-up between alternating pressure (active) air surfaces and foam surfaces.

\begin{tabular}{|c|c|c|c|c|c|c|c|}
\hline $\begin{array}{l}\text { Reactive sheep- } \\
\text { skin surfaces ver- } \\
\text { sus undefined 'stan- } \\
\text { dard hospital sur- } \\
\text { faces' (Shi } 2021 d \text {; } \\
\text { one RCT with } 588 \\
\text { participants; out- } \\
\text { come measured on a } \\
100-\text { point visual ana- } \\
\text { logue scale, higher = } \\
\text { better) }\end{array}$ & $\begin{array}{l}\text { Long-term } \\
\text { care setting }\end{array}$ & $\begin{array}{l}\text { The quality of life for those } \\
\text { with ulcers using reactive } \\
\text { sheepskin surfaces had a } \\
\text { mean of } 62.1 \text { on a } 100 \text {-point } \\
\text { visual analogue scale (high- } \\
\text { er = better) compared with } \\
61.3 \text { for those using stan- } \\
\text { dard hospital surfaces (Stu- } \\
\text { dent's t test } P=0.71 \text { ). }\end{array}$ & No pooling & No pooling & No pooling & $\begin{array}{l}\oplus \oplus \Theta \ominus \\
\text { LOW } \\
\text { (downgraded } \\
\text { twice for risk } \\
\text { of bias) }\end{array}$ & $\begin{array}{l}\text { There may be little to no } \\
\text { difference between reac- } \\
\text { tive sheepskin surfaces and } \\
\text { standard hospital surfaces } \\
\text { in the health-related quality } \\
\text { of life. }\end{array}$ \\
\hline \multicolumn{8}{|l|}{ - Cost-effectiveness } \\
\hline $\begin{array}{l}\text { Alternating pressure } \\
\text { (active) air surfaces } \\
\text { versus foam sur- } \\
\text { faces (Shi 2021a; Shi } \\
\text { 2021b; one RCT with } \\
2029 \text { participants) }\end{array}$ & $\begin{array}{l}\text { Acute and } \\
\text { long-term } \\
\text { care setting }\end{array}$ & $\begin{array}{l}\text { Incremental cost-effective- } \\
\text { ness ratio (ICER) = GBP - } \\
101,699 \text { and Net Monetary } \\
\text { Benefit (NMB) = GBP - } 2114 \\
\text { in the probabilistic analysis, } \\
\text { meaning alternating pres- } \\
\text { sure (active) air surfaces } \\
\text { have lower costs and high- } \\
\text { er QALY (quality-adjusted } \\
\text { life-years) values. Alternat- } \\
\text { ing pressure (active) air sur- } \\
\text { faces had a } 99 \% \text { probability } \\
\text { of being cost-effective at a } \\
\text { threshold of GBP } 20,000 \text { and } \\
\text { alternating pressure (active) }\end{array}$ & $\begin{array}{l}\text { Not applica- } \\
\text { ble }\end{array}$ & $\begin{array}{l}\text { Not applica- } \\
\text { ble }\end{array}$ & $\begin{array}{l}\text { Not applica- } \\
\text { ble }\end{array}$ & $\begin{array}{l}\oplus \oplus \oplus \ominus \\
\text { MODERATE } \\
\text { (downgraded } \\
\text { once for im- } \\
\text { precision). }\end{array}$ & $\begin{array}{l}\text { Alternating pressure (active) } \\
\text { air surfaces probably domi- } \\
\text { nate reactive foam surfaces, } \\
\text { meaning they are the cost- } \\
\text { effective option. }\end{array}$ \\
\hline
\end{tabular}




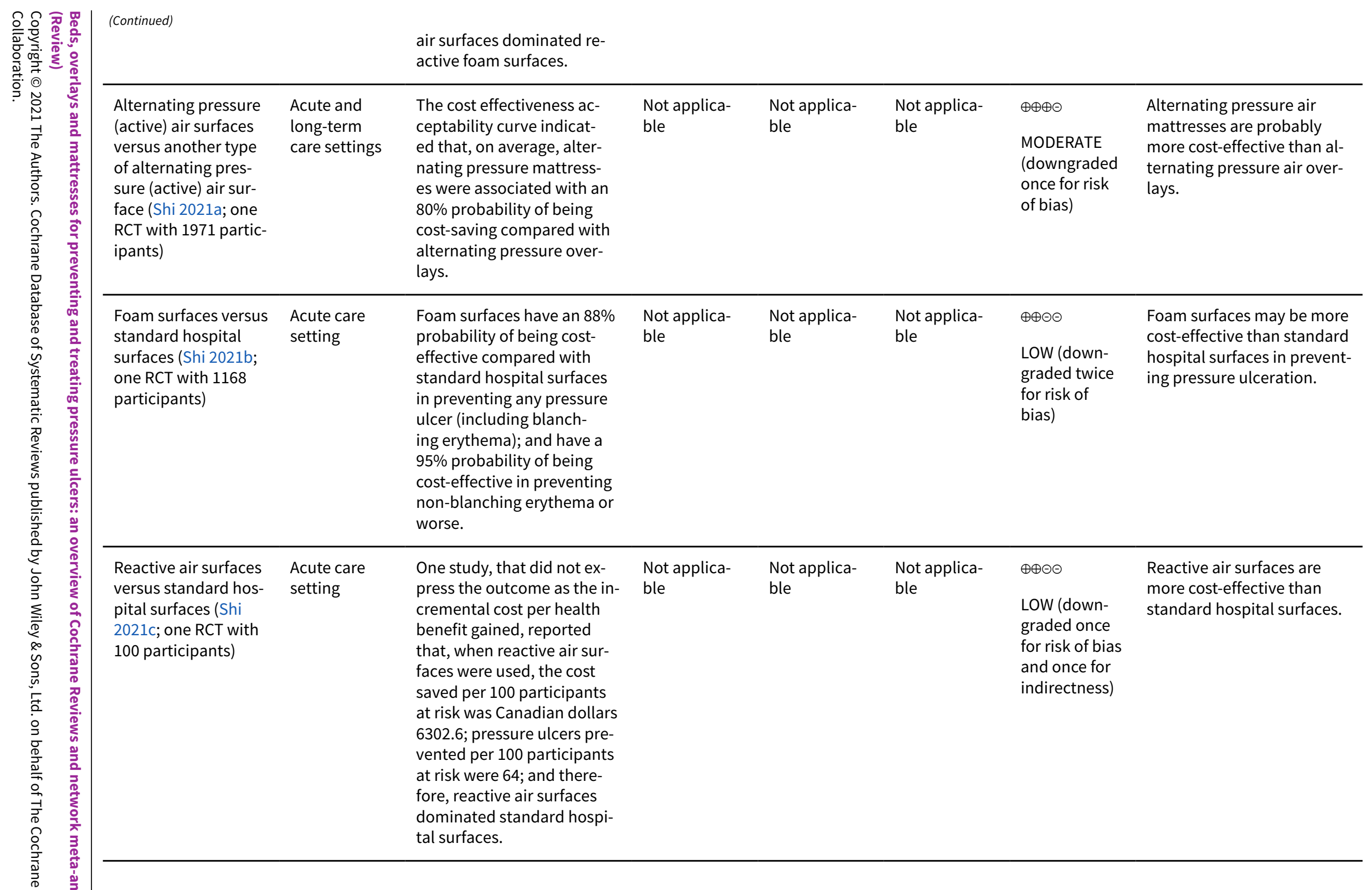




\begin{tabular}{|c|c|c|c|c|c|c|c|c|}
\hline 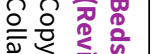 & ndix 6. Summar & t tindings & : overview of treatme & vidence & & & & \\
\hline 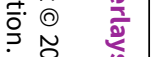 & Interventions versus & Care setting & Relative effect (RR, 95\% & Anticipated ab & olute effect (95 & $6 \mathrm{Cl})$ & Certainty of & Interpretation of find- \\
\hline 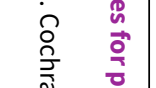 & & & & $\begin{array}{l}\text { Risk with } \\
\text { comparators }\end{array}$ & $\begin{array}{l}\text { Risk with in- } \\
\text { terventions }\end{array}$ & Difference & & \\
\hline 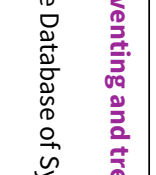 & $\begin{array}{l}\text { Proportion of par- } \\
\text { ticipants with pres- } \\
\text { sure ulcers com- } \\
\text { pletely healed }\end{array}$ & & & & & & & \\
\hline 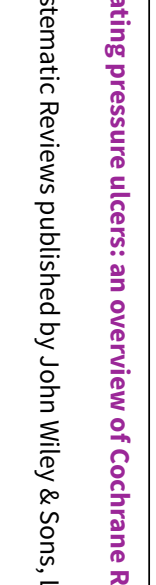 & $\begin{array}{l}\text { Alternating pressure } \\
\text { (active) air surfaces } \\
\text { versus foam surfaces } \\
\text { (Shi 2021e; } 2 \text { RCTs with } \\
132 \text { participants) }\end{array}$ & $\begin{array}{l}\text { Acute and } \\
\text { long-term } \\
\text { care setting }\end{array}$ & $\begin{array}{l}\text { Two studies reported this } \\
\text { outcome: } \\
\text { one study reported } \\
\text { analysable data and the } \\
\text { RR was } 0.97(95 \% \mathrm{Cl} 0.26 \\
\text { to } 3.58) \text {; another study } \\
\text { stated that the analysis } \\
\text { of covariance showed no } \\
\text { statistically significant dif- } \\
\text { ference in the healing of } \\
\text { pressure ulcers between } \\
\text { alternating pressure (ac- } \\
\text { tive) air surfaces versus } \\
\text { foam surfaces. }\end{array}$ & No pooling & No pooling & No pooling & $\begin{array}{l}\oplus \ominus \ominus \ominus \\
\text { VERY LOW } \\
\text { (downgraded } \\
\text { twice for high } \\
\text { risk of bias and } \\
\text { twice for sub- } \\
\text { stantial impre- } \\
\text { cision) }\end{array}$ & $\begin{array}{l}\text { It is uncertain if there is a } \\
\text { difference in the propor- } \\
\text { tion of participants with } \\
\text { healed pressure ulcers be- } \\
\text { tween alternating pres- } \\
\text { sure (active) air surfaces } \\
\text { and foam surfaces. }\end{array}$ \\
\hline 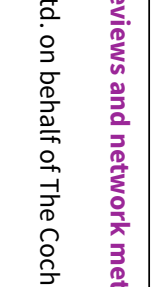 & $\begin{array}{l}\text { Reactive air surfaces } \\
\text { versus foam surfaces } \\
\text { (Shi 2021e; } 2 \text { RCTs with } \\
156 \text { participants) }\end{array}$ & $\begin{array}{l}\text { Acute and } \\
\text { long-term } \\
\text { care setting }\end{array}$ & RR $1.32,0.96$ to 1.80 & 442 per 1000 & $\begin{array}{l}583 \text { per } 1000 \\
\text { (424 to } 795 \text { ) }\end{array}$ & $\begin{array}{l}141 \text { more } \\
\text { per } 1000(18 \\
\text { fewer to } 353 \\
\text { more) }\end{array}$ & $\begin{array}{l}\oplus \oplus \odot \ominus \\
\text { LOW } \\
\text { (downgraded } \\
\text { twice for impre- } \\
\text { cision) }\end{array}$ & $\begin{array}{l}\text { It is unclear if there is a } \\
\text { difference in the propor- } \\
\text { tion of participants with } \\
\text { pressure ulcers complete- } \\
\text { ly healed between reac- } \\
\text { tive air surfaces and foam } \\
\text { surfaces. }\end{array}$ \\
\hline 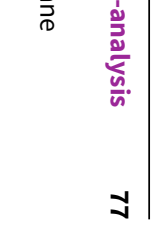 & $\begin{array}{l}\text { Foam surfaces versus } \\
\text { reactive water surfaces } \\
\text { (Shi 2021e; one RCT } \\
\text { with } 68 \text { participants) }\end{array}$ & $\begin{array}{l}\text { Long-term } \\
\text { care setting }\end{array}$ & RR $0.93,0.61$ to 1.42 & 481 per 1000 & $\begin{array}{l}447 \text { per } 1000 \\
\text { (293 to } 683 \text { ) }\end{array}$ & $\begin{array}{l}37 \text { fewer per } \\
1000(191 \\
\text { fewer to } 199 \\
\text { more) }\end{array}$ & $\begin{array}{l}\oplus \ominus \ominus \ominus \\
\text { VERY LOW } \\
\text { (downgraded } \\
\text { twice for risk of }\end{array}$ & $\begin{array}{l}\text { It is uncertain if there is a } \\
\text { difference in the propor- } \\
\text { tion of participants with } \\
\text { healed pressure ulcers be- }\end{array}$ \\
\hline
\end{tabular}




\begin{tabular}{|c|c|c|c|c|c|c|c|c|}
\hline 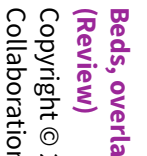 & (Continued) & & & & & & $\begin{array}{l}\text { bias, and twice } \\
\text { for impreci- } \\
\text { sion). }\end{array}$ & $\begin{array}{l}\text { tween foam surfaces and } \\
\text { reactive water surfaces. }\end{array}$ \\
\hline 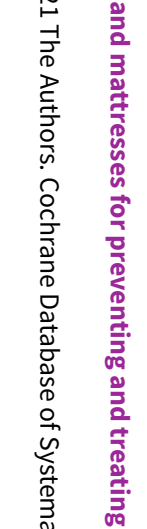 & $\begin{array}{l}\text { Alternating pressure } \\
\text { (active) air surfaces } \\
\text { compared with the an- } \\
\text { other type of alternat- } \\
\text { ing pressure (active) } \\
\text { air surface (Shi 2021e; } \\
\text { McGinnis 2014; } 3 \text { RCTs } \\
\text { with } 73 \text { participants) }\end{array}$ & $\begin{array}{l}\text { Acute and } \\
\text { long-term } \\
\text { care setting }\end{array}$ & $\begin{array}{l}\text { All studies reported no } \\
\text { statistical difference be- } \\
\text { tween Nimbus alternating } \\
\text { pressure air systems and } \\
\text { Pegasus systems for im- } \\
\text { provement or healing of } \\
\text { sacral pressure sores; } \\
\text { no significant difference } \\
\text { when using either mat- } \\
\text { tress system in the num- } \\
\text { ber of heel ulcers healed } \\
\text { (RR } 1.49 ; 95 \% \mathrm{Cl} 0.90 \text { to } \\
\text { 2.45). }\end{array}$ & No pooling & No pooling & No pooling & $\begin{array}{l}\oplus \odot \ominus \ominus \\
\text { VERY LOW } \\
\text { (downgraded } \\
\text { once for risk of } \\
\text { bias and twice } \\
\text { for impreci- } \\
\text { sion). }\end{array}$ & $\begin{array}{l}\text { It is unclear if there is a } \\
\text { difference in the propor- } \\
\text { tion of participants with } \\
\text { pressure ulcers complete- } \\
\text { ly healed between differ- } \\
\text { ent types of alternating } \\
\text { pressure (active) air sur- } \\
\text { faces (Nimbus vs. Pega- } \\
\text { sus). }\end{array}$ \\
\hline 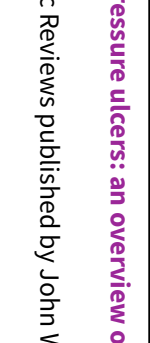 & $\begin{array}{l}\text { Reactive gel surfaces } \\
\text { versus undefined re- } \\
\text { active surfaces (Aiar- } \\
\text { tex; Shi 2021e; one RCT } \\
\text { with } 72 \text { participants) }\end{array}$ & $\begin{array}{l}\text { Long-term } \\
\text { care setting }\end{array}$ & $\mathrm{RR} 1.58,0.41$ to 6.11 & 86 per 1000 & $\begin{array}{l}136 \text { per } 1000 \\
(35 \text { to } 525)\end{array}$ & $\begin{array}{l}50 \text { more } 1000 \\
\text { ( } 51 \text { fewer to } \\
439 \text { more) }\end{array}$ & $\begin{array}{l}\oplus \ominus \ominus \ominus \\
\text { VERY LOW } \\
\text { (downgraded } \\
\text { twice for risk of } \\
\text { bias and twice } \\
\text { for impreci- } \\
\text { sion). }\end{array}$ & $\begin{array}{l}\text { It is uncertain if there is a } \\
\text { difference in the propor- } \\
\text { tions of participants with } \\
\text { pressure ulcers complete- } \\
\text { ly healed between people } \\
\text { using reactive gel surfaces } \\
\text { and those using undefined } \\
\text { reactive surfaces. }\end{array}$ \\
\hline 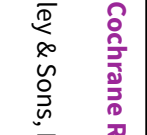 & $\begin{array}{l}\text { - Time to complete } \\
\text { pressure ulcer heal- } \\
\text { ing }\end{array}$ & & & & & & & \\
\hline 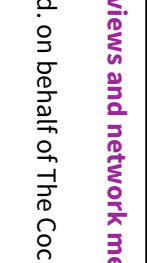 & $\begin{array}{l}\text { Reactive air surfaces } \\
\text { versus foam surfaces } \\
\text { (Shi 2021e; } 1 \text { RCT with } \\
84 \text { participants) }\end{array}$ & $\begin{array}{l}\text { Long-term } \\
\text { care setting }\end{array}$ & HR $2.66,1.34$ to 5.17 & 463 per 1000 & $\begin{array}{l}809 \text { per } 1000 \\
(566 \text { to } 960)\end{array}$ & $\begin{array}{l}346 \text { more per } \\
1000(103 \\
\text { more to } 497 \\
\text { more) }\end{array}$ & $\begin{array}{l}\oplus \oplus \ominus \ominus \\
\text { LOW } \\
\text { (downgraded } \\
\text { twice for impre- } \\
\text { cision) }\end{array}$ & $\begin{array}{l}\text { People using reactive air } \\
\text { surfaces may be more } \\
\text { likely to have healed pres- } \\
\text { sure ulcers compared with } \\
\text { people using foam sur- } \\
\text { faces. }\end{array}$ \\
\hline 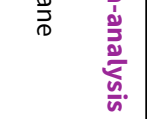 & $\begin{array}{l}\text { - Support surface-as- } \\
\text { sociated patient } \\
\text { comfort }\end{array}$ & & & & & & & \\
\hline
\end{tabular}


The mean

support sur-

active) air surfaces

versus foam surfaces

(Shi 2021e; one RCT

setting

face-associ-

ated patient

comfort was
MD 0.4 higher

(0.42 lower to 1.22 higher) $\oplus \ominus \ominus \ominus$

VERY LOW

(downgraded

twice for high

risk of bias and

once for impre-

cision)

\begin{tabular}{|c|c|c|c|c|c|c|}
\hline $\begin{array}{l}\text { Reactive air surfaces } \\
\text { versus foam surfaces } \\
\text { (Shi } 2021 \mathrm{e} \text {; one } \mathrm{RCT} \\
\text { with } 72 \text { participants) }\end{array}$ & $\begin{array}{l}\text { Acute care } \\
\text { setting }\end{array}$ & $\begin{array}{l}\text { One study reported this } \\
\text { outcome as the number } \\
\text { of participants having } \\
\text { changes in comfort from } \\
\text { baseline and reported } \\
\text { that } 8 \text { participants using } \\
\text { reactive air surfaces had } \\
\text { increased comfort, } 4 \text { had } \\
\text { no change, and } 1 \text { had de- } \\
\text { creased comfort; whilst } 3 \\
\text { participants using foam } \\
\text { surfaces had increased } \\
\text { comfort, } 4 \text { had no change } \\
\text { and } 6 \text { reported decreased } \\
\text { comfort (P value =0.04). }\end{array}$ & No pooling & No pooling & No pooling & $\begin{array}{l}\oplus \ominus \ominus \ominus \\
\text { VERY LOW } \\
\text { (downgraded } \\
\text { twice for risk of } \\
\text { bias and twice } \\
\text { for substantial } \\
\text { imprecision) }\end{array}$ \\
\hline
\end{tabular}

Alternating pressure Acute and Two small studies report-

(active) air surfaces

long-term

ed a statistical signifi-

No pooling

No pooling

No pooling

$\oplus \odot \ominus \ominus$ mared with an-

care setting

cance favouring Nimbus

system whilst two larger

studies reported no signif-

icance.

ir surface (Shi 2021e;

McGinnis 2014; 4 RCTs

with 256 participants)

(do)

\section{VERY LOW}

(downgraded

once for risk of

bias, once for

heterogeneity

and once for

imprecision)

ve air surfaces

'standard hospital sur-

faces' (Shi 2021e; one

RCT with 40 partici-

pants)

$\begin{array}{ll}\text { Acute care } & \text { The study reported this } \\ \text { setting } & \text { outcome defined as self- } \\ & \text { rated participant satisfac } \\ & \text { tion measured using an } 8 \\ & \text { item scale with a totality } \\ & \text { of } 11 \text { points ranging from } \\ & \text { 'total dissatisfaction' to } \\ & \text { 'complete satisfaction'. In } \\ & \text { total, } 18 \text { of } 40 \text { participant }\end{array}$

Nopooling No pooling No pooling

$\oplus \ominus \odot \odot$

\section{VERY LOW}

(downgraded

twice for risk of

bias, and once

for imprecision)
It is uncertain whether there is any difference be ween alternating pressure (active) air surfaces and foam surfaces in patient comfort responses.

\section{We are uncertain whether} there is any difference between reactive air surfaces and foam surfaces in patient comfort respons-

It is uncertain if there is a difference in patient comfort responses between different types of alternating pressure (active) air surfaces (Nimbus vs Pegasus).

It is uncertain if there is a difference in patient comfort responses between these support surfaces. 


\begin{tabular}{|c|c|c|c|c|c|c|c|c|}
\hline 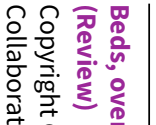 & (Continued) & & $\begin{array}{l}\text { responded on the scale. } \\
\text { No data analysis reported. }\end{array}$ & & & & & \\
\hline 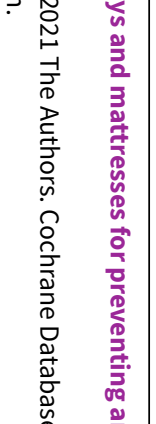 & $\begin{array}{l}\text { Reactive gel surfaces } \\
\text { versus undefined re- } \\
\text { active surfaces (Aiar- } \\
\text { tex; Shi 2021e; one RCT } \\
\text { with } 72 \text { participants) }\end{array}$ & $\begin{array}{l}\text { Long-term } \\
\text { care setting }\end{array}$ & $\begin{array}{l}18 \text { participants using re- } \\
\text { active gel surfaces re- } \\
\text { sponded with 'Poor', } 12 \\
\text { with 'Fair', six with 'Good', } \\
\text { and one with 'Excellent', } \\
\text { whilst } 8 \text { participants us- } \\
\text { ing the undefined reac- } \\
\text { tive surfaces responded } \\
\text { with 'Poor', } 13 \text { with 'Fair', } \\
10 \text { with 'Good', and } 4 \text { with } \\
\text { 'Excellent'. }\end{array}$ & No pooling & No pooling & No pooling & $\begin{array}{l}\oplus \ominus \ominus \ominus \\
\text { VERY LOW } \\
\text { (downgraded } \\
\text { twice for risk of } \\
\text { bias, and once } \\
\text { for imprecision) }\end{array}$ & $\begin{array}{l}\text { It is uncertain if there is a } \\
\text { difference in patient com- } \\
\text { fort responses between } \\
\text { these support surfaces. }\end{array}$ \\
\hline 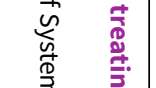 & $\begin{array}{l}\text { - All reported adverse } \\
\text { events }\end{array}$ & & & & & & & \\
\hline 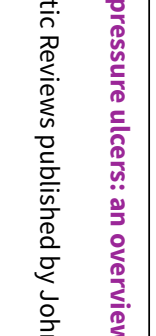 & $\begin{array}{l}\text { Alternating pressure } \\
\text { (active) air surfaces } \\
\text { versus foam surfaces } \\
\text { (Shi 2021e; one RCT } \\
\text { with } 49 \text { participants) }\end{array}$ & $\begin{array}{l}\text { Acute care } \\
\text { setting }\end{array}$ & $\begin{array}{l}\text { One study ( } 49 \text { partici- } \\
\text { pants) reported there } \\
\text { were no major adverse } \\
\text { events that could be at- } \\
\text { tributed to the support } \\
\text { surfaces used. }\end{array}$ & No pooling & No pooling & No pooling & $\begin{array}{l}\oplus \ominus \ominus \ominus \\
\text { VERY LOW } \\
\text { (downgraded } \\
\text { twice for risk of } \\
\text { bias and twice } \\
\text { for substantial } \\
\text { inconsistency). }\end{array}$ & $\begin{array}{l}\text { It is uncertain if there is } \\
\text { a difference in adverse } \\
\text { events between alternat- } \\
\text { ing pressure (active) air } \\
\text { surfaces and foam sur- } \\
\text { faces. }\end{array}$ \\
\hline 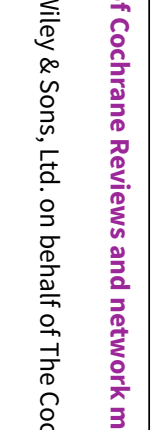 & $\begin{array}{l}\text { Foam surfaces versus } \\
\text { reactive water surfaces } \\
\text { (Shi } 2021 \text {; } \text { one RCT } \\
\text { with } 120 \text { participants) }\end{array}$ & $\begin{array}{l}\text { Long-term } \\
\text { care setting }\end{array}$ & $\begin{array}{l}\text { One study reported this } \\
\text { outcome, defined as the } \\
\text { percentages of partici- } \\
\text { pants with one or more } \\
\text { of the following types of } \\
\text { adverse events: eczema, } \\
\text { maceration, and pain. }\end{array}$ & No pooling & No pooling & No pooling & $\begin{array}{l}\oplus \ominus \ominus \ominus \\
\text { VERY LOW } \\
\text { (downgraded } \\
\text { once for risk of } \\
\text { bias and twice } \\
\text { for impreci- } \\
\text { sion). }\end{array}$ & $\begin{array}{l}\text { It is uncertain if there is } \\
\text { any difference in all re- } \\
\text { ported adverse events be- } \\
\text { tween alternating pres- } \\
\text { sure (active) air surfaces } \\
\text { applied on both operating } \\
\text { tables and hospital beds } \\
\text { and reactive gel surfaces } \\
\text { used on operating tables } \\
\text { followed by foam surfaces } \\
\text { applied on hospital beds. }\end{array}$ \\
\hline 产. & $\begin{array}{l}\text { Reactive air surfaces } \\
\text { versus foam surfaces } \\
\text { (Shi } 2021 \text { e; two studies } \\
\text { with } 156 \text { participants) }\end{array}$ & $\begin{array}{l}\text { Acute care } \\
\text { setting }\end{array}$ & $\begin{array}{l}\text { Two studies (156 partici- } \\
\text { pants) reported this out- } \\
\text { come and both did not } \\
\text { clearly suggest any differ- } \\
\text { ence in adverse events. }\end{array}$ & No pooling & No pooling & No pooling & $\begin{array}{l}\oplus \oplus \ominus \ominus \\
\text { LOW } \\
\text { (downgraded } \\
\text { once for im- }\end{array}$ & $\begin{array}{l}\text { It is unclear if there is } \\
\text { a difference in adverse } \\
\text { events between reactive } \\
\text { air surfaces and foam sur- } \\
\text { faces. }\end{array}$ \\
\hline
\end{tabular}




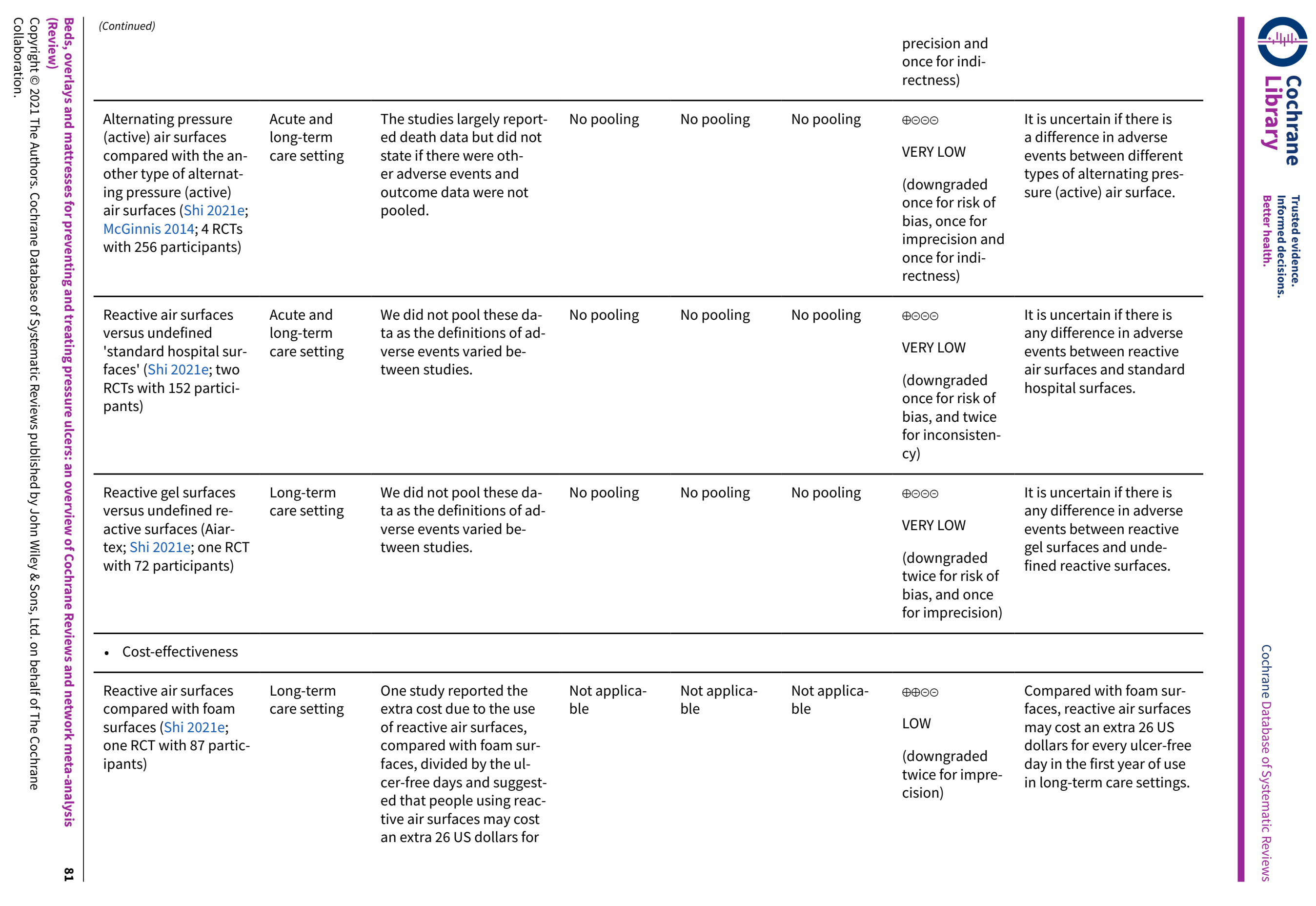




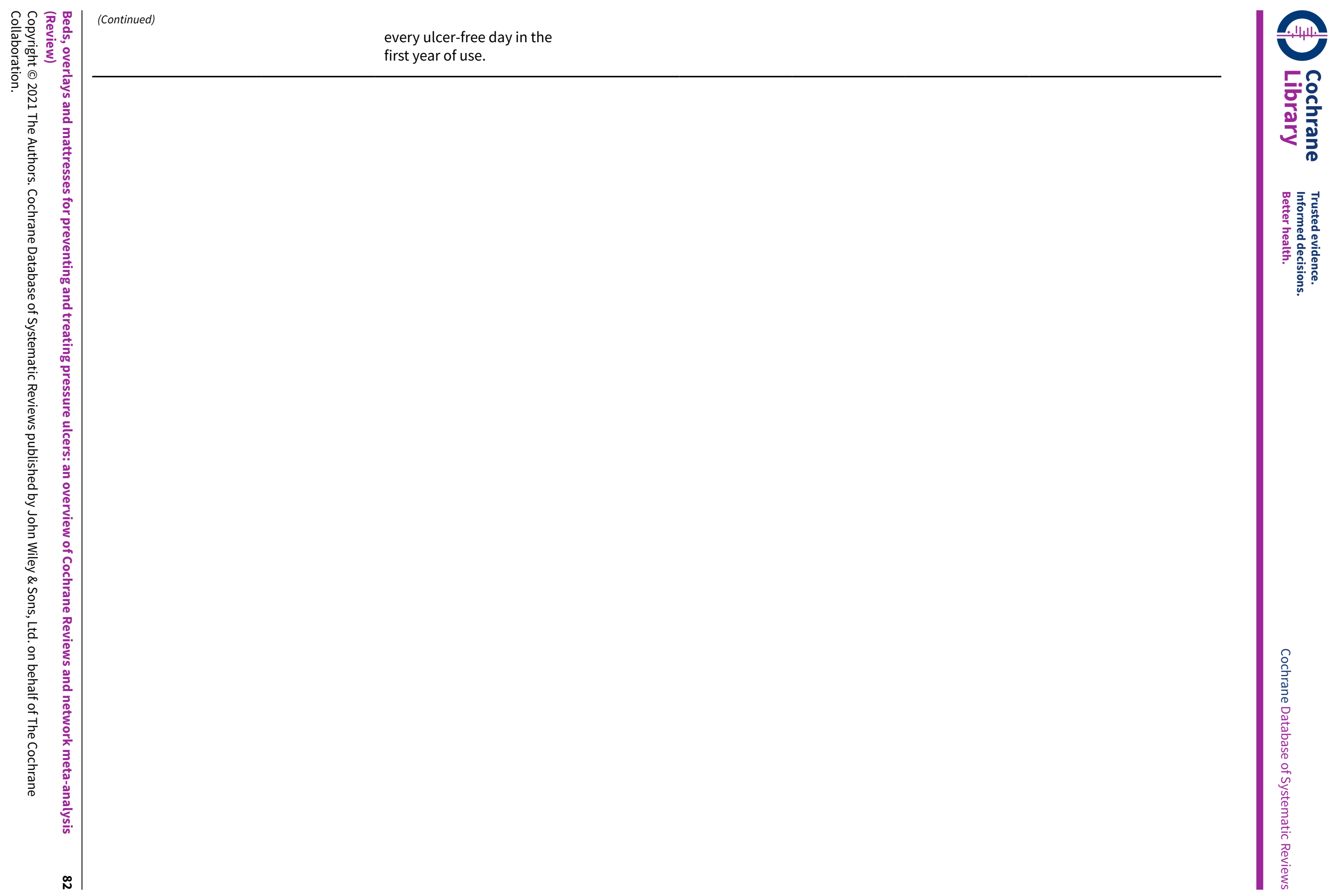


Appendix 7. ROBIS quality of included reviews

\begin{tabular}{llllll}
\hline Included reviews & $\begin{array}{l}\text { Domain 1: Study } \\
\text { eligibility crite- } \\
\text { ria }\end{array}$ & $\begin{array}{l}\text { Domain 2: Identifi- } \\
\text { cation \& search of } \\
\text { studies }\end{array}$ & $\begin{array}{l}\text { Domain 3: Data col- } \\
\text { lection \& study ap- } \\
\text { praisal }\end{array}$ & $\begin{array}{l}\text { Domain 4: Syn- } \\
\text { thesis \& find- } \\
\text { ings }\end{array}$ & $\begin{array}{l}\text { Risk of bias in } \\
\text { the review }\end{array}$ \\
\hline LCGinnis 2014 & Low & Unclear & Unclear & Unclear \\
\hline Shi 2021a & Low & Low & Low & Low & Low \\
\hline Shi 2021b & Low & Low & Low & Low & Low \\
\hline Shi 2021c & Low & Low & Low & Low & Low \\
\hline Shi 2021d & Low & Low & Low & Low & Low \\
\hline Shi 2021e & Low & Low & & Low
\end{tabular}

\section{Appendix 8. Prevention network: characteristics and data in the included studies and additional results of the prevention network analysis}

\section{Characteristics and data in the 69 potentially eligible studies}

In the table below, we report the characteristics and data of the 69 RCTs identified in the topic of pressure ulcer prevention. We note that not all studies connected to a network and studies with asterisks contributed data to network meta-analyses.

Table 1. Characteristics and data in the 69 potentially eligible studies 


\begin{tabular}{|c|c|c|c|c|c|c|c|c|c|c|c|c|c|c|}
\hline 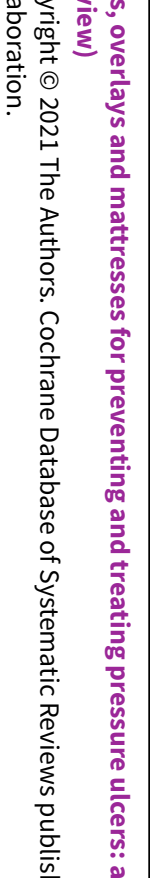 & $\begin{array}{l}\text { Study } \\
\text { ID }\end{array}$ & $\begin{array}{l}\text { Study } \\
\text { design }\end{array}$ & $\begin{array}{l}\text { Num- } \\
\text { ber of } \\
\text { arms }\end{array}$ & $\begin{array}{l}\text { Fol- } \\
\text { low-up } \\
\text { dura- } \\
\text { tion }\end{array}$ & $\begin{array}{l}\text { Coun- } \\
\text { try }\end{array}$ & $\begin{array}{l}\text { Fund- } \\
\text { ing } \\
\text { source }\end{array}$ & $\begin{array}{l}\text { Care } \\
\text { set- } \\
\text { ting }\end{array}$ & $\begin{array}{l}\text { Sam- } \\
\text { ple } \\
\text { size } \\
\text { (male/ } \\
\text { fe- } \\
\text { male) }\end{array}$ & $\begin{array}{l}\text { Aver- } \\
\text { age } \\
\text { age } \\
\text { (years) }\end{array}$ & $\begin{array}{l}\text { Baseline } \\
\text { skin sta- } \\
\text { tus }\end{array}$ & $\begin{array}{l}\text { Study arm } 1 \\
\text { (event/ total/ } \\
\text { missing data) }\end{array}$ & $\begin{array}{l}\text { Study arm } 2 \\
\text { (event/ total/ } \\
\text { missing data) }\end{array}$ & $\begin{array}{l}\text { Effect } \\
\text { esti- } \\
\text { mates } \\
\text { used } \\
\text { for the } \\
\text { time- } \\
\text { to- } \\
\text { event } \\
\text { net- } \\
\text { work } \\
\text { meta- } \\
\text { analy- } \\
\text { sis (ex- } \\
\text { pressed } \\
\text { as nat- } \\
\text { ural } \\
\text { loga- } \\
\text { rithm } \\
\text { of haz- } \\
\text { ard ra- } \\
\text { tio, } \\
\text { that is, } \\
\text { Inhr) }\end{array}$ & $\begin{array}{l}\text { Stan- } \\
\text { dard } \\
\text { errors } \\
\text { used } \\
\text { for the } \\
\text { time- } \\
\text { to- } \\
\text { event } \\
\text { net- } \\
\text { work } \\
\text { meta- } \\
\text { analy- } \\
\text { sis (ex- } \\
\text { pressed } \\
\text { as } \\
\text { selnhr) }\end{array}$ \\
\hline 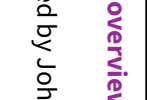 & $\begin{array}{l}\text { Allman } \\
1987^{*}\end{array}$ & $\mathrm{RCT}$ & 2 & $\begin{array}{l}13 \\
\text { days }\end{array}$ & USA & $\begin{array}{l}\text { Indus- } \\
\text { tries }\end{array}$ & $\begin{array}{l}\text { Hospi- } \\
\text { tal }\end{array}$ & $\begin{array}{l}72 \\
(27 / 38)\end{array}$ & 66.6 & $\begin{array}{l}\text { Severe ul- } \\
\text { cers }\end{array}$ & $\begin{array}{l}\text { Foam surfaces } \\
(15 / 34 / 2)\end{array}$ & $\begin{array}{l}\text { Reactive air sur- } \\
\text { faces }(9 / 31 / 5)\end{array}$ & & \\
\hline 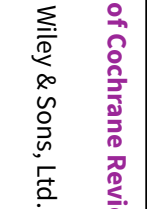 & $\begin{array}{l}\text { Ander- } \\
\text { sen } \\
1982 \text { * }\end{array}$ & $\mathrm{RCT}$ & 3 & $\begin{array}{l}10 \\
\text { days }\end{array}$ & $\begin{array}{l}\text { Den- } \\
\text { mark }\end{array}$ & ND & $\begin{array}{l}\text { Hospi- } \\
\text { tal }\end{array}$ & $\begin{array}{l}482 \\
(206 / 276)\end{array}$ & ND & $\begin{array}{l}\text { At risk; } \\
\text { free of ul- } \\
\text { cers }\end{array}$ & $\begin{array}{l}\text { Alternating pres- } \\
\text { sure (active) air } \\
\text { surfaces }(7 / 166 / 0)\end{array}$ & $\begin{array}{l}\text { Standard hos- } \\
\text { pital surfaces } \\
(21 / 161 / 0) ; \text { Reac- } \\
\text { tive water surfaces } \\
(7 / 155 / 0)\end{array}$ & & \\
\hline 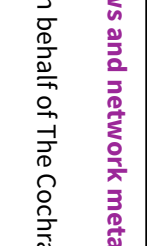 & $\begin{array}{l}\text { Aronovitc } \\
\text { 1999* }\end{array}$ & RCT & 2 & 7 days & USA & $\begin{array}{l}\text { Indus- } \\
\text { tries }\end{array}$ & $\begin{array}{l}\text { Hospi- } \\
\text { tal (op- } \\
\text { eration } \\
\text { theatre } \\
\text { and } \\
\text { wards) }\end{array}$ & $\begin{array}{l}217 \\
(156 / 58)\end{array}$ & 64.08 & $\begin{array}{l}\text { At risk; } \\
\text { free of ul- } \\
\text { cers }\end{array}$ & $\begin{array}{l}\text { Alternating pres- } \\
\text { sure (active) air } \\
\text { surfaces (1/112/ } \\
\text { ND) }\end{array}$ & $\begin{array}{l}\text { Reactive gel sur- } \\
\text { faces \& Foam sur- } \\
\text { faces ( } 7 / 105 / N D)\end{array}$ & & \\
\hline 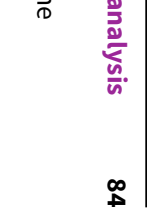 & $\begin{array}{l}\text { Ballard } \\
1997\end{array}$ & $\begin{array}{l}\text { Cross- } \\
\text { over }\end{array}$ & 2 & 3 days & UK & $\begin{array}{l}\text { Indus- } \\
\text { tries }\end{array}$ & $\begin{array}{l}\text { Com- } \\
\text { munity } \\
\text { \& long- }\end{array}$ & $\begin{array}{l}10 \\
(5 / 5)\end{array}$ & 84 & No risk & $\begin{array}{l}\text { Alternating pres- } \\
\text { sure (active) air } \\
\text { surfaces (ND) }\end{array}$ & $\begin{array}{l}\text { Alternating pres- } \\
\text { sure (active) air } \\
\text { surfaces (ND) }\end{array}$ & & \\
\hline
\end{tabular}




\begin{tabular}{|c|c|c|c|c|c|c|c|c|c|c|c|c|c|c|}
\hline 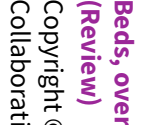 & (Continued) & & & & & & $\begin{array}{l}\text { term } \\
\text { care }\end{array}$ & & & & & & & \\
\hline 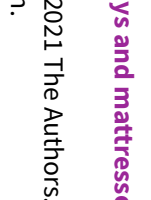 & $\begin{array}{l}\text { Beeck- } \\
\operatorname{man} \\
2019 \text { * }\end{array}$ & $\mathrm{RCT}$ & 2 & $\begin{array}{l}14 \\
\text { days }\end{array}$ & $\begin{array}{l}\text { Bel- } \\
\text { gium }\end{array}$ & $\begin{array}{l}\text { Indus- } \\
\text { tries }\end{array}$ & $\begin{array}{l}\text { Com- } \\
\text { munity } \\
\text { \& long- } \\
\text { term } \\
\text { care }\end{array}$ & $\begin{array}{l}308 \\
(71 / 237)\end{array}$ & 87 & $\begin{array}{l}\text { At risk; } \\
\text { free of ul- } \\
\text { cers }\end{array}$ & $\begin{array}{l}\text { Alternating pres- } \\
\text { sure (active) air } \\
\text { surfaces }(18 / 154)\end{array}$ & $\begin{array}{l}\text { Reactive air sur- } \\
\text { faces }(8 / 154)\end{array}$ & 0.81 & 0.39 \\
\hline 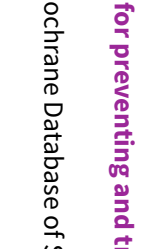 & $\begin{array}{l}\text { Ben- } \\
\text { nett } \\
1998 \text { * }\end{array}$ & $\mathrm{RCT}$ & 2 & $\begin{array}{l}60 \\
\text { days }\end{array}$ & USA & $\begin{array}{l}\text { Indus- } \\
\text { tries \& } \\
\text { Public }\end{array}$ & $\begin{array}{l}\text { Hospi- } \\
\text { tal \& } \\
\text { com- } \\
\text { muni- } \\
\text { ty mix- } \\
\text { ture }\end{array}$ & $\begin{array}{l}116 \\
(45 / 71)\end{array}$ & $\geq 80$ & $\begin{array}{l}\text { Mixed skin } \\
\text { status }\end{array}$ & $\begin{array}{l}\text { Reactive air sur- } \\
\text { faces }(8 / 42 / 16)\end{array}$ & $\begin{array}{l}\text { Standard hospital } \\
\text { surfaces }(4 / 56 / 2)\end{array}$ & & \\
\hline 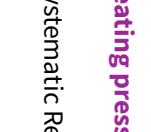 & $\begin{array}{l}\text { Berthe } \\
2007^{*}\end{array}$ & $\mathrm{RCT}$ & 2 & $\begin{array}{l}7 \\
\text { months }\end{array}$ & $\begin{array}{l}\text { Bel- } \\
\text { gium }\end{array}$ & None & $\begin{array}{l}\text { Hospi- } \\
\text { tal }\end{array}$ & 1729 & ND & $\begin{array}{l}\text { At risk; } \\
\text { free of ul- } \\
\text { cers }\end{array}$ & $\begin{array}{l}\text { Foam surfaces } \\
(21 / 657)\end{array}$ & $\begin{array}{l}\text { Standard hospital } \\
\text { surfaces (21/1072) }\end{array}$ & -1.05 & 0.32 \\
\hline 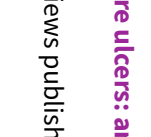 & $\begin{array}{l}\text { Bliss } \\
1967\end{array}$ & $\mathrm{RCT}$ & 2 & $\begin{array}{l}16 \\
\text { days }\end{array}$ & UK & Public & $\begin{array}{l}\text { Hospi- } \\
\text { tal }\end{array}$ & $\begin{array}{l}83 \\
(27 / 56)\end{array}$ & 81.2 & $\begin{array}{l}\text { Mixed skin } \\
\text { status }\end{array}$ & $\begin{array}{l}\text { Alternating pres- } \\
\text { sure (active) air } \\
\text { surfaces (ND) }\end{array}$ & $\begin{array}{l}\text { Standard hospital } \\
\text { surfaces (ND) }\end{array}$ & & \\
\hline 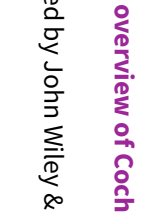 & $\begin{array}{l}\text { Bliss } \\
1995\end{array}$ & $\begin{array}{l}\text { Mul- } \\
\text { ti-arm } \\
\text { mul- } \\
\text { ti-stage }\end{array}$ & 8 & $\begin{array}{l}17.7 \\
\text { days }\end{array}$ & UK & $\begin{array}{l}\text { Indus- } \\
\text { tries }\end{array}$ & $\begin{array}{l}\text { Hospi- } \\
\text { tal }\end{array}$ & 457 & ND & $\begin{array}{l}\text { Mixed skin } \\
\text { status }\end{array}$ & $\begin{array}{l}\text { Alternating pres- } \\
\text { sure (active) air } \\
\text { surfaces (ND) }\end{array}$ & $\begin{array}{l}\text { Reactive fibre sur- } \\
\text { faces (ND); Reac- } \\
\text { tive water surfaces } \\
\text { (ND); Foam sur- } \\
\text { faces (ND) }\end{array}$ & & \\
\hline 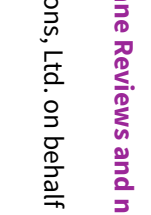 & $\begin{array}{l}\text { Bueno } \\
\text { de Ca- } \\
\text { margo } \\
2018 \\
\text { (NCT028 }\end{array}$ & 4166) & 2 & $\begin{array}{l}11.5 \\
\text { days }\end{array}$ & Brazil & $\begin{array}{l}\text { Indus- } \\
\text { tries }\end{array}$ & ICU & $\begin{array}{l}62 \\
(33 / 29)\end{array}$ & 67.9 & $\begin{array}{l}\text { At risk; } \\
\text { free of ul- } \\
\text { cers }\end{array}$ & $\begin{array}{l}\text { Foam surfaces } \\
(25 / 31)\end{array}$ & $\begin{array}{l}\text { Foam surfaces } \\
(10 / 31)\end{array}$ & & \\
\hline 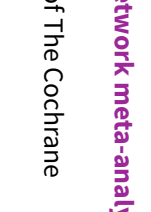 & $\begin{array}{l}\text { Cassi- } \\
\text { no } \\
2013^{*}\end{array}$ & $\mathrm{RCT}$ & 2 & $\begin{array}{l}12 \\
\text { weeks }\end{array}$ & Italy & $\begin{array}{l}\text { Indus- } \\
\text { tries }\end{array}$ & $\begin{array}{l}\text { Com- } \\
\text { munity } \\
\text { \& long- } \\
\text { term } \\
\text { care }\end{array}$ & $\begin{array}{l}72 \\
(17 / 55)\end{array}$ & 85.4 & $\begin{array}{l}\text { Severe ul- } \\
\text { cers }\end{array}$ & $\begin{array}{l}\text { Reactive gel sur- } \\
\text { faces }(1 / 37)\end{array}$ & $\begin{array}{l}\text { Aiartex surfaces } \\
(0 / 35)\end{array}$ & & \\
\hline
\end{tabular}




\begin{tabular}{|c|c|c|c|c|c|c|c|c|c|c|c|c|c|c|}
\hline 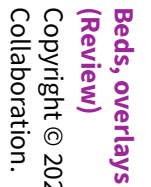 & $\begin{array}{l}\text { (Continued) } \\
\text { Cavic- } \\
\text { chioli } \\
2007^{\star}\end{array}$ & $\mathrm{RCT}$ & 2 & $\begin{array}{l}2 \\
\text { weeks }\end{array}$ & Italy & ND & $\begin{array}{l}\text { Hospi- } \\
\text { tal }\end{array}$ & $\begin{array}{l}170 \\
(40 / 100)\end{array}$ & 77.5 & $\begin{array}{l}\text { Mixed skin } \\
\text { status }\end{array}$ & $\begin{array}{l}\text { Alternating pres- } \\
\text { sure (active) air } \\
\text { surfaces }(2 / 69 / 17)\end{array}$ & $\begin{array}{l}\text { Reactive air sur- } \\
\text { faces }(1 / 71 / 13)\end{array}$ & & \\
\hline 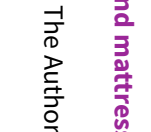 & $\begin{array}{l}\text { Cobb } \\
1997\end{array}$ & $\mathrm{RCT}$ & 2 & $\begin{array}{l}40 \\
\text { days }\end{array}$ & USA & ND & $\begin{array}{l}\text { Hospi- } \\
\text { tal }\end{array}$ & $\begin{array}{l}123 \\
(53 / 70)\end{array}$ & 58 & $\begin{array}{l}\text { At risk; } \\
\text { free of ul- } \\
\text { cers }\end{array}$ & $\begin{array}{l}\text { Reactive air sur- } \\
\text { faces }(12 / 61)\end{array}$ & $\begin{array}{l}\text { Reactive air sur- } \\
\text { faces }(8 / 62)\end{array}$ & & \\
\hline 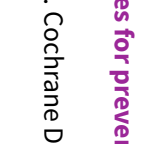 & $\begin{array}{l}\text { Collier } \\
1996\end{array}$ & $\mathrm{RCT}$ & 8 & ND & UK & ND & $\begin{array}{l}\text { Hospi- } \\
\text { tal }\end{array}$ & $\begin{array}{l}90 \\
(40 / 59)\end{array}$ & ND & $\begin{array}{l}\text { At risk; } \\
\text { free of ul- } \\
\text { cers }\end{array}$ & Foam surfaces (ND) & Foam surfaces (ND) & & \\
\hline 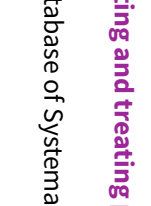 & $\begin{array}{l}\text { Conine } \\
1990^{*}\end{array}$ & $\mathrm{RCT}$ & 2 & $\begin{array}{l}3 \\
\text { months }\end{array}$ & $\begin{array}{l}\text { Cana- } \\
\text { da }\end{array}$ & Charity & $\begin{array}{l}\text { Com- } \\
\text { munity } \\
\text { \& long- } \\
\text { term } \\
\text { care }\end{array}$ & $\begin{array}{l}187 \\
(60 / 88)\end{array}$ & 37.16 & $\begin{array}{l}\text { At risk; } \\
\text { free of ul- } \\
\text { cers }\end{array}$ & $\begin{array}{l}\text { Alternating pres- } \\
\text { sure (active) air } \\
\text { surfaces }(39 / 72 / 21)\end{array}$ & $\begin{array}{l}\text { Reactive fibre sur- } \\
\text { faces }(45 / 76 / 18)\end{array}$ & & \\
\hline 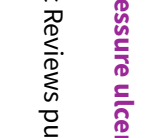 & $\begin{array}{l}\text { Cooper } \\
1998\end{array}$ & $\mathrm{RCT}$ & 2 & 7 days & UK & $\begin{array}{l}\text { Indus- } \\
\text { tries }\end{array}$ & $\begin{array}{l}\text { Hospi- } \\
\text { tal }\end{array}$ & $\begin{array}{l}100 \\
(16 / 84)\end{array}$ & 83 & $\begin{array}{l}\text { At risk; } \\
\text { free of ul- } \\
\text { cers }\end{array}$ & $\begin{array}{l}\text { Reactive air sur- } \\
\text { faces }(3 / 41 / 10)\end{array}$ & $\begin{array}{l}\text { Reactive air sur- } \\
\text { faces }(5 / 43 / 6)\end{array}$ & & \\
\hline 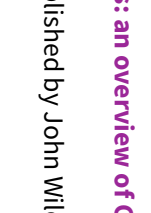 & $\begin{array}{l}\text { Daech- } \\
\text { sel } \\
1985^{*}\end{array}$ & $\mathrm{RCT}$ & 2 & $\begin{array}{l}3 \\
\text { months }\end{array}$ & $\begin{array}{l}\text { Cana- } \\
\text { da }\end{array}$ & $\begin{array}{l}\text { Indus- } \\
\text { tries }\end{array}$ & $\begin{array}{l}\text { Com- } \\
\text { munity } \\
\text { \& long- } \\
\text { term } \\
\text { care }\end{array}$ & $\begin{array}{l}32 \\
(16 / 16)\end{array}$ & 40.55 & $\begin{array}{l}\text { At risk; } \\
\text { free of ul- } \\
\text { cers }\end{array}$ & $\begin{array}{l}\text { Alternating pres- } \\
\text { sure (active) air } \\
\text { surfaces (4/16) }\end{array}$ & $\begin{array}{l}\text { Reactive fibre sur- } \\
\text { faces }(4 / 16)\end{array}$ & & \\
\hline 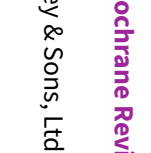 & $\begin{array}{l}\text { De- } \\
\text { marre } \\
2012\end{array}$ & $\mathrm{RCT}$ & 2 & $\begin{array}{l}14 \\
\text { days }\end{array}$ & $\begin{array}{l}\text { Bel- } \\
\text { gium }\end{array}$ & Public & $\begin{array}{l}\text { Hospi- } \\
\text { tal }\end{array}$ & $\begin{array}{l}610 \\
(241 / 369)\end{array}$ & 76.3 & $\begin{array}{l}\text { At risk; } \\
\text { free of ul- } \\
\text { cers }\end{array}$ & $\begin{array}{l}\text { Alternating pres- } \\
\text { sure (active) air } \\
\text { surfaces }(17 / 298 / 0)\end{array}$ & $\begin{array}{l}\text { Alternating pres- } \\
\text { sure (active) air } \\
\text { surfaces }(18 / 312 / 0)\end{array}$ & & \\
\hline 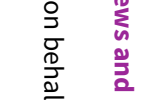 & $\begin{array}{l}\text { Ewing } \\
1964\end{array}$ & $\mathrm{RCT}$ & 2 & $\begin{array}{l}6 \\
\text { months }\end{array}$ & $\begin{array}{l}\text { Aus- } \\
\text { tralia }\end{array}$ & ND & $\begin{array}{l}\text { Hospi- } \\
\text { tal }\end{array}$ & 36 & 72.5 & ND & $\begin{array}{l}\text { Reactive sheepskin } \\
\text { surfaces (ND) }\end{array}$ & $\begin{array}{l}\text { Standard hospital } \\
\text { surfaces (ND) }\end{array}$ & & \\
\hline 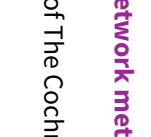 & $\begin{array}{l}\text { Feuchtinge } \\
2006^{*}\end{array}$ & $\mathrm{ERCT}$ & 2 & 5 days & $\begin{array}{l}\text { Ger- } \\
\text { many }\end{array}$ & ND & $\begin{array}{l}\text { Oper- } \\
\text { ating } \\
\text { room }\end{array}$ & $\begin{array}{l}175 \\
(125 / 50)\end{array}$ & 67.79 & $\begin{array}{l}\text { At risk; } \\
\text { free of ul- } \\
\text { cers }\end{array}$ & $\begin{array}{l}\text { Foam surfaces } \\
(15 / 85)\end{array}$ & $\begin{array}{l}\text { Standard hospital } \\
\text { surfaces }(10 / 90)\end{array}$ & 0.48 & 0.66 \\
\hline 离. & $\begin{array}{l}\text { Finnegan } \\
2008^{*}\end{array}$ & $\mathrm{RCT}$ & 2 & 8 days & USA & $\begin{array}{l}\text { Indus- } \\
\text { tries }\end{array}$ & $\begin{array}{l}\text { Hospi- } \\
\text { tal }\end{array}$ & $\begin{array}{l}40 \\
(21 / 12)\end{array}$ & 56 & $\begin{array}{l}\text { Severe ul- } \\
\text { cers }\end{array}$ & $\begin{array}{l}\text { Alternating pres- } \\
\text { sure (active) air } \\
\text { surfaces }(0 / 15 / 4)\end{array}$ & $\begin{array}{l}\text { Reactive air sur- } \\
\text { faces }(0 / 18 / 3)\end{array}$ & & \\
\hline
\end{tabular}




\begin{tabular}{|c|c|c|c|c|c|c|c|c|c|c|c|c|}
\hline 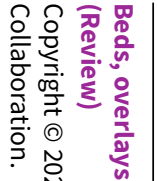 & $\begin{array}{l}\text { (Continued) } \\
\text { Gray } \\
1994\end{array}$ & $\mathrm{RCT}$ & 2 & $\begin{array}{l}10 \\
\text { days }\end{array}$ & UK & $\begin{array}{l}\text { Indus- } \\
\text { tries }\end{array}$ & $\begin{array}{l}\text { Hospi- } \\
\text { tal }\end{array}$ & $\begin{array}{l}170 \\
(66 / 104)\end{array}$ & 76 & $\begin{array}{l}\text { At risk; } \\
\text { free of ul- } \\
\text { cers }\end{array}$ & Foam surfaces (ND) & Foam surfaces (ND) \\
\hline 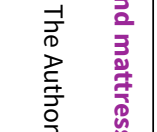 & $\begin{array}{l}\text { Gray } \\
2000\end{array}$ & $\mathrm{RCT}$ & 2 & $\begin{array}{l}10 \\
\text { days }\end{array}$ & UK & $\begin{array}{l}\text { Indus- } \\
\text { tries }\end{array}$ & $\begin{array}{l}\text { Hospi- } \\
\text { tal }\end{array}$ & $\begin{array}{l}100 \\
(61 / 39)\end{array}$ & 65 & $\begin{array}{l}\text { At risk; } \\
\text { free of ul- } \\
\text { cers }\end{array}$ & $\begin{array}{l}\text { Foam surfaces } \\
(1 / 50)\end{array}$ & $\begin{array}{l}\text { Foam surfaces } \\
(1 / 50)\end{array}$ \\
\hline 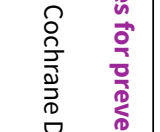 & $\begin{array}{l}\text { Gray } \\
2008\end{array}$ & $\mathrm{RCT}$ & 2 & $\begin{array}{l}6 \\
\text { months }\end{array}$ & UK & ND & $\begin{array}{l}\text { Hospi- } \\
\text { tal }\end{array}$ & 100 & 83.2 & $\begin{array}{l}\text { At risk; } \\
\text { free of ul- } \\
\text { cers }\end{array}$ & $\begin{array}{l}\text { Alternating pres- } \\
\text { sure (active) air } \\
\text { surfaces }(4 / 50 / 0)\end{array}$ & $\begin{array}{l}\text { Alternating pres- } \\
\text { sure (active) air } \\
\text { surfaces }(4 / 50 / 0)\end{array}$ \\
\hline 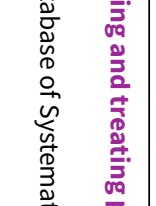 & $\begin{array}{l}\text { Grind- } \\
\text { ley } \\
1996\end{array}$ & $\begin{array}{l}\text { Cross- } \\
\text { over }\end{array}$ & 2 & 3 days & UK & $\begin{array}{l}\text { Indus- } \\
\text { tries }\end{array}$ & $\begin{array}{l}\text { Com- } \\
\text { munity } \\
\text { \& long- } \\
\text { term } \\
\text { care }\end{array}$ & $\begin{array}{l}20 \\
(8 / 12)\end{array}$ & 69.05 & $\begin{array}{l}\text { Mixed skin } \\
\text { status }\end{array}$ & $\begin{array}{l}\text { Alternating pres- } \\
\text { sure (active) air } \\
\text { surfaces (ND) }\end{array}$ & $\begin{array}{l}\text { Alternating pres- } \\
\text { sure (active) air } \\
\text { surfaces (ND) }\end{array}$ \\
\hline 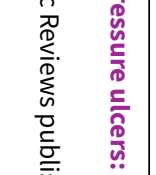 & $\begin{array}{l}\text { Gun- } \\
\text { ning- } \\
\text { berg } \\
2000^{*}\end{array}$ & $\mathrm{RCT}$ & 2 & $\begin{array}{l}14 \\
\text { days }\end{array}$ & $\begin{array}{l}\text { Swe- } \\
\text { den }\end{array}$ & $\begin{array}{l}\text { Indus- } \\
\text { tries }\end{array}$ & $\begin{array}{l}\text { Hospi- } \\
\text { tal }\end{array}$ & $\begin{array}{l}101 \\
(20 / 81)\end{array}$ & 84.5 & $\begin{array}{l}\text { At risk; } \\
\text { free of ul- } \\
\text { cers }\end{array}$ & $\begin{array}{l}\text { Foam surfaces } \\
(12 / 48)\end{array}$ & $\begin{array}{l}\text { Standard hospital } \\
\text { surfaces }(17 / 53)\end{array}$ \\
\hline 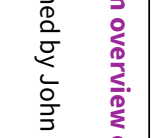 & $\begin{array}{l}\text { Hamp- } \\
\text { ton } \\
1997\end{array}$ & $\mathrm{RCT}$ & 2 & $\begin{array}{l}4 \\
\text { months }\end{array}$ & UK & ND & $\begin{array}{l}\text { Hospi- } \\
\text { tal }\end{array}$ & ND & ND & ND & $\begin{array}{l}\text { Alternating pres- } \\
\text { sure (active) air } \\
\text { surfaces }(0 / 36 / 0)\end{array}$ & $\begin{array}{l}\text { Alternating pres- } \\
\text { sure (active) air } \\
\text { surfaces (0/ND/ND) }\end{array}$ \\
\hline 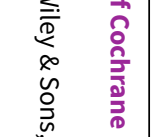 & $\begin{array}{l}\text { Hof- } \\
\text { man } \\
1994 \text { * }\end{array}$ & $\mathrm{RCT}$ & 2 & $\begin{array}{l}2 \\
\text { weeks }\end{array}$ & $\begin{array}{l}\text { Nether- } \\
\text { lands }\end{array}$ & ND & $\begin{array}{l}\text { Hospi- } \\
\text { tal }\end{array}$ & $\begin{array}{l}46 \\
(6 / 38)\end{array}$ & 84.45 & $\begin{array}{l}\text { At risk; } \\
\text { free of ul- } \\
\text { cers }\end{array}$ & $\begin{array}{l}\text { Foam surfaces } \\
(4 / 17 / 6)\end{array}$ & $\begin{array}{l}\text { Standard hospital } \\
\text { surfaces }(13 / 19 / 4)\end{array}$ \\
\hline 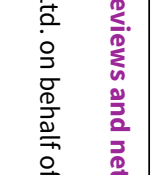 & $\begin{array}{l}\text { Hoshowsk } \\
1994\end{array}$ & $\begin{array}{l}\text { kPCT } \\
\text { (split } \\
\text { body } \\
\text { design) }\end{array}$ & 2 & ND & USA & ND & $\begin{array}{l}\text { Hospi- } \\
\text { tal }\end{array}$ & 505 & 47 & ND & Foam surfaces (ND) & $\begin{array}{l}\text { Reactive gel sur- } \\
\text { faces (ND); Reac- } \\
\text { tive foam and gel } \\
\text { surfaces (ND) }\end{array}$ \\
\hline 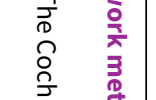 & $\begin{array}{l}\text { Inman } \\
1993^{*}\end{array}$ & $\mathrm{RCT}$ & 2 & $\begin{array}{l}18.8 \\
\text { days }\end{array}$ & $\begin{array}{l}\text { Cana- } \\
\text { da }\end{array}$ & $\begin{array}{l}\text { Indus- } \\
\text { tries }\end{array}$ & ICU & $\begin{array}{l}100 \\
(51 / 47)\end{array}$ & 64.4 & ND & $\begin{array}{l}\text { Reactive air sur- } \\
\text { faces }(3 / 49 / 1)\end{array}$ & $\begin{array}{l}\text { Standard hospital } \\
\text { surfaces }(14 / 49 / 1)\end{array}$ \\
\hline 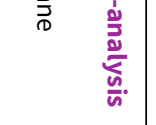 & $\begin{array}{l}\text { IRC- } \\
\text { T2015110 }\end{array}$ & $\begin{array}{l}\text { RCT } \\
619919 N 3\end{array}$ & 2 & ND & Iran & ND & $\begin{array}{l}\text { Oper- } \\
\text { ating } \\
\text { room }\end{array}$ & ND & ND & ND & $\begin{array}{l}\text { Reactive gel sur- } \\
\text { faces (ND) }\end{array}$ & $\begin{array}{l}\text { Standard hospital } \\
\text { surfaces (ND) }\end{array}$ \\
\hline
\end{tabular}




\begin{tabular}{|c|c|c|c|c|c|c|c|c|c|c|c|c|c|c|}
\hline 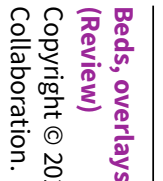 & $\begin{array}{l}\text { (Continued) } \\
\text { Jiang } \\
2014^{\star}\end{array}$ & $\mathrm{RCT}$ & 2 & 5 days & China & Public & $\begin{array}{l}\text { Hospi- } \\
\text { tal }\end{array}$ & $\begin{array}{l}1074 \\
(621 / 453)\end{array}$ & 57.94 & $\begin{array}{l}\text { At risk; } \\
\text { free of ul- } \\
\text { cers }\end{array}$ & $\begin{array}{l}\text { Alternating pres- } \\
\text { sure (active) air } \\
\text { surfaces (5/512) }\end{array}$ & $\begin{array}{l}\text { Reactive air sur- } \\
\text { faces }(6 / 562)\end{array}$ & & \\
\hline 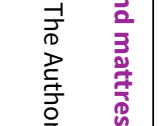 & $\begin{array}{l}\text { Jolley } \\
2004^{*}\end{array}$ & $\mathrm{RCT}$ & 2 & ND & $\begin{array}{l}\text { Aus- } \\
\text { tralia }\end{array}$ & $\begin{array}{l}\text { Indus- } \\
\text { tries \& } \\
\text { Public }\end{array}$ & $\begin{array}{l}\text { Hospi- } \\
\text { tal }\end{array}$ & $\begin{array}{l}539 \\
(223 / 218)\end{array}$ & 62.14 & $\begin{array}{l}\text { At risk; } \\
\text { free of ul- } \\
\text { cers }\end{array}$ & $\begin{array}{l}\text { Reactive sheep- } \\
\text { skin surfaces } \\
(21 / 218 / 52)\end{array}$ & $\begin{array}{l}\text { Standard hos- } \\
\text { pital surfaces } \\
(37 / 223 / 46)\end{array}$ & -0.94 & 0.29 \\
\hline 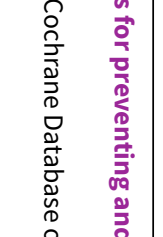 & $\begin{array}{l}\text { Kemp } \\
1993\end{array}$ & $\mathrm{RCT}$ & 2 & $\begin{array}{l}1 \\
\text { month }\end{array}$ & USA & Charity & $\begin{array}{l}\text { Hospi- } \\
\text { tal \& } \\
\text { com- } \\
\text { muni- } \\
\text { ty mix- } \\
\text { ture }\end{array}$ & $\begin{array}{l}84 \\
(26 / 58)\end{array}$ & 81 & $\begin{array}{l}\text { At risk; } \\
\text { free of ul- } \\
\text { cers }\end{array}$ & $\begin{array}{l}\text { Foam surfaces } \\
(21 / 45)\end{array}$ & $\begin{array}{l}\text { Foam surfaces } \\
(12 / 39)\end{array}$ & & \\
\hline 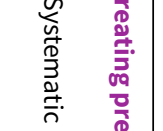 & $\begin{array}{l}\text { Lau- } \\
\text { rent } \\
1998 \text { * }\end{array}$ & $\begin{array}{l}\text { Facto- } \\
\text { rial de- } \\
\text { sign }\end{array}$ & 4 & $\begin{array}{l}15.04 \\
\text { days }\end{array}$ & $\begin{array}{l}\text { Bel- } \\
\text { gium }\end{array}$ & ND & $\begin{array}{l}\text { Hospi- } \\
\text { tal }\end{array}$ & $\begin{array}{l}312 \\
(214 / 98)\end{array}$ & 64 & ND & $\begin{array}{l}\text { Alternating pres- } \\
\text { sure (active) air } \\
\text { surfaces }(20 / 157)\end{array}$ & $\begin{array}{l}\text { Standard hospital } \\
\text { surfaces }(25 / 155)\end{array}$ & & \\
\hline 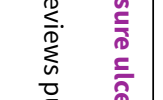 & & & & & & & & & & & $\begin{array}{l}\text { Foam surfaces } \\
(21 / 152)\end{array}$ & $\begin{array}{l}\text { Standard hospital } \\
\text { surfaces }(24 / 160)\end{array}$ & & \\
\hline 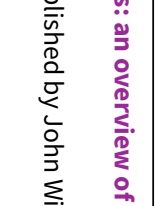 & $\begin{array}{l}\text { Laz- } \\
\text { zara } \\
1991 \text { * }\end{array}$ & $\mathrm{RCT}$ & 2 & $\begin{array}{l}6 \\
\text { months }\end{array}$ & USA & $\begin{array}{l}\text { Indus- } \\
\text { tries }\end{array}$ & $\begin{array}{l}\text { Com- } \\
\text { munity } \\
\text { \& long- } \\
\text { term } \\
\text { care }\end{array}$ & $\begin{array}{l}74 \\
(6 / 21)\end{array}$ & 83.6 & $\begin{array}{l}\text { At risk; } \\
\text { free of ul- } \\
\text { cers }\end{array}$ & $\begin{array}{l}\text { Reactive air sur- } \\
\text { faces }(10 / 33 / 4)\end{array}$ & $\begin{array}{l}\text { Reactive gel sur- } \\
\text { faces }(8 / 33 / 4)\end{array}$ & & \\
\hline 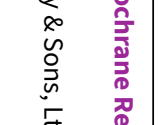 & $\begin{array}{l}\text { Mal- } \\
\text { brain } \\
2010^{*}\end{array}$ & $\mathrm{RCT}$ & 2 & $\begin{array}{l}13.6 \\
\text { days }\end{array}$ & $\begin{array}{l}\text { Bel- } \\
\text { gium }\end{array}$ & ND & ICU & $\begin{array}{l}16 \\
(8 / 8)\end{array}$ & 64.7 & $\begin{array}{l}\text { Mixed skin } \\
\text { status }\end{array}$ & $\begin{array}{l}\text { Alternating pres- } \\
\text { sure (active) air } \\
\text { surfaces }(2 / 8)\end{array}$ & $\begin{array}{l}\text { Reactive air sur- } \\
\text { faces }(2 / 8)\end{array}$ & & \\
\hline 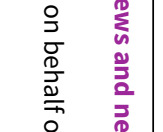 & $\begin{array}{l}\text { Mc- } \\
\text { Gowan } \\
2000^{*}\end{array}$ & $\mathrm{RCT}$ & 2 & ND & $\begin{array}{l}\text { Aus- } \\
\text { tralia }\end{array}$ & $\begin{array}{l}\text { Indus- } \\
\text { tries \& } \\
\text { Public }\end{array}$ & $\begin{array}{l}\text { Hospi- } \\
\text { tal }\end{array}$ & $\begin{array}{l}297 \\
(127 / 170)\end{array}$ & 73.79 & $\begin{array}{l}\text { At risk; } \\
\text { free of ul- } \\
\text { cers }\end{array}$ & $\begin{array}{l}\text { Reactive sheepskin } \\
\text { surfaces (14/155) }\end{array}$ & $\begin{array}{l}\text { Standard hospital } \\
\text { surfaces (43/142) }\end{array}$ & -1.17 & 0.31 \\
\hline 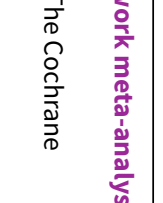 & $\begin{array}{l}\text { Mist- } \\
\text { iaen } \\
2009 \text { * }\end{array}$ & $\mathrm{RCT}$ & 2 & $\begin{array}{l}30 \\
\text { days }\end{array}$ & $\begin{array}{l}\text { Nether- } \\
\text { lands }\end{array}$ & Public & $\begin{array}{l}\text { Com- } \\
\text { munity } \\
\text { \& long- } \\
\text { term } \\
\text { care }\end{array}$ & $\begin{array}{l}588 \\
(183 / 405)\end{array}$ & 78 & $\begin{array}{l}\text { At risk; } \\
\text { free of ul- } \\
\text { cers }\end{array}$ & $\begin{array}{l}\text { Reactive sheep- } \\
\text { skin surfaces } \\
(60 / 271 / 24)\end{array}$ & $\begin{array}{l}\text { Standard hos- } \\
\text { pital surfaces } \\
(73 / 272 / 21)\end{array}$ & -0.27 & 0.36 \\
\hline
\end{tabular}




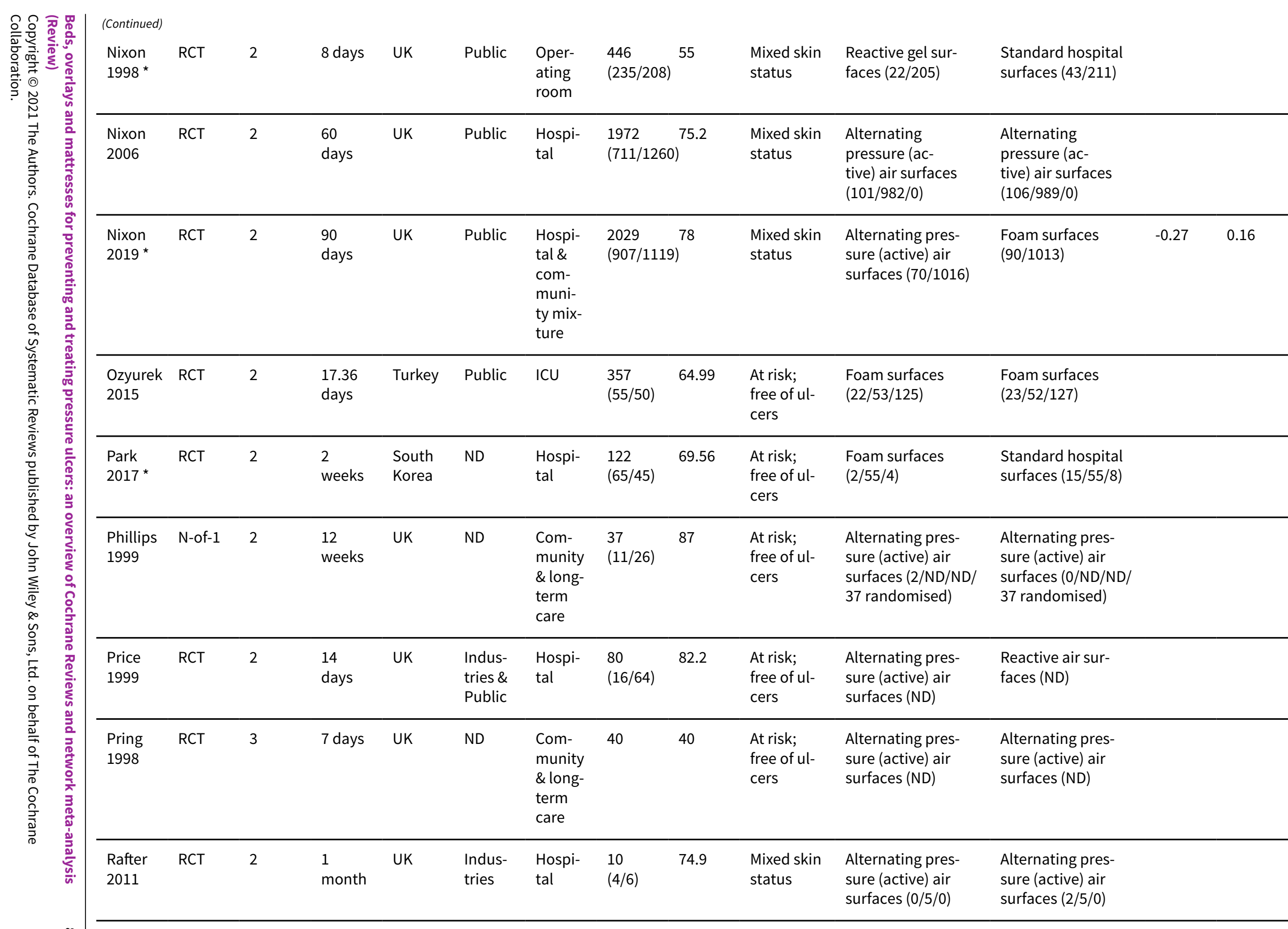




\begin{tabular}{|c|c|c|c|c|c|c|c|c|c|c|c|c|c|c|}
\hline 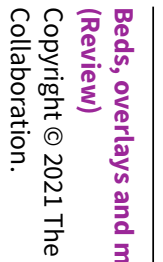 & $\begin{array}{l}\text { (Continued) } \\
\text { Ricci } \\
2013 \text { * }\end{array}$ & $\mathrm{RCT}$ & 2 & $\begin{array}{l}4 \\
\text { weeks }\end{array}$ & Italy & $\begin{array}{l}\text { Indus- } \\
\text { tries }\end{array}$ & $\begin{array}{l}\text { Com- } \\
\text { munity } \\
\text { \& long- } \\
\text { term } \\
\text { care }\end{array}$ & $\begin{array}{l}50 \\
(8 / 42)\end{array}$ & 84.7 & $\begin{array}{l}\text { Mixed skin } \\
\text { status }\end{array}$ & $\begin{array}{l}\text { Reactive gel sur- } \\
\text { faces }(0 / 25)\end{array}$ & $\begin{array}{l}\text { Aiartex surfaces } \\
(0 / 25)\end{array}$ & & \\
\hline 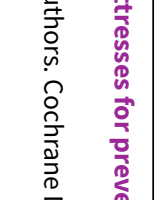 & $\begin{array}{l}\text { Rosen- } \\
\text { thal } \\
2003^{*}\end{array}$ & $\mathrm{RCT}$ & 2 & $\begin{array}{l}6 \\
\text { months }\end{array}$ & USA & ND & $\begin{array}{l}\text { Com- } \\
\text { munity } \\
\text { \& long- } \\
\text { term } \\
\text { care }\end{array}$ & 76 & 68.8 & $\begin{array}{l}\text { Severe ul- } \\
\text { cers }\end{array}$ & $\begin{array}{l}\text { Alternating pres- } \\
\text { sure (active) air } \\
\text { surfaces }(0 / 38)\end{array}$ & $\begin{array}{l}\text { Foam surfaces } \\
(0 / 38)\end{array}$ & & \\
\hline 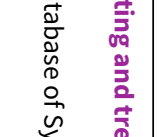 & $\begin{array}{l}\text { Russell } \\
2000^{*}\end{array}$ & $\mathrm{RCT}$ & 2 & 7 days & $\begin{array}{l}\text { Cana- } \\
\text { da }\end{array}$ & $\begin{array}{l}\text { Indus- } \\
\text { tries }\end{array}$ & $\begin{array}{l}\text { Hospi- } \\
\text { tal }\end{array}$ & $\begin{array}{l}198 \\
(150 / 48)\end{array}$ & 65.2 & $\begin{array}{l}\text { At risk; } \\
\text { free of ul- } \\
\text { cers }\end{array}$ & $\begin{array}{l}\text { Alternating pres- } \\
\text { sure (active) air } \\
\text { surfaces (2/98) }\end{array}$ & $\begin{array}{l}\text { Reactive gel sur- } \\
\text { faces \& Foam sur- } \\
\text { faces }(7 / 100)\end{array}$ & & \\
\hline 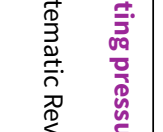 & $\begin{array}{l}\text { Russell } \\
2003^{*}\end{array}$ & $\mathrm{RCT}$ & 2 & $\begin{array}{l}11.5 \\
\text { days }\end{array}$ & UK & $\begin{array}{l}\text { Indus- } \\
\text { tries }\end{array}$ & $\begin{array}{l}\text { Hospi- } \\
\text { tal }\end{array}$ & $\begin{array}{l}1168 \\
(391 / 777)\end{array}$ & 83 & $\begin{array}{l}\text { At risk; } \\
\text { free of ul- } \\
\text { cers }\end{array}$ & $\begin{array}{l}\text { Foam surfaces } \\
(48 / 562 / 2)\end{array}$ & $\begin{array}{l}\text { Standard hospital } \\
\text { surfaces }(66 / 604 / 0)\end{array}$ & -0.16 & 0.22 \\
\hline 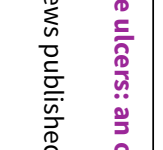 & $\begin{array}{l}\text { Sana- } \\
\text { da } \\
2003^{*}\end{array}$ & $\mathrm{RCT}$ & 3 & ND & Japan & ND & $\begin{array}{l}\text { Hospi- } \\
\text { tal }\end{array}$ & $\begin{array}{l}108 \\
(42 / 40)\end{array}$ & 71.3 & $\begin{array}{l}\text { At risk; } \\
\text { free of ul- } \\
\text { cers }\end{array}$ & $\begin{array}{l}\text { Alternating pres- } \\
\text { sure (active) air } \\
\text { surfaces }(6 / 55 / 18)\end{array}$ & $\begin{array}{l}\text { Standard hospital } \\
\text { surfaces }(10 / 27 / 8)\end{array}$ & & \\
\hline 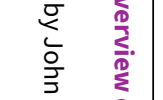 & $\begin{array}{l}\text { Santy } \\
1994\end{array}$ & $\mathrm{RCT}$ & 6 & $\begin{array}{l}12 \\
\text { days }\end{array}$ & UK & Public & $\begin{array}{l}\text { Hospi- } \\
\text { tal }\end{array}$ & 552 & 80.24 & $\begin{array}{l}\text { Mixed skin } \\
\text { status }\end{array}$ & Foam surfaces (ND) & Foam surfaces (ND) & & \\
\hline 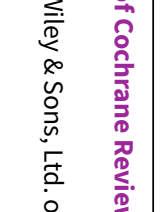 & $\begin{array}{l}\text { Sau- } \\
\text { vage } \\
2017^{*}\end{array}$ & $\mathrm{RCT}$ & 2 & $\begin{array}{l}30 \\
\text { days }\end{array}$ & France & ND & $\begin{array}{l}\text { Com- } \\
\text { munity } \\
\text { \& long- } \\
\text { term } \\
\text { care }\end{array}$ & $\begin{array}{l}76 \\
(22 / 54)\end{array}$ & 85.3 & $\begin{array}{l}\text { At risk; } \\
\text { free of ul- } \\
\text { cers }\end{array}$ & $\begin{array}{l}\text { Alternating pres- } \\
\text { sure (active) air } \\
\text { surfaces (2/39) }\end{array}$ & $\begin{array}{l}\text { Foam surfaces } \\
(13 / 37)\end{array}$ & -1.7 & 0.52 \\
\hline 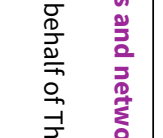 & $\begin{array}{l}\text { Schultz } \\
1999^{*}\end{array}$ & $\mathrm{RCT}$ & 2 & 6 days & USA & $\begin{array}{l}\text { Indus- } \\
\text { tries \& } \\
\text { Public }\end{array}$ & $\begin{array}{l}\text { Oper- } \\
\text { ating } \\
\text { room }\end{array}$ & $\begin{array}{l}413 \\
(266 / 147)\end{array}$ & 65.7 & $\begin{array}{l}\text { At risk; } \\
\text { free of ul- } \\
\text { cers }\end{array}$ & $\begin{array}{l}\text { Foam surfaces } \\
(55 / 206)\end{array}$ & $\begin{array}{l}\text { Standard hospital } \\
\text { surfaces }(34 / 207)\end{array}$ & & \\
\hline 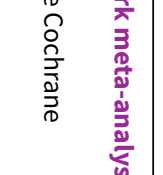 & $\begin{array}{l}\text { Sider- } \\
\text { anko } \\
1992 \text { * }\end{array}$ & $\mathrm{RCT}$ & 3 & $\begin{array}{l}9.5 \\
\text { days }\end{array}$ & USA & ND & ICU & $\begin{array}{l}57 \\
(33 / 24)\end{array}$ & 65.9 & $\begin{array}{l}\text { At risk; } \\
\text { free of ul- } \\
\text { cers }\end{array}$ & $\begin{array}{l}\text { Alternating pres- } \\
\text { sure (active) air } \\
\text { surfaces }(5 / 20)\end{array}$ & $\begin{array}{l}\text { Reactive water sur- } \\
\text { faces }(2 / 17) \text {; Re- } \\
\text { active air surfaces } \\
(1 / 20)\end{array}$ & & \\
\hline
\end{tabular}




\begin{tabular}{|c|c|c|c|c|c|c|c|c|c|c|c|c|c|c|}
\hline 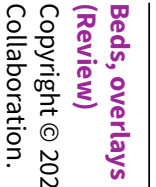 & $\begin{array}{l}\text { (Continued) } \\
\text { Sta- } \\
\text { pleton } \\
1986^{*}\end{array}$ & $\mathrm{RCT}$ & 2 & $\begin{array}{l}3 \\
\text { months }\end{array}$ & UK & Public & $\begin{array}{l}\text { Hospi- } \\
\text { tal }\end{array}$ & $\begin{array}{l}100 \\
(0 / 100)\end{array}$ & 81 & $\begin{array}{l}\text { At risk; } \\
\text { free of ul- } \\
\text { cers }\end{array}$ & $\begin{array}{l}\text { Alternating pres- } \\
\text { sure (active) air } \\
\text { surfaces (11/32) }\end{array}$ & $\begin{array}{l}\text { Reactive fibre sur- } \\
\text { faces }(12 / 34) \text {; Foam } \\
\text { surfaces }(14 / 34)\end{array}$ & & \\
\hline 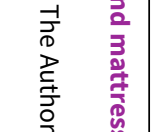 & $\begin{array}{l}\text { Takala } \\
\text { 1996 * }\end{array}$ & $\mathrm{RCT}$ & 2 & $\begin{array}{l}14 \\
\text { days }\end{array}$ & $\begin{array}{l}\text { Fin- } \\
\text { land }\end{array}$ & $\begin{array}{l}\text { Indus- } \\
\text { tries }\end{array}$ & ICU & $\begin{array}{l}40 \\
(25 / 15)\end{array}$ & 61.4 & $\begin{array}{l}\text { At risk; } \\
\text { free of ul- } \\
\text { cers }\end{array}$ & $\begin{array}{l}\text { Foam surfaces } \\
(7 / 19)\end{array}$ & $\begin{array}{l}\text { Reactive air sur- } \\
\text { faces }(0 / 21)\end{array}$ & & \\
\hline 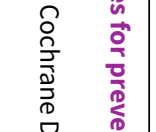 & $\begin{array}{l}\text { Taylor } \\
1999\end{array}$ & $\mathrm{RCT}$ & 2 & $\begin{array}{l}11.1 \\
\text { days }\end{array}$ & UK & ND & $\begin{array}{l}\text { Hospi- } \\
\text { tal }\end{array}$ & $\begin{array}{l}44 \\
(25 / 19)\end{array}$ & 68.4 & $\begin{array}{l}\text { At risk; } \\
\text { free of ul- } \\
\text { cers }\end{array}$ & $\begin{array}{l}\text { Alternating pres- } \\
\text { sure (active) air } \\
\text { surfaces }(0 / 22 / 0)\end{array}$ & $\begin{array}{l}\text { Alternating pres- } \\
\text { sure (active) air } \\
\text { surfaces }(2 / 22 / 0)\end{array}$ & & \\
\hline 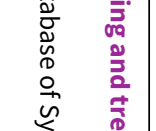 & $\begin{array}{l}\text { Theak- } \\
\text { er } 2005\end{array}$ & $\mathrm{RCT}$ & 2 & $\begin{array}{l}14 \\
\text { days }\end{array}$ & UK & $\begin{array}{l}\text { Indus- } \\
\text { tries }\end{array}$ & ICU & $\begin{array}{l}62 \\
(39 / 23)\end{array}$ & 65 & $\begin{array}{l}\text { At risk; } \\
\text { free of ul- } \\
\text { cers }\end{array}$ & $\begin{array}{l}\text { Alternating pres- } \\
\text { sure (active) air } \\
\text { surfaces (3/30) }\end{array}$ & $\begin{array}{l}\text { Alternating pres- } \\
\text { sure (active) air } \\
\text { surfaces (6/32) }\end{array}$ & & \\
\hline 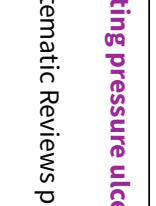 & $\begin{array}{l}\text { Van } \\
\text { Leen } \\
2011^{*}\end{array}$ & $\mathrm{RCT}$ & 2 & $\begin{array}{l}6 \\
\text { months }\end{array}$ & $\begin{array}{l}\text { Nether- } \\
\text { lands }\end{array}$ & None & $\begin{array}{l}\text { Com- } \\
\text { munity } \\
\text { \& long- } \\
\text { term } \\
\text { care }\end{array}$ & $\begin{array}{l}83 \\
(16 / 67)\end{array}$ & 82.1 & $\begin{array}{l}\text { At risk; } \\
\text { free of ul- } \\
\text { cers }\end{array}$ & $\begin{array}{l}\text { Foam surfaces } \\
(7 / 42)\end{array}$ & $\begin{array}{l}\text { Reactive air sur- } \\
\text { faces }(2 / 41)\end{array}$ & & \\
\hline 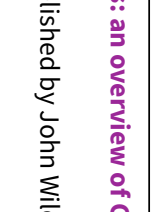 & $\begin{array}{l}\text { Van } \\
\text { Leen } \\
2013^{*}\end{array}$ & $\begin{array}{l}\text { Cross- } \\
\text { over }\end{array}$ & 2 & $\begin{array}{l}6 \\
\text { months }\end{array}$ & $\begin{array}{l}\text { Nether- } \\
\text { lands }\end{array}$ & ND & $\begin{array}{l}\text { Com- } \\
\text { munity } \\
\text { \& long- } \\
\text { term } \\
\text { care }\end{array}$ & $\begin{array}{l}41 \\
(32 / 9)\end{array}$ & 79.9 & $\begin{array}{l}\text { At risk; } \\
\text { free of ul- } \\
\text { cers }\end{array}$ & $\begin{array}{l}\text { Foam surfaces } \\
(3 / 21)\end{array}$ & $\begin{array}{l}\text { Reactive air sur- } \\
\text { faces }(1 / 20)\end{array}$ & & \\
\hline 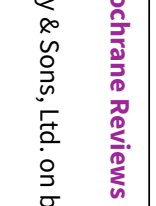 & $\begin{array}{l}\text { Van } \\
\text { Leen } \\
2018^{*}\end{array}$ & $\mathrm{RCT}$ & 2 & $\begin{array}{l}12 \\
\text { weeks }\end{array}$ & $\begin{array}{l}\text { Nether- } \\
\text { lands }\end{array}$ & $\begin{array}{l}\text { Indus- } \\
\text { tries }\end{array}$ & $\begin{array}{l}\text { Com- } \\
\text { munity } \\
\text { \& long- } \\
\text { term } \\
\text { care }\end{array}$ & $\begin{array}{l}206 \\
(60 / 146)\end{array}$ & 82.4 & $\begin{array}{l}\text { At risk; } \\
\text { free of ul- } \\
\text { cers }\end{array}$ & $\begin{array}{l}\text { Foam surfaces } \\
(5 / 103)\end{array}$ & $\begin{array}{l}\text { Bedcare surfaces } \\
(9 / 103)\end{array}$ & & \\
\hline 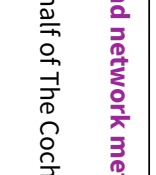 & $\begin{array}{l}\text { Van- } \\
\text { der- } \\
\text { wee } \\
2005^{*}\end{array}$ & $\mathrm{RCT}$ & 2 & $\begin{array}{l}20 \\
\text { weeks }\end{array}$ & $\begin{array}{l}\text { Bel- } \\
\text { gium }\end{array}$ & ND & $\begin{array}{l}\text { Hospi- } \\
\text { tal }\end{array}$ & $\begin{array}{l}447 \\
(163 / 283)\end{array}$ & 82 & $\begin{array}{l}\text { At risk; } \\
\text { free of ul- } \\
\text { cers }\end{array}$ & $\begin{array}{l}\text { Alternating pres- } \\
\text { sure (active) air } \\
\text { surfaces (34/222) }\end{array}$ & $\begin{array}{l}\text { Foam surfaces } \\
\text { plus 4-h turning } \\
(35 / 225)\end{array}$ & 0.11 & 0.24 \\
\hline 峁 & $\begin{array}{l}\text { Ver- } \\
\text { mette } \\
2012 \text { * }\end{array}$ & $\mathrm{RCT}$ & 2 & $\begin{array}{l}14 \\
\text { days }\end{array}$ & $\begin{array}{l}\text { Cana- } \\
\text { da }\end{array}$ & None & $\begin{array}{l}\text { Hospi- } \\
\text { tal }\end{array}$ & $\begin{array}{l}110 \\
(44 / 66)\end{array}$ & 77.8 & $\begin{array}{l}\text { At risk; } \\
\text { free of ul- } \\
\text { cers }\end{array}$ & $\begin{array}{l}\text { Reactive air sur- } \\
\text { faces }(2 / 55)\end{array}$ & $\begin{array}{l}\text { Alternating pres- } \\
\text { sure (active) air } \\
\text { surfaces or RIK } \\
\text { overlay }(6 / 55)\end{array}$ & & \\
\hline
\end{tabular}




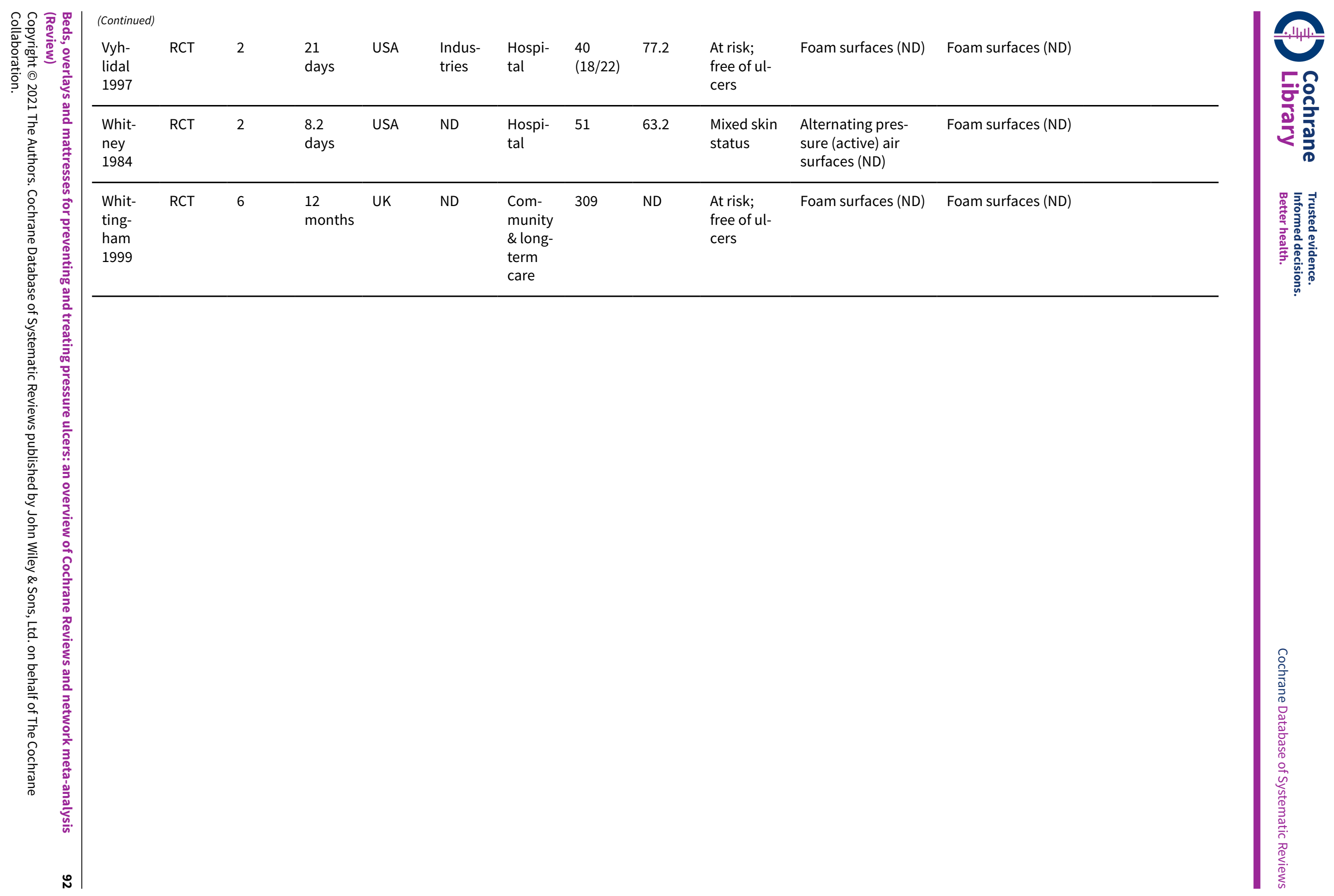


ND = no data available

\section{Summary characteristics of $\mathbf{4 0}$ studies connecting to a network}

Of the above 69 studies, 40 connected to a network. We report the summary characteristics of the 40 studies in the table below. This information reflects the applicability or generalisability of the network evidence.

Table 2. Summary characteristics of $\mathbf{4 0}$ studies connecting to a network

\section{Study characteristics Details of studies}

Types of studies

Two arms ( $\mathrm{n}=35)$ : Allman 1987; Aronovitch 1999; Beeckman 2019; Bennett 1998; Berthe 2007; Cassino 2013; Cavicchioli 2007; Conine 1990; Daechsel 1985; Feuchtinger 2006; Finnegan 2008; Gunningberg 2000; Hofman 1994; Inman 1993; Jiang 2014; Jolley 2004; Lazzara 1991; Malbrain 2010; McGowan 2000; Mistiaen 2009; Nixon 1998; Nixon 2019; Park 2017; Ricci 2013; Rosenthal 2003; Russell 2000; Russell 2003; Sauvage 2017; Schultz 1999; Takala 1996; Van Leen 2011; Van Leen 2013; Van Leen 2018; Vanderwee 2005; Vermette 2012.

Three or more arms ( $n=5)$ : Andersen 1982; Laurent 1998; Sanada 2003; Sideranko 1992; Stapleton 1986.

- three studies contributing three separate arms to network meta-analysis (Andersen 1982; Sideranko 1992; Stapleton 1986);

- Laurent 1998 with 2x2 factorial design contributing two separate comparisons in the analysis;

- two of three arms in Sanada 2003 were combined into one group, thus contributing one comparison to the analysis.

\begin{tabular}{ll} 
Follow-up duration & Median 14 days (range: 5 days to 7 months) \\
\hline Funding sources & Public funding ( $\mathrm{n}=9$ ): Berthe 2007; Conine 1990; Jiang 2014; Mistiaen 2009; Nixon 1998; Nixon \\
& 2019; Stapleton 1986; van Leen 2011; Vermette 2012); \\
- & Industries ( $\mathrm{n}=18$ ): Allman 1987; Aronovitch 1999; Beeckman 2019; Bennett 1998; Cassino 2013; \\
& Daechsel 1985; Finnegan 2008; Gunningberg 2000; Inman 1993; Jolley 2004; Lazzara 1991; Mc- \\
& Gowan 2000; Ricci 2013; Russell 2000; Russell 2003; Schultz 1999; Takala 1996; van Leen 2018.
\end{tabular}

\begin{tabular}{ll}
\hline Age of participants & Average participant age: median 72.5 years (range 37.2 to 87.0 years) \\
\hline Sex proportions & Male: $4702(45.1 \%)$ in 38 studies \\
& Female: $5730(54.9 \%)$ in 38 studies \\
\hline
\end{tabular}

Skin status at baseline $\quad 38$ studies specified the skin status at baseline

- 34 studies (11,845 participants) with people at risk of having a new ulcer, with risk assessed largely using the Waterlow, Norton or Braden scales

- 28 studies (9018 participants) with people free of pressure ulcers at baseline;

- 6 studies (2827 participants) enrolling people with superficial ulcers.

- four studies (260 participants; Allman 1987; Cassino 2013; Finnegan 2008; Rosenthal 2003) recruited people with severe full-thickness pressure ulcers alone.

Care settings

- Acute care settings (including accident and emergency departments, and hospitals in general) (n $=21$ ),

- Intensive care units $(n=4)$,

- Operating room $(n=3)$, and

- Community and long-term care settings (including hospice, community, nursing homes, longterm facilities) $(\mathrm{n}=12)$ 
Risk of bias assessment for the included studies and network evidence from the base-case analysis

We summarise risk of bias assessments for the included studies in the topic of prevention in Figure 7.

Copyright $\odot 2021$ The Authors. Cochrane Database of Systematic Reviews published by John Wiley \& Sons, Ltd. on behalf of The Cochrane Collaboration. 
Figure 7. Prevention network: risk of bias summary of review authors' judgements about each risk of bias item for each study. Studies with asterisk contributed data for network meta-analyses

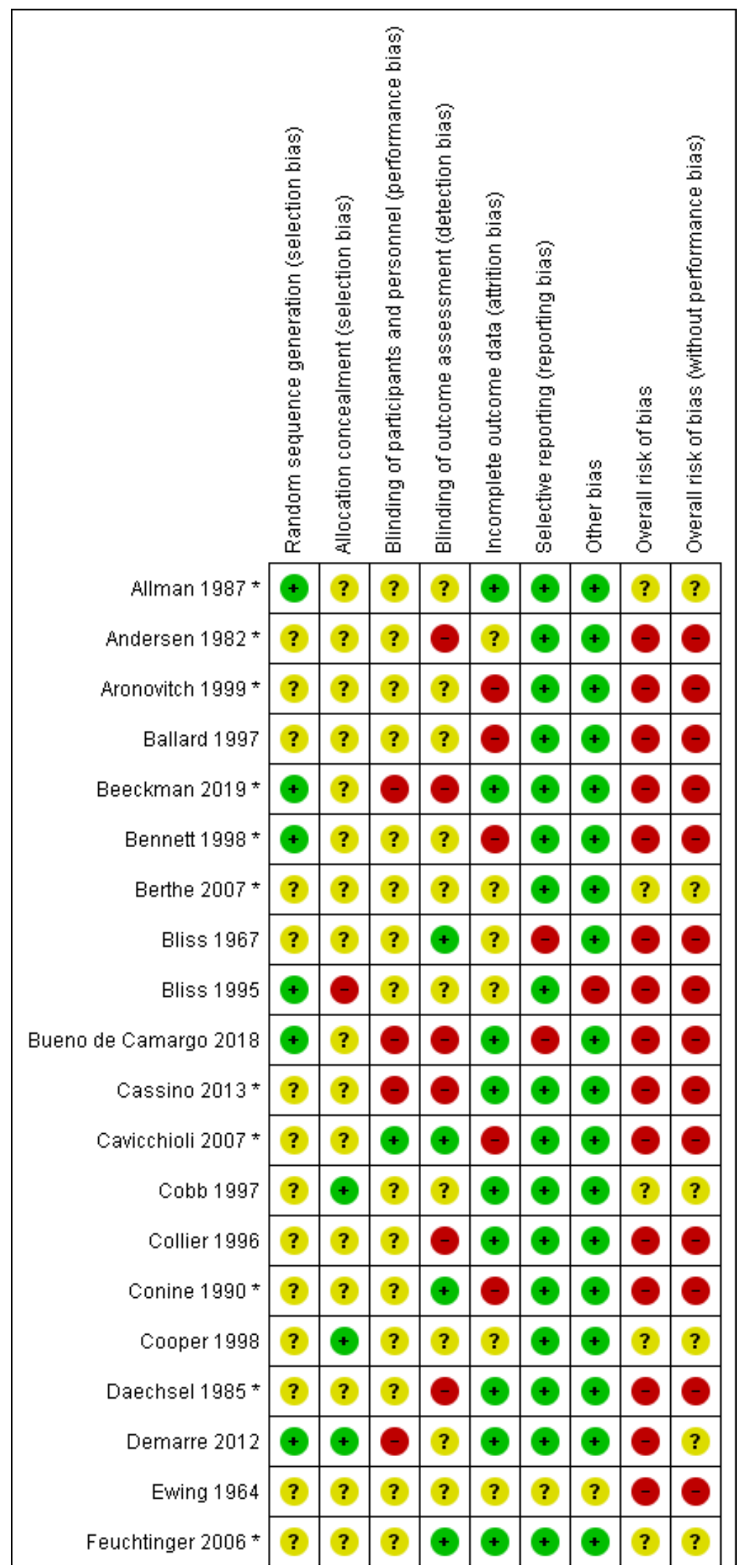

Beds, overlays and mattresses for preventing and treating pressure ulcers: an overview of Cochrane Reviews and network meta-analysis 
Figure 7. (Continued)

\begin{tabular}{|c|c|c|c|c|c|c|c|c|c|}
\hline Feuchtinger 2006 * & $?$ & $?$ & $?$ & + & + & + & $\odot$ & $?$ & $?$ \\
\hline Finnegan $2008 *$ & $\odot$ & $?$ & $?$ & $\odot$ & $?$ & $\odot$ & $\odot$ & $\odot$ & $\Theta$ \\
\hline Gray 1994 & $?$ & $?$ & $?$ & $?$ & $?$ & $\odot$ & $\odot$ & $?$ & $?$ \\
\hline Gray 2000 & $?$ & $?$ & $?$ & + & $?$ & $\odot$ & $\odot$ & $?$ & $?$ \\
\hline Gray 2008 & $?$ & $?$ & $?$ & $?$ & $?$ & $\odot$ & $\odot$ & $?$ & $?$ \\
\hline Grindley 1996 & $\odot$ & $\odot$ & $?$ & $?$ & $?$ & $\odot$ & + & $?$ & ? \\
\hline Gunningberg 2000 * & $?$ & $?$ & $?$ & + & $\odot$ & $\odot$ & $\odot$ & $?$ & $?$ \\
\hline Hampton 1997 & $?$ & $?$ & $?$ & $?$ & $?$ & $?$ & $?$ & $\odot$ & - \\
\hline Hofman 1994 * & $?$ & $?$ & $\odot$ & $\odot$ & $\odot$ & $\odot$ & $?$ & $\odot$ & $\odot$ \\
\hline Hoshowsky 1994 & $?$ & $?$ & - & 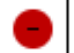 & $?$ & $?$ & $\Theta$ & - & $\Theta$ \\
\hline Inman $1993 *$ & $?$ & $?$ & $?$ & $?$ & $\odot$ & + & + & $?$ & $?$ \\
\hline IRCT2015110619919N3 & $?$ & $?$ & $?$ & $?$ & $?$ & $?$ & $?$ & $\odot$ & $\odot$ \\
\hline Jiang 2014 * & $\odot$ & $?$ & $?$ & $?$ & $\odot$ & $\odot$ & $\odot$ & $?$ & $?$ \\
\hline Jolley $2004 *$ & $\odot$ & $\odot$ & $\odot$ & - & $\odot$ & $\odot$ & $\odot$ & $\odot$ & $\odot$ \\
\hline Kemp 1993 & $\odot$ & $?$ & $?$ & $?$ & + & $\odot$ & $\odot$ & $?$ & $?$ \\
\hline Laurent 1998 * & $?$ & $?$ & $\odot$ & $\odot$ & + & $\odot$ & $\ominus$ & $\odot$ & $\odot$ \\
\hline Lazara 1991 * & + & $?$ & $?$ & $?$ & $?$ & + & + & $?$ & $?$ \\
\hline Malbrain $2010^{*}$ & $\odot$ & $?$ & $?$ & $?$ & $\odot$ & $\odot$ & $\odot$ & $?$ & $?$ \\
\hline McGowan $2000^{*}$ & $?$ & $?$ & $\odot$ & $\odot$ & $\odot$ & $\odot$ & $\odot$ & $\odot$ & $\odot$ \\
\hline Mistiaen $2010^{*}$ & $\odot$ & $\odot$ & $\odot$ & $\odot$ & $\odot$ & + & $\odot$ & $\odot$ & $\odot$ \\
\hline Nixon $1998 *$ & $\odot$ & + & $?$ & + & + & $\odot$ & + & $?$ & + \\
\hline Nixon 2006 & $\odot$ & $\odot$ & - & $?$ & $\odot$ & $\odot$ & $\odot$ & $\odot$ & $?$ \\
\hline Nixon 2019* & + & $\odot$ & $\odot$ & + & $\odot$ & $\odot$ & $\odot$ & $\odot$ & $\odot$ \\
\hline Ozyurek 2015 & + & + & $?$ & $?$ & $\odot$ & $\odot$ & $\odot$ & $\odot$ & $\odot$ \\
\hline Park $2017^{*}$ & $\odot$ & $?$ & $?$ & $?$ & $\odot$ & $\odot$ & $\odot$ & $\odot$ & $\odot$ \\
\hline Phillips 1999 & $?$ & $?$ & $?$ & $?$ & $?$ & $\odot$ & $\odot$ & $\odot$ & $\odot$ \\
\hline Price 1999 & $\odot$ & + & $\odot$ & $\odot$ & $\odot$ & + & $\odot$ & $\odot$ & $\odot$ \\
\hline Pring 1998 & $?$ & $?$ & $\odot$ & $\odot$ & + & + & $\odot$ & $\odot$ & $\odot$ \\
\hline Rafter 2011 & $?$ & $?$ & $\odot$ & $\odot$ & + & + & $\odot$ & $\odot$ & $\odot$ \\
\hline Ricci 2013* & + & $?$ & $?$ & $?$ & + & + & + & $?$ & $?$ \\
\hline Rosenthal $2003 *$ & $\odot$ & $?$ & $?$ & ? & $?$ & + & + & $?$ & $?$ \\
\hline
\end{tabular}

Beds, overlays and mattresses for preventing and treating pressure ulcers: an overview of Cochrane Reviews and network meta-analysis 
Figure 7. (Continued)

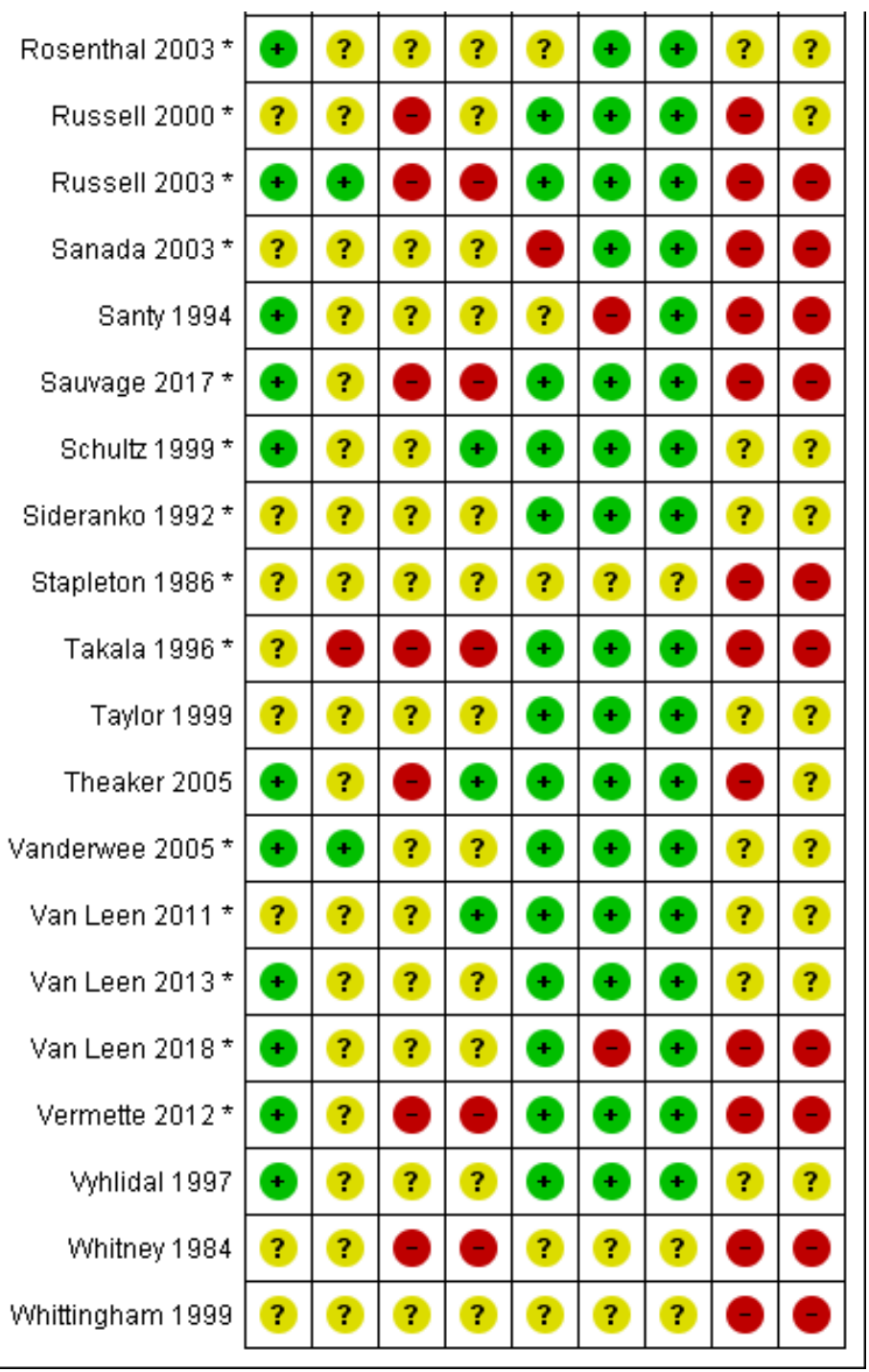

Based on overall risk of bias in the 40 included studies, we assessed overall risk of bias for each of 78 network contrasts of the base-case analysis. See Figure 8.

Figure 8. Risk of bias assessment for each network contrast. The CINeMA tool uses the percentage contribution matrix and combines this with the risk of bias assessments of the included studies $(n=40)$. Each row represents a network contrast of the prevention network. For each network contrast, the CINeMA tool computes the percentage contribution from studies judged to be at low, moderate, and high risk of bias. Green bars within each row indicate 
the percentage contribution from studies at low risk of bias, yellow for unclear risk of bias, and red for high risk of bias. Note not all of the $\mathbf{4 0}$ studies contributed data to each contrast's effectiveness estimation.

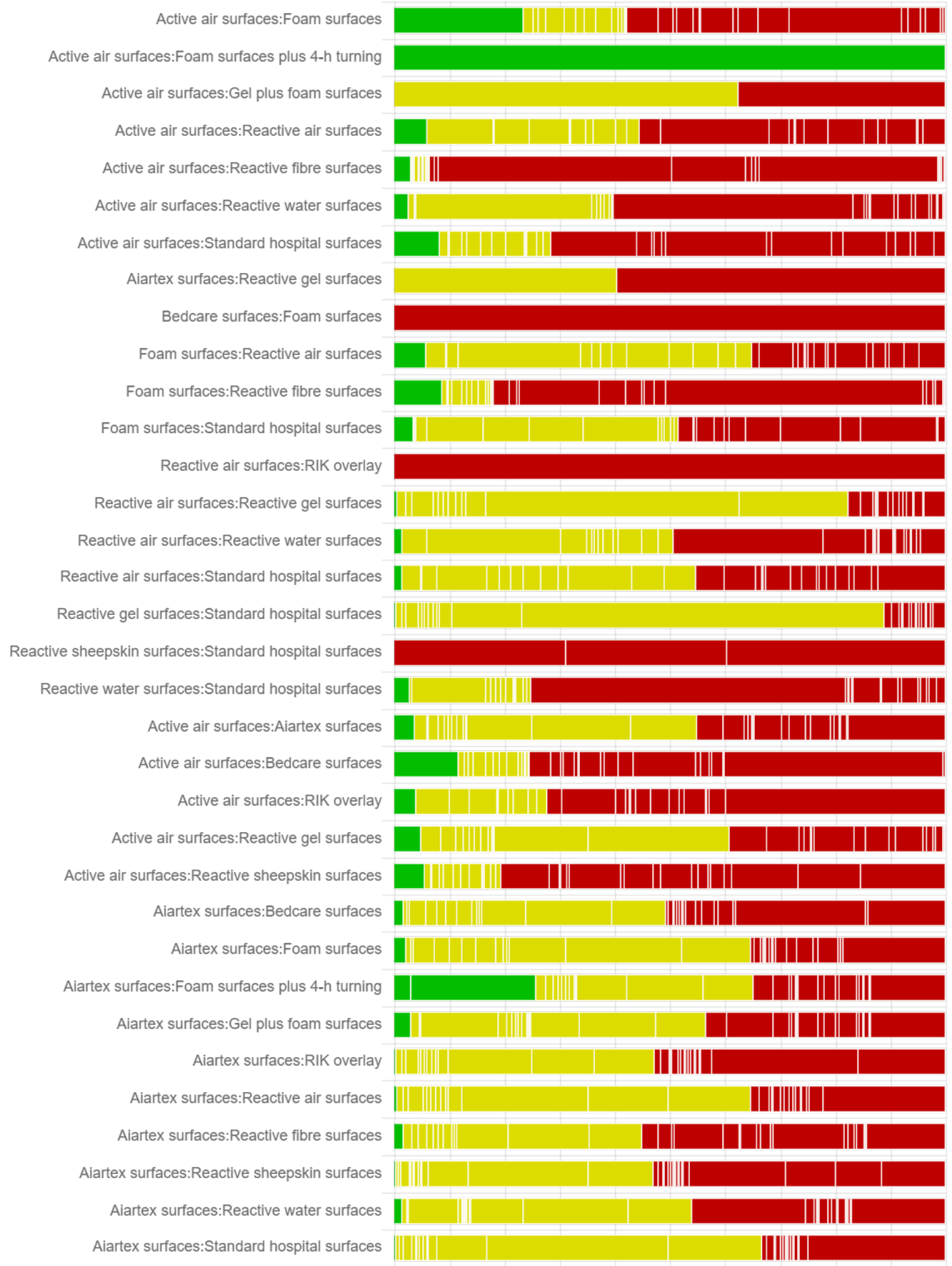

Beds, overlays and mattresses for preventing and treating pressure ulcers: an overview of Cochrane Reviews and network meta-analysis 


\section{Figure 8. (Continued)}

Aiartex surfaces:Standard hospital surfaces Bedcare surfaces:Foam surfaces plus 4-h turning

Bedcare surfaces:Gel plus foam surfaces Bedcare surfaces:RIK overlay Bedcare surfaces:Reactive air surfaces Bedcare surfaces:Reactive fibre surfaces Bedcare surfaces:Reactive gel surfaces Bedcare surfaces:Reactive sheepskin surfaces

Bedcare surfaces:Reactive water surfaces Bedcare surfaces:Standard hospital surfaces

Foam surfaces plus 4-h turning:Gel plus foam surfaces

Foam surfaces plus 4-h turning:RIK overlay

Foam surfaces plus 4-h turning:Reactive air surfaces

Foam surfaces plus 4-h turning:Reactive fibre surfaces

Foam surfaces plus 4-h turning:Reactive gel surfaces

Foam surfaces plus 4-h turning:Reactive sheepskin surfaces

Foam surfaces plus 4-h turning:Reactive water surfaces

Foam surfaces plus 4-h turning:Standard hospital surfaces

Foam surfaces:Foam surfaces plus 4-h turning

Foam surfaces:Gel plus foam surfaces

Foam surfaces:RIK overlay

Foam surfaces:Reactive gel surfaces

Foam surfaces:Reactive sheepskin surfaces

Foam surfaces:Reactive water surfaces

Gel plus foam surfaces:RIK overlay

Gel plus foam surfaces:Reactive air surfaces

Gel plus foam surfaces:Reactive fibre surfaces

Gel plus foam surfaces:Reactive gel surfaces

Gel plus foam surfaces:Reactive sheepskin surfaces

Gel plus foam surfaces:Reactive water surfaces

Gel plus foam surfaces:Standard hospital surfaces

RIK overlay:Standard hospital surfaces

Reactive air surfaces:Reactive fibre surfaces

Reactive air surfaces:Reactive sheepskin surfaces
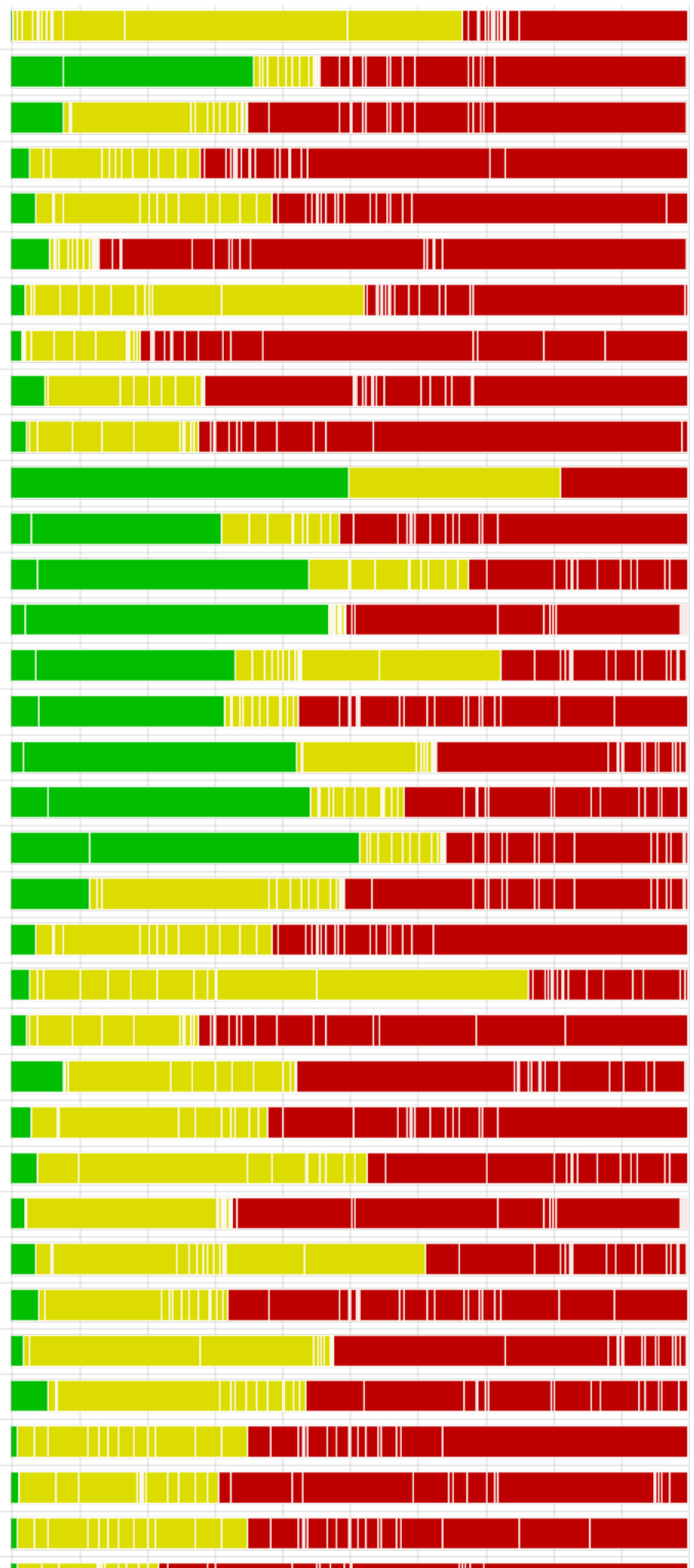

Beds, overlays and mattresses for preventing and treating pressure ulcers: an overview of Cochrane Reviews and network meta-analysis 99 (Review)

Copyright $\odot 2021$ The Authors. Cochrane Database of Systematic Reviews published by John Wiley \& Sons, Ltd. on behalf of The Cochrane Collaboration. 
Figure 8. (Continued)

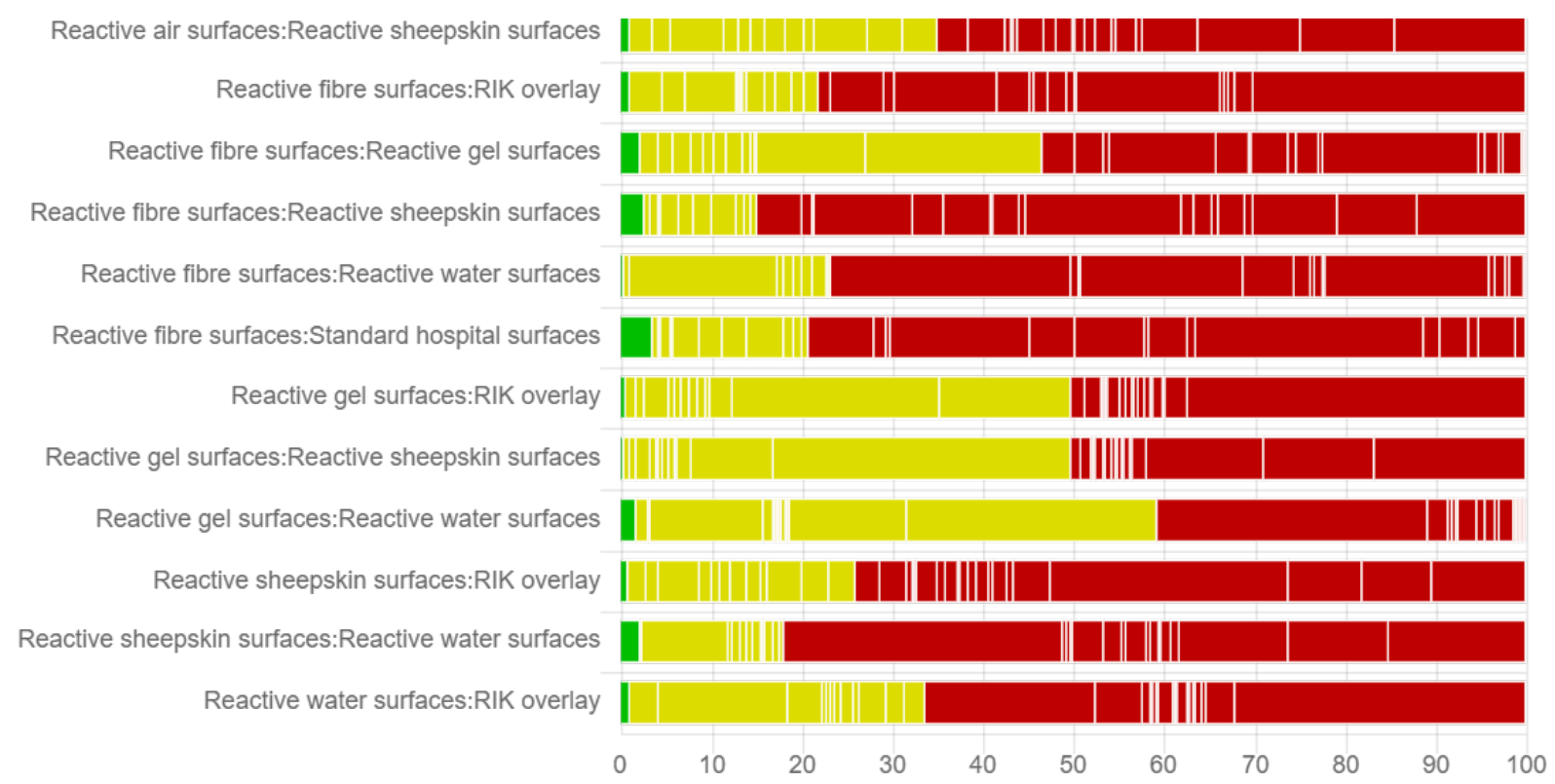

\section{Assessing transitivity, homogeneity and consistency assumptions for the base-case analysis}

We assessed the transitivity, homogeneity and consistency assumptions for the base-case analysis below.

\section{(1) Transitivity assumption assessment}

We summarised the characteristics of the included studies for each direct contrast and compared these direct contrast-level summary characteristics across these direct contrasts (see the table below). This aims to assess if there are systematic differences between the direct contrasts other than the treatments under evaluations. Thus, data from direct contrasts can be used to calculate indirect evidence (transitivity). The 19 direct contrasts are heterogeneous in terms of risk of bias (also see Figure 2), and follow-up duration (11/19 of direct contrasts with short-term follow-up, 6/19 with medium-term follow-up, and 2/19 with long-term follow-up). We considered these direct contrasts homogeneous in terms of care settings (mainly acute and long-term care settings), and participants' characteristics: generally equal proportions of sex in 14/19 direct contrasts contributing the majority of data, age (mainly older adults), and baseline skin status (mainly at risk but free of existing ulcers). We assumed the transitivity assumption held.

Table 3. Summary characteristics of studies for 19 direct comparisons 


\begin{tabular}{|c|c|c|c|c|c|c|c|c|c|c|c|}
\hline 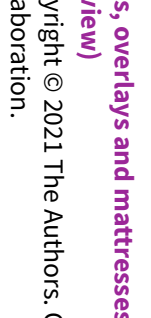 & Direct comparisons & $\begin{array}{l}\text { Number } \\
\text { of studies }\end{array}$ & $\begin{array}{l}\text { Study de- } \\
\text { sign, no. } \\
\text { of mul- } \\
\text { ti-arm } \\
\text { studies } \\
\text { (\% of to- } \\
\text { tal partic- } \\
\text { ipants) }\end{array}$ & $\begin{array}{l}\text { Median of } \\
\text { follow-up }\end{array}$ & $\begin{array}{l}\text { Care settings } \\
\text { (\% of total } \\
\text { participants) }\end{array}$ & $\begin{array}{l}\text { Number } \\
\text { of events/ } \\
\text { number } \\
\text { of total } \\
\text { partici- } \\
\text { pants (\%) }\end{array}$ & Male (\%) & $\begin{array}{l}\text { Female } \\
(\%)\end{array}$ & $\begin{array}{l}\text { Median } \\
\text { of aver- } \\
\text { age age } \\
\text { reported } \\
\text { (years) }\end{array}$ & $\begin{array}{l}\text { Baseline skin } \\
\text { status (\% of } \\
\text { total partici- } \\
\text { pants) }\end{array}$ & $\begin{array}{l}\text { Overall } \\
\text { risk of } \\
\text { bias level } \\
\text { (\% of to- } \\
\text { tal partic- } \\
\text { ipants) }\end{array}$ \\
\hline 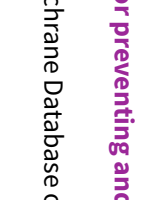 & $\begin{array}{l}\text { Alternating pressure (ac- } \\
\text { tive) air surfaces vs foam } \\
\text { surfaces }\end{array}$ & 4 & $\begin{array}{l}\text { RCTs in- } \\
\text { cluding } \\
\text { one three- } \\
\text { arm study } \\
(3 \%)\end{array}$ & 90 days & $\begin{array}{l}\text { Acute care } \\
\text { setting }(93 \%) \text {, } \\
\text { Long-term } \\
\text { care setting } \\
(7 \%)\end{array}$ & $\begin{array}{l}200 / 2247 \\
(9 \%)\end{array}$ & $929(43 \%)$ & $\begin{array}{l}1239 \\
(57 \%)\end{array}$ & 80 & $\begin{array}{l}\text { At risk, free of } \\
\text { ulcers }(97 \%) ; \\
\text { Existing ulcers } \\
(3 \%)\end{array}$ & $\begin{array}{l}\text { Low and } \\
\text { unclear } \\
(93 \%) ; \\
\text { High }(7 \%)\end{array}$ \\
\hline 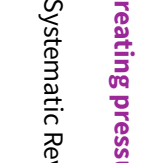 & $\begin{array}{l}\text { Alternating pressure (ac- } \\
\text { tive) air surfaces vs foam } \\
\text { surfaces plus 4-hourly } \\
\text { turning }\end{array}$ & 1 & $\mathrm{RCT}$ & 20 weeks & $\begin{array}{l}\text { Acute care } \\
\text { setting }(100 \%)\end{array}$ & $\begin{array}{l}69 / 447 \\
(15 \%)\end{array}$ & $163(37 \%)$ & $283(63 \%)$ & 82 & $\begin{array}{l}\text { At risk, free of } \\
\text { ulcers }(100 \%)\end{array}$ & $\begin{array}{l}\text { Low } \\
(100 \%)\end{array}$ \\
\hline 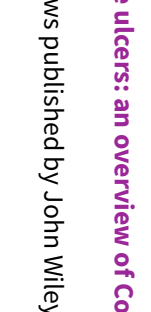 & $\begin{array}{l}\text { Alternating pressure (ac- } \\
\text { tive) air surfaces vs reac- } \\
\text { tive air surfaces }\end{array}$ & 6 & $\begin{array}{l}\text { RCTs in- } \\
\text { cluding } \\
\text { one three- } \\
\text { arm study } \\
(2 \%)\end{array}$ & 11.5 days & $\begin{array}{l}\text { Acute care } \\
\text { setting }(77 \%) \\
\text { ICU (4\%); } \\
\text { Long-term } \\
\text { care setting } \\
(19 \%)\end{array}$ & $\begin{array}{l}50 / 1611 \\
(3 \%)\end{array}$ & $794(49 \%)$ & $834(51 \%)$ & 65 & $\begin{array}{l}\text { At risk, free of } \\
\text { ulcers }(98 \%) ; \\
\text { Existing ulcers } \\
(2 \%)\end{array}$ & $\begin{array}{l}\text { Unclear } \\
(67 \%) ; \\
\text { High } \\
(33 \%)\end{array}$ \\
\hline 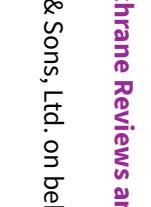 & $\begin{array}{l}\text { Alternating pressure (ac- } \\
\text { tive) air surfaces vs reac- } \\
\text { tive fibre surfaces }\end{array}$ & 3 & RCTs & 3 months & $\begin{array}{l}\text { Acute care } \\
\text { setting }(23 \%) ; \\
\text { Long-term } \\
\text { care setting } \\
(73 \%)\end{array}$ & $\begin{array}{l}115 / 246 \\
(47 \%)\end{array}$ & $76(27 \%)$ & $204(73 \%)$ & 41 & $\begin{array}{l}\text { At risk, free of } \\
\text { ulcers }(100 \%)\end{array}$ & $\begin{array}{l}\text { High } \\
(100 \%)\end{array}$ \\
\hline 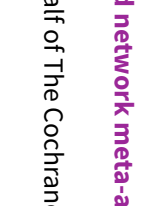 & $\begin{array}{l}\text { Alternating pressure (ac- } \\
\text { tive) air surfaces vs re- } \\
\text { active gel surfaces fol- } \\
\text { lowed by foam surfaces }\end{array}$ & 2 & RCTs & 7 days & $\begin{array}{l}\text { Operating } \\
\text { room fol- } \\
\text { lowed by } \\
\text { wards }(100 \%)\end{array}$ & $\begin{array}{l}17 / 415 \\
(4 \%)\end{array}$ & $306(74 \%)$ & $106(26 \%)$ & 65 & $\begin{array}{l}\text { At risk, free of } \\
\text { ulcers }(100 \%)\end{array}$ & $\begin{array}{l}\text { Unclear } \\
(48 \%) ; \\
\text { High } \\
(52 \%)\end{array}$ \\
\hline$\sum_{\frac{\omega}{n}}^{\frac{0}{n}}$ & $\begin{array}{l}\text { Alternating pressure (ac- } \\
\text { tive) air surfaces vs reac- } \\
\text { tive water surfaces }\end{array}$ & 2 & $\begin{array}{l}\text { Both RCTs } \\
\text { with three } \\
\text { arms } \\
(100 \%)\end{array}$ & 10 days & $\begin{array}{l}\text { Acute care } \\
\text { setting }(90 \%) \text {; } \\
\text { ICU }(10 \%)\end{array}$ & $\begin{array}{l}21 / 358 \\
(6 \%)\end{array}$ & $239(44 \%)$ & $300(56 \%)$ & 66 & $\begin{array}{l}\text { At risk, free of } \\
\text { ulcers }(100 \%)\end{array}$ & $\begin{array}{l}\text { Unclear } \\
(10 \%) ;\end{array}$ \\
\hline
\end{tabular}




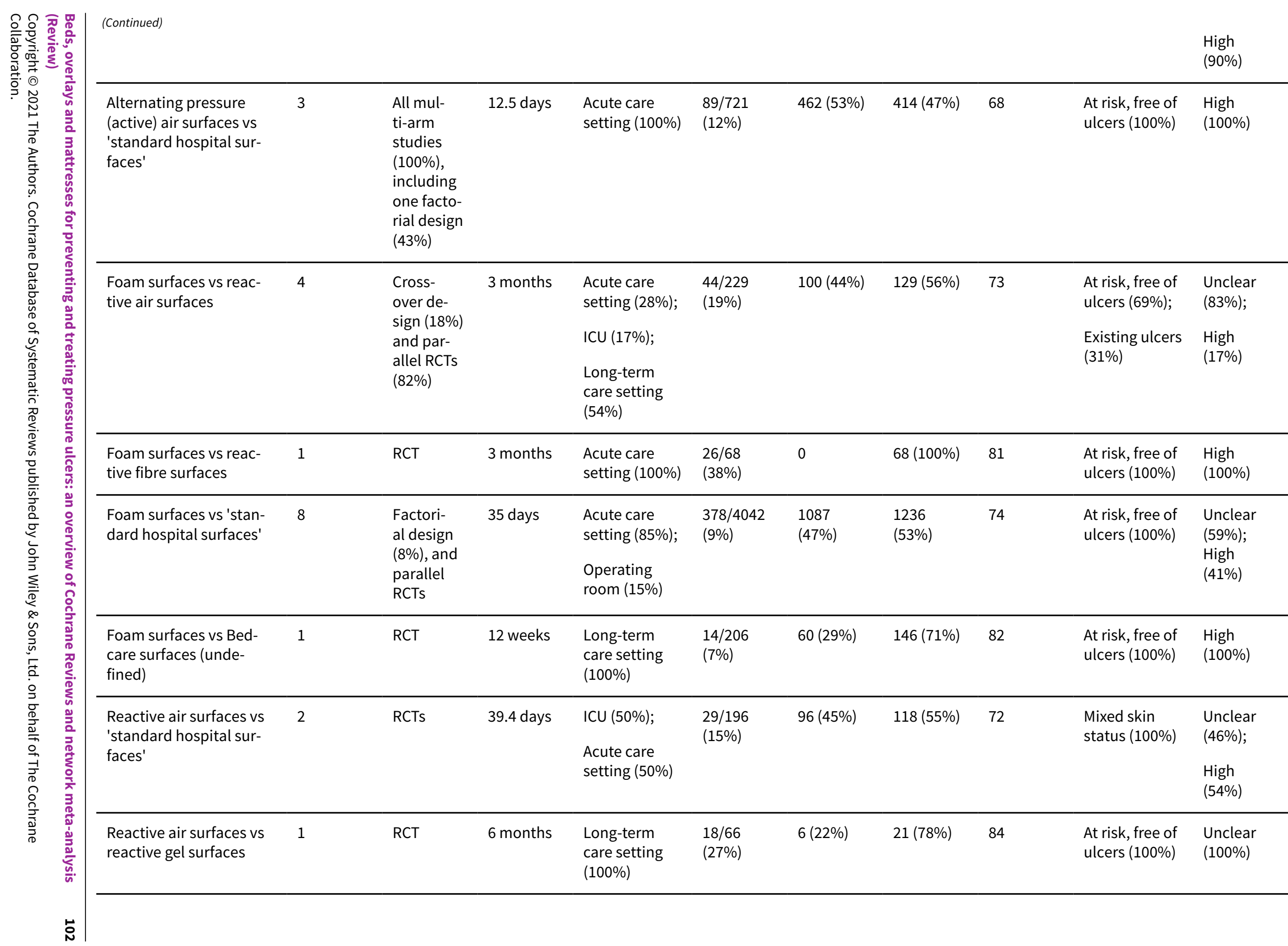




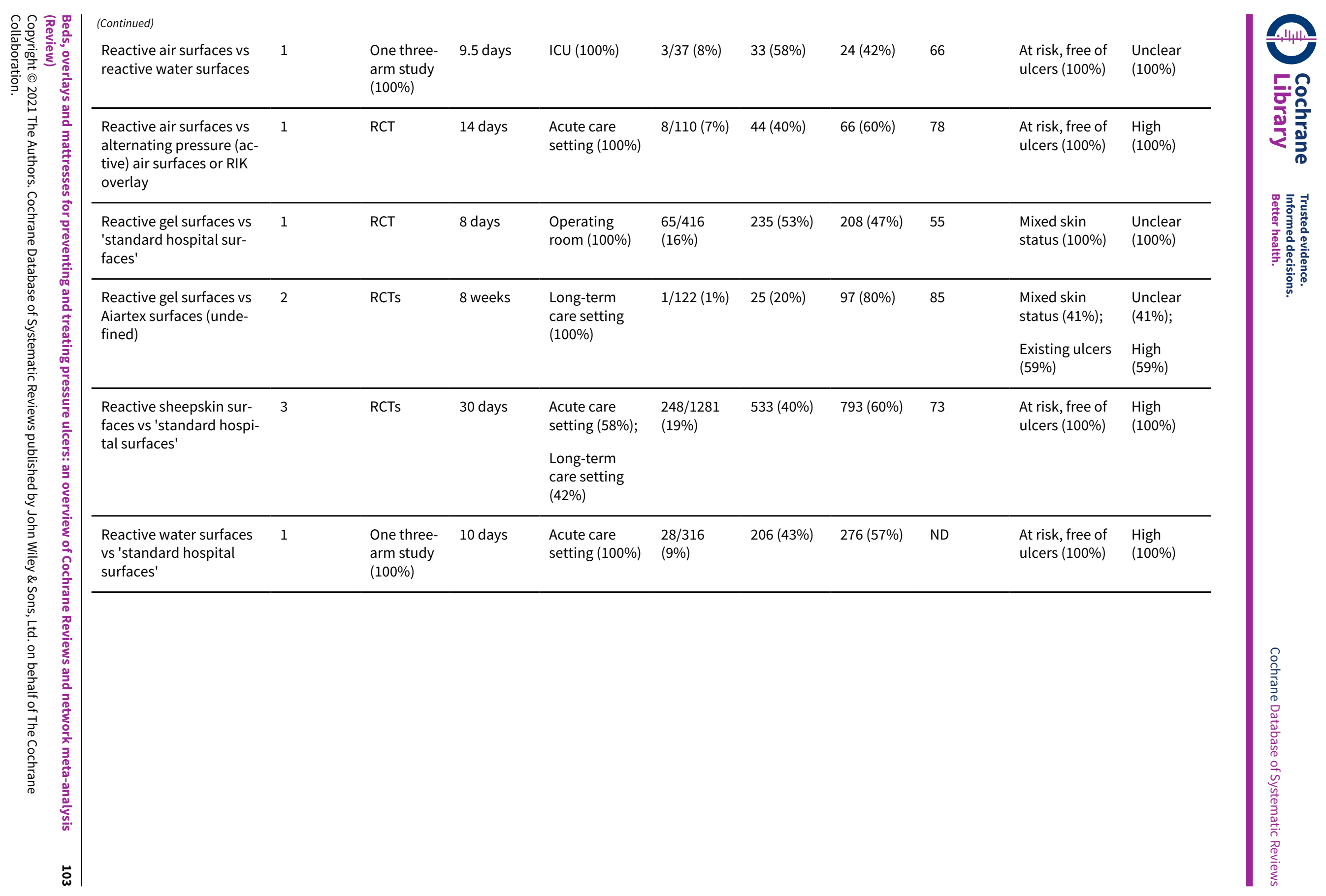


ND = no data available

\section{(2) Homogeneity assumption tests and subgroup analyses}

\section{Heterogeneity tests}

The between-study variance in this network $\left(\mathrm{Tau}^{2}\right)$ is 0.146 which is much larger than median Tau $2=0.056$ (IQR 0.005 to 0.651 ), reference values for non-pharmacological interventions used in semi-objective outcomes (Turner 2012). We therefore considered this network had substantial heterogeneity. This resulted in downgrading for heterogeneity in assessing the certainty of evidence using the GRADE approach.

We considered downgrading for the following nine network contrasts.

Four network contrasts had moderate heterogeneity:

- alternating pressure (active) air surfaces versus foam surfaces: between-study heterogeneity $12=43.2 \%, \mathrm{Tau}^{2}=0.117$;

- alternating pressure (active) air surfaces versus reactive gel surfaces followed by foam surfaces: prediction interval extends into clinically important effects $(\mathrm{RR}=1)$ in both directions;

- alternating pressure (active) air surfaces versus standard hospital surfaces: between-study heterogeneity $12=60.7 \%$, Tau $^{2}=0.229$;

- foam surfaces versus reactive air surfaces: prediction interval extends into clinically important effects $(R R=1)$ in both directions.

Four network contrasts with substantial heterogeneity:

- reactive air surfaces versus standard hospital surfaces: between-study heterogeneity $\mathrm{I}^{2}=85.9 \%, \operatorname{Tau}^{2}=2.142$;

- reactive gel surfaces versus standard hospital surfaces: prediction interval extends into clinically important effects $(R R=1)$ in both directions;

- reactive sheepskin surfaces versus standard hospital surfaces: between-study heterogeneity $1^{2}=79.8 \%$, Tau $^{2}=0.206$; and

- reactive water surfaces versus standard hospital surfaces: prediction interval extends into clinically important effects $(R R=1)$ in both directions.

\section{Subgroup analysis}

We performed subgroup analyses to investigate further the heterogeneity of the base-case analysis (Tau $\left.{ }^{2}=0.146\right)$ by considering four study-level characteristics:

- risk of bias (binary: low or unclear risk of bias as the reference versus high risk of bias): this regression resulted in a Tau ${ }^{2}$ of 0.146, showing that the factor could not explain the heterogeneity. Therefore, risk of bias factor may not be an important effect modifier for the basecase analysis.

- care settings (categorical: acute care setting as the reference versus long-term care settings, operating theatre setting, and intensive care unit): this exploratory regression resulted in a Tau 2 of 0.075 and suggested that the care setting may be an important effect modifier for the network meta-analysis. However, due to the small number of included studies, we did not undertake analyses for individual care settings.

- baseline skin status (categorical: participants at risk as the reference versus other skin status or non-reporting, existing ulcers of stage 2 or more severe): this regression resulted in a Tau ${ }^{2}$ of 0.202 , suggesting that baseline skin status could not explain the heterogeneity of the base-case analysis.

- follow-up duration in weeks (categorical: short-term duration as the reference versus medium-term duration, long-term duration, and no reporting): this exploratory regression resulted in a Tau ${ }^{2}$ of 0.117 , suggesting that this factor only explained a small amount of heterogeneity of the base-case analysis.

Note that there is a small number of studies in these exploratory analyses and they may be under-powered.

\section{(3) Consistency tests}

We considered the estimates of treatment effects from direct and indirect evidence consistent globally (global design-by-treatment interaction model: $x^{2}$ statistic: 3.853 , P value: 0.921 ) and locally (no inconsistency resulting from the tests of separating indirect from direct evidence): that is, the consistency assumption held in the network.

\section{GRADE assessment for network evidence from the base-case analysis}

We assessed the certainty of the evidence for all network contrasts in the base-case analysis. See the table below.

Table 4. GRADE assessment for network evidence from the base-case analysis 


\begin{tabular}{|c|c|c|c|c|c|c|c|c|}
\hline Comparison & $\begin{array}{l}\text { Number of } \\
\text { studies }\end{array}$ & $\begin{array}{l}\text { With- } \\
\text { in-study } \\
\text { bias }\end{array}$ & $\begin{array}{l}\text { Reporting } \\
\text { bias }\end{array}$ & $\begin{array}{l}\text { Indirect- } \\
\text { ness }\end{array}$ & Imprecision & $\begin{array}{l}\text { Hetero- } \\
\text { geneity }\end{array}$ & $\begin{array}{l}\text { Incoher- } \\
\text { ence }\end{array}$ & $\begin{array}{l}\text { Confidence } \\
\text { rating }\end{array}$ \\
\hline $\begin{array}{l}\text { Alternating pressure (active) air surfaces:A- } \\
\text { iartex surfaces }\end{array}$ & 0 & $\begin{array}{l}\text { Some con- } \\
\text { cerns }\end{array}$ & Undetected & No concerns & $\begin{array}{l}\text { Major con- } \\
\text { cerns }\end{array}$ & No concerns & No concerns & Very low \\
\hline $\begin{array}{l}\text { Alternating pressure (active) air sur- } \\
\text { faces:Bedcare surfaces }\end{array}$ & 0 & $\begin{array}{l}\text { Major con- } \\
\text { cerns }\end{array}$ & Undetected & No concerns & $\begin{array}{l}\text { Major con- } \\
\text { cerns }\end{array}$ & No concerns & No concerns & Very low \\
\hline $\begin{array}{l}\text { Alternating pressure (active) air sur- } \\
\text { faces:Foam surfaces }\end{array}$ & 4 & $\begin{array}{l}\text { Some con- } \\
\text { cerns }\end{array}$ & Undetected & No concerns & No concerns & $\begin{array}{l}\text { Some con- } \\
\text { cerns }\end{array}$ & No concerns & Low \\
\hline $\begin{array}{l}\text { Alternating pressure (active) air sur- } \\
\text { faces:Foam surfaces plus 4-h turning }\end{array}$ & 1 & No concerns & Undetected & No concerns & $\begin{array}{l}\text { Major con- } \\
\text { cerns }\end{array}$ & No concerns & No concerns & Low \\
\hline $\begin{array}{l}\text { Alternating pressure (active) air sur- } \\
\text { faces:Reactive gel surfaces followed by } \\
\text { foam surfaces }\end{array}$ & 2 & $\begin{array}{l}\text { Some con- } \\
\text { cerns }\end{array}$ & Undetected & No concerns & No concerns & $\begin{array}{l}\text { Some con- } \\
\text { cerns }\end{array}$ & No concerns & Low \\
\hline $\begin{array}{l}\text { Alternating pressure (active) air sur- } \\
\text { faces:Reactive air surfaces }\end{array}$ & 6 & $\begin{array}{l}\text { Some con- } \\
\text { cerns }\end{array}$ & Undetected & No concerns & $\begin{array}{l}\text { Major con- } \\
\text { cerns }\end{array}$ & No concerns & No concerns & Very low \\
\hline $\begin{array}{l}\text { Alternating pressure (active) air sur- } \\
\text { faces:Reactive fibre surfaces }\end{array}$ & 3 & $\begin{array}{l}\text { Major con- } \\
\text { cerns }\end{array}$ & Undetected & No concerns & $\begin{array}{l}\text { Major con- } \\
\text { cerns }\end{array}$ & No concerns & No concerns & Very low \\
\hline $\begin{array}{l}\text { Alternating pressure (active) air sur- } \\
\text { faces:Reactive gel surfaces }\end{array}$ & 0 & $\begin{array}{l}\text { Some con- } \\
\text { cerns }\end{array}$ & Undetected & No concerns & $\begin{array}{l}\text { Major con- } \\
\text { cerns }\end{array}$ & No concerns & No concerns & Very low \\
\hline $\begin{array}{l}\text { Alternating pressure (active) air sur- } \\
\text { faces:Reactive sheepskin surfaces }\end{array}$ & 0 & $\begin{array}{l}\text { Major con- } \\
\text { cerns }\end{array}$ & Undetected & No concerns & $\begin{array}{l}\text { Major con- } \\
\text { cerns }\end{array}$ & No concerns & No concerns & Very low \\
\hline $\begin{array}{l}\text { Alternating pressure (active) air sur- } \\
\text { faces:Reactive water surfaces }\end{array}$ & 2 & $\begin{array}{l}\text { Major con- } \\
\text { cerns }\end{array}$ & Undetected & No concerns & $\begin{array}{l}\text { Major con- } \\
\text { cerns }\end{array}$ & No concerns & No concerns & Very low \\
\hline $\begin{array}{l}\text { Alternating pressure (active) air sur- } \\
\text { faces:RIK overlay }\end{array}$ & 0 & $\begin{array}{l}\text { Major con- } \\
\text { cerns }\end{array}$ & Undetected & No concerns & $\begin{array}{l}\text { Major con- } \\
\text { cerns }\end{array}$ & No concerns & No concerns & Very low \\
\hline $\begin{array}{l}\text { Alternating pressure (active) air surfaces:S- } \\
\text { tandard hospital surfaces }\end{array}$ & 3 & $\begin{array}{l}\text { Major con- } \\
\text { cerns }\end{array}$ & Undetected & No concerns & No concerns & $\begin{array}{l}\text { Some con- } \\
\text { cerns }\end{array}$ & No concerns & Very low \\
\hline Aiartex surfaces:Bedcare surfaces & 0 & $\begin{array}{l}\text { Some con- } \\
\text { cerns }\end{array}$ & Undetected & No concerns & $\begin{array}{l}\text { Major con- } \\
\text { cerns }\end{array}$ & No concerns & No concerns & Very low \\
\hline
\end{tabular}




\begin{tabular}{|c|c|c|c|c|c|c|c|c|c|}
\hline 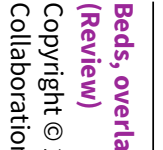 & $\begin{array}{l}\text { (Continued) } \\
\text { Aiartex surfaces:Foam surfaces }\end{array}$ & 0 & $\begin{array}{l}\text { Some con- } \\
\text { cerns }\end{array}$ & Undetected & No concerns & $\begin{array}{l}\text { Major con- } \\
\text { cerns }\end{array}$ & No concerns & No concerns & Very low \\
\hline 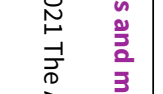 & $\begin{array}{l}\text { Aiartex surfaces:Foam surfaces plus 4-h } \\
\text { turning }\end{array}$ & 0 & $\begin{array}{l}\text { Some con- } \\
\text { cerns }\end{array}$ & Undetected & No concerns & $\begin{array}{l}\text { Major con- } \\
\text { cerns }\end{array}$ & No concerns & No concerns & Very low \\
\hline 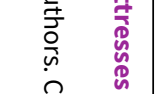 & $\begin{array}{l}\text { Aiartex surfaces:Reactive gel surfaces fol- } \\
\text { lowed by foam surfaces }\end{array}$ & 0 & $\begin{array}{l}\text { Some con- } \\
\text { cerns }\end{array}$ & Undetected & No concerns & $\begin{array}{l}\text { Major con- } \\
\text { cerns }\end{array}$ & No concerns & No concerns & Very low \\
\hline 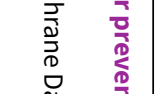 & Aiartex surfaces:Reactive air surfaces & 0 & $\begin{array}{l}\text { Some con- } \\
\text { cerns }\end{array}$ & Undetected & No concerns & $\begin{array}{l}\text { Major con- } \\
\text { cerns }\end{array}$ & No concerns & No concerns & Very low \\
\hline 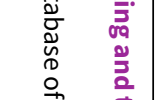 & Aiartex surfaces:Reactive fibre surfaces & 0 & $\begin{array}{l}\text { Some con- } \\
\text { cerns }\end{array}$ & Undetected & No concerns & $\begin{array}{l}\text { Major con- } \\
\text { cerns }\end{array}$ & No concerns & No concerns & Very low \\
\hline 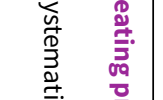 & Aiartex surfaces:Reactive gel surfaces & 2 & $\begin{array}{l}\text { Major con- } \\
\text { cerns }\end{array}$ & Undetected & No concerns & $\begin{array}{l}\text { Major con- } \\
\text { cerns }\end{array}$ & No concerns & No concerns & Very low \\
\hline 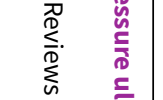 & $\begin{array}{l}\text { Aiartex surfaces:Reactive sheepskin sur- } \\
\text { faces }\end{array}$ & 0 & $\begin{array}{l}\text { Some con- } \\
\text { cerns }\end{array}$ & Undetected & No concerns & $\begin{array}{l}\text { Major con- } \\
\text { cerns }\end{array}$ & No concerns & No concerns & Very low \\
\hline 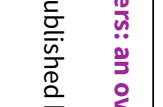 & Aiartex surfaces:Reactive water surfaces & 0 & $\begin{array}{l}\text { Some con- } \\
\text { cerns }\end{array}$ & Undetected & No concerns & $\begin{array}{l}\text { Major con- } \\
\text { cerns }\end{array}$ & No concerns & No concerns & Very low \\
\hline 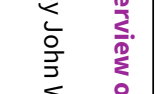 & Aiartex surfaces:RIK overlay & 0 & $\begin{array}{l}\text { Some con- } \\
\text { cerns }\end{array}$ & Undetected & No concerns & $\begin{array}{l}\text { Major con- } \\
\text { cerns }\end{array}$ & No concerns & No concerns & Very low \\
\hline 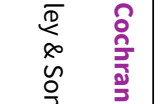 & Aiartex surfaces:Standard hospital surfaces & 0 & $\begin{array}{l}\text { Some con- } \\
\text { cerns }\end{array}$ & Undetected & No concerns & $\begin{array}{l}\text { Major con- } \\
\text { cerns }\end{array}$ & No concerns & No concerns & Very low \\
\hline 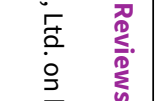 & Bedcare surfaces:Foam surfaces & 1 & $\begin{array}{l}\text { Major con- } \\
\text { cerns }\end{array}$ & Undetected & No concerns & $\begin{array}{l}\text { Major con- } \\
\text { cerns }\end{array}$ & No concerns & No concerns & Very low \\
\hline 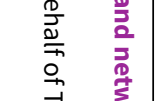 & $\begin{array}{l}\text { Bedcare surfaces:Foam surfaces plus 4-h } \\
\text { turning }\end{array}$ & 0 & $\begin{array}{l}\text { Some con- } \\
\text { cerns }\end{array}$ & Undetected & No concerns & $\begin{array}{l}\text { Major con- } \\
\text { cerns }\end{array}$ & No concerns & No concerns & Very low \\
\hline 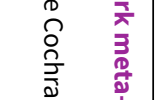 & $\begin{array}{l}\text { Bedcare surfaces:Reactive gel surfaces fol- } \\
\text { lowed by foam surfaces }\end{array}$ & 0 & $\begin{array}{l}\text { Major con- } \\
\text { cerns }\end{array}$ & Undetected & No concerns & $\begin{array}{l}\text { Major con- } \\
\text { cerns }\end{array}$ & No concerns & No concerns & Very low \\
\hline 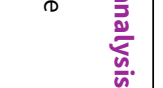 & Bedcare surfaces:Reactive air surfaces & 0 & $\begin{array}{l}\text { Major con- } \\
\text { cerns }\end{array}$ & Undetected & No concerns & $\begin{array}{l}\text { Major con- } \\
\text { cerns }\end{array}$ & No concerns & No concerns & Very low \\
\hline
\end{tabular}




\begin{tabular}{|c|c|c|c|c|c|c|c|c|c|}
\hline 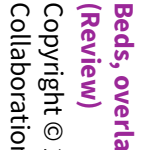 & $\begin{array}{l}\text { (Continued) } \\
\text { Bedcare surfaces:Reactive fibre surfaces }\end{array}$ & 0 & $\begin{array}{l}\text { Major con- } \\
\text { cerns }\end{array}$ & Undetected & No concerns & $\begin{array}{l}\text { Major con- } \\
\text { cerns }\end{array}$ & No concerns & No concerns & Very low \\
\hline 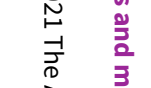 & Bedcare surfaces:Reactive gel surfaces & 0 & $\begin{array}{l}\text { Some con- } \\
\text { cerns }\end{array}$ & Undetected & No concerns & $\begin{array}{l}\text { Major con- } \\
\text { cerns }\end{array}$ & No concerns & No concerns & Very low \\
\hline 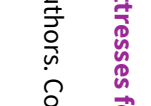 & $\begin{array}{l}\text { Bedcare surfaces:Reactive sheepskin sur- } \\
\text { faces }\end{array}$ & 0 & $\begin{array}{l}\text { Major con- } \\
\text { cerns }\end{array}$ & Undetected & No concerns & $\begin{array}{l}\text { Major con- } \\
\text { cerns }\end{array}$ & No concerns & No concerns & Very low \\
\hline 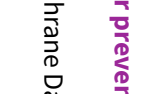 & Bedcare surfaces:Reactive water surfaces & 0 & $\begin{array}{l}\text { Major con- } \\
\text { cerns }\end{array}$ & Undetected & No concerns & $\begin{array}{l}\text { Major con- } \\
\text { cerns }\end{array}$ & No concerns & No concerns & Very low \\
\hline 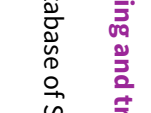 & Bedcare surfaces:RIK overlay & 0 & $\begin{array}{l}\text { Major con- } \\
\text { cerns }\end{array}$ & Undetected & No concerns & $\begin{array}{l}\text { Major con- } \\
\text { cerns }\end{array}$ & No concerns & No concerns & Very low \\
\hline 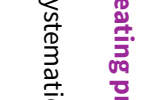 & $\begin{array}{l}\text { Bedcare surfaces:Standard hospital sur- } \\
\text { faces }\end{array}$ & 0 & $\begin{array}{l}\text { Major con- } \\
\text { cerns }\end{array}$ & Undetected & No concerns & $\begin{array}{l}\text { Major con- } \\
\text { cerns }\end{array}$ & No concerns & No concerns & Very low \\
\hline 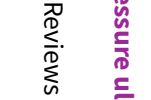 & $\begin{array}{l}\text { Foam surfaces plus 4-h turning:Reactive gel } \\
\text { surfaces followed by foam surfaces }\end{array}$ & 0 & No concerns & Undetected & No concerns & $\begin{array}{l}\text { Major con- } \\
\text { cerns }\end{array}$ & No concerns & No concerns & Low \\
\hline 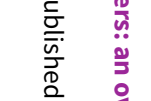 & $\begin{array}{l}\text { Foam surfaces plus 4-h turning:Reactive air } \\
\text { surfaces }\end{array}$ & 0 & No concerns & Undetected & No concerns & $\begin{array}{l}\text { Major con- } \\
\text { cerns }\end{array}$ & No concerns & No concerns & Low \\
\hline 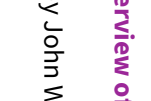 & $\begin{array}{l}\text { Foam surfaces plus 4-h turning:Reactive fi- } \\
\text { bre surfaces }\end{array}$ & 0 & $\begin{array}{l}\text { Some con- } \\
\text { cerns }\end{array}$ & Undetected & No concerns & $\begin{array}{l}\text { Major con- } \\
\text { cerns }\end{array}$ & No concerns & No concerns & Very low \\
\hline 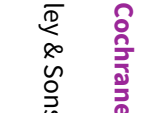 & $\begin{array}{l}\text { Foam surfaces plus 4-h turning: Reactive gel } \\
\text { surfaces }\end{array}$ & 0 & No concerns & Undetected & No concerns & $\begin{array}{l}\text { Major con- } \\
\text { cerns }\end{array}$ & No concerns & No concerns & Low \\
\hline 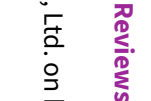 & $\begin{array}{l}\text { Foam surfaces plus 4-h turning: Reactive } \\
\text { sheepskin surfaces }\end{array}$ & 0 & $\begin{array}{l}\text { Major con- } \\
\text { cerns }\end{array}$ & Undetected & No concerns & $\begin{array}{l}\text { Major con- } \\
\text { cerns }\end{array}$ & No concerns & No concerns & Very low \\
\hline 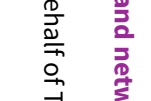 & $\begin{array}{l}\text { Foam surfaces plus 4-h turning:Reactive wa- } \\
\text { ter surfaces }\end{array}$ & 0 & $\begin{array}{l}\text { Some con- } \\
\text { cerns }\end{array}$ & Undetected & No concerns & $\begin{array}{l}\text { Major con- } \\
\text { cerns }\end{array}$ & No concerns & No concerns & Very low \\
\hline 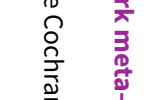 & Foam surfaces plus 4-h turning:RIK overlay & 0 & $\begin{array}{l}\text { Some con- } \\
\text { cerns }\end{array}$ & Undetected & No concerns & $\begin{array}{l}\text { Major con- } \\
\text { cerns }\end{array}$ & No concerns & No concerns & Very low \\
\hline 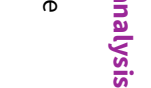 & $\begin{array}{l}\text { Foam surfaces plus 4-h turning:Standard } \\
\text { hospital surfaces }\end{array}$ & 0 & $\begin{array}{l}\text { Some con- } \\
\text { cerns }\end{array}$ & Undetected & No concerns & $\begin{array}{l}\text { Major con- } \\
\text { cerns }\end{array}$ & No concerns & No concerns & Very low \\
\hline
\end{tabular}




\begin{tabular}{|c|c|c|c|c|c|c|c|c|c|}
\hline 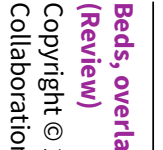 & $\begin{array}{l}\text { (Continued) } \\
\text { Foam surfaces:Foam surfaces plus 4-h turn- } \\
\text { ing }\end{array}$ & 0 & No concerns & Undetected & No concerns & $\begin{array}{l}\text { Major con- } \\
\text { cerns }\end{array}$ & No concerns & No concerns & Low \\
\hline 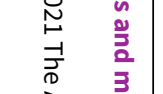 & $\begin{array}{l}\text { Foam surfaces: Reactive gel surfaces fol- } \\
\text { lowed by foam surfaces }\end{array}$ & 0 & $\begin{array}{l}\text { Some con- } \\
\text { cerns }\end{array}$ & Undetected & No concerns & $\begin{array}{l}\text { Major con- } \\
\text { cerns }\end{array}$ & No concerns & No concerns & Very low \\
\hline 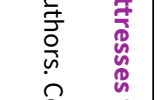 & Foam surfaces:Reactive air surfaces & 4 & $\begin{array}{l}\text { Some con- } \\
\text { cerns }\end{array}$ & Undetected & No concerns & No concerns & $\begin{array}{l}\text { Some con- } \\
\text { cerns }\end{array}$ & No concerns & Low \\
\hline 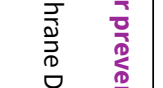 & Foam surfaces:Reactive fibre surfaces & 1 & $\begin{array}{l}\text { Major con- } \\
\text { cerns }\end{array}$ & Undetected & No concerns & $\begin{array}{l}\text { Major con- } \\
\text { cerns }\end{array}$ & No concerns & No concerns & Very low \\
\hline 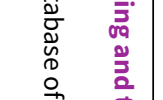 & Foam surfaces:Reactive gel surfaces & 0 & No concerns & Undetected & No concerns & $\begin{array}{l}\text { Major con- } \\
\text { cerns }\end{array}$ & No concerns & No concerns & Low \\
\hline 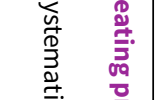 & Foam surfaces:Reactive sheepskin surfaces & 0 & $\begin{array}{l}\text { Major con- } \\
\text { cerns }\end{array}$ & Undetected & No concerns & $\begin{array}{l}\text { Major con- } \\
\text { cerns }\end{array}$ & No concerns & No concerns & Very low \\
\hline 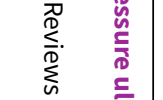 & Foam surfaces:Reactive water surfaces & 0 & $\begin{array}{l}\text { Major con- } \\
\text { cerns }\end{array}$ & Undetected & No concerns & $\begin{array}{l}\text { Major con- } \\
\text { cerns }\end{array}$ & No concerns & No concerns & Very low \\
\hline $\begin{array}{l}\frac{5}{\bar{\sigma}} \\
\frac{\bar{v}}{\widehat{D}}\end{array}$ & Foam surfaces:RIK overlay & 0 & $\begin{array}{l}\text { Major con- } \\
\text { cerns }\end{array}$ & Undetected & No concerns & $\begin{array}{l}\text { Major con- } \\
\text { cerns }\end{array}$ & No concerns & No concerns & Very low \\
\hline 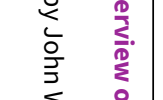 & Foam surfaces:Standard hospital surfaces & 8 & $\begin{array}{l}\text { Some con- } \\
\text { cerns }\end{array}$ & Undetected & No concerns & $\begin{array}{l}\text { Major con- } \\
\text { cerns }\end{array}$ & No concerns & No concerns & Very low \\
\hline 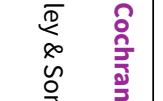 & $\begin{array}{l}\text { Reactive gel surfaces followed by foam sur- } \\
\text { faces:Reactive air surfaces }\end{array}$ & 0 & $\begin{array}{l}\text { Some con- } \\
\text { cerns }\end{array}$ & Undetected & No concerns & No concerns & No concerns & No concerns & Moderate \\
\hline 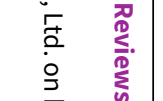 & $\begin{array}{l}\text { Reactive gel surfaces followed by foam sur- } \\
\text { faces:Reactive fibre surfaces }\end{array}$ & 0 & $\begin{array}{l}\text { Major con- } \\
\text { cerns }\end{array}$ & Undetected & No concerns & $\begin{array}{l}\text { Major con- } \\
\text { cerns }\end{array}$ & No concerns & No concerns & Very low \\
\hline$\frac{2}{\frac{3}{3}}$ & $\begin{array}{l}\text { Reactive gel surfaces followed by foam sur- } \\
\text { faces:Reactive gel surfaces }\end{array}$ & 0 & $\begin{array}{l}\text { Some con- } \\
\text { cerns }\end{array}$ & Undetected & No concerns & No concerns & No concerns & No concerns & Moderate \\
\hline 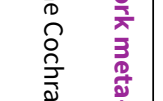 & $\begin{array}{l}\text { Reactive gel surfaces followed by foam sur- } \\
\text { faces:Reactive sheepskin surfaces }\end{array}$ & 0 & $\begin{array}{l}\text { Major con- } \\
\text { cerns }\end{array}$ & Undetected & No concerns & No concerns & $\begin{array}{l}\text { Some con- } \\
\text { cerns }\end{array}$ & No concerns & Very low \\
\hline 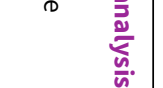 & $\begin{array}{l}\text { Reactive gel surfaces followed by foam sur- } \\
\text { faces:Reactive water surfaces }\end{array}$ & 0 & $\begin{array}{l}\text { Some con- } \\
\text { cerns }\end{array}$ & Undetected & No concerns & No concerns & No concerns & No concerns & Moderate \\
\hline
\end{tabular}




\begin{tabular}{|c|c|c|c|c|c|c|c|c|c|}
\hline 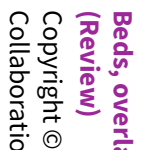 & $\begin{array}{l}\text { (Continued) } \\
\text { Reactive gel surfaces followed by foam sur- } \\
\text { faces:RIK overlay }\end{array}$ & 0 & $\begin{array}{l}\text { Major con- } \\
\text { cerns }\end{array}$ & Undetected & No concerns & $\begin{array}{l}\text { Major con- } \\
\text { cerns }\end{array}$ & No concerns & No concerns & Very low \\
\hline 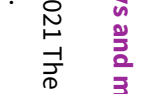 & $\begin{array}{l}\text { Reactive gel surfaces followed by foam sur- } \\
\text { faces:Standard hospital surfaces }\end{array}$ & 0 & $\begin{array}{l}\text { Major con- } \\
\text { cerns }\end{array}$ & Undetected & No concerns & $\begin{array}{l}\text { Major con- } \\
\text { cerns }\end{array}$ & No concerns & No concerns & Very low \\
\hline 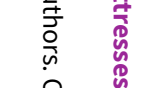 & Reactive air surfaces:Reactive fibre surfaces & 0 & $\begin{array}{l}\text { Major con- } \\
\text { cerns }\end{array}$ & Undetected & No concerns & $\begin{array}{l}\text { Major con- } \\
\text { cerns }\end{array}$ & No concerns & No concerns & Very low \\
\hline 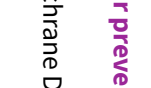 & Reactive air surfaces:Reactive gel surfaces & 1 & No concerns & Undetected & No concerns & $\begin{array}{l}\text { Major con- } \\
\text { cerns }\end{array}$ & No concerns & No concerns & Low \\
\hline 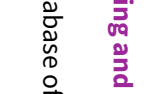 & $\begin{array}{l}\text { Reactive air surfaces:Reactive sheepskin } \\
\text { surfaces }\end{array}$ & 0 & $\begin{array}{l}\text { Major con- } \\
\text { cerns }\end{array}$ & Undetected & No concerns & $\begin{array}{l}\text { Major con- } \\
\text { cerns }\end{array}$ & No concerns & No concerns & Very low \\
\hline 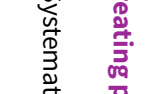 & $\begin{array}{l}\text { Reactive air surfaces:Reactive water sur- } \\
\text { faces }\end{array}$ & 1 & $\begin{array}{l}\text { Some con- } \\
\text { cerns }\end{array}$ & Undetected & No concerns & $\begin{array}{l}\text { Major con- } \\
\text { cerns }\end{array}$ & No concerns & No concerns & Very low \\
\hline 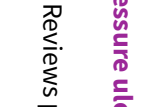 & Reactive air surfaces:RIK overlay & 1 & $\begin{array}{l}\text { Major con- } \\
\text { cerns }\end{array}$ & Undetected & No concerns & $\begin{array}{l}\text { Major con- } \\
\text { cerns }\end{array}$ & No concerns & No concerns & Very low \\
\hline $\begin{array}{l}\frac{\bar{\sigma}}{\sigma} \\
\frac{\overline{\bar{T}}}{\bar{\sigma}} \\
\frac{\bar{D}}{\alpha}\end{array}$ & $\begin{array}{l}\text { Reactive air surfaces:Standard hospital sur- } \\
\text { faces }\end{array}$ & 2 & $\begin{array}{l}\text { Some con- } \\
\text { cerns }\end{array}$ & Undetected & No concerns & No concerns & $\begin{array}{l}\text { Major con- } \\
\text { cerns }\end{array}$ & No concerns & Very low \\
\hline 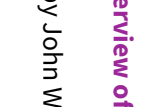 & Reactive fibre surfaces:Reactive gel surfaces & 0 & $\begin{array}{l}\text { Major con- } \\
\text { cerns }\end{array}$ & Undetected & No concerns & $\begin{array}{l}\text { Major con- } \\
\text { cerns }\end{array}$ & No concerns & No concerns & Very low \\
\hline $\begin{array}{l}\delta \\
\frac{0}{2} \\
\overline{\frac{\partial}{3}}\end{array}$ & $\begin{array}{l}\text { Reactive fibre surfaces:Reactive sheepskin } \\
\text { surfaces }\end{array}$ & 0 & $\begin{array}{l}\text { Major con- } \\
\text { cerns }\end{array}$ & Undetected & No concerns & $\begin{array}{l}\text { Major con- } \\
\text { cerns }\end{array}$ & No concerns & No concerns & Very low \\
\hline 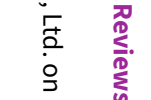 & $\begin{array}{l}\text { Reactive fibre surfaces: Reactive water sur- } \\
\text { faces }\end{array}$ & 0 & $\begin{array}{l}\text { Major con- } \\
\text { cerns }\end{array}$ & Undetected & No concerns & $\begin{array}{l}\text { Major con- } \\
\text { cerns }\end{array}$ & No concerns & No concerns & Very low \\
\hline 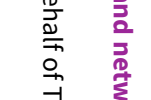 & Reactive fibre surfaces:RIK overlay & 0 & $\begin{array}{l}\text { Major con- } \\
\text { cerns }\end{array}$ & Undetected & No concerns & $\begin{array}{l}\text { Major con- } \\
\text { cerns }\end{array}$ & No concerns & No concerns & Very low \\
\hline 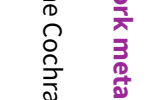 & $\begin{array}{l}\text { Reactive fibre surfaces:Standard hospital } \\
\text { surfaces }\end{array}$ & 0 & $\begin{array}{l}\text { Major con- } \\
\text { cerns }\end{array}$ & Undetected & No concerns & $\begin{array}{l}\text { Major con- } \\
\text { cerns }\end{array}$ & No concerns & No concerns & Very low \\
\hline 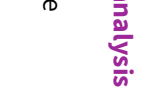 & $\begin{array}{l}\text { Reactive gel surfaces:Reactive sheepskin } \\
\text { surfaces }\end{array}$ & 0 & $\begin{array}{l}\text { Some con- } \\
\text { cerns }\end{array}$ & Undetected & No concerns & $\begin{array}{l}\text { Major con- } \\
\text { cerns }\end{array}$ & No concerns & No concerns & Very low \\
\hline
\end{tabular}




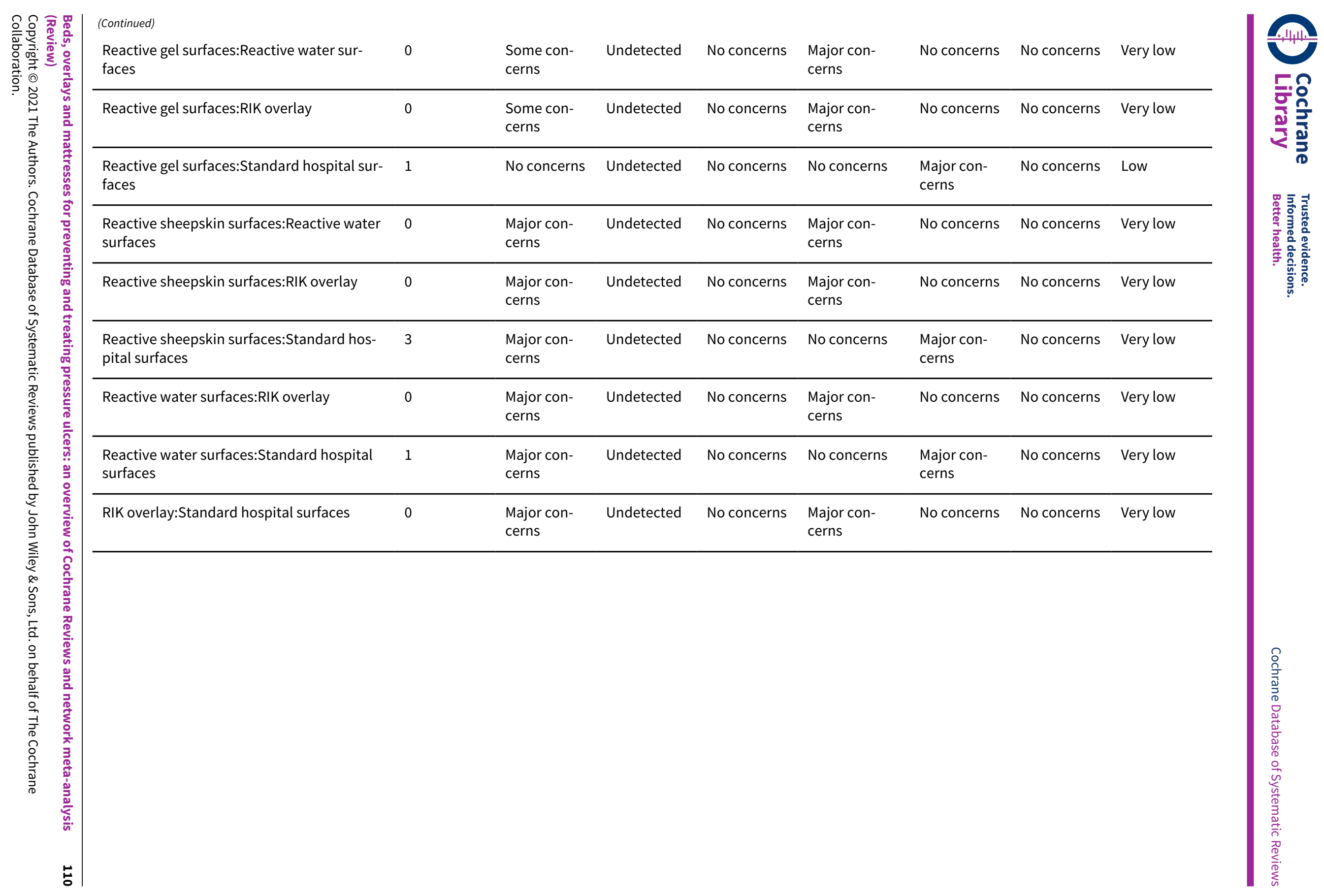


Ranking probabilities of each intervention in the base-case analysis

We present the cumulative probability plot for each support surface in Figure 9.

Figure 9. Prevention network: cumulative probability plot for each support surface evaluated in the base-case network. Cumulative probability plots show cumulative rank probabilities of each intervention being less than or equal to a given rank order. Note that SUCRA is the area under the plot for each support surface: higher SUCRA value $=$ higher probability of being the best intervention. The closer the probability of a rank to $100 \%$ and the narrower the overlap with the ranks of other interventions, the greater the confidence in the ranking. Note predictive probabilities incorporate heterogeneity into probability estimates.

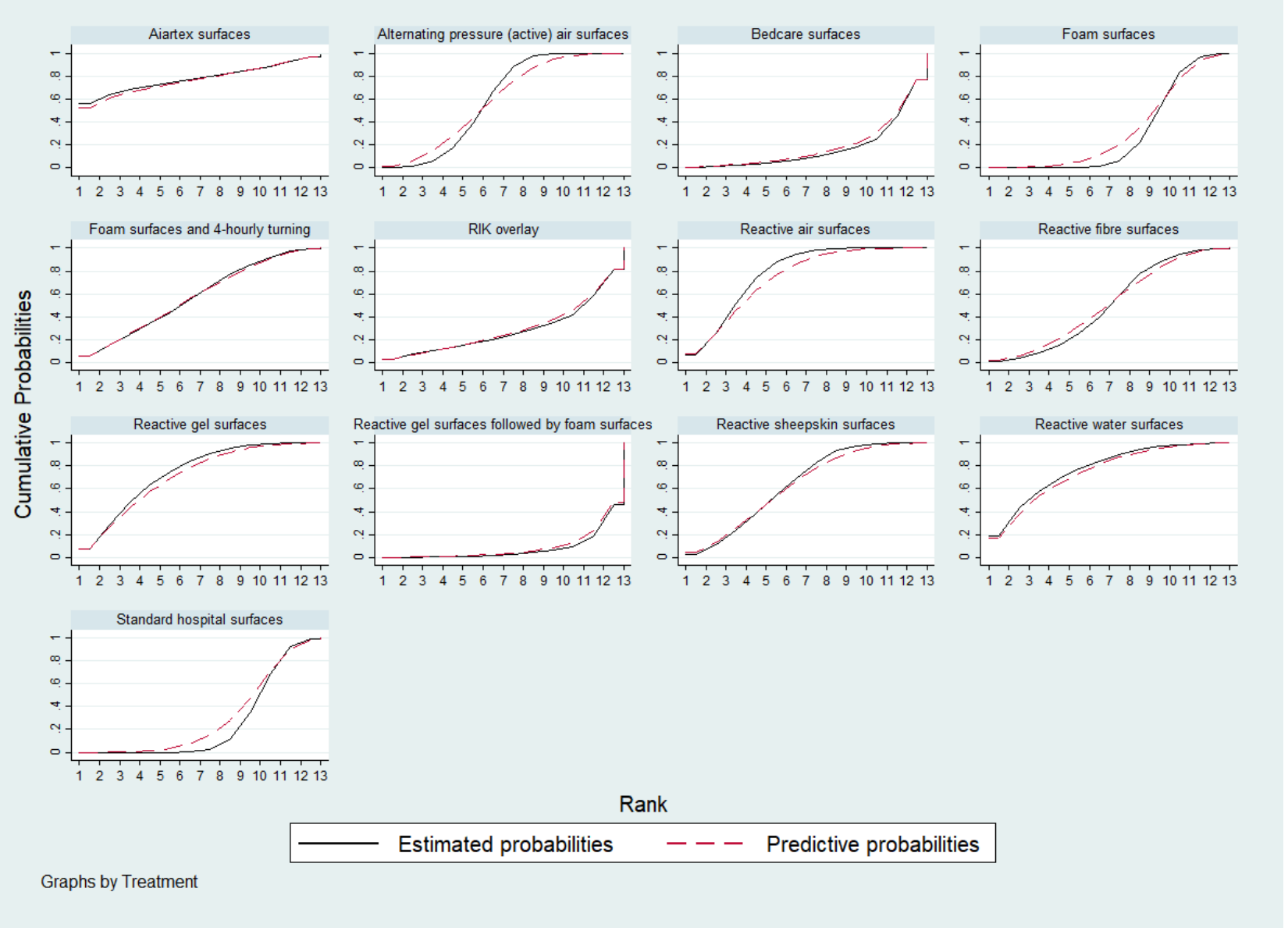

We estimated values of three ranking measures for each intervention in the base-case analysis. See full results in the table below.

Table 5. Ranking probabilities of each intervention in the base-case analysis

\begin{tabular}{llll}
\hline Interventions & $\begin{array}{l}\text { SUCRA (estimated \% } \\
\text { (predicted \%)) }\end{array}$ & $\begin{array}{l}\text { Probability of being the } \\
\text { best (estimated \% (pre- } \\
\text { dicted \%)) }\end{array}$ & $\begin{array}{l}\text { Mean rank (estimated } \\
\text { values (predicted val- } \\
\text { ues)) }\end{array}$ \\
\hline Foam surfaces & $30.2(33.5)$ & $0.0(0.0)$ & $9.4(9.0)$ \\
\hline Reactive air surfaces & $78.1(74.5)$ & $6.0(7.8)$ & $3.6(4.1)$ \\
\hline Alternating pressure (active) air surfaces & $59.3(59.0)$ & $0.1(1.4)$ & $5.9(5.9)$ \\
\hline
\end{tabular}

Beds, overlays and mattresses for preventing and treating pressure ulcers: an overview of Cochrane Reviews and network meta-analysis 111 (Review)

Copyright $\odot 2021$ The Authors. Cochrane Database of Systematic Reviews published by John Wiley \& Sons, Ltd. on behalf of The Cochrane Collaboration. 
(Continued)

\begin{tabular}{llll} 
Reactive gel surfaces & $74.6(71.7)$ & $7.0(7.8)$ & $4.0(4.4)$ \\
\hline Reactive sheepskin surfaces & $64.1(62.7)$ & $2.6(3.5)$ & $0.3(5.5)$ \\
\hline Reactive fibre surfaces & $50.6(51.5)$ & $0.7(1.5)$ & $3.7(4.0)$ \\
\hline Reactive water surfaces & $77.7(75.0)$ & $18.4(16.7)$ & $12.1(11.9)$ \\
\hline Reactive gel surfaces followed by foam surfaces & $7.6(9.2)$ & $0.1(0.1)$ & $9.9(9.4)$ \\
\hline Standard hospital surfaces & $25.7(29.9)$ & $0.0(0.0)$ & $3.6(3.7)$ \\
\hline Aiartex surfaces & $78.3(77.4)$ & $56.5(52.7)$ & $10.9(10.7)$ \\
\hline Bedcare surfaces & $17.3(18.9)$ & $0.4(0.4)$ & $9.5(9.4)$ \\
\hline RIK overlay & $29.0(29.7)$ & $3.3(2.9)$ & $6.1(6.2)$ \\
\hline Foam surfaces and 4-hourly turning & $57.5(57.0)$ & $4.9(5.2)$ & \\
\hline
\end{tabular}

In the Table, SUCRA value is a numerical summary of the cumulative probability plot for each support surface, and the plot shows cumulative rank probabilities that each intervention is less than or equal to a specific rank order against all possible ranks. The higher the SUCRA value, the higher the probability of being the best intervention. Probability of being the best value is the proportion of an intervention being ranked at the first place among a great number of repeated estimations for the intervention (simulations). Mean rank is the mean value of the distribution for the rank of each intervention. In the above table, all predicted values incorporate heterogeneity into value estimates.

All SUCRA values were less than $80.0 \%$ and they show considerable overlap, reflecting uncertainties in ranking. There are also overlaps between interventions for other two ranking measures (probability values of being the best interventions, and mean ranks). Here, Aiartex surfaces had the highest probability of being the best intervention. However, the ranking is probably artificially high: the direct evidence for the Aiartex surfaces involves only two small studies with a total of 122 participants (one event) and Aiartex surfaces correspond to 60 participants (no events). The NMA results of network contrasts involving Aiartex surfaces all have very wide Cls. These data limitations mean that it is unlikely that Aiartex surfaces are the most effective intervention.

We assessed the certainty of evidence regarding ranking and considered the ranking evidence of very low certainty. We downgraded once for risk of bias as the majority of data contributing to the base-case network (73.5\%) were at high risk of bias. We downgraded only once for both heterogeneity and inconsistency together. This is because the network had an overall substantial heterogeneity $\left(\right.$ Tau $\left.{ }^{2}=0.146\right)$ but the heterogeneity has limited impact on the rank order and the network had no global inconsistency.

We downgraded the evidence twice for imprecision: the network had sparse data and there are overlaps between interventions in terms of all rank order measures. We did not downgrade for indirectness. We did not downgrade for publication bias. This is because Figure 4 appears not to strongly suggest small-studies effects and the small number of included studies per each direct contrast $(40 / 13=3)$.

\section{Full results of sensitivity analyses}

\section{Sensitivity analysis using complete case data}

This sensitivity analysis included the same number of studies $(n=40)$ and 12,183 available participants. The analysis removed 334 cases from the total number of participants for the base-case analysis (12,517 participants). The sensitivity analysis had the same network as the base-case analysis. As with the base-case analysis, the sensitivity analysis had limitations in terms of risk of bias, heterogeneity (Tau ${ }^{2}$ $=0.165$ ), inconsistency (global test $P$ value $=0.918$ ), and imprecision. However, both analyses had no difference in relative effectiveness results for all but one network contrast, and no difference in rank orders of interventions. The exception is the comparison of standard hospital surfaces with reactive water surfaces. Its RR is 2.49 (95\% Cl 1.01 to 6.15$)$, not crossing RR = 1 in the base-case analysis, but in the sensitivity analysis, its RR is $2.46(95 \% \mathrm{Cl} 0.97$ to 6.20$)$, crossing RR $=1$. However, we considered this difference is not substantial and therefore the base-case network meta-analysis is not sensitive to missing data. Therefore, we did not report the details and results of this sensitivity analysis network. 


\section{Post hoc sensitivity analysis using eligible and well-defined support surfaces}

The post hoc sensitivity analysis contained 24 studies assessing seven interventions in 5686 participants with 494 events. It excluded interventions that were not well described and could not be classified, or were ineligible: Aiartex surfaces, Bedcare surfaces, RIK overlay, 'standard hospital surfaces', and foam surfaces plus four-hourly turning. As a result of these removals, reactive sheepskin surfaces that were linked to standard hospital surfaces only were also removed. This sensitivity analysis explored the impact of restricting the network to the set of support surfaces that could be classified and widely accessible in practice: foam surfaces, reactive air surfaces, alternating pressure (active) air surfaces, reactive gel surfaces, reactive fibre surfaces, reactive water surfaces, and reactive gel surfaces followed by foam surfaces.

\section{Network diagram and risk of bias assessment}

The network diagram for this sensitivity analysis is shown in Figure 10. This network had nine direct contrasts and three triangular loops. Three of the nine direct contrasts included only one study: foam surfaces versus reactive fibre surfaces; reactive air surfaces versus reactive gel surfaces; and reactive air surfaces versus reactive water surfaces. The comparison of alternating pressure (active) air surfaces versus foam surfaces included four studies; the comparison of alternating pressure (active) air surfaces versus reactive air surfaces included six studies; alternating pressure (active) air surfaces versus reactive fibre surfaces included three studies; alternating pressure (active) air surfaces versus reactive gel surfaces followed by foam surfaces included two studies; alternating pressure (active) air surfaces versus reactive water surfaces included two studies; and foam surfaces versus reactive air surfaces included four studies.

\section{Figure 10. Prevention network: network diagram of post hoc sensitivity analysis of seven eligible and well defined} support surfaces

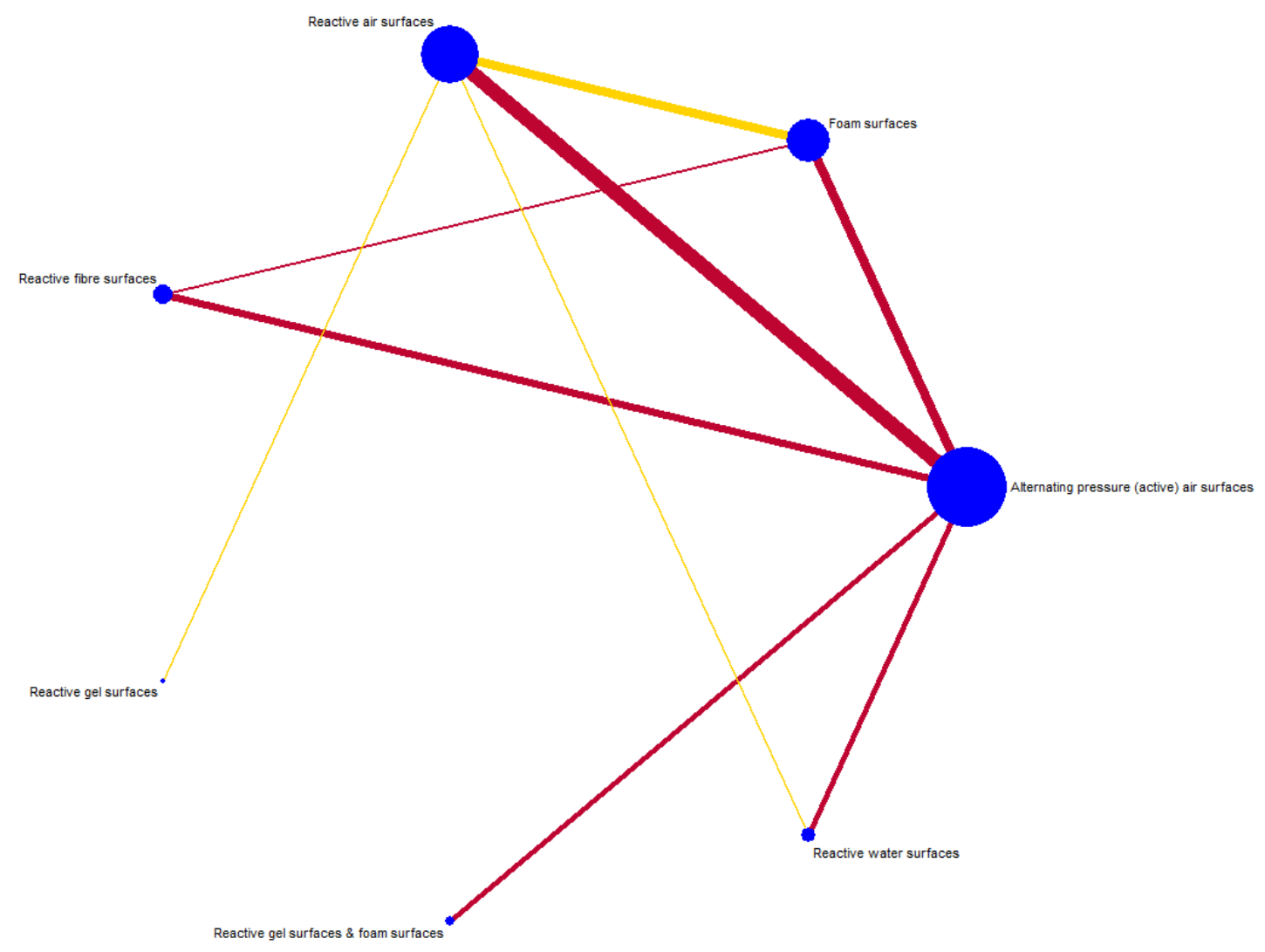

The sensitivity analysis network has 21 network contrasts. The average number of events per network contrast was around 24 (494/21). The data were sparse and the relative effectiveness estimates of almost all network contrasts had wide confidence intervals and crossed RR $=1$.

Figure 10 shows that three of nine direct comparisons were at unclear risk of bias whilst the remaining six direct comparisons were at high risk. Considering the risk of bias for each direct comparison and their percentage contributions to the whole network, we found that $23.4 \%$ of data were at unclear risk of bias and the remaining $76.6 \%$ were at high risk of bias.

Beds, overlays and mattresses for preventing and treating pressure ulcers: an overview of Cochrane Reviews and network meta-analysis 


\section{Network meta-analysis results}

We undertook a random-effects network meta-analysis and report the relative effectiveness results for all 21 network contrasts with RRs and their $95 \% \mathrm{Cls}$ in Figure 11. In comparison with the base-case analysis (Figure 3), the post hoc sensitivity analysis resulted in no substantial difference in the relative effectiveness results for 19 of these 21 network contrasts (Figure 11). There are two exceptions, however: alternating pressure (active) air surfaces versus reactive air surfaces had a RR of 1.66 ( $95 \% \mathrm{Cl} 1.08$ to 2.53 ), and reactive fibre surfaces versus reactive air surfaces had a RR of $1.83(95 \% \mathrm{Cl} 1.13$ to 3.05$)$ in the sensitivity analysis. The base-case analysis reported similar results for these two comparisons but their Cls crossed $R R=1$ in the base-case analysis. Therefore, the base-case analysis is not sensitive to the exclusion of the above five interventions despite the fact that this sensitivity analysis appears to suggest that reactive air surfaces result in a lower pressure ulcer risk compared with alternating pressure (active) air surfaces and reactive fibre surfaces. We should be cautious about interpretations of these two contrasts' results in the base-case analysis.

\section{Figure 11. Prevention network: relative effectiveness results expressed in RRs and $95 \% \mathrm{Cls}$ for the post hoc sensitivity analysis}

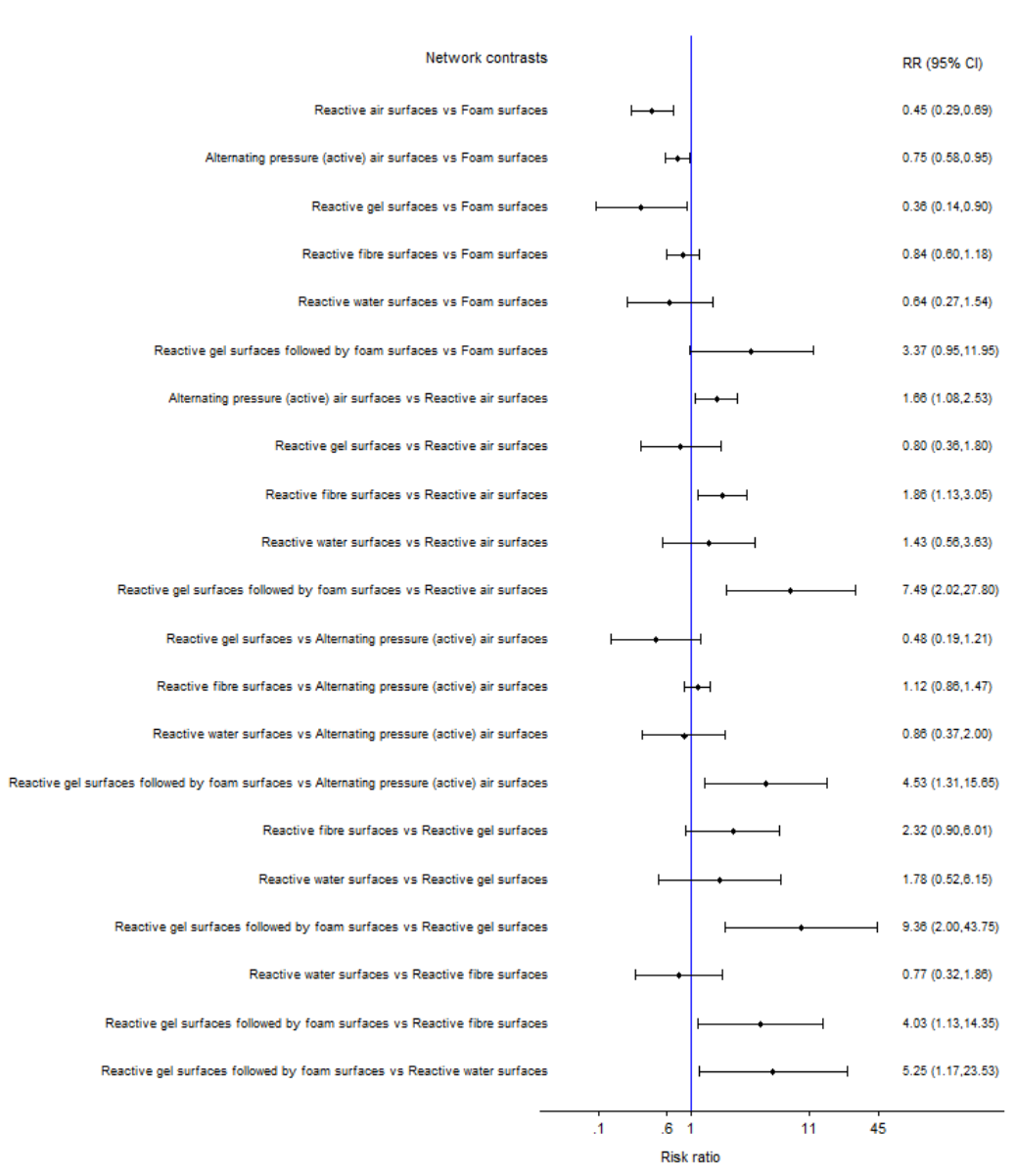

We report the rank order for all seven support surfaces in the network and the cumulative probability of a particular intervention being the best, second best, third best (etc.) intervention for preventing pressure ulcers in Figure 12. The SUCRA probabilities of being the best, and mean rank for each support surface are below. 
Figure 12. Prevention network: cumulative probability plot for each support surface evaluated in the post hoc sensitivity analysis. Cumulative probability plots show cumulative rank probabilities of each intervention being less than or equal to a given rank order. Note that SUCRA is the area under the plot for each support surface: higher SUCRA value = higher probability of being the best intervention. Note predictive probabilities incorporate heterogeneity into probability estimates.
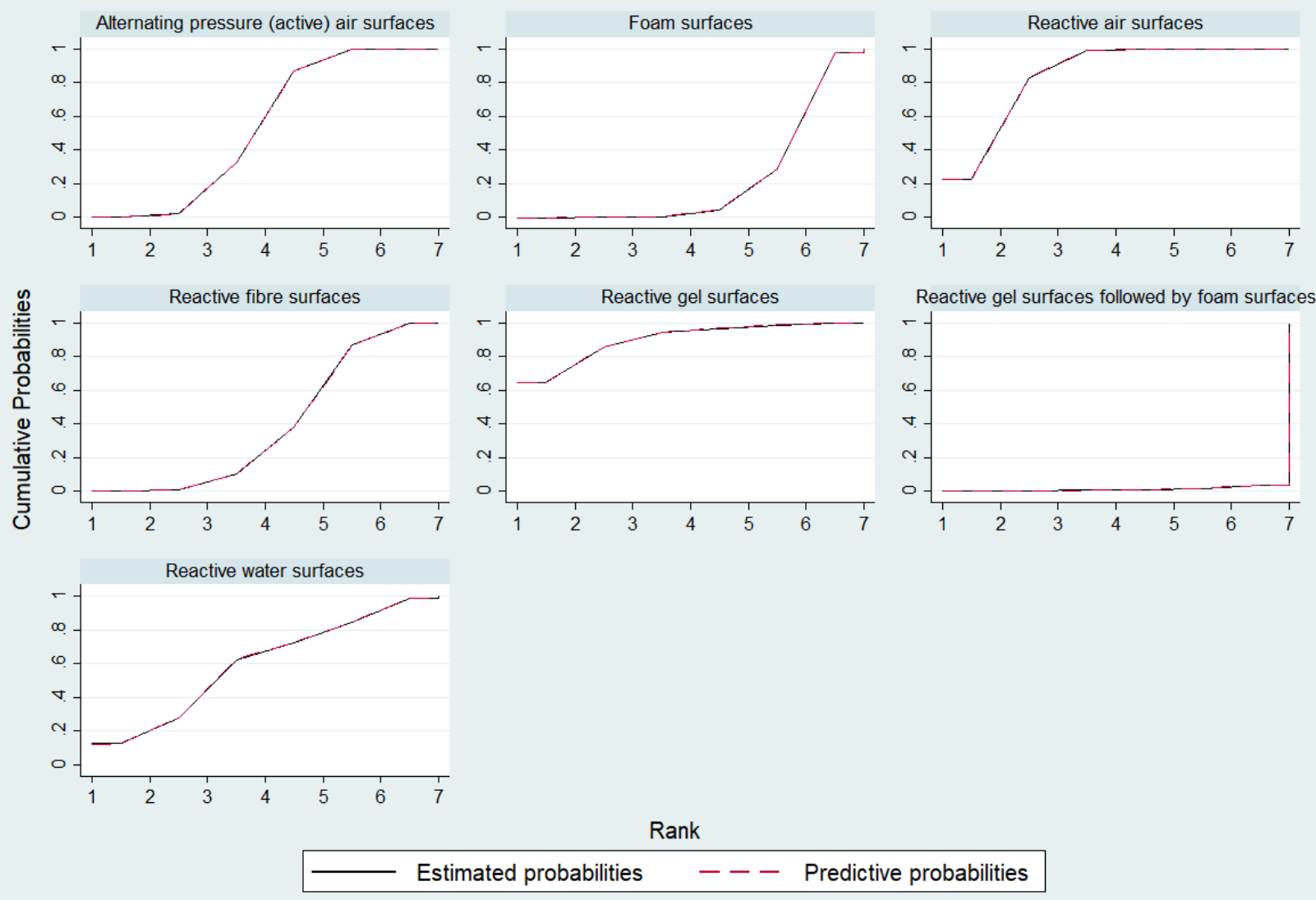

Graphs by Treatment

Table 6. Ranking probabilities of each intervention in the sensitivity analysis

\begin{tabular}{llll}
\hline Interventions & $\begin{array}{l}\text { SUCRA (estimated \% } \\
\text { (predicted \%)) }\end{array}$ & $\begin{array}{l}\text { Probability of being the } \\
\text { best (estimated \% (pre- } \\
\text { dicted \%)) }\end{array}$ & $\begin{array}{l}\text { Mean rank (estimated } \\
\text { values (predicted val- } \\
\text { ues)) }\end{array}$ \\
\hline Foam surfaces & $21.9(21.9)$ & $0.0(0.0)$ & $5.7(5.7)$ \\
\hline Reactive air surfaces & $84.1(84.1)$ & $22.6(22.5)$ & $3.0(2.0)$ \\
\hline Alternating pressure (active) air surfaces & $53.7(53.6)$ & $0.1(0.1)$ & $1.6(3.8)$ \\
\hline Reactive gel surfaces & $89.9(90.0)$ & $64.4(64.7)$ & $4.6(4.6)$ \\
\hline Reactive fibre surfaces & $39.3(39.3)$ & $0.1(0.1)$ & $3.4(3.4)$ \\
\hline Reactive water surfaces & $59.9(59.9)$ & $12.7(12.5)$ & \\
\hline
\end{tabular}

Beds, overlays and mattresses for preventing and treating pressure ulcers: an overview of Cochrane Reviews and network meta-analysis 
(Continued)

Reactive gel surfaces followed by foam surfaces
$1.3(1.2)$

$0.1(0.0)$

$6.9(6.9)$

This table suggests that, numerically, reactive air surfaces, reactive water surfaces and reactive gel surfaces still have the highest estimated SUCRA values (84.1\%, 59.9\% and 89.9\%, respectively; Figure 12). However, the overlaps in terms of rank orders between these support surfaces are smaller in the sensitivity analysis than in the base-case analysis. Therefore, interpretations of their rank orders for the basecase analysis should be cautious.

The sensitivity analysis network presents no heterogeneity $\left(\operatorname{Tau}^{2}=0\right)$. Regarding publication bias, Figure 13 also appears to indicate a slight small-studies-effect, which is consistent with the base-case analysis.

Figure 13. Prevention network: funnel plot of the sensitivity analysis network for pressure ulcer incidence outcome

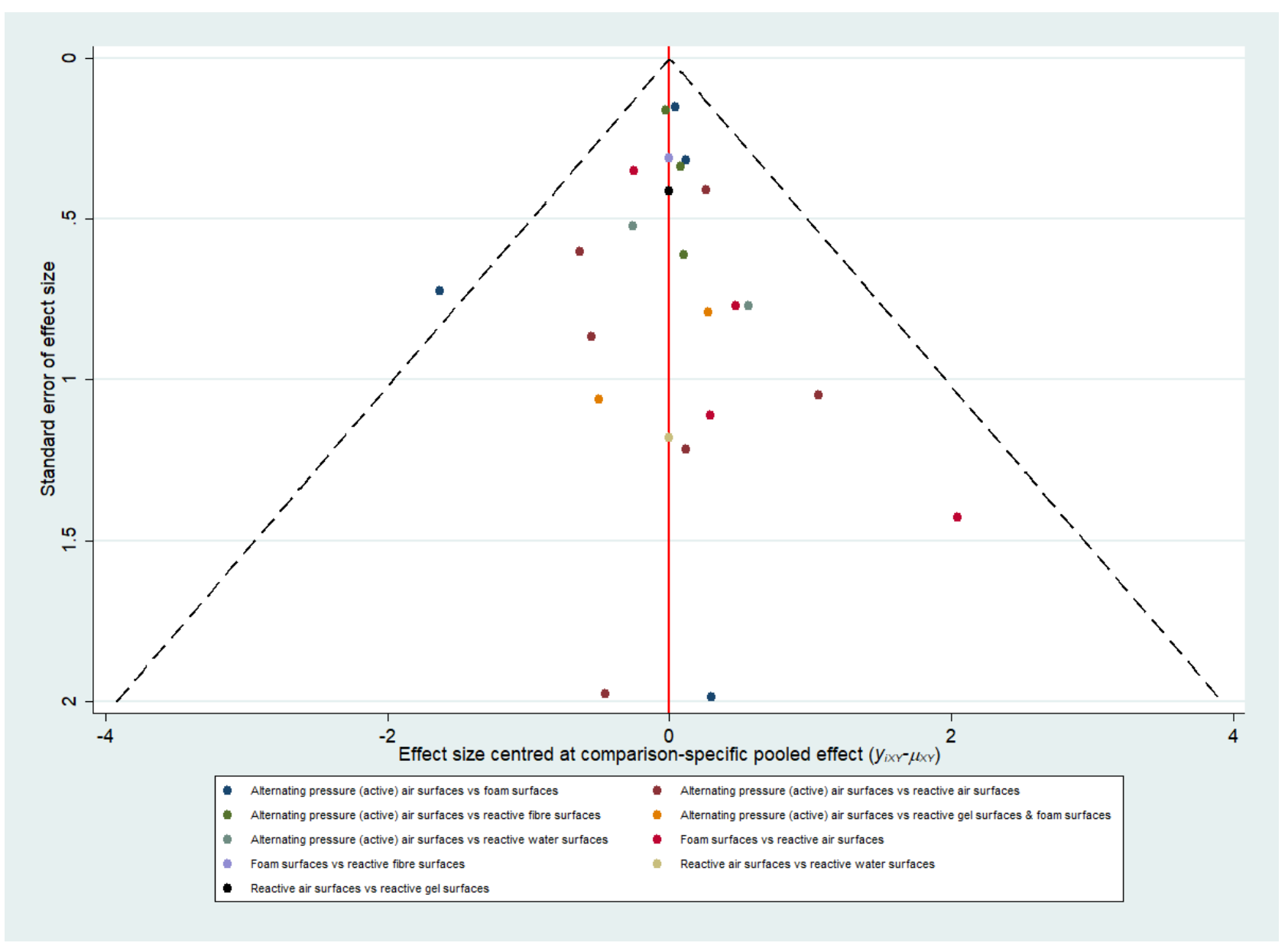

\section{Comparison of results from standard (pairwise) meta-analysis with NMA findings}

We reproduced results of standard (pairwise) meta-analysis using reported data for 12 direct comparisons and compared these with the corresponding results from the base-case network meta-analysis. The table below shows that no statistical difference was identified for these 12 comparisons.

Table 7. Comparison of results from standard (pairwise) meta-analysis with NMA findings

Beds, overlays and mattresses for preventing and treating pressure ulcers: an overview of Cochrane Reviews and network meta-analysis 


\begin{tabular}{|c|c|c|c|}
\hline Interventions & $\begin{array}{l}\text { Pairwise meta- } \\
\text { analysis results, } \\
\text { RR }(95 \% \mathrm{CI})\end{array}$ & $\begin{array}{l}\text { NMA results, RR } \\
(95 \% \mathrm{CI})\end{array}$ & $\begin{array}{l}\text { Difference between two } \\
\text { types of analysis results }\end{array}$ \\
\hline Alternating pressure (active) air surfaces vs foam surfaces & $0.63(0.34$ to 1.17$)$ & 0.63 (0.42 to 0.93$)$ & No statistical difference \\
\hline $\begin{array}{l}\text { Alternating pressure (active) air surfaces vs reactive air } \\
\text { surfaces }\end{array}$ & 1.61 (0.90 to 2.88$)$ & 1.35 (0.82 to 2.20$)$ & No statistical difference \\
\hline $\begin{array}{l}\text { Reactive water surfaces vs alternating pressure (active) air } \\
\text { surfaces vs }\end{array}$ & 0.83 (0.35 to 1.92$)$ & 0.69 (0.28 to 1.70$)$ & No statistical difference \\
\hline $\begin{array}{l}\text { Reactive fibre surfaces vs alternating pressure (active) air } \\
\text { surfaces }\end{array}$ & 1.11 (0.84 to 1.47$)$ & 1.14 (0.66 to 1.98$)$ & No statistical difference \\
\hline $\begin{array}{l}\text { Reactive gel surfaces followed by foam surfaces vs alter- } \\
\text { nating pressure (active) air surfaces }\end{array}$ & 4.55 (1.28 to 16.67$)$ & 4.60 (1.18 to 17.86$)$ & No statistical difference \\
\hline Reactive air surfaces vs foam surfaces & 0.42 (0.18 to 0.96$)$ & $0.46(0.29$ to 0.75$)$ & No statistical difference \\
\hline Reactive fibre surfaces vs foam surfaces & 0.85 (0.47 to 1.56$)$ & $0.71(0.38$ to 1.34$)$ & No statistical difference \\
\hline Bedcare surfaces vs foam surfaces & 1.79 (0.62 to 5.26$)$ & 1.80 (0.49 to 6.58$)$ & No statistical difference \\
\hline Reactive water surfaces vs reactive air surfaces & $2.33(0.22$ to 25.00$)$ & $0.93(0.35$ to 2.47$)$ & No statistical difference \\
\hline Reactive gel surfaces vs reactive air surfaces & $0.80(0.36$ to 1.79$)$ & $1.02(0.48$ to 2.16$)$ & No statistical difference \\
\hline $\begin{array}{l}\text { Alternating pressure (active) air surfaces or RIK overlay vs } \\
\text { reactive air surfaces vs }\end{array}$ & $3.03(0.64$ to 14.29$)$ & $3.00(0.53$ to 16.87$)$ & No statistical difference \\
\hline Standard hospital surfaces vs reactive water surfaces & $2.86(1.25$ to 6.67$)$ & $1.50(0.78$ to 2.88$)$ & No statistical difference \\
\hline
\end{tabular}

\section{Appendix 9. References of the primary studies included in network meta-analyses}

\section{References of studies for the topic of pressure ulcer prevention}

We identified 69 potentially eligible studies in the topic of pressure ulcer prevention. Here is the list of references for these studies. We use an asterisk to indicate the primary reference where a study has multiple references.

\section{Allman 1987}

Allman RM, Walker JM, Hart MK, Laprade CA, Noel LB, Smith CR. Air-fluidized beds or conventional therapy for pressure sores. A randomised trial. Annals of Internal Medicine 1987;107(5):641-8.

\section{Andersen 1982}

Andersen KE, Jensen O, Kvorning SA, Bach E. Decubitus prophylaxis: a prospective trial on the efficacy of alternating-pressure airmattresses and water-mattresses. Acta Dermatovener (Stockholm) 1982;63:227-30.

\section{Aronovitch 1999}

* Aronovitch SA, Wilber M, Slezak S, Martin T, Utter D. A comparative study of an alternating air mattress for the prevention of pressure ulcers in surgical patients. Ostomy/Wound Management 1999;45(3):34-44.

Aronovitch SA. A comparative, randomised, controlled study to determine safety and efficacy of preventive pressure ulcer systems: preliminary analysis. Advances in Wound Care 1998;11 (3 Suppl):15-6. 


\section{Ballard 1997}

Ballard K. Pressure-relief mattresses and patient comfort. Professional Nurse 1997;13(1):27-32.

\section{Beeckman 2019}

Anrys C, Van Tiggelen H, Verhaeghe S, Van Hecke A, Beeckman D. Independent risk factors for pressure ulcer development in a highrisk nursing home population receiving evidence-based pressure ulcer prevention: results from a study in 26 nursing homes in Belgium. International Wound Journal 2019;16(2):325-33.

* Beeckman D, Serraes B, Anrys C, Van Tiggelen H, Van Hecke A, Verhaeghe S. A multicentre prospective randomised controlled clinical trial comparing the effectiveness and cost of a static air mattress and alternating air pressure mattress to prevent pressure ulcers in nursing home residents. International Journal of Nursing Studies 2019;97:105-13.

NCT03597750. Comparison of static air support devices (Repose $\left.{ }^{\circledR}\right)$ and alternating-pressure devices in the prevention of pressure ulcers. ClinicalTrials.gov/show/NCT03597750.

\section{Bennett 1998}

Bennett RG, Baran PJ, DeVone LV, Bacetti H, Kristo B, Tayback M, et al. Low airloss hydrotherapy versus standard care for incontinent hospitalized patients. Journal of the American Geriatrics Society 1998;46(5):569-76.

\section{Berthe 2007}

Berthe JV, Bustillo A, Mélot C, De Fontaine D. Does a foamy-block mattress system prevent pressure sores? A prospective randomised clinical trial in 1729 patients. Acta Chirurgica Belgica 2007;107(2):155-61.

\section{Bliss 1967}

Bliss MR, McLaren R, Exton-Smith AN. Preventing pressure sores in hospital: controlled trial of a large-celled ripple mattress. BMJ 1967;1(5537):394-7.

\section{Bliss 1995}

* Bliss MR. Preventing pressure sores in elderly patients: a comparison of seven mattress overlays. Age and Ageing 1995;24:297-302.

Bliss MR. Randomised controlled trial of seven pressure relieving mattress overlays for preventing pressure sores in elderly patients. Tissue Viability Society Conference 1994:5.

\section{Bueno de Camargo 2018}

* Bueno de Camargo WH, Pereira RD, Tanita MT, Heko L, Grion IC, Festti J, et al. The effect of support surfaces on the incidence of pressure injuries in critically ill patients: a randomised clinical trial. Critical Care Research and Practice 2018;2018:Article ID 3712067.

NCT02844166. Support surfaces to prevent pressure injuries. clinicaltrials.gov/show/NCT02844166.

\section{Cassino 2013}

Cassino R, Ippolito AM, Ricci E. Comparison of two mattress overlays in the prevention of pressure ulcers. Acta Vulnologica 2013;11(1):15-21.

\section{Cavicchioli 2007}

Cavicchioli A, Carella G. Clinical effectiveness of a low-tech versus high-tech pressure-redistributing mattress. Journal of Wound Care 2007;16(7):285-9.

\section{Cobb 1997}

Cobb GA, Yoder LH, Warren JB. Pressure ulcers: patient outcomes on a KinAir bed or EHOB waffle mattress. TriService Nursing Research Program (TSNRP) 1997.

\section{Collier 1996}

Collier ME. Pressure-reducing mattresses. Journal of Wound Care 1996;5(5):207-11.

\section{Conine 1990}

*Conine TA, Daechsel D, Choi AK, Lau MS. Costs and acceptability of two special overlays for the prevention of pressure sores. Rehabilitation Nursing 1990;15(3):133-7.

Conine TA, Daechsel D, Lau MS. The role of alternating air and Silicore overlays in preventing decubitus ulcers. International Journal of Rehabilitation Research 1990;13(1):133-7.

Beds, overlays and mattresses for preventing and treating pressure ulcers: an overview of Cochrane Reviews and network meta-analysis 118 (Review)

Copyright (c) 2021 The Authors. Cochrane Database of Systematic Reviews published by John Wiley \& Sons, Ltd. on behalf of The Cochrane Collaboration. 


\section{Cooper 1998}

Cooper PJ, Gray DG, Mollison J. A randomised controlled trial of two pressure-reducing surfaces. Journal of Wound Care 1998;7(8):374-6.

\section{Daechsel 1985}

Daechsel D, Conine TA. Special mattresses: effectiveness in preventing decubitus ulcers in chronic neurologic patients. Archives of Physical Medicine and Rehabilitation 1985;66(4):246-8.

\section{Demarre 2012}

* Demarre L, Beeckman D, Vanderwee K, Defloor T, Grypdonck M, Verhaeghe S. Multi-stage versus single-stage inflation and deflation cycle for alternating low pressure air mattresses to prevent pressure ulcers in hospitalised patients: a randomised-controlled clinical trial. International Journal of Nursing Studies 2012;49(4):416-26.

Demarre L, Vanderwee K, Beeckman D, Defloor T. Pressure ulcer prevention: randomised controlled trial comparing the effect of a standard alternating pressure air mattress and a alternating low pressure air mattress with gradual inflation and deflation. EWMA Journal 2010;10(2):44.

Demarre L, Vanderwee K, Beeckman D, Defloor T. The effectiveness of a multistage low pressure air mattress in pressure ulcer prevention: an RCT Fourth European Nursing Congress. Journal of Clinical Nursing 2010;19:41.

Demarre L, Verhaeghe S, Van Hecke A, Grypdonck M, Clays E, Vanderwee K, et al. The effectiveness of three types of alternating pressure air mattresses in the prevention of pressure ulcers in Belgian hospitals. Research in Nursing \& Health 2013;36(5):439-52.

\section{Ewing 1964}

Ewing MR, Garrow C, Presley TA, Ashley C, Kisella NM. Further experiences in the use of sheep skins as an aid in nursing. Australian Nurses' Journal 1964;1964 September:215-9.

\section{Feuchtinger 2006}

* Feuchtinger J, De Bie R, Dassen T, Halfens R. A 4-cm thermoactive viscoelastic foam pad on the operating room table to prevent pressure ulcer during cardiac surgery. Journal of Clinical Nursing 2006;15(2):162-7.

Feuchtinger J. [Preventing decubitus ulcer in heart surgery interventions: visco-elastic foam layer on the operating room table--a study] [Dekubituspravention wahrend kardiochirurgischer Eingriffe: Viskoelastische Schaumstoffauflage auf dem Operationstisch--eine Studie]. Pflege Zeitschrift 2006;59(8):498-501.

\section{Finnegan 2008}

Finnegan MJ, Gazzerro L, Finnegan JO, Lo P. Comparing the effectiveness of a specialized alternating air pressure mattress replacement system and an air-fluidized integrated bed in the management of post-operative flap patients: a randomized controlled pilot study. Journal of Tissue Viability 2008;17(1):2-9.

\section{Gray 1994}

Gray D. A randomised clinical trial of two foam mattresses. Aberdeen Royal Hospitals NHS Trust. Medical Support System 1994:1-4.

Gray D. A randomised controlled trial of two foam mattresses. Journal of Tissue Viability 1994;4(3):92.

* Gray DG, Campbell M. A randomised clinical trial of two types of foam mattresses. Journal of Tissue Viability 1994;4(4):128-32.

Gray DG, Cooper PJ, Campbell M. A study of the performance of a pressure reducing foam mattress after three years of use. Journal of Tissue Viability 1998;8(3):9-13.

\section{Gray 2000}

Gray D, Smith M. A randomized controlled trial of two pressure-reducing foam mattresses. European Wound Management Association Conference; 1998 November; Harrogate (UK) 1998:4.

* Gray DG, Smith M. Comparison of a new foam mattress with the standard hospital mattress. Journal of Wound Care 2000;9(1):29-31.

\section{Gray 2008}

Gray D, Cooper P, Bertram M, Duguid K, Pirie G. A clinical audit of the Softform Premier Active ${ }^{\mathrm{TM}}$ mattress in two acute care of the elderly wards. Wounds UK 2008;4(4):124-8.

Beds, overlays and mattresses for preventing and treating pressure ulcers: an overview of Cochrane Reviews and network meta-analysis 


\section{Grindley 1996}

Grindley A, Acres J. Alternating pressure mattresses: comfort and quality of sleep. British Journal of Nursing (Mark Allen Publishing) 1996;5(21):1303-10.

\section{Gunningberg 2000}

Gunningberg L, Lindholm C, Carlsson M, Sjoden PO. Effect of visco-elastic foam mattresses on the development of pressure ulcers in patients with hip fractures. Journal of Wound Care 2000;9(10):455-60.

\section{Hampton 1997}

Hampton S. Evaluation of the new Cairwave Therapy System in one hospital trust. British Journal of Nursing (Mark Allen Publishing) 1997;6(3):167-70

\section{Hofman 1994}

Hofman A, Geelkerken RH, Wille J, Hamming JJ, Hermans J, Breslau PJ. Pressure sores and pressure-decreasing mattresses: controlled clinical trial. Lancet (London, England) 1994;343(8897):568-71.

\section{Hoshowsky 1994}

Hoshowsky VM, Schramm CA. Intraoperative pressure sore prevention: an analysis of bedding materials. Research in Nursing \& Health 1994;17(5):333-9.

\section{Inman 1993}

Inman KJ, Sibbald WJ, Rutledge FS, Clark BJ. Clinical utility and cost-effectiveness of an air suspension bed in the prevention of pressure ulcers. JAMA 1993;269(9):1139-43.

\section{IRCT2015110619919N3}

IRCT2015110619919N3. The effect of silicone protective pad on pressure ulcer. apps.who.int/trialsearch/Trial2.aspx? TrialID=IRCT2015110619919N3 2016.

\section{Jiang 2014}

Jiang Q, Li X, Zhang A, Guo Y, Liu Y, Liu H, et al. Multicenter comparison of the efficacy on prevention of pressure ulcer in postoperative patients between two types of pressure-relieving mattresses in China. International Journal of Clinical and Experimental Medicine 2014;7(9):2820-7.

\section{Jolley 2004}

* Jolley DJ, Wright R, McGowan S, Hickey MB, Campbell DA, Sinclair RD, et al. Preventing pressure ulcers with the Australian Medical Sheepskin: an open-label randomised controlled trial. Medical Journal of Australia 2004;180(7):324-7.

Jolley DJ. A multilevel analysis of three randomised controlled trials of the Australian Medical Sheepskin in the prevention of sacral pressure ulcers. Medical Journal of Australia 2011;194(2):104.

\section{Kemp 1993}

Kemp MG, Kopanke D, Tordecilla L, Fogg L, Shott S, Matthiesen V, et al. The role of support surfaces and patient attributes in preventing pressure ulcers in elderly patients. Research in Nursing \& Health 1993;16(2):89-96.

\section{Laurent 1998}

Laurent S. Effectiveness of pressure decreasing mattresses in cardiovascular surgery patients: a controlled clinical trial. 3rd European Conference for Nurse Managers, 1997 Oct; Brussels (Belgium) 1998.

\section{Lazzara 1991}

Lazzara DJ, Buschmann MT. Prevention of pressure ulcers in elderly nursing home residents: are special support surfaces the answer? Decubitus 1991;4(4):42-4, 46, 48.

\section{Malbrain 2010}

Malbrain M, Hendriks B, Wijnands P, Denie D, Jans A, Vanpellicom J, et al. A pilot randomised controlled trial comparing reactive air and active alternating pressure mattresses in the prevention and treatment of pressure ulcers among medical ICU patients. Journal of Tissue Viability 2010;19(1):7-15.

Beds, overlays and mattresses for preventing and treating pressure ulcers: an overview of Cochrane Reviews and network meta-analysis 


\section{McGowan 2000}

McGowan S, Montgomery K, Jolley D, Wright R. The role of sheepskins in preventing pressure ulcers in elderly orthopaedic patients. Primary Intention 2000:127-34.

\section{Mistiaen 2010}

Mistiaen P, Achterberg W, Ament A, Halfens R, Huizinga J, Montgomery K, et al. Cost-effectiveness of the Australian Medical Sheepskin for the prevention of pressure ulcers in somatic nursing home patients: study protocol for a prospective multi-centre randomised controlled trial (ISRCTN17553857). BMC Health Services Research 2008;8:4.

* Mistiaen P, Achterberg W, Ament A, Halfens R, Huizinga J, Montgomery K, et al. The effectiveness of the Australian Medical Sheepskin for the prevention of pressure ulcers in somatic nursing home patients: a prospective multicenter randomized-controlled trial (ISRCTN17553857). Wound Repair and Regeneration 2010;18(6):572-9.

Mistiaen P, Ament A, Francke AL, Achterberg W, Halfens R, Huizinga J, et al. An economic appraisal of the Australian Medical Sheepskin for the prevention of sacral pressure ulcers from a nursing home perspective. BMC Health Services Research 2010;10:226.

Mistiaen P, Francke A, Achterberg W, Ament A, Halfens R, Huizinga J. Australian Medical Sheepskin is effective for the prevention of pressure ulcers. Tijdschrift voor Ouderengeneeskunde 2009;5:186-90.

\section{Nixon 1998}

Bridel-Nixon J, McElvenny D, Brown J, Mason S. A randomized controlled trial using a double-triangular sequential design: methodology and management issues. European Wound Management Association Conference; 1997 April 27-29; Milan (Italy) 1997:65-6.

Bridel-Nixon J, McElvenny D, Brown J, Mason S. Findings from a double-triangular sequential-design randomized clinical trial of a dry polymer gel pad. European Wound Management Association Conference; 1997 April 27-29; Milan (Italy) 1997:20-1.

Brown J, McElvenny D, Nixon J, Bainbridge J, Mason S. Some practical issues in the design, monitoring and analysis of a sequential randomized trial in pressure sore prevention. Statistics in Medicine 2000;19(24):3389-400.

ISRCTN43076542. Pressure sore risk in the operating department. www.who.int/trialsearch/Trial2.aspx?TrialID=ISRCTN43076542.

* Nixon J, McElvenny D, Mason S, Brown J, Bond S. A sequential randomised controlled trial comparing a dry visco-elastic polymer pad and standard operating table mattress in the prevention of post-operative pressure sores. International Journal of Nursing Studies 1998;35(4):193-203.

\section{Nixon 2006}

ISRCTN78646179. Randomised controlled trial comparing alternating pressure overlays with alternating pressure mattresses for pressure sore prevention and treatment. isrctn.com/ISRCTN78646179.

Nelson EA, Nixon J, Mason S, Barrow H, Phillips A, Cullum N. A nurse-led randomised trial of pressure-relieving support surfaces. Professional Nurse (London, England) 2003;18(9):513-6.

Nixon J, Cranny G, Iglesias C, Nelson EA, Hawkins K, Phillips A, et al. Randomised, controlled trial of alternating pressure mattresses compared with alternating pressure overlays for the prevention of pressure ulcers: PRESSURE (pressure relieving support surfaces) trial. BMJ 2006;332(7555):1413-5.

Nixon J, Cranny G, Nelson A, Iglesias C, Phillips A, Hawkins K, et al. Pressure trial clinical and patient outcomes. European Wound Management Association; 1998 November; Harrogate, UK 2005:157.

Nixon J, Cranny G, Nelson A, Iglesias C, Phillips A, Hawkins K, et al. The NHS Health Technology Assessment Programme. Pressure trial clinical and patient outcomes. EWMA Journal 2006;6(1):38.

* Nixon J, Nelson EA, Cranny G, Iglesias CP, Hawkins K, Cullum NA, et al. Pressure relieving support surfaces: a randomised evaluation. Health Technology Assessment (Winchester, England) 2006;10(22):1-163.

Nixon J, Thorpe H, Barrow H, Phillips A, Nelson EA, Mason SA, et al. Reliability of pressure ulcer classification and diagnosis. Journal of Advanced Nursing 2005;50(6):613-23.

Nixon J. Erratum: randomised, controlled trial of alternating pressure mattresses compared with alternating pressure overlays for the prevention of pressure ulcers: PRESSURE (pressure relieving support surfaces) trial (British Medical Journal (July 1, 2006) 333 (30)). BMJ 2006;333:30.

Beds, overlays and mattresses for preventing and treating pressure ulcers: an overview of Cochrane Reviews and network meta-analysis 


\section{Nixon 2019}

Brown S, Smith I, Brown J, Hulme C, Nixon J. Pressure relieving support surfaces: a randomised evaluation 2 (PRESSURE 2). Trials 2013;14(Suppl 1):P68.

Brown S, Smith IL, Brown JM, Hulme C, McGinnis E, Stubbs N, et al. Pressure RElieving Support SUrfaces: a Randomised Evaluation 2 (PRESSURE 2): study protocol for a randomised controlled trial. Trials 2016;17(1):604.

ISRCTN01151335. Pressure RElieving Support SUrfaces: a Randomised Evaluation 2. isrctn.com/ISRCTN01151335.

McGinnis E, Brown S, Collier H, Faulks P, Gilberts R, Greenwood C, et al. Pressure RElieving Support SUrfaces: a Randomised Evaluation 2 (PRESSURE 2) photographic validation sub-study: study protocol for a randomised controlled trial. Trials 2017;18(1):132.

* Nixon J, Brown S, Smith IL, McGinnis E, Vargas-Palacios A, Nelson EA, et al. Comparing alternating pressure mattresses and highspecification foam mattresses to prevent pressure ulcers in high-risk patients: the PRESSURE 2 RCT. Health Technology Assessment (Winchester, England) 2019;23(52):1-176.

Nixon J, Smith IL, Brown S, McGinnis E, Vargas-Palacios A, Nelson EA, et al. Pressure relieving support surfaces for pressure ulcer prevention (PRESSURE 2): clinical and health economic results of a randomised controlled trial. E Clinical Medicine 2019;14:42-52.

\section{Ozyurek 2015}

Ozyurek P, Yavuz M. Prevention of pressure ulcers in the intensive care unit: a randomized trial of 2 viscoelastic foam support surfaces. Clinical Nurse Specialist CNS 2015;29(4):210-7.

\section{Park 2017}

Park KH, Park J. The efficacy of a viscoelastic foam overlay on prevention of pressure injury in acutely ill patients: a prospective randomized controlled trial. Journal of Wound, Ostomy, and Continence Nursing 2017;44(5):440-4.

\section{Phillips 1999}

Phillips L. Providing correct pressure-relieving devices for optimum outcome. British Journal of Nursing (Mark Allen Publishing) 1999;8(21):1447-52.

\section{Price 1999}

Price P, Bale S, Newcombe R, Harding K. Challenging the pressure sore paradigm. Journal of Wound Care 1999;8(4):187-90.

\section{Pring 1998}

Pring J, Millman P. Evaluating pressure-relieving mattresses. Journal of Wound Care 1998;7(4):177-9.

\section{Rafter 2011}

Rafter L. Evaluation of patient outcomes: pressure ulcer prevention mattresses. British Journal of Nursing 2011;20(11):32.

\section{Ricci 2013}

Ricci E, Roberto C, Ippolito A, Bianco A, Scalise MT. A randomized study on the effectiveness of a new pressure-relieving mattress overlay for the prevention of pressure ulcers in elderly patients at risk. EWMA Journal 2013;13(1):27-32.

\section{Rosenthal 2003}

Rosenthal MJ, Felton RM, Nastasi AE, Naliboff BD, Harker J, Navach JH. Healing of advanced pressure ulcers by a generic total contact seat: 2 randomized comparisons with low air loss bed treatments. Archives of Physical Medicine and Rehabilitation 2003;84(12):1733-42.

\section{Russell 2000}

Dunlop V. Preliminary results of a randomized, controlled study of a pressure ulcer prevention system. Advances in Wound Care 1998;11(3 Suppl):14.

Lichtenstein S. A 7 day comparative randomized parallel single centre study to determine the safety and efficacy of the Micropulse system for the prevention of pressure ulcers. Micropulse 1997.

${ }^{*}$ Russell JA, Lichtenstein SL. Randomized controlled trial to determine the safety and efficacy of a multi-cell pulsating dynamic mattress system in the prevention of pressure ulcers in patients undergoing cardiovascular surgery. Ostomy/Wound Management 2000;46(2):46-51, 54-5.

Beds, overlays and mattresses for preventing and treating pressure ulcers: an overview of Cochrane Reviews and network meta-analysis 


\section{Russell 2003}

Russell LJ, Reynolds TM, Park C, Rithalia S, Gonsalkorale M, Birch J, et al. Randomized clinical trial comparing 2 support surfaces: results of the prevention of pressure ulcers study. Advances in Skin \& Wound Care 2003;16(6):317-27.

\section{Sanada 2003}

Matsui Y, Miyake S, Kawasaki T, Konya C, Sugama J, Sanada H. Randomized controlled trial of a two layer type air cell mattress in the prevention of pressure ulcers. Japanese Journal of Pressure Ulcers 2001;3(3):331-7.

* Sanada H, Sugama J, Matsui Y, Konya C, Kitagawa A, Okuwa M, et al. Randomised controlled trial to evaluate a new double-layer air-cell overlay for elderly patients requiring head elevation. Journal of Tissue Viability 2003;13(3):112-4, 116, 118.

\section{Santy 1994}

Santy JE, Butler MK, Whyman JD. A comparison study of 6 types of hospital mattress to determine which most effectively reduces the incidence of pressure sores in elderly patients with hip fractures in a District General Hospital. Report to Northern \& Yorkshire Regional Health Authority 1994.

\section{Sauvage 2017}

Sauvage P, Touflet M, Pradere C, Portalier F, Michel JM, Charru P, et al. Pressure ulcers prevention efficacy of an alternating pressure air mattress in elderly patients: E(2)MAO a randomised study. Journal of Wound Care 2017;26(6):304-12.

\section{Schultz 1999}

* Schultz A, Bien M, Dumond K, Brown K, Myers A. Etiology and incidence of pressure ulcers in surgical patients. AORN Journal 1999;70(3):434, 437-40, 443-9.

Schultz AA. Study results: prediction and prevention of pressure ulcers in surgical patients. Advances in Wound Care 1998;11(3):11.

\section{Sideranko 1992}

Sideranko S, Quinn A, Burns K, Froman RD. Effects of position and mattress overlay on sacral and heel pressures in a clinical population. Research in Nursing \& Health 1992;15(4):245-51.

\section{Stapleton 1986}

Stapleton M. Preventing pressure sores--an evaluation of three products. Geriatric Nursing (London, England) 1986;6(2):23-5.

\section{Takala 1996}

Takala J, Varmavuo S, Soppi E. Prevention of pressure sores in acute respiratory failure: a randomised controlled trial. Clinical Intensive Care 1996;7(5):228-35.

\section{Taylor 1999}

Taylor L. Evaluating the Pegasus Trinova: a data hierarchy approach. British Journal of Nursing (Mark Allen Publishing) 1999;8(12):771-4, 776-8.

\section{Theaker 2005}

Theaker C, Kuper M, Soni N. Pressure ulcer prevention in intensive care - a randomised control trial of two pressure-relieving devices. Anaesthesia 2005;60(4):395-9.

\section{Vanderwee 2005}

Vanderwee K, Grypdonck MH, Defloor T. Effectiveness of an alternating pressure air mattress for the prevention of pressure ulcers. Age and Ageing 2005;34(3):261-7.

\section{Van Leen 2011}

Van Leen M, Hovius S, Neyens J, Halfens R, Schols J. Pressure relief, cold foam or static air? A single center, prospective, controlled randomized clinical trial in a Dutch nursing home. Journal of Tissue Viability 2011;20(1):30-4.

\section{Van Leen 2013}

Van Leen M, Hovius S, Halfens R, Neyens J, Schols J. Pressure relief with visco-elastic foam or with combined static air overlay? A prospective, crossover randomized clinical trial in a Dutch nursing home. Wounds 2013;25(10):287-92.

Beds, overlays and mattresses for preventing and treating pressure ulcers: an overview of Cochrane Reviews and network meta-analysis 


\section{Van Leen 2018}

NTR4557. Is lowering of shear and friction forces (cost)effective for prevention of pressure ulcers? trialregister.nl/trial/4435.

* Van Leen M, Halfens R, Schols J. Preventive effect of a microclimate-regulating system on pressure ulcer development: a prospective, randomized controlled trial in Dutch nursing homes. Advances in Skin \& Wound Care 2018;31(1):1-5.

\section{Vermette 2012}

Vermette S, Reeves I, Lemaire J. Cost effectiveness of an air-inflated static overlay for pressure ulcer prevention: a randomized, controlled trial. Wounds 2012;24(8):207-14.

\section{Vyhlidal 1997}

Vyhlidal SK, Moxness D, Bosak KS, Van Meter FG, Bergstrom N. Mattress replacement or foam overlay? A prospective study on the incidence of pressure ulcers. Applied Nursing Research 1997;10(3):111-20.

\section{Whitney 1984}

Whitney JD, Fellows BJ, Larson E. Do mattresses make a difference? Journal of Gerontological Nursing 1984;10(9):20-1, 24-5.

\section{Whittingham 1999}

Whittingham K. Randomized control trial of six pressure-redistributing foam mattresses. Journal of Tissue Viability 1999;9(3):104.

\section{References of studies in the topic of treatment}

We identified 12 potentially eligible studies in the topic of pressure ulcer treatment. Here is the list of studies. We use an asterisk to indicate the primary reference where a study has multiple references.

\section{Allman 1987}

Allman RM, Walker JM, Hart MK, Laprade CA, Noel LB, Smith CR. Air-fluidized beds or conventional therapy for pressure sores. A randomized trial. Annals of Internal Medicine 1987;107(5):641-8.

\section{Cassino 2013}

Cassino R, Ippolito AM, Cuffaro C, Corsi A, Ricci E. A controlled, randomized study on the effectiveness of two overlays in the treatment of decubitus ulcers. Minerva Chirurgica 2013;68(1):105-16.

\section{Day 1993}

Day A, Leonard F. Seeking quality care for patients with pressure ulcers. Decubitus 1993;6(1):32-43.

\section{Devine 1995}

Devine B. Alternating pressure air mattresses in the management of established pressure sores. Journal of Tissue Viability 1995;5(3):94-8.

\section{Evans 2000a}

Evans D, Land L, Geary A. A clinical evaluation of the Nimbus 3 alternating pressure mattress replacement system. Journal of Wound Care 2000;9(4):181-6.

\section{Evans 2000b}

Evans D, Land L, Geary A. A clinical evaluation of the Nimbus 3 alternating pressure mattress replacement system. Journal of Wound Care 2000;9(4):181-6.

\section{Ferrell 1993}

Ferrell BA, Osterweil D, Christenson P. A randomized trial of low-air-loss beds for treatment of pressure ulcers. JAMA 1993;269(4):494-7.

\section{Groen 1999}

Groen HW, Groenier KH, Schuling J. Comparative study of a foam mattress and a water mattress. Journal of Wound Care 1999;8(7):333-5.

\section{Mulder 1994}

Mulder GD, Taro N, Seeley J, Andrews K. A study of pressure ulcer response to low air loss beds vs. conventional treatment. Journal of Geriatric Dermatology 1994;2(3):87-91.

Beds, overlays and mattresses for preventing and treating pressure ulcers: an overview of Cochrane Reviews and network meta-analysis 


\section{Munro 1989}

Munro BH, Brown L, Heitman BB. Pressure ulcers: one bed or another? How does an air-fluidized bed compare with pads and other devices on a standard bed? Geriatric Nursing 1989;10:190-2.

\section{Russell 2000}

* Russell L, Reynolds T, Carr J, Evans A, Holmes M. A comparison of healing rates on two pressure-relieving systems. British Journal of Nursing (Mark Allen Publishing) 2000;9(22):2270-80.

Russell L, Reynolds TM, Carr J, Evans A, Holmes M. Randomised controlled trial of two pressure-relieving systems. Journal of Wound Care 2000;9(2):52-5.

Russell L. Randomized comparative clinical trial of Pegasus Cairwave mattress and Proactive seating cushion and Huntleigh Nimbus 3 \& Aura seating cushion. Journal of Tissue Viability 1999;9(3):103-4.

Russell L. Randomized comparative clinical trial of the Pegasus Cairwave mattress and Proactive seating cushion and the Huntleigh Nimbus III mattress and Alpha Transcell seating cushion. European Wound Management Association and Journal of Wound Care Autumn Conference; 1998 November; Harrogate (UK) 1998:4.

\section{Strauss 1991}

Strauss MJ, Gong J, Gary BD, Kalsbeek WD, Spear S. The cost of home air-fluidized therapy for pressure sores. A randomized controlled trial. Journal of Family Practice 1991;33(1):52-9.

\section{Appendix 10. Time-to-event network: assessing transitivity, homogeneity and consistency assumptions}

We assessed the transitivity, homogeneity and consistency assumptions for the time-to-event network analysis below.

\section{(1) Transitivity assumption assessment}

We summarised the characteristics of the included studies for each direct contrast and compared these direct contrast-level summary characteristics across these direct contrasts. See the table below. This aims to assess if there are systematic differences between the direct contrasts other than the treatments under evaluations. Thus, data from direct contrasts can be used to calculate indirect evidence (transitivity). The five direct contrasts are heterogeneous in terms of risk of bias, and follow-up duration ( $3 / 5$ of direct contrasts with shortterm follow-up, $1 / 5$ with medium-term follow-up, and $1 / 5$ with long-term follow-up). We considered these direct contrasts homogeneous in terms of care settings (mainly acute care settings), and participants' characteristics: proportions of sex, age (mainly older adults), and baseline skin status (mainly at risk but free of existing ulcers). We assumed the transitivity assumption held.

Table 1. Summary characteristics of included studies for each direct comparison in the network of time to pressure ulcer development 


\begin{tabular}{|c|c|c|c|c|c|c|c|c|c|c|c|}
\hline 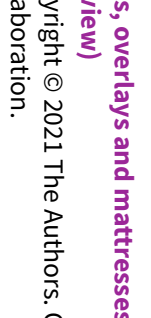 & Direct comparisons & $\begin{array}{l}\text { Number } \\
\text { of studies }\end{array}$ & $\begin{array}{l}\text { Study de- } \\
\text { sign, no. } \\
\text { of mul- } \\
\text { ti-arm } \\
\text { studies } \\
\text { (\% of to- } \\
\text { tal partic- } \\
\text { ipants) }\end{array}$ & $\begin{array}{l}\text { Median of } \\
\text { follow-up }\end{array}$ & $\begin{array}{l}\text { Care settings } \\
\text { (\% of total par- } \\
\text { ticipants) }\end{array}$ & $\begin{array}{l}\text { Number } \\
\text { of events/ } \\
\text { number } \\
\text { of total } \\
\text { partici- } \\
\text { pants (\%) }\end{array}$ & Male (\%) & $\begin{array}{l}\text { Female } \\
(\%)\end{array}$ & $\begin{array}{l}\text { Median } \\
\text { of aver- } \\
\text { age age } \\
\text { reported } \\
\text { (years) }\end{array}$ & $\begin{array}{l}\text { Baseline skin } \\
\text { status (\% of } \\
\text { total partici- } \\
\text { pants) }\end{array}$ & $\begin{array}{l}\text { Overall } \\
\text { risk of } \\
\text { bias level } \\
\text { (\% of to- } \\
\text { tal partic- } \\
\text { ipants) }\end{array}$ \\
\hline 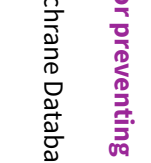 & $\begin{array}{l}\text { Alternating pressure } \\
\text { (active) air surfaces vs } \\
\text { foam surfaces }\end{array}$ & 2 & $\begin{array}{l}\text { Two-arm } \\
\text { RCTs }\end{array}$ & 60 days & $\begin{array}{l}\text { Acute care set- } \\
\text { ting }(96 \%) \text {, } \\
\text { Long-term care } \\
\text { setting }(4 \%)\end{array}$ & $\begin{array}{l}175 / 2105 \\
(8 \%)\end{array}$ & $929(44 \%)$ & $\begin{array}{l}1173 \\
(56 \%)\end{array}$ & 82 & $\begin{array}{l}\text { At risk, free of } \\
\text { ulcers }(100 \%)\end{array}$ & $\begin{array}{l}\text { Low } \\
(96 \%) ; \\
\text { High (4\%) }\end{array}$ \\
\hline 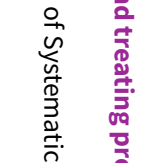 & $\begin{array}{l}\text { Alternating pressure } \\
\text { (active) air surfaces vs } \\
\text { foam surfaces plus 4- } \\
\text { hourly turning }\end{array}$ & 1 & $\begin{array}{l}\text { Two-arm } \\
\text { RCT }\end{array}$ & 20 weeks & $\begin{array}{l}\text { Acute care set- } \\
\text { ting }(100 \%)\end{array}$ & $\begin{array}{l}69 / 447 \\
(15 \%)\end{array}$ & $163(37 \%)$ & $283(63 \%)$ & 82 & $\begin{array}{l}\text { At risk, free of } \\
\text { ulcers }(100 \%)\end{array}$ & $\begin{array}{l}\text { Low } \\
(100 \%)\end{array}$ \\
\hline 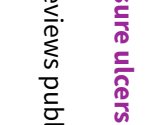 & $\begin{array}{l}\text { Alternating pressure } \\
\text { (active) air surfaces vs } \\
\text { reactive air surfaces }\end{array}$ & 1 & $\begin{array}{l}\text { Two-arm } \\
\text { RCT }\end{array}$ & 14 days & $\begin{array}{l}\text { Long-term care } \\
\text { setting }(100 \%)\end{array}$ & $\begin{array}{l}26 / 308 \\
(8 \%)\end{array}$ & $71(23 \%)$ & $237(77 \%)$ & 87 & $\begin{array}{l}\text { At risk, free of } \\
\text { ulcers }(100 \%)\end{array}$ & $\begin{array}{l}\text { High } \\
(100 \%)\end{array}$ \\
\hline 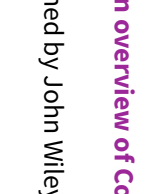 & $\begin{array}{l}\text { Foam surfaces vs } \\
\text { 'standard hospital sur- } \\
\text { faces' }\end{array}$ & 3 & $\begin{array}{l}\text { Two-arm } \\
\text { RCTs }\end{array}$ & 11.5 days & $\begin{array}{l}\text { Acute care set- } \\
\text { ting }(94 \%) ; \\
\text { Operating room } \\
(6 \%)\end{array}$ & $\begin{array}{l}181 / 3072 \\
(6 \%)\end{array}$ & $516(38 \%)$ & $827(62 \%)$ & 75 & $\begin{array}{l}\text { At risk, free of } \\
\text { ulcers }(100 \%)\end{array}$ & $\begin{array}{l}\text { Unclear } \\
(62 \%) ; \\
\text { High } \\
(38 \%)\end{array}$ \\
\hline 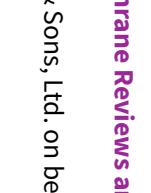 & $\begin{array}{l}\text { Reactive sheepskin } \\
\text { surfaces vs 'standard } \\
\text { hospital surfaces' }\end{array}$ & 3 & $\begin{array}{l}\text { Two-arm } \\
\text { RCTs }\end{array}$ & 30 days & $\begin{array}{l}\text { Acute care set- } \\
\text { ting }(58 \%) ; \\
\text { Long-term care } \\
\text { setting }(42 \%)\end{array}$ & $\begin{array}{l}248 / 1281 \\
(19 \%)\end{array}$ & $533(40 \%)$ & $793(60 \%)$ & 73 & $\begin{array}{l}\text { At risk, free of } \\
\text { ulcers }(100 \%)\end{array}$ & $\begin{array}{l}\text { High } \\
(100 \%)\end{array}$ \\
\hline
\end{tabular}




\section{(2) Homogeneity assumption tests}

The network has Tau ${ }^{2}=0.329$. This indicates the existence of heterogeneity. This resulted in downgrading for heterogeneity in assessing the certainty of evidence using the GRADE approach.

We considered downgrading for these two network contrasts:

- alternating pressure (active) air surfaces versus foam surfaces: $P$ value $=0.009$; and

- foam surfaces versus standard hospital surfaces: $P$ value $=0.029$.

\section{(3) Consistency tests}

The network has no closed loop. We did not identify any evidence of global or local inconsistency: design-by-treatment interaction model $\mathrm{Chi}^{2}(1)=1.36$; probably $>\mathrm{Chi}^{2}=0.243$. The consistency assumption held in the network

\section{Publication bias}

We report the funnel plot for the time-to-event network analysis in Figure 14. The plot did not strongly suggest publication bias.

Figure 14. Time-to-event network: funnel plot of the analysis for time to pressure ulcer development outcome

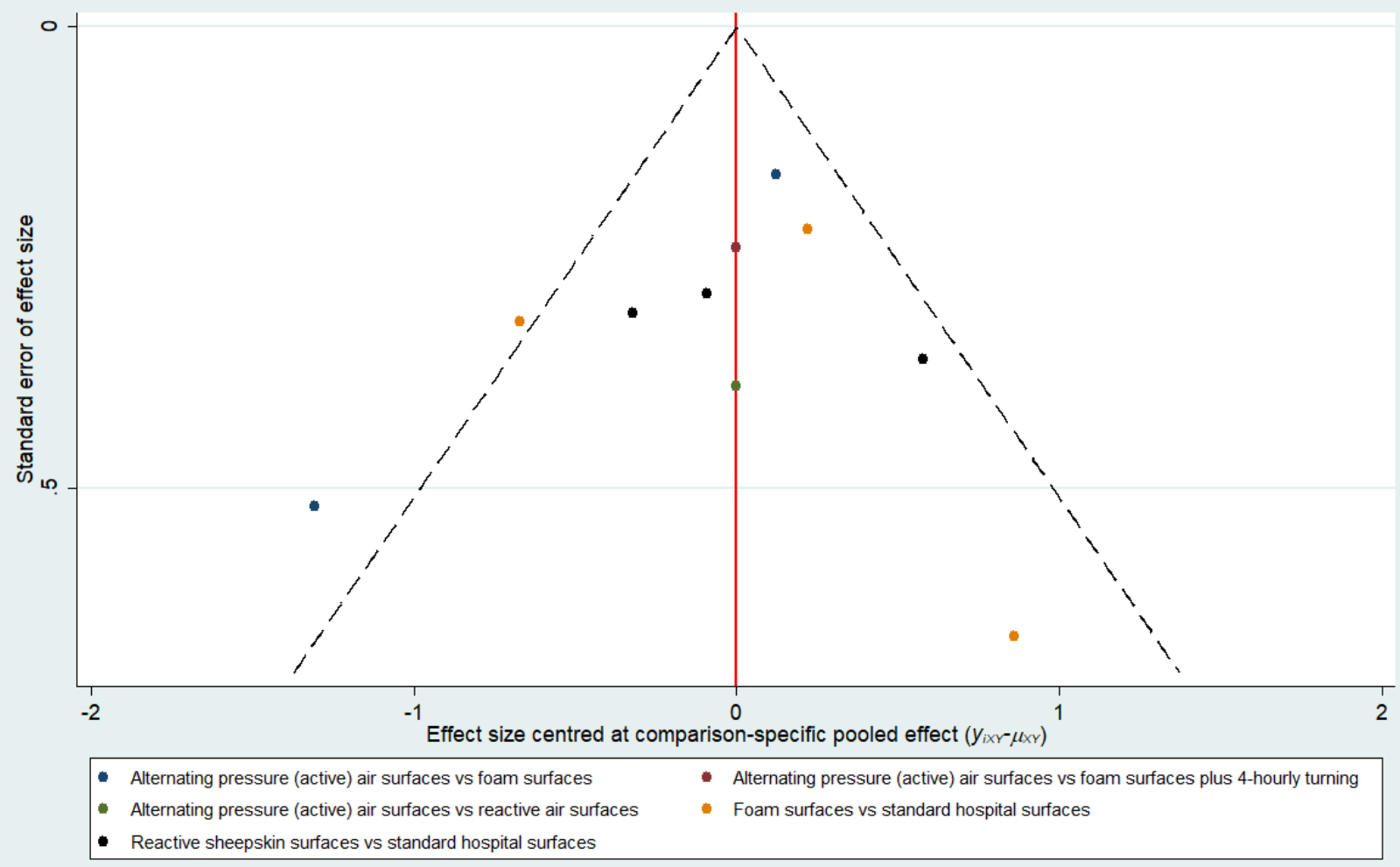

Appendix 11. Treatment network: characteristics and data in the included studies and full ranking evidence Characteristics and data of the 12 potentially eligible studies

In the table below, we report the characteristics and data of the 12 RCTs identified for the topic of pressure ulcer healing. We note that not all studies connected to a network and studies with an asterisk contributed data to network meta-analyses.

\section{Table 1. Characteristics and data of the 12 potentially eligible studies}

Beds, overlays and mattresses for preventing and treating pressure ulcers: an overview of Cochrane Reviews and network meta-analysis

Copyright (c) 2021 The Authors. Cochrane Database of Systematic Reviews published by John Wiley \& Sons, Ltd. on behalf of The Cochrane 


\begin{tabular}{|c|c|c|c|c|c|c|c|c|c|c|c|c|c|}
\hline 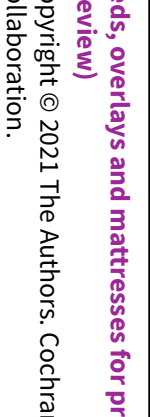 & Study ID & $\begin{array}{l}\text { Study } \\
\text { design }\end{array}$ & $\begin{array}{l}\text { Number } \\
\text { of arms }\end{array}$ & Country & $\begin{array}{l}\text { Being } \\
\text { fully or } \\
\text { partly } \\
\text { funded } \\
\text { by in- } \\
\text { dustry }\end{array}$ & $\begin{array}{l}\text { Fol- } \\
\text { low-up } \\
\text { duration }\end{array}$ & $\begin{array}{l}\text { Care set- } \\
\text { ting }\end{array}$ & $\begin{array}{l}\text { Total } \\
\text { partic- } \\
\text { ipants } \\
\text { (male/ } \\
\text { female, } \\
\text { only } \\
\text { those } \\
\text { with } \\
\text { available } \\
\text { data) }\end{array}$ & Age & $\begin{array}{l}\text { Ulcer } \\
\text { stage at } \\
\text { baseline }\end{array}$ & $\begin{array}{l}\text { Aver- } \\
\text { age ul- } \\
\text { cer sur- } \\
\text { face area } \\
\left(\mathrm{cm}^{2}\right)\end{array}$ & $\begin{array}{l}\text { Study arm } 1 \text { (heal- } \\
\text { ing/total/ missing) }\end{array}$ & $\begin{array}{l}\text { Study arm } 2 \\
\text { (healing/to- } \\
\text { tal/ missing) }\end{array}$ \\
\hline 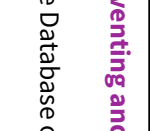 & $\begin{array}{l}\text { Allman } \\
1987^{\star}\end{array}$ & $\mathrm{RCT}$ & 2 & USA & Partly & 13 days & Hospital & $\begin{array}{l}72 \\
(27 / 38)\end{array}$ & 66.6 & $\begin{array}{l}\text { super- } \\
\text { ficial \& } \\
\text { deep }\end{array}$ & 9.4 & $\begin{array}{l}\text { Reactive air sur- } \\
\text { faces }(20 / 36)\end{array}$ & $\begin{array}{l}\text { Foam sur- } \\
\text { faces }(15 / 36)\end{array}$ \\
\hline 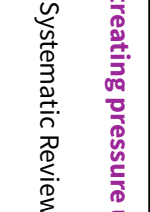 & $\begin{array}{l}\text { Cassino } \\
2013\end{array}$ & $\mathrm{RCT}$ & 2 & Italy & Fully & 12 weeks & $\begin{array}{l}\text { Com- } \\
\text { munity } \\
\text { \& long- } \\
\text { term } \\
\text { care }\end{array}$ & $\begin{array}{l}72 \\
(17 / 55)\end{array}$ & 85.4 & 1 to 4 & ND & $\begin{array}{l}\text { Reactive gel sur- } \\
\text { faces }(5 / 37)\end{array}$ & $\begin{array}{l}\text { Standard hos- } \\
\text { pital surfaces } \\
(3 / 35)\end{array}$ \\
\hline 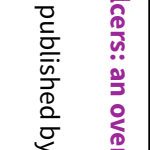 & Day 1993 & $\mathrm{RCT}$ & 2 & USA & Partly & 7 days & Hospital & $\begin{array}{l}83 \\
(35 / 48)\end{array}$ & 76 & $\begin{array}{l}2 \text { to } 4 \text {, } \\
\text { unstage- } \\
\text { able }\end{array}$ & ND & $\begin{array}{l}\text { Alternating pres- } \\
\text { sure (active) air } \\
\text { surfaces (ND) }\end{array}$ & $\begin{array}{l}\text { Foam sur- } \\
\text { faces (ND) }\end{array}$ \\
\hline 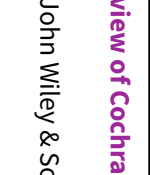 & $\begin{array}{l}\text { Devine } \\
1995\end{array}$ & $\mathrm{RCT}$ & 2 & UK & Partly & 4 weeks & Hospital & $\begin{array}{l}41 \\
(17 / 24)\end{array}$ & 82.5 & 2 to 4 & 12.8 & $\begin{array}{l}\text { Alternating pres- } \\
\text { sure (active) air } \\
\text { surfaces }(10 / 16 / 6)\end{array}$ & $\begin{array}{l}\text { Alternating } \\
\text { pressure (ac- } \\
\text { tive) air sur- } \\
\text { faces }(5 / 14 / 5)\end{array}$ \\
\hline 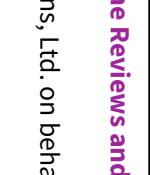 & $\begin{array}{l}\text { Evans } \\
2000 a\end{array}$ & $\mathrm{RCT}$ & 2 & UK & Fully & $\begin{array}{l}20.5 \\
\text { days }\end{array}$ & Hospital & $12(6 / 6)$ & 72.2 & 2 to 4 & 4.2 & $\begin{array}{l}\text { Alternating pres- } \\
\text { sure (active) air } \\
\text { surfaces }(3 / 7 / 0)\end{array}$ & $\begin{array}{l}\text { Alternating } \\
\text { pressure (ac- } \\
\text { tive) air sur- } \\
\text { faces }(3 / 5 / 0)\end{array}$ \\
\hline 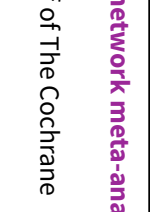 & $\begin{array}{l}\text { Evans } \\
2000 \mathrm{~b}\end{array}$ & $\mathrm{RCT}$ & 2 & UK & Fully & $\begin{array}{l}53.5 \\
\text { days }\end{array}$ & $\begin{array}{l}\text { Com- } \\
\text { munity } \\
\text { \& long- } \\
\text { term } \\
\text { care }\end{array}$ & $20(1 / 19)$ & 86.5 & 2 to 4 & 6.6 & $\begin{array}{l}\text { Alternating pres- } \\
\text { sure (active) air } \\
\text { surfaces }(1 / 10 / 0)\end{array}$ & $\begin{array}{l}\text { Alternating } \\
\text { pressure (ac- } \\
\text { tive) air sur- } \\
\text { faces }(5 / 10 / 0)\end{array}$ \\
\hline$\underset{\infty}{\stackrel{\sim}{N}}$ & $\begin{array}{l}\text { Ferrell } \\
1993^{*}\end{array}$ & $\mathrm{RCT}$ & 2 & USA & Partly & $\begin{array}{l}37.5 \\
\text { days }\end{array}$ & $\begin{array}{l}\text { Com- } \\
\text { munity } \\
\text { \& long- }\end{array}$ & $\begin{array}{l}84 \\
(42 / 42)\end{array}$ & 84.5 & 2 to 4 & 4.2 & $\begin{array}{l}\text { Reactive air sur- } \\
\text { faces }(26 / 43)\end{array}$ & $\begin{array}{l}\text { Foam sur- } \\
\text { faces }(19 / 41)\end{array}$ \\
\hline
\end{tabular}




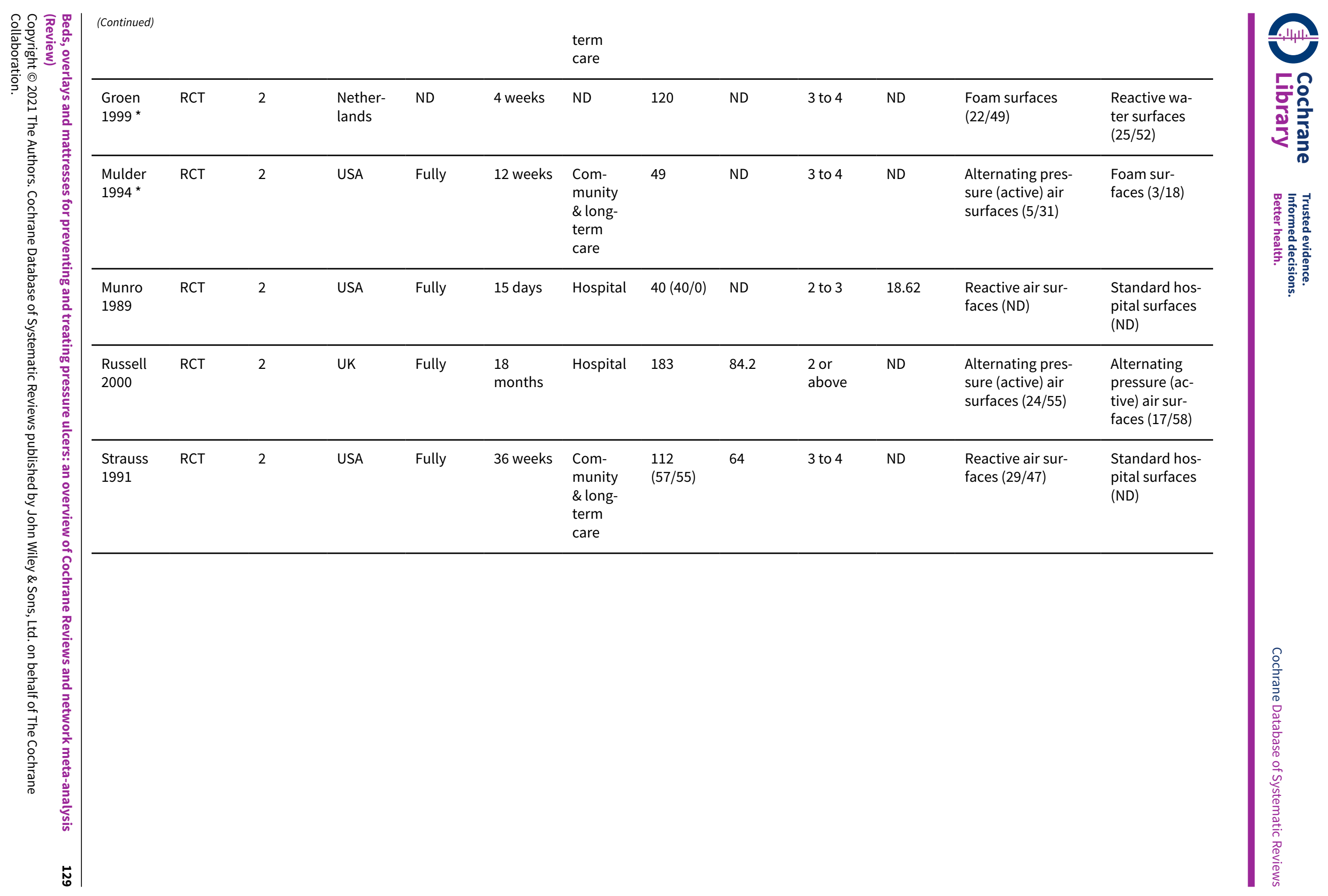


ND = no data available

\section{Risk of bias assessment for the included studies connecting to the treatment network}

We summarise risk of bias assessments for the included studies in the topic of prevention in Figure 15. 
Figure 15. Treatment network: risk of bias summary of review authors' judgements about each risk of bias item for each study. Studies with asterisk contributed data for network meta-analysis.

\begin{tabular}{|c|c|c|c|c|c|c|c|c|c|}
\hline & 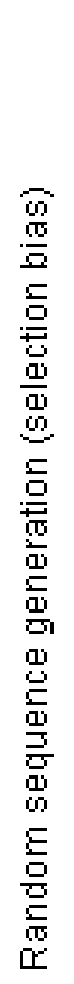 & 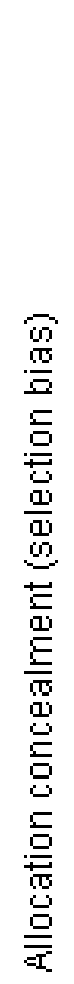 & 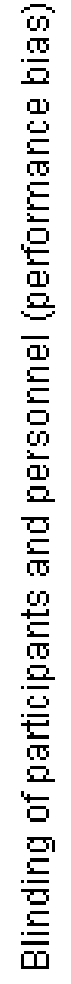 & 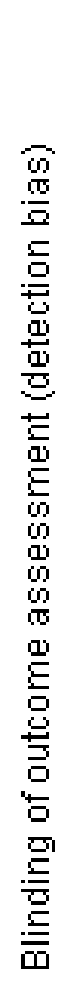 & 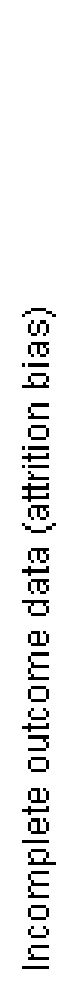 & 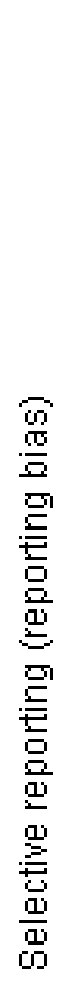 & 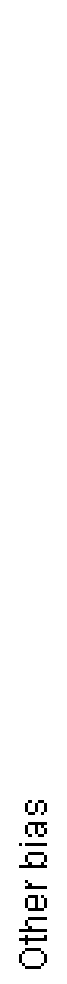 & 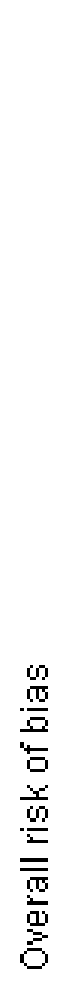 & 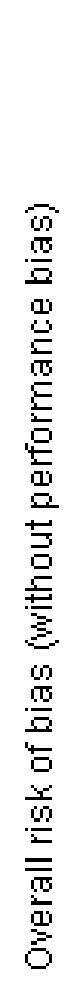 \\
\hline Allman $1987^{*}$ & + & $?$ & $?$ & + & + & + & + & $?$ & $?$ \\
\hline Cassino 2013 & $?$ & $?$ & $?$ & $?$ & & $?$ & + & & \\
\hline Day 1993 & $?$ & $?$ & 0 & 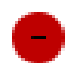 & $?$ & + & + & & \\
\hline Devine 1995 & + & $?$ & $?$ & $?$ & + & + & + & $?$ & $?$ \\
\hline Evans 2000a & $?$ & $?$ & $?$ & + & + & + & + & $?$ & $?$ \\
\hline Evans 2000b & ? & $?$ & $?$ & + & + & + & + & $?$ & $?$ \\
\hline Ferrell 1993 * & $?$ & $?$ & $?$ & $?$ & + & + & + & $?$ & $?$ \\
\hline Groen 1999* & $?$ & $?$ & $?$ & & & + & + & & \\
\hline Mulder 1994 * & $?$ & $?$ & $?$ & $?$ & & $?$ & 尺 & & \\
\hline Munro 1989 & $?$ & $?$ & & $?$ & & & + & & \\
\hline Russell 2000 & $?$ & + & $?$ & + & & & + & & \\
\hline Strauss 1991 & + & $?$ & $?$ & + & $?$ & + & + & $?$ & $?$ \\
\hline
\end{tabular}

Beds, overlays and mattresses for preventing and treating pressure ulcers: an overview of Cochrane Reviews and network meta-analysis 
Ranking probabilities of each support surface in the treatment network meta-analysis

We estimated values of three ranking measures for each type of support surface in the treatment network meta-analysis. See full results in the Table below.

Table 2. Ranking probabilities of each support surface in the treatment network meta-analysis

\begin{tabular}{llll}
\hline Interventions & $\begin{array}{l}\text { SUCRA (estimated \% } \\
\text { (predicted \%)) }\end{array}$ & $\begin{array}{l}\text { Probability of being the best } \\
\text { (estimated \% (predicted \%)) }\end{array}$ & $\begin{array}{l}\text { Mean rank (estimated val- } \\
\text { ues (predicted values)) }\end{array}$ \\
\hline Foam surfaces & $35.3(35.2)$ & $1.2(1.1)$ & $2.9(2.9)$ \\
\hline Reactive air surfaces & $83.9(83.8)$ & $59.9(59.8)$ & $1.5(1.5)$ \\
\hline $\begin{array}{l}\text { Alternating pressure (active) air sur- } \\
\text { faces }\end{array}$ & $43.0(43.1)$ & $31.8(32.2)$ & $2.7(2.7)$ \\
\hline Reactive water surfaces & $37.9(37.8)$ & $7.1(7.0)$ & $2.9(2.9)$ \\
\hline
\end{tabular}

SUCRA value is a numerical summary of the cumulative probability plot for each support surface and the plot shows cumulative rank probabilities that each intervention is less than or equal to a specific rank order against all possible ranks. The higher the SUCRA value, the higher the probability of being the best intervention. Probability of being the best value is the proportion of an intervention being ranked at the first place among a great number of repeated estimations for the intervention (simulations). Mean rank is the mean value of the distribution for the rank of each intervention. In the above table, all predicted values incorporate heterogeneity into value estimates.

We considered the ranking evidence is of very low certainty: we downgraded twice for risk of bias as $66.7 \%$ of data contributing to the basecase network were at high risk of bias. We did not downgrade for both heterogeneity and inconsistency as the network had no substantial heterogeneity $\left(\operatorname{Tau}^{2}=0.0\right)$, the ranking curves based on both estimated and predicted probabilities agree with each other, and the network had no global inconsistency.

We downgraded the evidence once for imprecision: the network had sparse data and there are overlaps between interventions in terms of rank orders. We did not downgrade for indirectness. We did not downgrade for publication bias too: the analysis included only four studies and the funnel plot did not strongly suggest small-studies effects (Figure 16). 
Figure 16. Treatment network: funnel plot of the analysis for pressure ulcer healing outcome

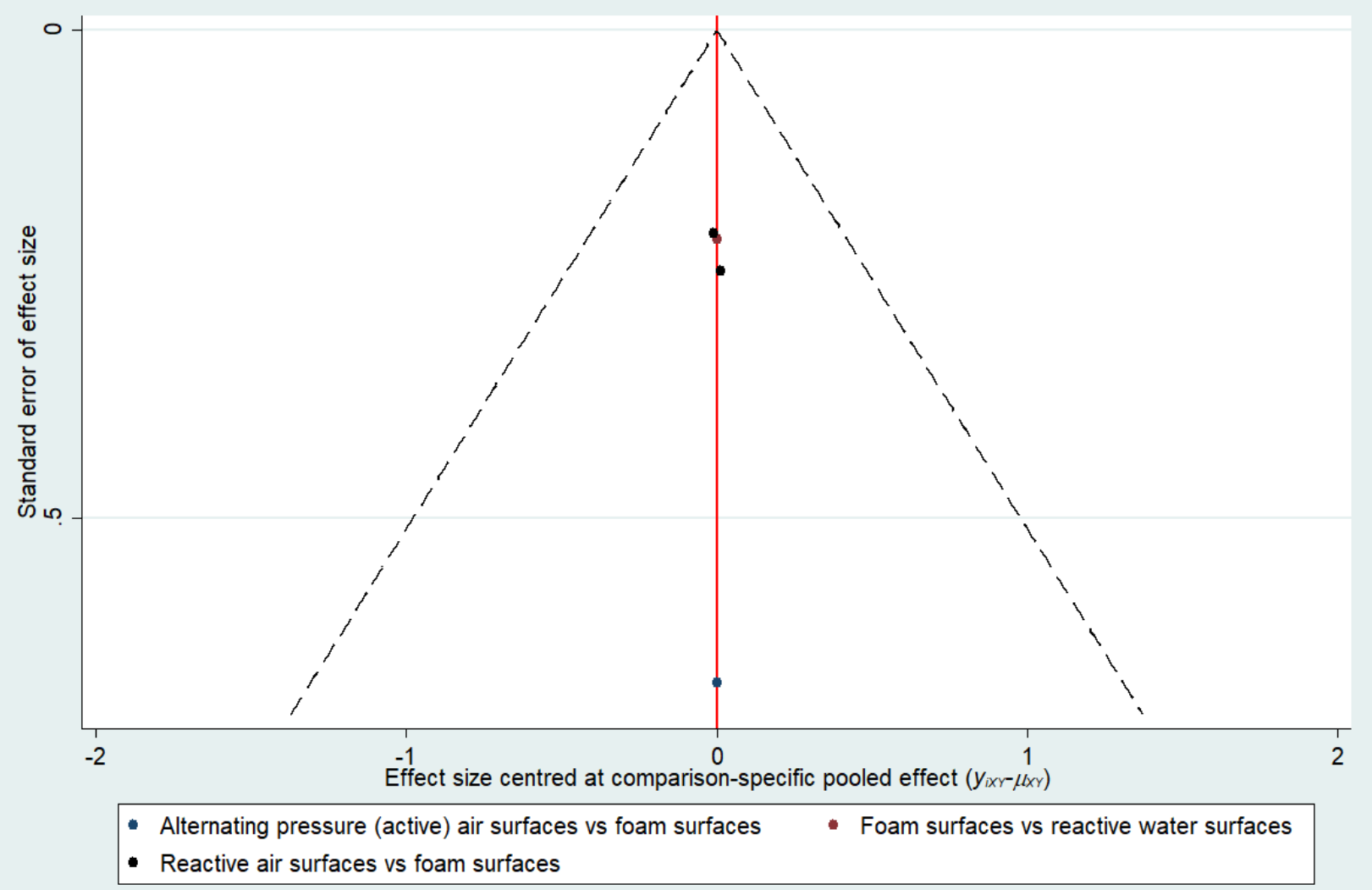

\section{HISTORY}

Protocol first published: Issue 10, 2020

\section{CONTRIBUTIONS OF AUTHORS}

Chunhu Shi: conceived the overview; designed the overview; coordinated the overview; extracted data; analysed or interpreted data; undertook quality assessment; performed statistical analysis; produced the first draft of the overview; contributed to writing or editing the overview; wrote to study authors/experts/companies; approved the final overview prior to publication; and is guarantor of the overview.

Jo Dumville: conceived the overview; designed the overview; coordinated the overview; analysed or interpreted data; produced the first draft of the overview; contributed to writing or editing the overview; advised on the overview; secured funding; performed previous work that was the foundation of the current overview; and approved the final overview prior to publication.

Nicky Cullum: conceived the overview; designed the overview; analysed or interpreted data; contributed to writing or editing the overview; advised on the overview; performed previous work that was the foundation of the current overview; and approved the final overview prior to publication.

Sarah Rhodes: analysed or interpreted data; performed statistical analysis; checked quality of statistical analysis; contributed to writing or editing the overview; advised on the overview; approved the final overview prior to publication.

Elizabeth McInnes: coordinated the overview; performed previous work that was the foundation of the current overview; approved the final overview prior to publication; and was the lead author of the previous version of the related reviews.

En Lin Goh: extracted data; checked quality of data extraction; undertook quality assessment; checked quality assessment; and approved the final overview prior to publication.

Beds, overlays and mattresses for preventing and treating pressure ulcers: an overview of Cochrane Reviews and network meta-analysis 
Gill Norman: analysed or interpreted data; checked quality assessment; contributed to writing or editing the overview; advised on the overview; and approved the final overview prior to publication.

\section{Contributions of the editorial base}

Gill Norman (Editor): edited the protocol; advised on methodology, interpretation and content; approved the final protocol prior to publication.

Gill Rizzello (Managing Editor): coordinated the editorial process; advised on content; edited the overview.

Sophie Bishop (Information Specialist): edited the search methods sections.

Tom Patterson (Editorial Assistant): edited the reference sections of the overview.

\section{DECLARATIONS OF INTEREST}

Chunhu Shi: I received research funding from the National Institute for Health Research (Research for Patient Benefit, Evidence synthesis for pressure ulcer prevention and treatment, PB-PG-1217-20006). I received support from the Tissue Viability Society to attend conferences unrelated to this work. The Doctoral Scholar Awards Scholarship and Doctoral Academy Conference Support Fund (University of Manchester) also supported a PhD and conference attendance respectively; both were unrelated to this work.

Jo Dumville: I am Chief Investigator on a National Institute for Health Research grant that funded the conduct of this review (Research for Patient Benefit, Evidence synthesis for pressure ulcer prevention and treatment, PB-PG-1217-20006). This research was co-funded by the National Institute for Health Research Manchester Biomedical Research Centre, and partly funded by the National Institute for Health Research Applied Research Collaboration Greater Manchester.

Nicky Cullum: I am Co-investigator on a National Institute for Health Research grant that funded the conduct of this review (Research for Patient Benefit, Evidence synthesis for pressure ulcer prevention and treatment, PB-PG-1217-20006). This research was co-funded by the National Institute for Health Research Manchester Biomedical Research Centre, and partly funded by the National Institute for Health Research Applied Research Collaboration Greater Manchester.

My previous and current employers received research grant funding from the NHS Research and Development Programme, and subsequently the NIHR, for my participation in reviews contained in this work. The funders had no role in the conduct of these reviews. My previous employer received research grant funding from the NIHR for an RCT comparing different alternating pressure air surfaces for pressure ulcer prevention.

Sarah Rhodes: my salary is funded from three National Institute for Health Research grants and a grant from Greater Manchester Cancer.

Elizabeth McInnes: none known.

En Lin Goh: none known.

Gill Norman: my employment at the University of Manchester is funded by the National Institute for Health Research (NIHR). This research was co-funded by the National Institute for Health Research Manchester Biomedical Research Centre.

Gill Worthy (peer reviewer) states: I have previously worked with three of the authors and performed the analysis of one of the included trials (PRESSURE).

\section{SOURCES OF SUPPORT}

\section{Internal sources}

- Division of Nursing, Midwifery and Social Work, School of Health Sciences, Faculty of Biology, Medicine and Health, University of Manchester, UK

\section{External sources}

- National Institute for Health Research, UK

This project is funded by the National Institute for Health Research (NIHR) under its Research for Patient Benefit (RfPB) Programme (Grant Reference Number PB-PG-1217-20006). The views expressed are those of the author(s) and not necessarily those of the NIHR or the Department of Health and Social Care.

- NIHR Manchester Biomedical Research Centre (BRC), UK

This research was co-funded by the NIHR Manchester BRC. The views expressed in this publication are those of the authors and not necessarily those of the National Health Service, the NIHR or the Department of Health and Social Care.

Beds, overlays and mattresses for preventing and treating pressure ulcers: an overview of Cochrane Reviews and network meta-analysis 
- National Institute for Health Research (NIHR), UK

This project was supported by the National Institute for Health Research, via Cochrane Infrastructure funding to Cochrane Wounds. The views expressed are those of the authors and not necessarily those of the NIHR or the Department of Health and Social Care.

- National Institute for Health Research Applied Research Collaboration (ARC) Greater Manchester, UK

Nicky Cullum and Jo Dumville's work on this project was partially funded by the National Institute for Health Research Applied Research Collaboration Greater Manchester. The views expressed in this publication are those of the authors and not necessarily those of the National Institute for Health Research or the Department of Health and Social Care.

\section{DIFFERENCES BETWEEN PROTOCOL AND REVIEW}

- We clarified the eligibility criteria further and included ongoing Cochrane Reviews in this overview, which was not specified in our protocol.

- We changed the titles of Shi 2021d and Shi 2021e.

- We assessed overall risk of bias for the included studies based on (1) all risk of bias domains; and (2) all but the performance bias domain. This was not specified in our protocol.

- We clarified the methods used for assessing risk of bias for direct comparisons, each network contrast and the whole base-case network. This was not specified in our protocol.

- We undertook a post hoc sensitivity analysis to assess the impact of including only well-defined support surfaces in the pressure ulcer incidence network meta-analysis.

- We did not report the results of subgroup analysis or sensitivity analyses of the included reviews in this overview.

- We present cumulative rank probability plots rather than rankograms.

- In exploring network heterogeneity in network meta-analysis, we categorised the continuous values of follow-up duration factor into three-level indicators (i.e. short-term; medium-term; and long-term) and performed a subgroup analysis for this rather than metaregression for a continuous factor. 